\title{
Heat Budget for an Anaerobic Bioreactor Landfill in Sainte-Sophie, Quebec, Canada
}

by

James Bonany

B. Eng. Environmental Engineering, Carleton University, 2010

A thesis submitted to the Faculty of Graduate Studies and Postdoctoral Affairs in partial fulfillment of requirements for the degree of

Master of Applied Science

in

Environmental Engineering

The Ottawa-Carleton Institute for Environmental Engineering (OCIENE) Carleton University

Ottawa, Ontario, Canada

C2012

James Bonany 
Library and Archives

Canada

Published Heritage

Branch

395 Wellington Street

Ottawa ON K1A ON4

Canada
Bibliothèque et

Archives Canada

Direction du

Patrimoine de l'édition

395 , rue Wellington

Ottawa ON K1A ON4

Canada
Your file Votre référence

ISBN: 978-0-494-93491-3

Our file Notre référence

ISBN: $978-0-494-93491-3$
NOTICE:

The author has granted a nonexclusive license allowing Library and Archives Canada to reproduce, publish, archive, preserve, conserve, communicate to the public by telecommunication or on the Internet, loan, distrbute and sell theses worldwide, for commercial or noncommercial purposes, in microform, paper, electronic and/or any other formats.

The author retains copyright ownership and moral rights in this thesis. Neither the thesis nor substantial extracts from it may be printed or otherwise reproduced without the author's permission.
AVIS:

L'auteur a accordé une licence non exclusive permettant à la Bibliothèque et Archives Canada de reproduire, publier, archiver, sauvegarder, conserver, transmettre au public par télécommunication ou par l'Internet, prêter, distribuer et vendre des thèses partout dans le monde, à des fins commerciales ou autres, sur support microforme, papier, électronique et/ou autres formats.

L'auteur conserve la propriété du droit d'auteur et des droits moraux qui protege cette thèse. $\mathrm{Ni}$ la thèse ni des extraits substantiels de celle-ci ne doivent être imprimés ou autrement reproduits sans son autorisation.
In compliance with the Canadian Privacy Act some supporting forms may have been removed from this thesis.

While these forms may be included in the document page count, their removal does not represent any loss of content from the thesis.
Conformément à la loi canadienne sur la protection de la vie privée, quelques formulaires secondaires ont été enlevés de cette thèse.

Bien que ces formulaires aient inclus dans la pagination, il n'y aura aucun contenu manquant. 


\section{Abstract}

This thesis examines the heat energy balance in an operating bioreactor landfill. The landfill was instrumented with sensors to record the temperature, total load, settlement, percent oxygen, moisture content, electrical conductivity and mounding of leachate. While the ambient temperatures during the summer increased above $30^{\circ} \mathrm{C}$, the temperatures recorded in the middle of a waste layer placed during the winter months remained at minus $2-3{ }^{\circ} \mathrm{C}$. Modelling of the instrument bundle temperature data has confirmed the waste is a great insulator, having a low thermal conductivity and high latent heat of fusion. A sensitivity analysis of the thermal parameters indicated the latent heat of fusion and heat generation from biodegradation are important parameters when modelling a landfill in northern climates. The heat budget indicated a significant portion of the heat entering the waste is stored as latent heat. Ultimately, the model can help landfill operators improve their current operating practices. 


\section{Acknowledgements}

Thank you to the principal project sponsors, Waste Management of Canada (WM) and the Ontario Centres of Excellence, for their extensive support throughout the project. Special thanks to Simon Mercier and Benoit Marsolais of the WM Sainte-Sophie landfill site for their hard work and in-kind support.

Thank you to our consulting group partners for their interest and feedback on the project, including AECOM, Genivar, Golder Associates, WESA, and Alston \& Associates Inc. Thanks also to Hoskin Scientific, RST Instruments, Decagon, and Apogee, who have designed the instrumentation and provided technical support for the instrument bundles.

I would like to thank my supervisor, Professor Paul Van Geel, for his hard work, extensive advice and support throughout the project. Special thanks to Burak Gunay and Professor Burkan Isgor for their help with the modelling effort and contributions to the journal papers. 


\section{Table of Contents}

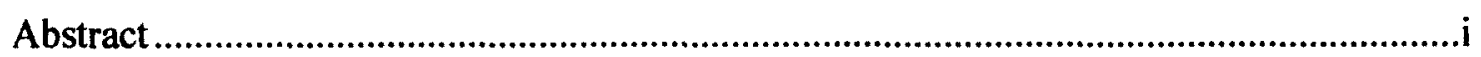

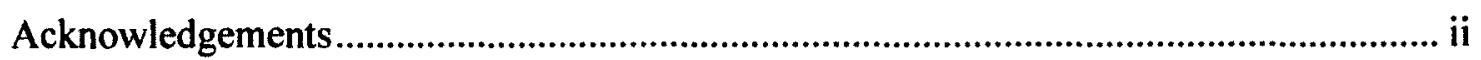

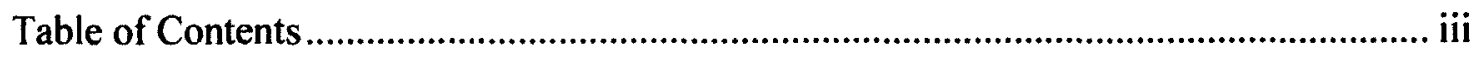

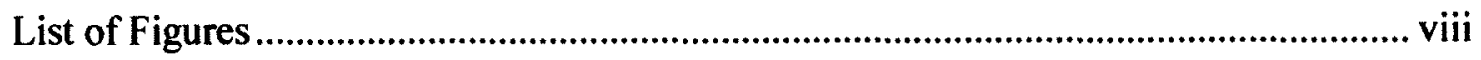

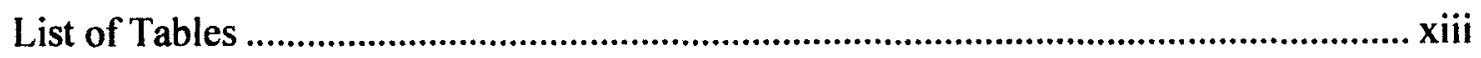

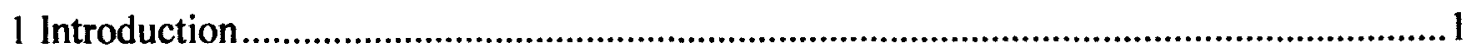

1.1 Project Significance ............................................................................................

1.1.1 Progression of Landfills ...............................................................................2

1.2 Description of Problem .........................................................................................

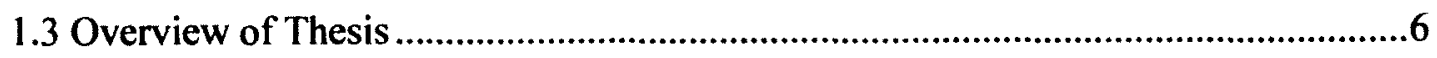

1.4 Sainte-Sophie Bioreactor Landfill .......................................................................

1.5 Project Description...........................................................................................

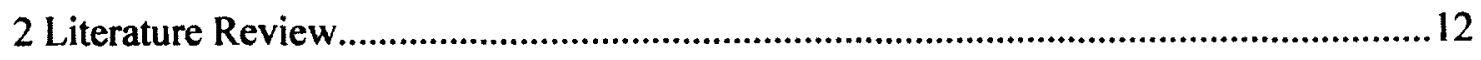

2.1 Engineered Components of a Bioreactor Landfill ...................................................12

2.1.1 Leachate Recirculation System ....................................................................13

2.1.2 Landfill Gas Collection System ....................................................................14

2.1.3 Liner and Leachate Collection Systems.......................................................15

2.1.4 Daily, Intermediate and Final Cover................................................................16

2.2 Waste Stabilization in an Anaerobic Bioreactor Landfill .........................................17 


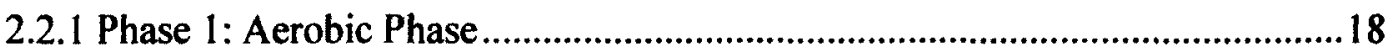

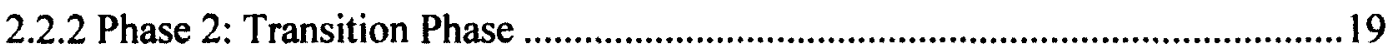

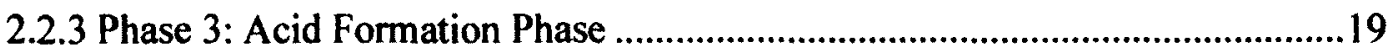

2.2.4 Phase 4: Methane Fermentation Phase ...........................................................20

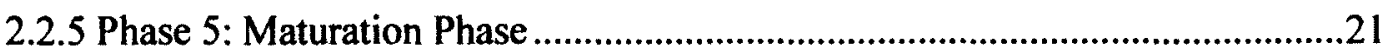

2.3 Physical Properties of MSW and their Impact on Waste Stabilization ......................21

2.3.1 Moisture Content and Field Capacity .................................................................21

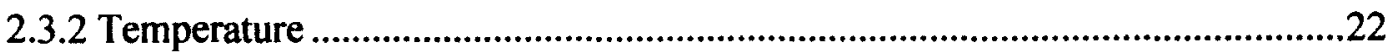

2.3.3 Oxygen Concentration ....................................................................................24

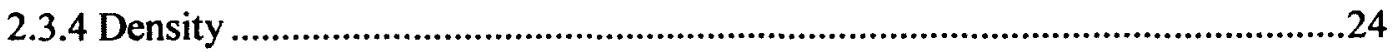

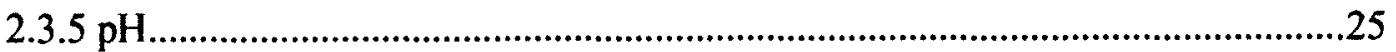

2.3.6 Nutrients and Inhibitory Compounds...........................................................26

2.4 Thermal Properties of MSW ................................................................................27

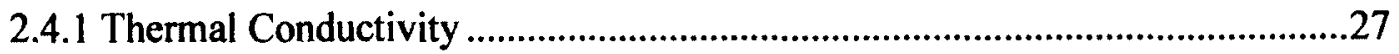

2.4.2 Specific Heat and Volumetric Heat Capacity ....................................................28

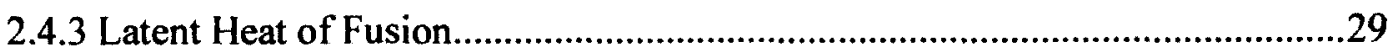

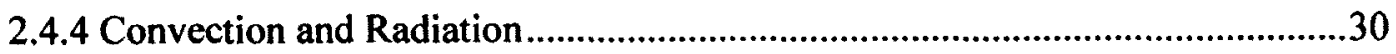

2.5 Instrument Installation in Full-Scale Landfills ........................................................31

2.5.1 New River Regional Landfill..........................................................................32

2.5.2 Sauk Trail Hills Development .........................................................................34 
2.6 Evaluation of Bioreactor Landfills in Cold Climates ..............................................36

2.6.1 City of Calgary Shepard Landfill.....................................................................36

2.6.2 Northern Oaks Recycling and Disposal Facility............................................38

2.6.3 Anchorage Regional Landfill.......................................................................

2.7 Modelling Efforts in Municipal Solid Waste............................................................41

3 Instrumentation of a Field Scale Bioreactor Landfill ................................................47

3.1 Instrument Bundle Sensors ...............................................................................50

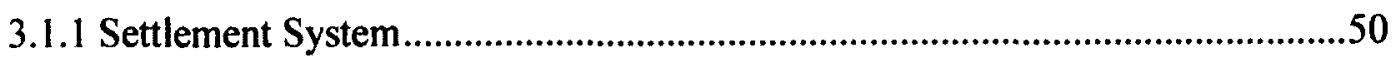

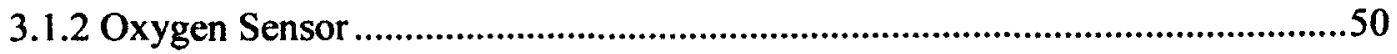

3.1.3 Moisture and Electrical Conductivity Sensor ..................................................5I

3.1.4 Total Earth Pressure Cell ...............................................................................

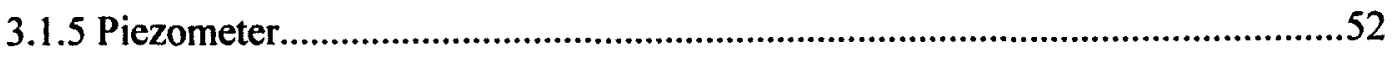

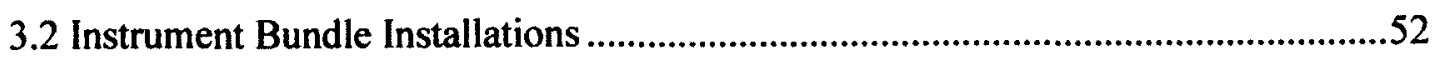

4 Instrument Bundle Results...................................................................................56

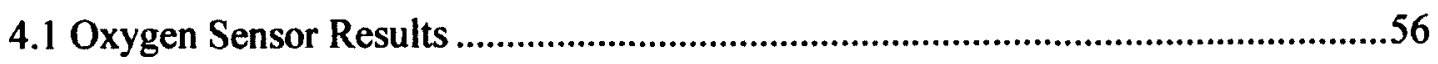

4.2 Temperature Results ............................................................................................63

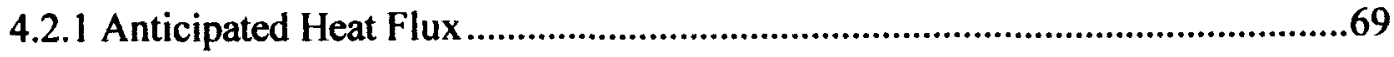

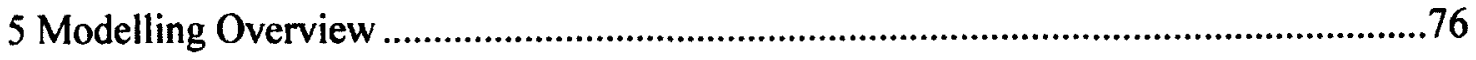

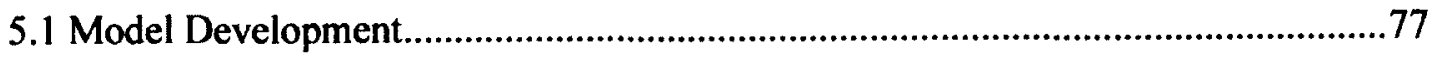




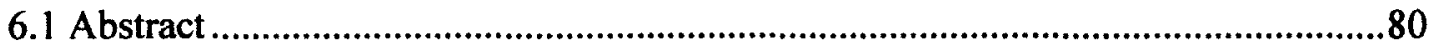

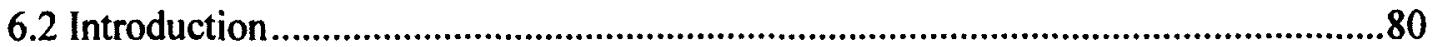

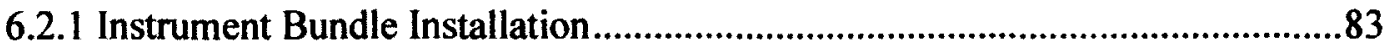

6.2.2 Instrument Bundle Temperature Data.....................................................86

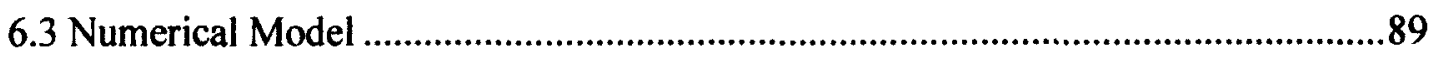

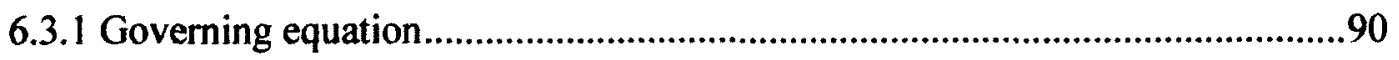

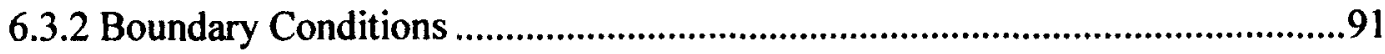

6.3.3 Solution Procedure ......................................................................................92

6.4 Model Calibration using Sainte-Sophie Data .......................................................93

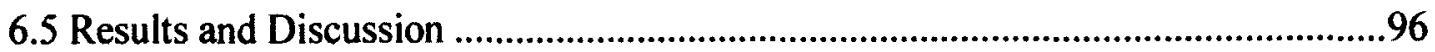

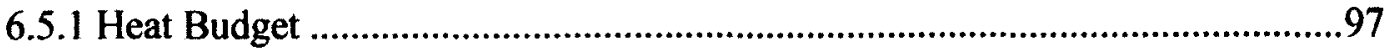

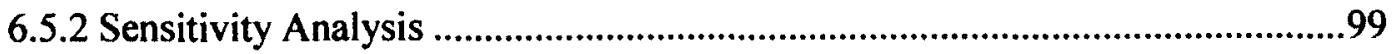

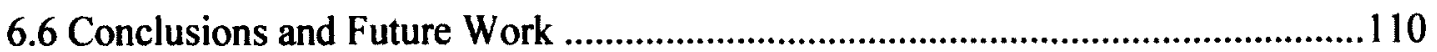

7 Simulating the impacts of temperatures in northern climates on waste stabilization at an operating bioreactor landfill in Quebec, Canada ...................................................113

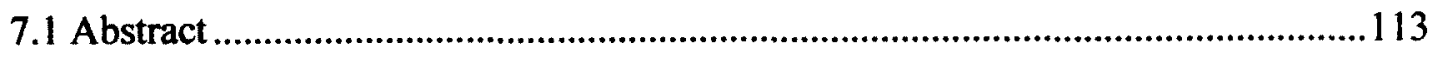

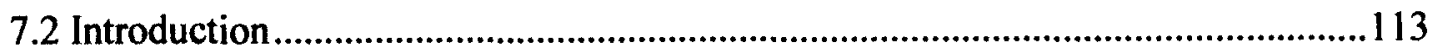

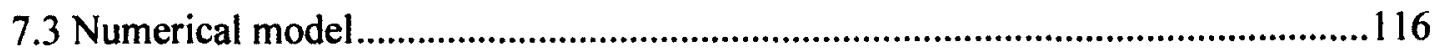

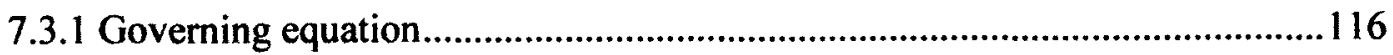


7.3.2 Boundary Conditions

7.4 Instrumentation of the Sainte-Sophie Landfill and Results ......................................119

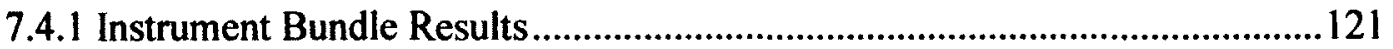

7.4.2 Modelling of the Sainte-Sophie Temperature Data .......................................125

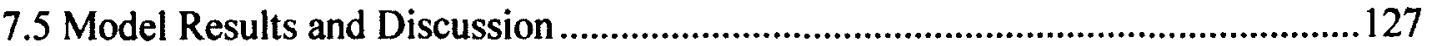

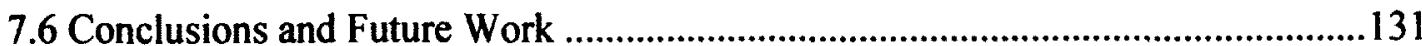

8 Overall Conclusions and Recommendations ...............................................................134

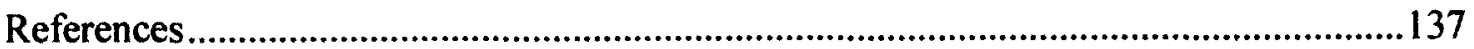

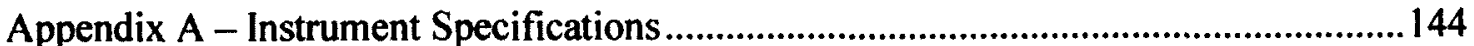

Appendix B - Thermistor Temperature Data .................................................................149

Appendix C - Temperature Data Linear Regression Analysis........................................156

Appendix D - Model Dimensions with Bundles .......................................................163 


\section{List of Figures}

Figure 1: Zone 4 of the Sainte-Sophie bioreactor landfill (modified from Genivar, 2008) 8

Figure 2: Anaerobic bioreactor illustrating leachate recirculation (Waste Management, 2004) 12

Figure 3: Landfill gas production from convential and bioreactor landfills (modified from Townsend et al., 2008). 15

Figure 4: Phases of biodegradation within a landfill (modified from Kim \& Pohland, 2003) 18

Figure 5: Microbial activity within the landfill based on temperature (with permission from Gholamifard et al., 2008). .23

Figure 6: Biocell Schematic (modified from Davies \& Colbran, 2010). 37

Figure 7: Heat generation functions used in model (with permission from Hanson et al., 2008) 44

Figure 8: Scaling factor for bioheat generation (with permission from Neusinger et al., 2005) .46

Figure 9: Instrument bundle placement elevations (Bonany et al., 2012a) 48

Figure 10: Instrument bundle (Bonany et al., 2012b). 49

Figure 11: First layer instrument bundle installation in October 2009 (left) and fourth layer instrument bundle installation in February 2011 (right) (Bonany et al., 2012a) .....54

Figure 12: History of waste lift placement ........................................................................55

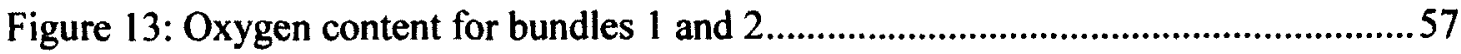

Figure 14: Oxygen pump test procedure......................................................................58

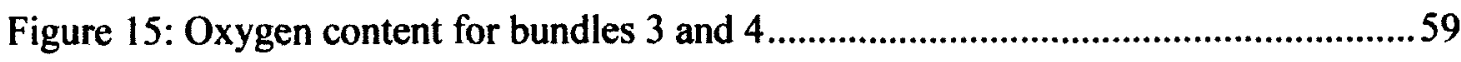


Figure 16: Oxygen content for bundles 5 and 6..........................................................61

Figure 17: Oxygen content for bundles 7 and 8 ...........................................................62

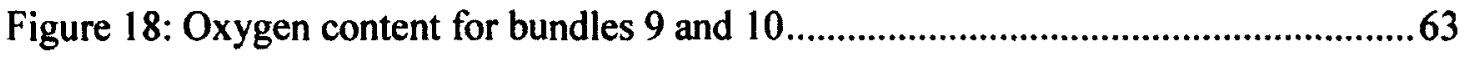

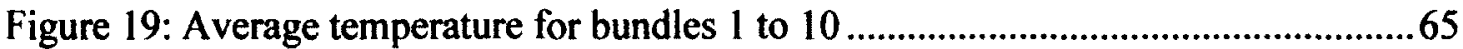

Figure 20: Temperature profile in soil with depth at Mirabel airport (Environment

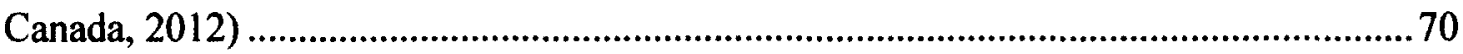

Figure 21: Temperature profile of waste in bioreactor landfill from Column 1 (modified from Vingerhoeds, 2011) ...............................................................................................

Figure 22: Temperature profile of waste in bioreactor landfill from Column 2 (modified from Vingerhoeds, 2011) ……………………...............................................................73

Figure 23: Progression of the model to arrive at base case.................................................... 78

Figure 24: Instrument Bundle (Bonany et al., 2012b) ........................................................83

Figure 25: Elevation of Instrument Bundles at Placement (Bonany et al., 2012a)............84

Figure 26: First Layer Instrument Bundle Installation in October 2009 ............................85

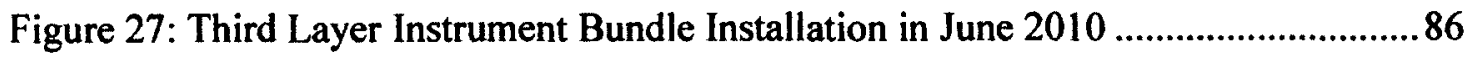

Figure 28: Average Temperatures from Bundles 1 through 6, November 2009 to March

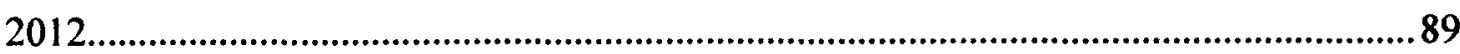

Figure 29: Analysis Domain ......................................................................................99

Figure 30: Ambient and soil temperatures as input to the analysis ..................................94

Figure 31: Modelled and measured temperatures at bundle locations at 3, 4, 5, and 6 ...96

Figure 32: Heat fluxes to/from the waste....................................................................98

Figure 33: Summary of heat budget..............................................................................99 
Figure 34: Sensitivity analysis of the thermal conductivity parameter $k_{i}(W / m \cdot K)$ at instrument (a) bundle 3, (b) bundle 4, (c) bundle 5, and (d) bundle 6 101 Figure 35: Sensitivity analysis of the thermal conductivity parameter $k_{s}\left(W / m \cdot K^{2}\right)$ at instrument (a) bundle 3, (b) bundle 4, (c) bundle 5, and (d) bundle 6 102

Figure 36: Sensitivity analysis of the density $\rho\left(\mathrm{kg} / \mathrm{m}^{3}\right)$ at instrument (a) bundle 3 , (b) bundle 4, (c) bundle 5 , and (d) bundle 6 103

Figure 37: Sensitivity analysis of the specific heat $C_{p}(J / k g \cdot K)$ at instrument (a) bundle 3, (b) bundle 4, (c) bundle 5, and (d) bundle 6 104

Figure 38: Sensitivity analysis of the heat generation parameter $Q_{\mathrm{i}}\left(\mathrm{W} / \mathrm{m}^{3}\right)$ at instrument (a) bundle 3, (b) bundle 4, (c) bundle 5, and (d) bundle 6 106

Figure 39: Sensitivity analysis of the latent heat of fusion $L(\mathrm{~kJ} / \mathrm{kg})$ at instrument (a) bundle 3 , (b) bundle 4 , (c) bundle 5 , and (d) bundle 6 107

Figure 40: Sensitivity analysis of the emissivity constant $\varepsilon$ at instrument (a) bundle 3, (b) bundle 4, (c) bundle 5 , and (d) bundle 6 108

Figure 41: Sensitivity analysis of the coefficient of convection parameter $h_{i}\left(\mathrm{~W} / \mathrm{m}^{2} \cdot \mathrm{K}\right)$ at instrument (a) bundle 3, (b) bundle 4, (c) bundle 5, and (d) bundle 6 109

Figure 42: Instrument Bundle (Bonany et al., 2012b) 119

Figure 43: Timeline of waste lift placement in Sainte-Sophie landfill. 121

Figure 44: Heat fluxes for Column 2 of instrument bundles with time (modified from Vingerhoeds, 2011) 122

Figure 45: Modelled domains used in (a) first, (b) second and (c) third time periods ... 126 Figure 46: Modelled and measured temperatures at instrument bundle locations 3, 4, 5, 6, 7 and 8 129 
Figure 47: Heat fluxes to/from the waste column.

Figure 48: Domain temperature distribution $\left({ }^{\circ} \mathrm{C}\right)$ in the final time step of the analysis. 131

Figure Al: Liquid settlement system ............................................................................ 144

Figure A2: Oxygen sensor ...................................................................................... 145

Figure A3: Moisture and electrical conductivity sensor.................................................. 146

Figure A4: Total earth pressure cell.............................................................................. 147

Figure A5: Vibrating wire piezometer............................................................................ 148

Figure B1: Thermistor temperatures for bundle 1 ........................................................151

Figure B2: Thermistor temperatures for bundle 2 .......................................................... 151

Figure B3: Thermistor temperatures for bundle 3 ........................................................... 152

Figure B4: Thermistor temperatures for bundle 4 ...................................................... 152

Figure B5: Thermistor temperatures for bundle 5 ....................................................... 153

Figure B6: Thermistor temperatures for bundle 6 ........................................................... 153

Figure B7: Thermistor temperatures for bundle 7 ....................................................... 154

Figure B8: Thermistor temperatures for bundle 8 ....................................................... 154

Figure B9: Thermistor temperatures for bundle 9 ........................................................155

Figure B10: Thermistor Temperatures for bundle 10 .................................................. 155

Figure C1: Ambient temperature function for first time period - January $16^{\text {th }}$ to December

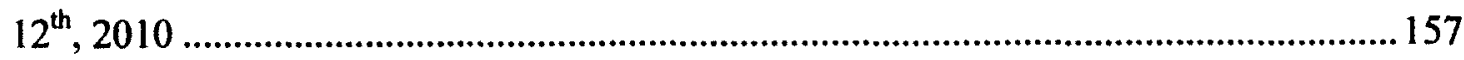

Figure C2: Bottom boundary temperature function for first time period - January $16^{\text {th }}$ to

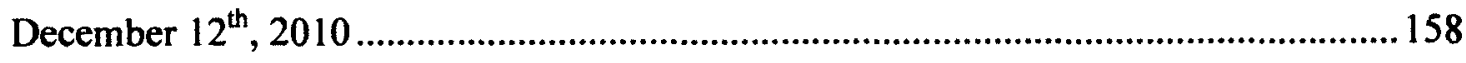

Figure C3: Ambient temperature function for second time period - December $13^{\text {th }}, 2010$

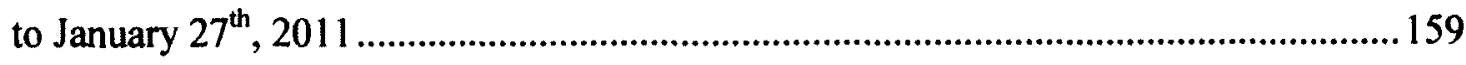


Figure C4: Bottom boundary temperature function for second time period - December $13^{\text {th }}, 2010$ to January $27^{\text {th }}, 2011$ 160

Figure C5: Ambient temperature function for third time period - January $28^{\text {th }}$ to August $22^{\text {nd }}, 2011$ 161

Figure C6: Bottom boundary temperature function for third time period - January $28^{\text {th }}$ to August $22^{\text {nd }}, 2011$ 162

Figure D1: Relative placement of instrument bundles 164 


\section{List of Tables}

Table 1: Waste disposal and diversion rates in Canada (modified from Statistics Canada, 2011). 2

Table 2: Comparison of leachate characterictics between convential and bioreactor landfills (modified from Reinhart \& Townsend, 1998) 14

Table 3: Effect of metal compounds on methane generation $(\mathrm{mg} / \mathrm{L})$ (modified from

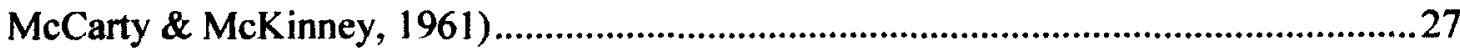

Table 4: Convective heat transfer coefficients between soil and air .............................31

Table 5: Thermal parameters used for modelling (Hanson et al., 2008) .........................43

Table 6: Thermal parameters used to model Tokyo Port Landfill (modified from Yoshida

\& Rowe, 2003)

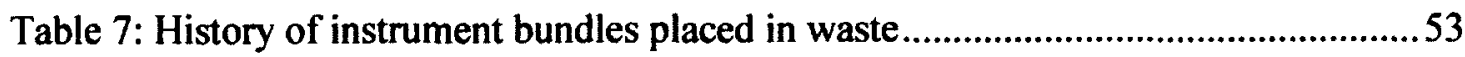

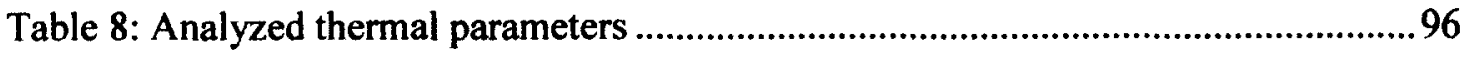

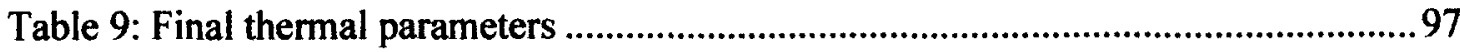

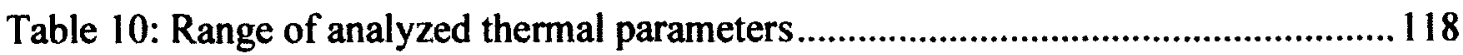

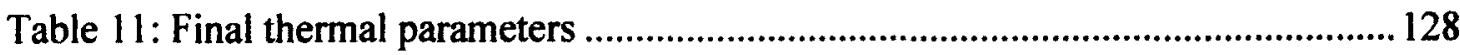

Table A1: Liquid settlement system (RST Instruments Ltd., 2008)............................. 144

Table A2: Oxygen sensor (Apogee Instruments Inc., 2009) ..................................... 145

Table A3: Moisture and electrical conductivity sensor (Decagon Devices, Inc., 2010) 146

Table A4: Total earth pressure cell (RST Instruments Ltd., 2004b) ............................. 147

Table A5: Vibrating wire piezometer (RST Instruments Ltd., 2006)............................ 148

Table D1: Horizontal and vertical separation of bundle layers ..................................163

Table D2: Settlement of instrument bundle locations (masl) with time ....................... 165 


\section{Introduction}

\subsection{Project Significance}

The generation of municipal solid waste (MSW) has increased globally due to population growth and increased consumer spending (Pichtel, 2005). In developing countries, globalisation has caused a rapid increase in per capita waste generation (Pichtel, 2005). Furthermore, in Canada and many Organisation for Economic Co-operation and Development (OCED) countries, there is still an increase in waste generation despite increased education and programs to help reduce waste generation. Thus, waste management is a critical global issue that needs to be addressed.

The term MSW is commonly used to describe the waste originating in residential and industrial, commercial and institutional (IC\&I) sources (Ontario Auditor General, 2010). MSW primarily consists of food waste, paper products, yard waste, metals, plastics, textiles, and glass. The quantity and composition of the waste varies depending on the economy, education and MSW management programs, weather and climate, seasons and type of housing in the area (Pichtel, 2005).

Diversion represents the portion of waste that isn't sent to landfills. Table 1 shows the change in the amount of waste disposed per capita and diversion rate across Canada from 2002 to 2008. Nova Scotia is a leader in waste management practices in Canada, generating the lowest quantity of waste per capita and maintaining the highest diversion rates (Statistics Canada, 2011). The current diversion rate in Ontario is only $22.6 \%$ and in Canada it's only $24.7 \%$ (Statistics Canada, 2011). Therefore, even with programs in place to increase diversion, such as the Green Bin program in Ottawa, landfilling remains the 
dominant method of waste disposal in Canada (Statistics Canada, 2011; Warith et al., 2005).

Table 1: Waste disposal and diversion rates in Canada (modified from Statistics Canada, 2011).

\begin{tabular}{|l|l|l|l|l|l|l|}
\cline { 2 - 8 } \multicolumn{1}{c|}{} & \multicolumn{3}{c|}{ Waste Disposed of Per Capita } & \multicolumn{3}{c|}{ Diversion Rate } \\
\cline { 2 - 8 } & $\mathbf{2 0 0 2}$ & $\mathbf{2 0 0 8}$ & $\%$ Change & $\mathbf{2 0 0 2}$ & $\mathbf{2 0 0 8}$ & $\%$ Change \\
\hline Ontario & 797.8 & 744.8 & -6.6 & 19.0 & 22.6 & 3.6 \\
\hline $\begin{array}{l}\text { Newfoundland \& } \\
\text { Labrador }\end{array}$ & 724.9 & 811.1 & 11.9 & 7.5 & - & \\
\hline $\begin{array}{l}\text { Prince Edward } \\
\text { Island }\end{array}$ & - & - & & & & \\
\hline Nova Scotia & 416.2 & 378.2 & -9.1 & 33.0 & 45.0 & 12.0 \\
\hline New Brunswick & 552 & 641.9 & 16.3 & 24.0 & 35.8 & 11.8 \\
\hline Quebec & 785.7 & 794.5 & 1.1 & 23.0 & 28.6 & 5.6 \\
\hline Manitoba & 775.2 & 801.5 & 3.4 & 19.4 & 15.0 & -4.4 \\
\hline Saskatchewan & 797.7 & 890.7 & 11.7 & 12.8 & 14.2 & 1.4 \\
\hline Alberta & 923.9 & $1,122.0$ & 21.4 & 19.3 & 15.3 & -4.0 \\
\hline British Columbia & 655.9 & 641.3 & -2.2 & 31.2 & 34.9 & 3.7 \\
\hline Canada & 768.1 & 776.5 & 1.1 & 21.6 & 24.7 & 3.1 \\
\hline
\end{tabular}

\subsubsection{Progression of Landfills}

Up until 1950 open-pit dumps remained a common practice, and then the concept of a landfill was introduced (Pichtel, 2005). A sanitary landfill involved placing the waste in layers into a large hole, compacting the waste as much as possible and then covering it with soil (Pichtel, 2005). The initial advantages of landfills were a significant reduction in odour and less risk to public health and safety. Over time, research has improved upon the initial landfill design. Modern landfills now include a leachate collection system, a liner to reduce contamination into the subsurface and a vegetative cover that can hide the presence of the landfill (Pichtel, 2005). Furthermore, as of 2008 in Ontario, it is now mandatory for larger landfills to have an operational gas collection system (MOE, 2010) 
Modern landfills are engineered as either a low-infiltration design or a high-infiltration design. The low-infiltration design limits the amount of leachate generated in order to reduce leachate treatment costs and possibility of groundwater contamination. In this alternative however, the contaminating lifespan is much longer and the waste stabilization rate is decreased substantially. This means the waste can act as a source of contamination well beyond the design life of the engineered components of the landfill (Pichtel, 2005; Tchobanoglous et al., 1993). For this reason the majority of Canada has opted to use the high-infiltration design. In Ontario, landfill covers are designed according to Ontario Regulation $232 / 98$ which requires a high infiltration design (MOE, 2010). The increased infiltration results in a higher moisture content within the waste, which increases the rate of waste stabilization.

The term waste seems to indicate something without value; it is defined as an unusable or

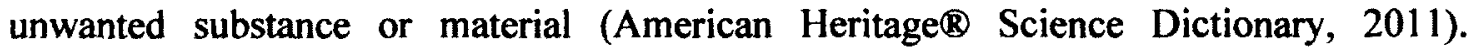
However, with advances in waste management technology it is now possible to consider waste a resource. One of the methods that utilizes this resource is an alternative to the conventional methods of landfilling, a bioreactor landfill. The bioreactor landfill functions by ensuring the conditions in the landfill are ideal for biodegradation, thus enhancing the waste stabilization process (Swati \& Joseph, 2005; Reinhart \& Townsend, 1998; Sharma \& Reddy, 2004). Furthermore, the landfill gas produced from biodegradation of the organics can be collected as an energy resource, making bioreactor landfills an effective waste-to-energy technology. This technology would enable energy generation from the $75.3 \%$ of MSW currently being sent to landfills in Canada (Statistics Canada, 2011). 


\subsection{Description of Problem}

A bioreactor landfill is an engineered landfill that aims to optimize the conditions within the waste in order to maximize waste stabilization (Swati \& Joseph, 2005; Reinhart \& Townsend, 1998; Sharma \& Reddy, 2004). The conditions are controlled to make an ideal environmental for microbial biodegradation of the waste to occur. The parameters that are often optimized include temperature, moisture content, oxygen content, and $\mathrm{pH}$ (Reinhart \& Townsend, 1998; Sharma \& Reddy, 2004; Christensen \& Kjeldsen, 1989).

There are numerous benefits of a bioreactor in comparison to conventional landfilling. Due to the increased rate of biodegradation, the waste stabilizes within 5 to 10 years as opposed to a dry tomb landfill where the waste can slowly degrade for over 100 years (Swati \& Joseph, 2005; Townsend et al., 2008; Pacey et al., 1999; Reinhart \& Townsend, 1998; Pichtel, 2005). As a result, the contaminating lifespan of a bioreactor landfill is much shorter and therefore there is less risk of contaminants leaching into the subsurface after closure of the landfill (Karthikeyan \& Joseph, 2007). In addition, an increased rate of waste biodegradation also maximizes the available airspace (Reinhart \& Townsend, 1998; Pichtel, 2005). This means a greater waste volume can be placed over the same geographical footprint, increasing the landfill lifetime and saving on future construction costs associated with preparing new landfill cells (Karthikeyan \& Joseph, 2007).

Bioreactor landfills also provide a reduction in leachate treatment costs, as recirculating the leachate through the waste can provide treatment of the leachate. This can reduce the costs associated with storing and treating the leachate outside of the landfill (Karthikeyan \& Joseph, 2007; Sharma \& Reddy, 2004; Pichtel, 2005). In addition, as the leachate is 
treated within the landfill, the contaminant concentrations within the leachate are reduced which has numerous advantages (Reinhart \& Townsend, 1998; Reinhart, 1996; Warith, 2002). Firstly, the treatment costs of the leachate are substantially reduced. Secondly, if there is a failure of the engineered components of the landfill such as the liner, the adverse environmental impacts are reduced (Reinhart \& Al-Yousfi, 1996).

Bioreactor landfills can be operated either as anaerobic bioreactor landfills or aerobic bioreactor landfills. Aerobic bioreactor landfills function by injecting air into the waste to promote stabilization through aerobic activity, while limiting methane generation (Karthikeyan \& Joseph, 2007; Reinhart \& Townsend, 1998; Sharma \& Reddy, 2004; Lefebvre et al., 2000). The principle advantage of aerobic bioreactor landfills is the waste stabilization process is faster than the anaerobic process. This allows for the greatest gain of valuable airspace and the shortest contaminating lifespan.

Anaerobic bioreactor landfills involve enhancing the environmental conditions within the landfill in the absence of oxygen (Pichtel, 2005; Reinhart \& Townsend, 1998; Karthikeyan \& Joseph, 2007). Anaerobic bioreactors are able to increase the amount and quality of landfill gas production, which can be used to produce energy (Karthikeyan \& Joseph, 2007). If properly engineered, the gas collection system captures the majority of the landfill gas thereby reducing the amount of greenhouse gases released to the atmosphere (Warith, 2002; Sharma \& Reddy, 2004). In addition, the enhanced waste stabilization means the rate of settlement will increase, maximizing the airspace and minimizing the landfill footprint. 
Although the advantages of bioreactor landfills are known, the technology is still relatively new and on-going research will maximize the efficiency of bioreactor landfills. Lab-scale studies have proven the concept of bioreactor landfills to be extremely beneficial (Pohland, 1975; Tittlebaum, 1982). The results demonstrate that with leachate recirculation, it is possible to expedite biodegradation and significantly improve the quantity and quality of landfill gas (Reinhart \& Townsend, 1998). However, the beneficial results experienced in the lab-scale and pilot-scale experiments are more difficult to extrapolate to a full-scale setup, primarily due to the different environmental conditions in the field and heterogeneous nature of the waste (Karthikeyan \& Joseph, 2007). In addition, much of the research to date has focussed on bioreactors operating in warmer climates whereas a bioreactor landfill in Canada would operate under much different conditions. The cold weather experienced by landfills in Canada, can make it extremely difficult to optimize the conditions within the waste, especially temperature. Therefore, there is a need to better understand and optimize the waste stabilization process occurring in the field in northern climates in order to maximize the benefits of this technology.

\subsection{Overview of Thesis}

This thesis consists of 7 sections. Section 1 provides a site overview of the Sainte-Sophie bioreactor landfill and project description. Section 2 contains a literature review of the components of a bioreactor landfill, description of the waste stabilization process and important parameters that impact the rate of stabilization, studies where instrumentation was installed within a bioreactor in order to analyze the waste stabilization process, 
important thermal parameters of waste and a summary of efforts made to model the heat transfer within waste.

The Sainte-Sophie bioreactor landfill was instrumented with sensors that measure important parameters that impact the rate of waste stabilization as described in Section 3. Section 4 discusses the temperature data collected from the thermistors and oxygen content data measured by the oxygen sensor. Sections 5 provides an introduction to modelling the transfer of heat through the waste, which was used to develop a heat budget for a bioreactor landfill operating in a northern climate. Sections 6 and 7 are presented as two separate journal papers. The first paper summarizes a sensitivity analysis that was completed to determine the most important parameters that impact the heat transfer through the waste. The second paper provides a refined model and heat budget for the first three lifts of waste placed in the area.

\subsection{Sainte-Sophie Bioreactor Landfill}

The Sainte-Sophie bioreactor landfill (Écocentre de Sainte-Sophie) is located near the village of Sainte-Sophie, approximately $50 \mathrm{~km}$ northwest of Montreal, Quebec. The facility is owned and operated by Waste Management of Canada Corporation (WM). The facility includes the first full-scale bioreactor to be constructed in Canada, which was filled with waste between 2000 and 2005. A second anaerobic bioreactor landfill was constructed and began accepting waste in 2006.

The new bioreactor at the Sainte-Sophie landfill, known as Zone 4, has a footprint of approximately $475 \mathrm{~m}$ by $650 \mathrm{~m}$ and is permitted to receive up to one million tonnes of waste per year. The estimated waste depth once the cell is completely full is $25 \mathrm{~m}$. Figure 
1 shows a plan view of the Zone 4 . The relative location of the two columns of instrument bundles are shown as blue dots in the figure and the instrument shed containing the datalogging equipment is shown in red. Phases 1 and 2 are currently at full capacity and a final cover has been placed over this section of the landfill. Filling of Phase 3 began in September 2009, starting from the southeast side of the cell. Phase 3, the area of the landfill containing the instrument bundles, is currently nearing capacity. The landfill is expanding to include Phase 4, located to the right of the figure boundary, which is now under development.

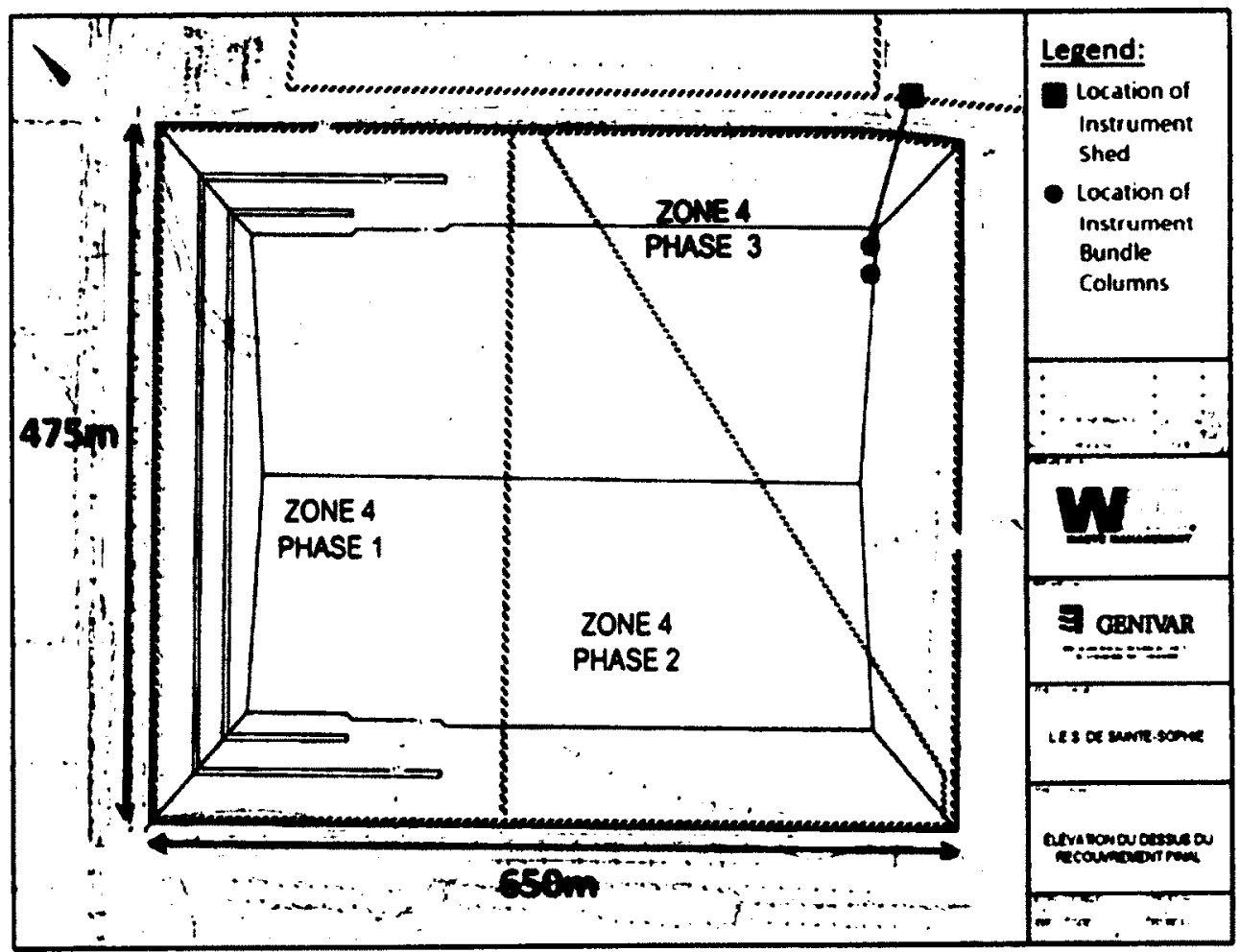

Figure 1: Zone 4 of the Sainte-Sophie bioreactor landfill (modified from Genivar, 2008)

The Sainte-Sophie landfill contains a double-composite liner system. This is similar to the system recommended by the Ontario regulations and commonly used by landfills in 
Ontario. The first layer consists of a gravel layer, which contains a leachate collection system, underlain by a composite liner which consists of high density polyethylene (HDPE) liner underlain by a geosynthetic clay liner. Beneath the upper composite liner system is a second leachate collection system or leak detection system which consists of a gravel layer underlain with a composite liner consisting of a HDPE liner underlain a lowpermeability natural clay.

Both bioreactor landfills contain a horizontal gas collection system. In total, over 70 million cubic metres of landfill gas $\left(9000 \mathrm{~m}^{3} / \mathrm{h}\right)$ are produced annually from the biodegradation of waste. The landfill gas is transported to the nearby Cascades Inc. pulp and paper mill in Saint-Jérôme, Quebec which uses the landfill gas for heating purposes.

\subsection{Project Description}

This thesis was part of a three-year research effort to instrument a waste cell of a bioreactor landfill. The overall goal of the research project is to develop a better understanding of how operating practices and environmental conditions influence waste stabilization, in order to maximize landfill gas production and airspace utilization and minimize the landfill footprint. Instruments were installed within the Sainte-Sophie bioreactor landfill as it was progressively filled with waste to monitor parameters that impact the rate of waste stabilization. Twelve instrument bundles were installed in two vertical columns to measure the temperature, settlement, moisture content, total load, percent oxygen, mounding of leachate and electrical conductivity. A data acquisition system installed in a shed at the landfill, stored the data collected from the instrument bundles. The system was connected to a modem to enable access to the data from Ottawa 
in real-time. The quantity and quality of landfill gas were also monitored at the site by WM. A weather station was installed to monitor environmental conditions at the site including wind speed and direction, precipitation, ambient air temperatures and relative humidity. The weather station was not completely functional throughout the entire duration of the project and therefore temperature and precipitation data were obtained from the Pierre Elliot Trudeau International Airport weather station (approximately 50 $\mathrm{km}$ South of the site) operated by Environment Canada. The data obtained from the weather station was compared to the data from Environment Canada to ensure accuracy.

The ambient temperatures and temperature data within the waste were modelled with the ultimate goal of developing a model for the transfer and generation of heat throughout the landfill. Ultimately, the model will allow us to link parameters such as lift placement and thickness, compaction, moisture content, oxygen content, and temperature at placement to the rate of waste degradation. In addition, the model will allow landfill operators to better understand how operating practices and environmental conditions affect waste stabilization in northern climates. In coupling the model to the landfill gas production and settlement data, the model will allow users to compare various waste placement scenarios with the efficiency of waste stabilization. Ultimately, the model can be used as a tool to improve current operating practices, thus maximizing the usable airspace and gas generation.

This thesis presents and discusses the data from the temperature and oxygen sensors, from the time of the first instrument bundle installation in November 2009 through to March 2012. The temperature data were modelled using a commercial finite element software package in order to estimate the thermal parameters of the waste and develop a 
heat budget for the waste. The thermal parameters are of particular significance when modelling waste placed under winter weather conditions. A sensitivity analysis was completed to determine the relative importance of each parameter when modelling the heat transfer within the waste, which impacts the rate of waste stabilization in northern climates. The model was used to develop a heat budget that estimates the various heat fluxes to/from the waste, and how the heat is stored within the waste. The model allows us to increase our understanding of the waste stabilization process, the feasibility of a bioreactor, and best waste management practices in northern climates. 


\section{Literature Review}

\subsection{Engineered Components of a Bioreactor Landfill}

Many components of a bioreactor landfill are designed according to the Ontario landfill regulations (MOE, 2010). These include the leachate recirculation system, landfill gas collection system, liner system and final cover. Figure 2 shows an example of an anaerobic bioreactor landfill (Waste Management, 2004). In the figure, vertical leachate recirculation pipes are used to equally distribute moisture throughout the waste and a vertical gas collection system collects landfill gas. The collected landfill gas then sent to a generator in order to be converted into electrical energy. The next section discusses the guidelines and industry best practices for the various components of a bioreactor landfill.

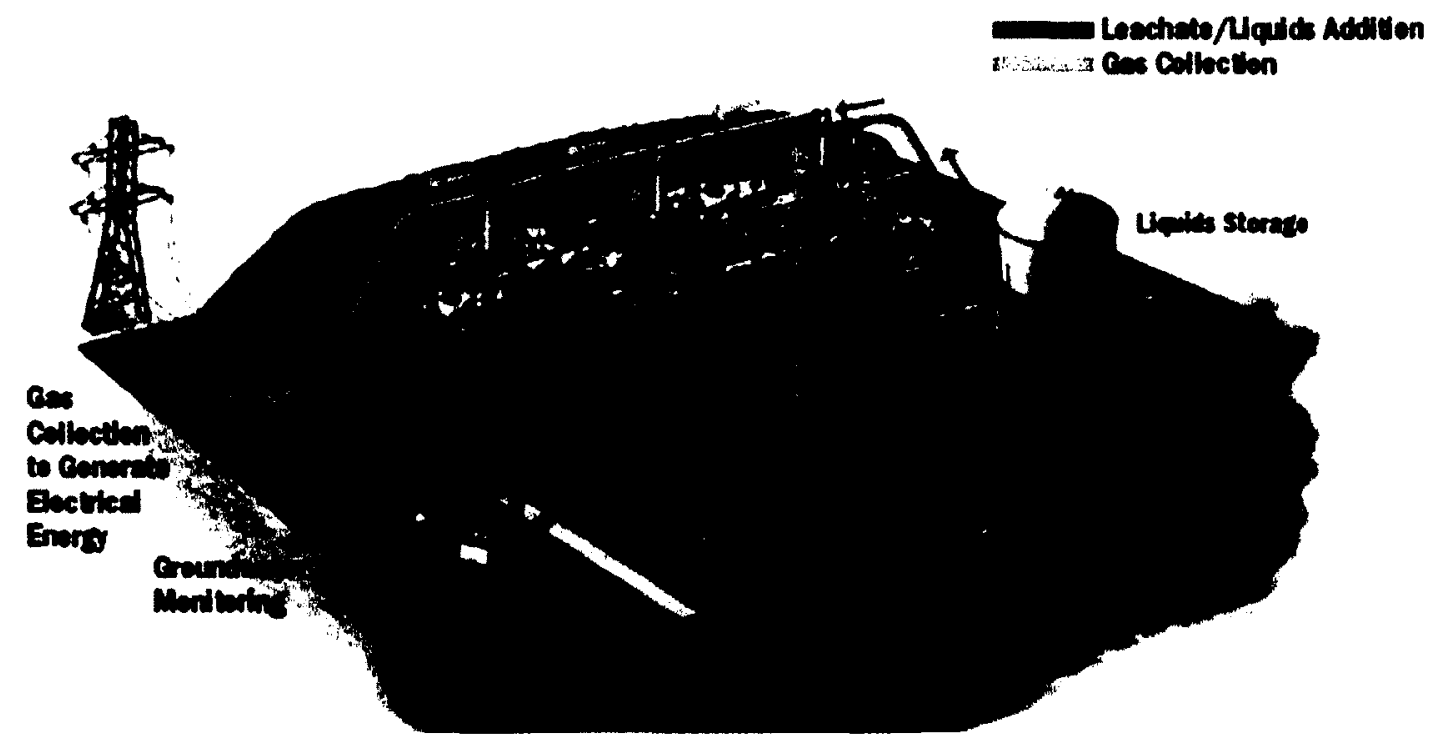

Figure 2: Anaerobic bioreactor illustrating leachate recirculation (Waste Management, 2004). 


\subsubsection{Leachate Recirculation System}

Leachate recirculation systems aim to control the moisture content within the waste at an optimum level for biodegradation (Karthikeyan \& Joseph, 2007; Reinhart \& Townsend, 1998). As a result, leachate recirculation can have a significant impact on the rate of stabilization. Furthermore, leachate recirculation serves as a medium for leachate treatment and storage (Karthikeyan \& Joseph, 2007; Reinhart \& Townsend, 1998; Sharma \& Reddy, 2004). The positive impact of leachate treatment is illustrated in Table 2. Leachate recirculation helps to optimize the levels of nutrients and microorganisms within the landfill, dilute amounts of inhibitory compounds and regulate $\mathrm{pH}$ (Reinhart \& Townsend, 1998; Reinhart, 1996; Sharma \& Reddy, 2004). The most common leachate recirculation setups are horizontal and vertical injection systems. Horizontal leachate recirculation systems are generally used as they allow for large volumes of leachate to be recirculated and don't negatively impact the normal landfill operation (Reinhart \& Townsend, 1998). At many operating bioreactors, it is much more difficult to distribute the moisture equally throughout the landfill than anticipated due to the heterogeneous nature of the waste (Rowe et al., 2004). 
Table 2: Comparison of leachate characterictics between convential and bioreactor landfills (modified from Reinhart \& Townsend, 1998)

\begin{tabular}{|l|c|c|}
\hline \multicolumn{1}{|c|}{ Parameter (mg/L) } & $\begin{array}{c}\text { Conventional } \\
\text { Landfill }\end{array}$ & Bioreactor Landfill \\
\hline Iron & $20-2100$ & $4-1095$ \\
\hline BOD & $20-40000$ & $12-28000$ \\
\hline COD & $500-60000$ & $20-34560$ \\
\hline Ammonia & $30-3000$ & $6-1850$ \\
\hline Chloride & $100-5000$ & $9-1884$ \\
\hline Zinc & $6-370$ & $0.1-66$ \\
\hline pH & $4.7-8.8$ & $5.4-8.6$ \\
\hline
\end{tabular}

\subsubsection{Landfill Gas Collection System}

The product produced as a result of biodegradation of the MSW is known as landfill gas. It is composed primarily of 40 to $70 \%$ methane, and 30 to $60 \%$ carbon dioxide (Zimmerman \& Issacson, 1988). Hydrogen, nitrogen and oxygen gases as well as water vapour can also be present in small quantities (El-Fadel et al., 1996b). Due to the optimization of the conditions within the landfill, landfill gas production is significantly higher than in conventional landfills (Pichtel, 2005; Reinhart \& Townsend, 1998) as illustrated in Figure 3. This increase in landfill gas can be extremely beneficial provided the majority of the landfill gas is collected, resulting in a large source of energy. However, capturing this potential energy is only possible if an engineered gas collection system and proper monitoring procedure are in place. The most common gas collection systems are horizontal gas collection pipes (Reinhart \& Townsend, 1998). 


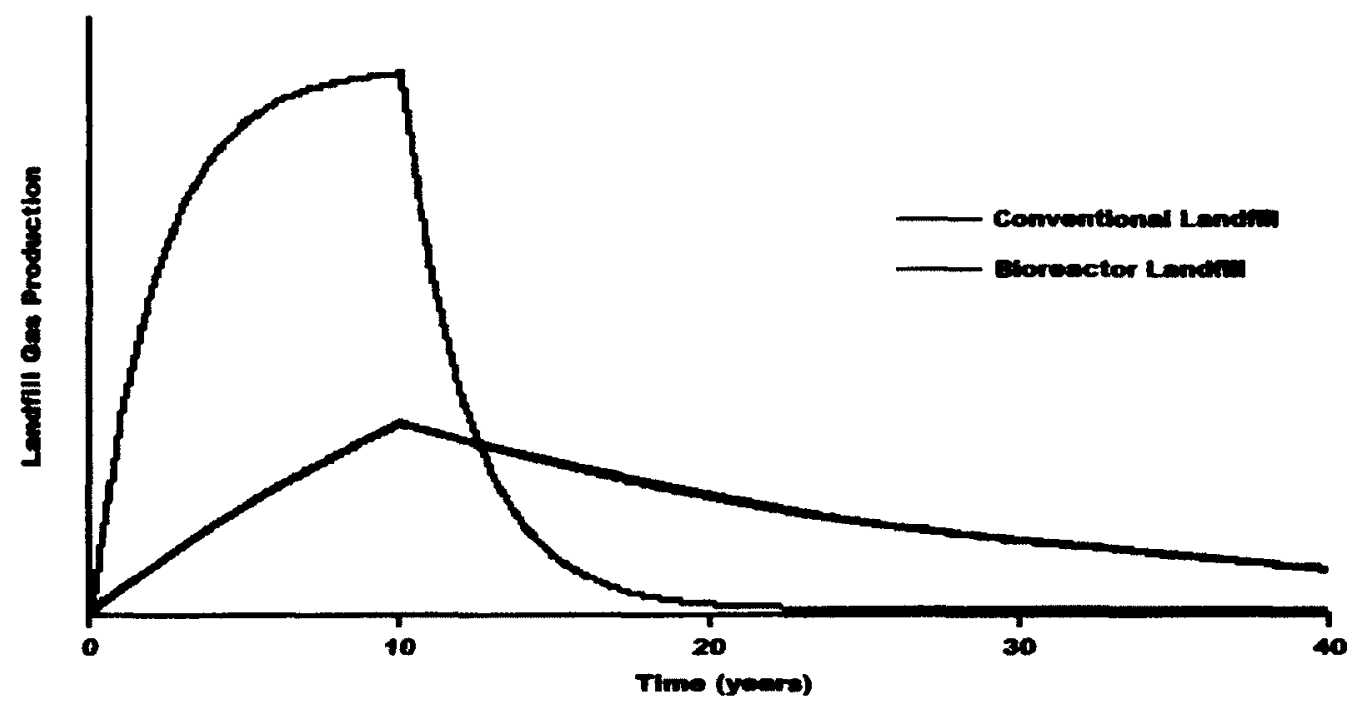

Figure 3: Landfill gas production from convential and bioreactor landfills (modified from Townsend et al., 2008)

According to the Ontario regulations, all larger landfills are now required to collect the landfill gas produced as a result of waste degradation (MOE, 2010). The gas is preferentially used by a direct user, who can use the landfill gas for both heating and energy. If this option is not feasible, the landfill gas can be combusted in a generator, in order to produce electricity. As a minimum effort, the gas must be flared to reduce the methane to carbon dioxide and water vapour. Methane has an extremely high greenhouse gas potential (21 times greater than carbon dioxide); indicating the importance of having a proper landfill gas collection system in place to reduce methane gas emissions from landfills.

\subsubsection{Liner and Leachate Collection Systems}

The landfill liner and leachate collection systems are designed to meet standards established in the Ontario regulations (MOE, 2010). The liner system consists of a drainage layer, a liner and the leachate collection system (Pichtel, 2005; Reinhart \& 
Townsend, 1998). The main goal of the liner and leachate collection system is to prevent the leaching of landfill contaminants into the subsurface groundwater. One of the main problems associated with the leachate collection system is clogging, which leads to mounding of leachate. Clogging generally occurs during the acidogenic phase of degradation, when calcium, iron, magnesium and other metals are likely to form precipitates (Reinhart \& Townsend, 1998). Some researchers believe a bioreactor landfill can induce clogging due to the increased rate of stabilization (Reinhart \& Townsend, 1998).

\subsubsection{Daily, Intermediate and Final Cover}

Daily cover is a thin layer of material placed over the waste at the end of each day in order to reduce odour and particulates from escaping the landfill and decrease the attraction of vermin (Reinhart \& Townsend, 1998). At the Sainte-Sophie landfill, the daily cover material commonly used is contaminated soil. The daily cover must consist of a high permeability material to allow for infiltration into the waste and prevent ponding of rain water on the surface (Reinhart \& Townsend, 1998). Intermediate cover is slightly thicker than the daily cover and is used to cover a waste lift. Similarly to the daily cover, the intermediate cover must be composed of a high permeability material to allow for infiltration. The final cover is added once the entire landfill cell has been filled. The regulations in Ontario require the final cover to minimize infiltration (MOE, 2010). This is often done via a clay liner that has a low hydraulic conductivity or a very low density polyethylene (VLDPE) liner. The clay layer should remain saturated to form a relatively impermeable membrane for landfill gas migration (Reinhart \& Townsend, 1998). Above 
the clay or VLDPE layer there is a layer of top soil, which helps to ensure slope stability and promotes the grow of vegetation (Koemer \& Daniel, 1997).

\subsection{Waste Stabilization in an Anaerobic Bioreactor Landfill}

Anaerobic bioreactor landfills optimize the conditions within the landfill in order to promote rapid biodegradation of the waste (Swati \& Joseph, 2005; Reinhart \& Townsend, 1998; Sharma \& Reddy, 2004). Biodegradation occurs without the presence of oxygen in order to produce landfill gas, primarily consisting of carbon dioxide and methane. Researchers studying the degradation of waste, suggest the stabilization process occurs in five phases (Pichtel, 2005; Kim \& Pohland, 2003; Warith et al., 2005; Christensen \& Kjeldsen, 1989; Reinhart \& Townsend, 1998). The quality and quantity of both landfill gas and leachate vary tremendously depending on the phase of degradation, as shown in Figure 4. There are many simultaneous reactions that occur throughout the landfill, and the phase of stabilization is dependent on the moisture content, level of compaction and time of waste placement (El-Fadel et al., 1996a; Pichtel, 2005). This section describes the various phases of waste biodegradation. 


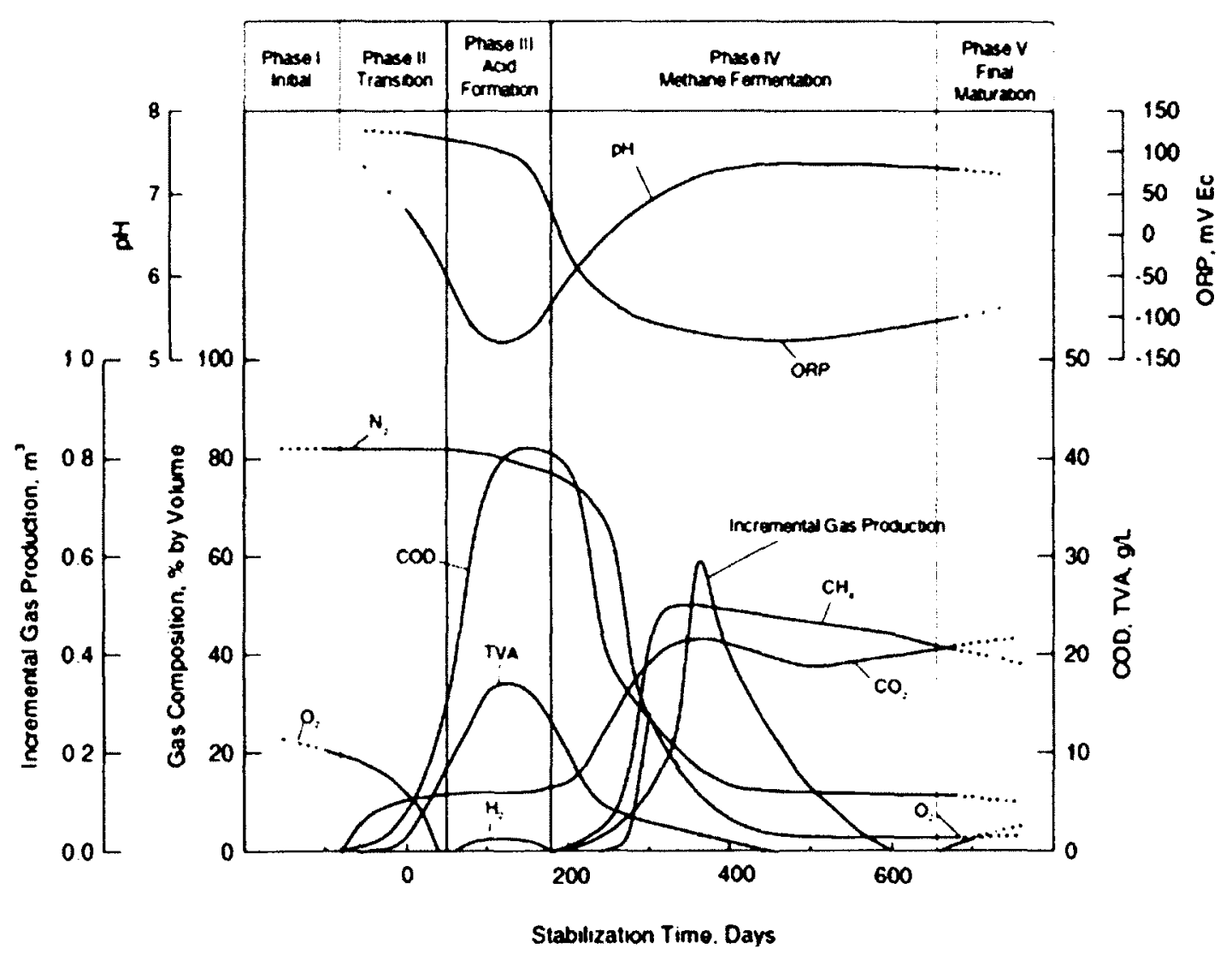

Figure 4: Phases of biodegradation within a landfill (modified from Kim \& Pohland, 2003)

\subsubsection{Phase 1: Aerobic Phase}

Phase 1 occurs directly after placement of the waste and includes the period of time required for the bacteria to acclimatize to the environmental conditions in the waste. The first phase is considered aerobic, as oxygen is present in the void space of the waste. However, the overall quantity of oxygen available is relatively small, depending on the degree of waste compaction (Warith et al., 2005). Although all the bacteria required for methanogenesis are present, the level of microbial activity is low until moisture levels increase sufficiently to promote waste biodegradation (Reinhart \& Townsend, 1998). 
Qian et al. (2002) concluded the aerobic phase of biodegradation could last between 3 to 18 months. The aerobic phase of degradation generates significantly more heat per mass of organics than any of the anaerobic phases (El-Fadel, 1999).

\subsubsection{Phase 2: Transition Phase}

The transition phase is the first anaerobic degradation phase and occurs immediately after the oxygen in the landfill is depleted (Christensen \& Kjeldsen, 1989; Reinhart \& Townsend, 1998). Hydrolysis of the more complex organics within the landfill occurs as these molecules are broken down into sugars, amino acids, and fatty acids (Warith et al., 2005). The complex organics are more difficult to break down and therefore this is the rate limiting phase of biodegradation within the landfill. The limited quantities of available oxygen result in a shift towards reducing conditions as nitrates and sulphates become the primary electron acceptors (Reinhart \& Townsend, 1998). The result of these reduction reactions is the production of nitrogen, hydrogen sulfide, carbon dioxide and organic acids (Christensen \& Kjeldsen, 1989). Some of the carbon dioxide within the system dissolves to form carbonic acid (Tchobanoglous et al., 1993). This change, along with the formation of the acids causes the $\mathrm{pH}$ within the landfill to decrease (Warith et al., 2005; Tchobanoglous et al., 1993). The hydrolysis of complex organics is the anaerobic process that generates the largest amount of heat (El-Fadel, 1999). However, the amount of heat is still negligible in comparison to the amount of heat generated during the aerobic phase.

\subsubsection{Phase 3: Acid Formation Phase}

The second anaerobic phase that occurs in the landfill is the acid formation phase. During this phase of the biodegradation process, acidogenic fermentation converts the products 
from the first anaerobic phase into volatile fatty acids (VFAs), primarily acetic, butyric, lactic and propionic acids (Pichtel, 2005). During this phase, the majority of nutrients and easily degradable organics in the MSW are consumed (Reinhart \& Townsend, 1998). The production of the VFAs decreases the $\mathrm{pH}$ within the landfill to approximately 5 (Pichtel, 2005). There is no methane production during this phase as the landfill is too acidic for the methanogenic activity, and therefore carbon dioxide and hydrogen are the main gases produced (Pichtel, 2005). With the increased acidity, metals such as calcium, iron and manganese are solubilized in the leachate (Pichtel, 2005; Warith et al., 2005). The formation of butyric and propionic acids are endothermic processes, and this phase of biodegradation absorbs a small amount of heat (El-Fadel, 1999).

\subsubsection{Phase 4: Methane Fermentation Phase}

The fourth phase of biodegradation is the methane fermentation phase, during which methanogenic bacteria transform the acetic acid, carbon dioxide and hydrogen gas into methane (Warith et al., 2005). The pH increases to between 6 to 8 , the optimal range for the grown of methanogenic bacteria (Tchobanoglous et al., 1993; Pichtel, 2005). This stage can last upwards of 10 years, and it is during this phase where the majority of the landfill gas is produced. In addition, this phase is when the concentration of the methane in the landfill gas is the highest (Pichtel, 2005). As the pH increases, the metals dissolved in the previous phase begin to precipitate (Pichtel, 2005; Warith et al., 2005). The production of methane is an exothermic process however the reactions generate a very small amount of heat (El-Fadel, 1999) 


\subsubsection{Phase 5: Maturation Phase}

The final phase of stabilization occurs once the majority of the readily degradable organics have been converted into methane and carbon dioxide (Pichtel, 2005). This causes the overall generation of landfill gas to decrease substantially (Karthikeyan \& Joseph, 2007; Warith et al., 2005; Pichtel, 2005). Eventually, nitrogen gas and oxygen will start to diffuse deeper into the landfill from the ambient air (Christensen \& Kjeldsen, 1989).

\subsection{Physical Properties of MSW and their Impact on Waste}

\section{Stabilization}

The most important physical properties of MSW are moisture content, field capacity, temperature, oxygen content, density, $\mathrm{pH}$ and the level of nutrients within the waste. Each parameter plays an important role in determining the rate of waste stabilization within a landfill.

\subsubsection{Moisture Content and Field Capacity}

Moisture content is an extremely important parameter as the biodegradation process is delayed until sufficient moisture is present in the landfill. The initial volumetric water content of MSW is approximately $10 \%$ to $20 \%$ (Oweis et al., 1990). The addition of moisture to a bioreactor landfill is generally completed through controlled leachate recirculation. At the newer Sainte-Sophie bioreactor landfill, leachate is not recirculated and the moisture content is controlled by increasing the compaction and allowing sufficient moisture to enter the waste during the filling phase. 
Recirculating the leachate accelerates the start of biodegradation and significantly reduces the stabilization period of MSW (Swati \& Joseph, 2005; Townsend et al., 2008; Pacey et al., 1999; Sharma \& Reddy, 2004; Pichtel, 2005). Many researchers have shown that the methane production rate increases by increasing the moisture content of the MSW (Reinhart \& Townsend, 1998). The minimum gravimetric moisture content required to operate a bioreactor is $25 \%$, with optimum gravimetric moisture contents between $40 \%$ and $70 \%$ (Reinhart \& Townsend, 1998). The gravimetric moisture content is defined as the mass of water divided by the mass of dry solid waste. By increasing the gravimetric water to the optimal range both the rate of gas production and the percentage of methane in the gas are increased (Warith, 2003; Rees, 1980).

The field capacity of MSW is the maximum amount of moisture that can be held within waste prior to gravity drainage (Tchobanoglous et al., 1993; Oweis et al., 1990). Thus, leachate generation will only begin once the field capacity of the waste is exceeded. The field capacity is a function of the age of waste, density and porosity (Pichtel, 2005; Tchobanoglous et al., 1993). As the waste is compacted and degraded with time, the organic fraction and pore space within the waste decreases, reducing the capability of the waste to retain water (Holmes, 1983). The field capacity of solid waste within a landfill was found to be approximately $20 \%$ to $30 \%$ (Holmes, 1983; Tchobanoglous et al., 1993; Oweis et al., 1990).

\subsubsection{Temperature}

Decomposition of waste, through aerobic and anaerobic processes, is the main generator of heat in a landfill (Yesiller et al., 2005). The biodegradation of waste occurs from mesophilic bacteria at temperatures between $30^{\circ} \mathrm{C}$ to $40^{\circ} \mathrm{C}$ or thermophilic bacteria at 
temperatures between $50^{\circ} \mathrm{C}$ to $60^{\circ} \mathrm{C}$ (El-Fadel et al., 1996b; Rowe \& Islam, 2009; Ham et al., 1994; Barlaz et al., 1990). Hartz et al. (1982) found the optimum temperature for methanogens to be $41^{\circ} \mathrm{C}$, while Pfeffer (1974) concluded the optimum temperature was $42^{\circ} \mathrm{C}$. When raising the temperature from $20^{\circ} \mathrm{C}$ to $40^{\circ} \mathrm{C}$, the methane production can increase as much as 100 times (Christensen \& Kjeldsen, 1989). Lab-scale studies have shown temperatures above $40^{\circ} \mathrm{C}$ can actually decrease the rate of methane production (Hartz et al., 1992; Rees, 1980; Mata-Alvarez \& Martinez-Viturtia, 1986; Kasali \& Senior, 1989).

Temperature impacts both the reaction rates of the degradation process as well as the amount of bacteria present in the landfill (Hartz et al., 1982). The impact of temperature on the microbial population within the landfill is summarized in Figure 5. Temperatures over $70^{\circ} \mathrm{C}$ are described as lethal to the methanogenic population (El-Fadel et al., 1996b).
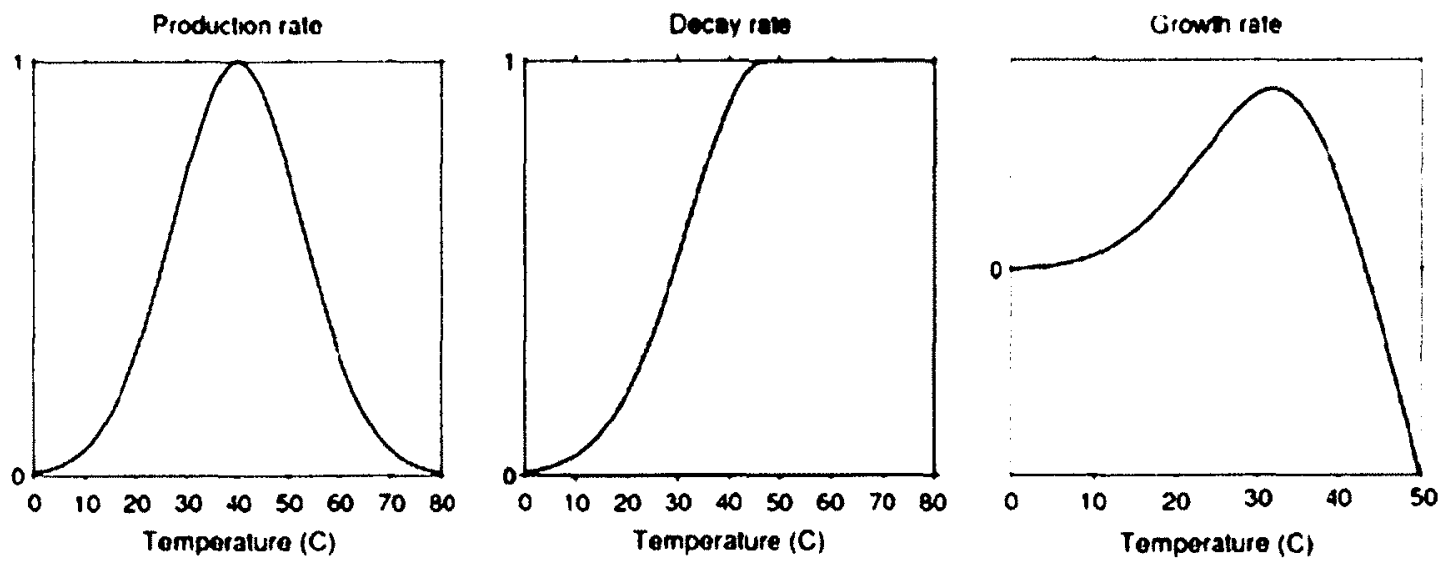

Figure 5: Microbial activity within the landfill based on temperature (with permission from Gholamifard et al., 2008)

Various procedures have been used at bioreactor landfills in an attempt to control temperature. For example, air can be injected into the landfill via the gas collection pipes, 
promoting aerobic biodegradation and heat generation within the waste (Reinhart \& Townsend, 1998; Hinkley Center et al., 2008). In addition, heated leachate can be recirculated to raise the temperature within the landfill (Reinhart \& Townsend, 1998).

\subsubsection{Oxygen Concentration}

The type of biodegradation, either aerobic or anaerobic, occurring within the landfill is determined by the presence of oxygen. Methanogens, the group of microorganisms that degrade the MSW into methane and carbon dioxide are anaerobic organisms and therefore when oxygen is present in the void space of the waste, methane is not produced. Generally there is a short aerobic phase where the oxygen within the pore space is consumed and then the system becomes anaerobic. In addition, in the top layers of the landfill, there is an aerobic zone that results from oxygen that diffuses into the landfill from the atmosphere (Warith, 2003; Lefebvre et al., 2000). This zone is generally confined to the top $1 \mathrm{~m}$ of the landfill, however if the suction in the gas collection pipes is too high, oxygen can be pulled into the system increasing the zone of aerobic activity (Christensen \& Kjeldsen, 1989). The heat produced from the consumption of oxygen initially within the void space has been estimated to account for $18.5 \%$ of the temperature rise within the landfill (Lefebvre et al., 2000). Therefore, it was concluded that a majority of the temperature increase within the landfill results from aerobic activity occurring from the consumption of the oxygen diffusing into the landfill from the ambient air (Lefebvre et al., 2000).

\subsubsection{Density}

The MSW exiting the truck has a density between 180 to $415 \mathrm{~kg} / \mathrm{m}^{3}$, that can increase to over $800 \mathrm{~kg} / \mathrm{m}^{3}$ after compaction using a sheepsfoot compactor (Tchobanoglous et al., 
1993). In comparison, Pichtel (2005) concluded compacted waste within the landfill had densities between 300 to $900 \mathrm{~kg} / \mathrm{m}^{3}$. The better the degree of compaction, the higher the resulting density of the waste. Furthermore, the density of the waste increases with an increase in the degree of saturation (Karthikeyan \& Joseph, 2007; Pacey et al., 1999). Therefore, in a bioreactor landfill the density is generally much higher due to the increased moisture content of the waste (Pacey et al., 1999). As a result, engineered components such as the leachate collection system and gas collection system must be designed to withstand the additional load (Pacey et al., 1999).

\section{$2.3 .5 \mathrm{pH}$}

The $\mathrm{pH}$ of leachate within the landfill can have a significant impact on the stabilization process and production of methane. The methanogenic bacteria are extremely sensitive to changes in $\mathrm{pH}$ in comparison to the fermentative and acidogenic microorganisms. The optimum $\mathrm{pH}$ for methanogenic activity is within a $\mathrm{pH}$ range of 6.0 to 8.0 (Christensen \& Kjeldsen, 1989; Warith, 2003; El-Fadel et al., 1996b). Outside of this range, the rate of activity of the methanogens decreases substantially, and therefore less methane is produced.

The $\mathrm{pH}$ level within the landfill is often one of the more difficult parameters to control. If the rate of methanogenic bacteria are decreased by other factors such as the presence of hydrogen, the conversion of acetic acid to methane stops, leading to an accumulation of acids in the landfill (Christensen \& Kjeldsen, 1989). This in turn, can decrease the pH outside the healthy range, stopping the production of methane gas altogether (Christensen \& Kjeldsen, 1989). At $\mathrm{pH}$ values less than 6.8 , sulphate reducing bacteria take over, and the organics within the waste are converted to carbon dioxide (Christensen \& Kjeldsen, 
1989). The microorganisms operating within a bioreactor are particularly sensitive to changes in pH due to the increased rate of stabilization (Pacey et al., 1999). During the early stages of leachate recirculation, the $\mathrm{pH}$ should be monitored and $\mathrm{pH}$ buffering can be done to ensure the microorganisms are not negatively impacted (Pacey et al., 1999).

\subsubsection{Nutrients and Inhibitory Compounds}

Bacteria within the waste require various nutrients to ensure their proper function. Many of the nutrients, such as nitrogen and phosphorous, are readily available in the landfill. Other metals required for the microorganisms to function are sodium, potassium, calcium, magnesium, zinc, iron and copper (Christensen \& Kjeldsen, 1989). These metals are also generally available but may be deficient in certain areas of the landfill (Christensen \& Kjeldsen, 1989). For most compounds, there is an ideal concentration for microbial activity and high concentrations of metals such as sodium, magnesium and ammonium can actually inhibit the biodegradation of MSW (Christensen \& Kjeldsen, 1989; McCarty \& McKinney, 1961). The ideal concentrations are summarized by McCarty \& McKinney (1961) in Table 3. In addition, high sulphate concentrations inhibit the production of methane, as sulphate can be reduced from $\mathrm{SO}_{4}$ to $\mathrm{S}_{2}$ which is toxic to methanogenic bacteria (Rees, 1980; Christensen \& Kjeldsen, 1989). 
Table 3: Effect of metal compounds on methane generation $(\mathrm{mg} / \mathrm{L})($ modified from McCarty \& McKinney, 1961)

\begin{tabular}{|l|c|c|c|}
\hline \multicolumn{1}{|c|}{ Compound } & $\begin{array}{c}\text { Stimulating } \\
\text { Effect }\end{array}$ & $\begin{array}{c}\text { Moderate } \\
\text { Inhibition }\end{array}$ & $\begin{array}{c}\text { Significant } \\
\text { Inhibition }\end{array}$ \\
\hline Sodium & $100-200$ & $3500-5500$ & 8000 \\
\hline Potassium & $200-400$ & $2500-4500$ & 12000 \\
\hline Calcium & $100-200$ & $2500-4500$ & 8000 \\
\hline Magnesium & $75-150$ & $1000-1500$ & 3000 \\
\hline Ammonium & $50-200$ & $1000-3000$ & 3000 \\
\hline
\end{tabular}

\subsection{Thermal Properties of MSW}

The thermal parameters of the waste play an important role in the rate of waste stabilization. The depth to which the various heat fluxes are able to penetrate into the waste is determined by the thermal parameters of the waste (Farouki, 1981).

\subsubsection{Thermal Conductivity}

Thermal conductivity, $k$, has units of watts per meter per degree Celsius. Thus, thermal conductivity is considered the ability of a material to conduct heat, representing the rate at which heat transfer will occur within the waste (Holman, 2010). The thermal conductivity of MSW varies within waste and it is dependent upon the type of waste, moisture content, temperature, and degree of compaction. Increasing density and the degree of saturation both increase the thermal conductivity of MSW (Mitchell, 1993). Thermal conductivity is a function of the solid, liquid and gas phases of the waste (ElFadel, 1999):

$$
k=w_{s} k_{s}+w_{l} k_{l}+w_{g} k_{g}
$$




$$
w_{s}=1-n ; w_{l}=S_{l} n ; w_{g}=S_{g} n
$$

where $w_{s}, w_{l}, w_{g}$ are the volume fractions of the solid, liquid and gas phases respectively, $\mathrm{n}$ is the porosity, $\mathrm{S}_{\mathrm{g}}, \mathrm{S}_{1}$ are the gas and liquid saturations and $k_{s,}, k_{l,}, k_{\mathrm{g}}(\mathrm{W} / \mathrm{m} \cdot \mathrm{K})$ are the thermal conductivities of the solid, liquid and gas phases respectively. The thermal conductivity of the solid phase is much higher than the liquid and gas phases. Therefore, the majority of conduction occurs through contact between the solid waste particles as opposed to the void space (Mitchell, 1993).

\subsubsection{Specific Heat and Volumetric Heat Capacity}

Similarly to thermal conductivity, the specific heat, $c$, is a function of the solid, liquid and gas phases of the waste (El-Fadel, 1999):

$c=\frac{\left(c_{s} \rho_{s}+c_{l} \rho_{l}+c_{g} \rho_{g}\right)}{\rho}$

where $c_{s}, c_{l}, c_{g}(\mathrm{~J} / \mathrm{kg} \cdot \mathrm{K})$ are the specific heats of the solid, liquid and gas phases respectively, $\rho_{s}, \rho_{l}, \rho_{g}\left(\mathrm{~kg} / \mathrm{m}^{3}\right)$ are the average densities of the solid, liquid and gas phases

respectively, $\rho\left(\mathrm{kg} / \mathrm{m}^{3}\right)$ is the bulk density of waste and $c(\mathrm{~J} / \mathrm{kg} \cdot \mathrm{K})$ is the specific heat of waste.

The volumetric heat capacity, $C$, is the heat energy required to raise the temperature of a unit volume of waste by $1^{\circ} \mathrm{C}$. The larger the value, the longer the waste will take to increase in temperature under equivalent heat fluxes. The volumetric heat capacity is the product of the mass specific heat, $c(\mathrm{~J} / \mathrm{kg} \cdot \mathrm{K})$, and the density, $\rho\left(\mathrm{kg} / \mathrm{m}^{3}\right)$ (Farouki, 1981):

$$
C=c \rho
$$




\subsubsection{Latent Heat of Fusion}

The latent heat of fusion represents the amount of heat that is absorbed when a material undergoes a phase change from solid to liquid (Vinson \& Jahn, 1985). It is expressed as the amount of energy in $\mathrm{kJ}$ required to complete the phase change per unit mass of material. The latent heat of fusion for water is $334 \mathrm{~kJ} / \mathrm{kg}$.

For non-uniform materials such as a soil or waste sample, it is much more difficult to quantify a value for the latent heat of fusion. Generally for soils, the amount of heat required is based on the volume of water within the soil matrix undergoing phase change (Andersland \& Anderson, 1978):

$$
L_{s}=L_{w} w \gamma_{d}\left(1-W_{u}\right)
$$

where $L_{s}\left(k J / m^{3}\right)$ is the volumetric latent heat of fusion of soil, $w$ (decimal fraction by mass) is the water content of soil, $\mathrm{W}_{\mathrm{u}}$ (decimal fraction) is the ratio of unfrozen water to total water content, $\gamma_{d}\left(\mathrm{~kg} / \mathrm{m}^{3}\right)$ is the dry density of soil and $L_{w}(\mathrm{~kJ} / \mathrm{kg})$ is the volumetric latent heat of fusion of water.

It is recognized that in soils, even at temperatures below freezing, water will be present in both frozen and unfrozen states (Andersland \& Anderson, 1978). This concept is particularly important when analyzing a lift of waste placed in winter weather conditions, as leachate may be present both as a liquid and as a solid.

Rouse (1984) analyzed forest and tundra soils in Churchill, Manitoba to see the impact of freezing and thawing cycles on the soil stability and vegetation in the area. The forest soils have a high water content and during the winter months, the freezing was delayed 
due to the amount of energy released as latent heat. It was determined that approximately $80 \%$ to $90 \%$ of the total heat entering the soil was stored in the form of latent heat (Rouse, 1984). Of greater significance when considering the case of waste in a landfill, this resulted in the thawing of the soil to take much longer than anticipated.

\subsubsection{Convection and Radiation}

The magnitude of the convective heat flux between the ambient air and waste has not been significantly researched. Many researchers, such as Neusinger et al. (2006), grouped the overall convection and radiation into an overall heat transfer coefficient of 20 $\mathrm{W} / \mathrm{m}^{2} \cdot \mathrm{K}$. The convective heat flux between soil and air has been more extensively researched. In particular, the effect of the soil-air convective heat flux has been analyzed in greenhouses. This environment was reasonable to use as a basis for the landfill, as the mulch-soil characteristics are similar to that of the municipal solid waste. The total magnitude of the convective flux from an air-soil medium is defined as:

$$
\text { convective flux }=h\left(T_{a m b}-T\right)
$$

where $T_{a m b}(\mathrm{~K})$ is the ambient air temperature, $T(\mathrm{~K})$ is the temperature of waste at the surface and $h\left(\mathrm{~W} / \mathrm{m}^{2} \cdot \mathrm{K}\right)$ is the coefficient of convective heat transfer. Table 4 shows the various formulas used to calculate the convective heat transfer coefficient found within the literature. 
Table 4: Convective heat transfer coefficients between soil and air

\begin{tabular}{|c|c|}
\hline $\begin{array}{c}\text { Convective Heat Transfer Coefficient } \\
\left(\mathbf{W} / \mathbf{m}^{2} \cdot \mathbf{K}\right)\end{array}$ & Conditions \\
\hline $3.4 \Delta \mathrm{T}^{0.33}$ & Screened Greenhouse $^{\mathbf{1}}$ \\
\hline $10.0 \Delta \mathrm{T}^{0.33}$ & Bare Soil $^{2}$ \\
\hline $1.86 \Delta \mathrm{T}^{0.33}$ & Large-scale greenhouse $^{3}$ \\
\hline $5.2 \Delta \mathrm{T}^{0.33}$ & Heated Floor Surface $^{4}$ \\
\hline
\end{tabular}

Stoffers, $1985 ;{ }^{2}$ Silva, $1988 ;{ }^{3}$ De Halleux, $1989 ;{ }^{4}$ Lamrani et al., 2001

Similar to convective heat flux, the magnitude of the radiative heat flux entering the landfill has not been extensively researched. The radiative heat flux to the waste can be defined by:

Radiative flux $=\sigma \varepsilon\left(T_{a m b}{ }^{4}-T^{4}\right)$

where $\varepsilon$ is the surface emissivity constant and $\sigma\left(\mathrm{W} / \mathrm{m}^{2} \cdot \mathrm{K}^{4}\right)$ is the Stefan-Boltzmann constant for black body radiation. The surface emissivity is a value that reflects the ability of a surface to absorb the energy from radiation (Axelsson, 1984). The emissivity value for the majority of soils is between 0.9 to 0.96 (Axelsson, 1984).

\subsection{Instrument Installation in Full-Scale Landfills}

Many studies have been performed to monitor the stabilization process within a landfill in order to determine the effectiveness of the bioreactor technology. In Florida (Townsend et al., 2008; Hinkley Center et al., 2008; Reinhart et al., 2002), in Michigan (Hanson et al., 2005) and in California (Yazdani et al., 2000; Reinhart \& Townsend, 1998) efforts were undertaken to instrument full-scale landfills with a variety of sensors to measure important parameters of waste stabilization. In these studies, valuable lessons were learned to improve the effectiveness of bioreactor technology. However, it is often 
found that full-scale bioreactors do not function as expected and/or there is a high failure rate for the instrumentation installed within the landfill due to the harsh nature of the waste.

\subsubsection{New River Regional Landfill}

The Hinkley Center for Solid and Hazardous Waste Management, with direction from the University of Florida and the University of Central Florida, undertook a large scale bioreactor project known as the Florida Bioreactor Demonstration Project. The purpose of the project was to evaluate the concept of a bioreactor in order to determine the feasibility of the technology as a long term waste management solution in Florida (Townsend et al., 2008; Hinkley Center et al., 2008; Reinhart et al., 2002). The New River Regional Landfill (NRRL) is located in Union County, Florida and was selected to be the first landfill in Florida to be operated as a full-scale bioreactor landfill. The landfill contained three lined cells totalling 26 acres and received approximately 800 tons of waste daily from 2001 until 2008 (Reinhart et al., 2002). The landfill contained a gas extraction system that could also be operated as an air injection system in order to switch from anaerobic to aerobic conditions in the landfill. In addition, cells 1 and 2 contained a leachate recirculation system.

The bioreactor landfill was installed with instrumentation to monitor of in-situ parameters of the waste and progression of waste stabilization. The instrumentation installed included sensors to measure the moisture content, temperature, leachate flowrate, landfill gas flowrate and composition, settlement, leachate head on the liner and total pressure on the liner (Reinhart et al., 2002). To measure the pressure on the liner resulting from the waste, total pressure cells, were installed in the drainage system of the landfill cell 
(Reinhart et al., 2002). The data showed incremental increases in pressure measured corresponding to when lifts of waste were placed over the area (Reinhart et al., 2002). However, the pressure readings were approximately half of the expected load when estimated based on the mass of waste above the pressure cells (Hinkley Center et al., 2008). It is believed the lower than expected results were caused by arching of the load; however there is also the possibility the sensors failed. Pressure transducers were installed to measure the ponding of leachate above the leachate collection system. Unfortunately, over $75 \%$ the pressure transducers failed and therefore, a good estimation of leachate ponding could not be made (Hinkley Center et al., 2008). To measure the settlement, the elevations changes of specific GPS coordinates were measure on the surface of the landfill. In addition, changes in elevations of vertical wells placed throughout the landfill were also measured. The average settlement that occurred throughout the landfill was $10 \%$ (Hinkley Center et al., 2008). This value was considerably lower than settlement results from other bioreactor landfills.

Two types of moisture sensors, a time domain reflectometry (TDR) and an electrical resistance sensor referred to as MTG were installed at various locations throughout the landfill. This was done to minimize the impacts of problems experienced at other landfills (Vingerhoeds, 2011), where moisture sensor readings were impacted by the high electrical conductivity of the waste. Therefore, two sensors were used for redundancy, as moisture content is a critical parameter of waste stabilization and it was necessary to ensure accurate results. Both sensors showed similar results, with initial gravimetric moisture levels of $34 \%$ to $40 \%$ increasing to over $65 \%$ after leachate recirculation (Hinkley Center et al., 2008). Moisture contents of over $65 \%$ were higher than the 
expected moisture levels predicted from a water balance calculation. As a result, it was suggested the sensors could be affected by the high electrical conductivity of the leachate (Hinkley Center et al., 2008).

Thermocouples installed within the bioreactor, found temperatures stabilized between $35^{\circ} \mathrm{C}$ to $55^{\circ} \mathrm{C}$, two years after filling of the cell (Hinkley Center et al., 2008). In addition, leachate recirculation significantly helped to increase temperatures within the landfill. The results also demonstrated that ambient air temperature had little impact on the temperatures within a landfill (Hinkley Center et al., 2008). Upon injecting air into the landfill, a rapid temperature increase occurred where the air had been added, as high as $70^{\circ} \mathrm{C}$ in some areas (Hinkley Center et al., 2008). This provides incentive for the possibility that air could be added to landfills operating in colder climates in order to raise the temperature.

\subsubsection{Sauk Trail Hills Development}

The Sauk Trail Hills Landfill located in Detroit, Michigan was instrumented in order to monitor the temperatures of a landfill over long periods of time, and the impacts of the temperature on heat generation and landfill gas production (Hanson et al., 2005). Temperature sensors and gas sampling ports were installed at over 140 locations within the landfill. Sensors were placed in the waste, as well as the liner and cover. Data collected from the site suggested the aerobic phase of degradation could last for 160 days after placement of the waste (Hanson et al., 2005). In contrast to other researchers, Hanson et al. (2005) suggested the majority of the temperature rise within the landfill occurred during the anaerobic phase of degradation. 
The data were also used to determine how the temperatures varied spatially within the landfill. Temperatures closer to the surface and perimeter of the landfill closely followed the ambient temperatures. In comparison, maximum temperatures of $56^{\circ} \mathrm{C}$ were reached at depths greater than $8 \mathrm{~m}$ from the surface. Landfill gas samples taken from these high temperature areas had methane gas concentrations as high as $60 \%$ (Hanson et al., 2005). The project demonstrated the quality of landfill gas is dependent on the temperature at which the biodegradation is occurring.

\subsubsection{Yolo County Controlled Bioreactor Landfill Project}

The Yolo County Controlled Bioreactor Landfill Project which took place in Davis, California wanted to directly compare the stabilization of waste in a bioreactor landfill to a conventional landfill (Yazdani et al., 2000; Reinhart \& Townsend, 1998). This was completed by constructing two cells that would accept the same type of waste throughout the same periods of the year. One cell would be operated as a conventional landfill while the other would be operated as a bioreactor landfill, using leachate recirculation (Yazdani et al., 2000; Reinhart \& Townsend, 1998). Both cells were designed with a $100 \mathrm{ft}$ by 100 ft footprint, and accepted approximately 9000 tons of MSW from April to October 1995 (Yazdani et al., 2000). Sensors were installed throughout the waste to measure parameters important to waste stabilization. Parameters were measured for five years, and included settlement, hydraulic head, temperature, landfill gas quality and quantity and moisture content (Yazdani et al., 2000).

The sensors provided valuable results that demonstrated the value of using a bioreactor in comparison to conventional landfilling. The optimized conditions resulted in the bioreactor landfill cell producing more than double the amount of landfill gas in 
comparison to the conventional landfill (Yazdani et al., 2000). Furthermore, analysis of the composition of landfill gas also showed the concentration of methane gas was consistently higher in the bioreactor cell (Yazdani et al., 2000).

Settlement measurements of markers on the surface of the landfill were measured from May 1996 to September 1998 and results were significantly different (Yazdani et al., 2000). The settlement measured within the bioreactor cell was approximately $16 \%$ in comparison to control cell where the waste only had $2 \%$ settlement (Yazdani et al., 2000). This research demonstrated valuable airspace could be gained by using the bioreactor landfill technology.

\subsection{Evaluation of Bioreactor Landfills in Cold Climates}

From the research at the full scale bioreactors, it was clear optimizing the conditions within the landfill can be much more difficult in a full-scale operation than expected. In northern climates this issue is further complicated as the cold weather makes it difficult to optimize the conditions within the waste, especially temperature. Some researchers have examined the feasibility of operating landfills in Alberta (Hunte et al., 2011; Davies \& Colbran, 2010), Alaska (Hanson, 2006) and Michigan (Zhao et al., 2008; Zhao et al., 2006).

\subsubsection{City of Calgary Shepard Landfill}

At the City of Calgary Shepard Landfill, the concept of a bioreactor was evaluated by constructing a biocell (Hunte et al., 2011). A biocell builds on the idea of a bioreactor landfill however it differs from a bioreactor as the intention is to operate the cell as temporary storage only. Waste is processed within the biocell in order to produce large 
quantities of methane gas and to expedite the decomposition of the waste (Hunte et al., 2011). Generally, the biocell is operated for multiple years under anaerobic conditions followed by a single year of aerobic biodegradation in order to maximize the stabilization. Once the majority of the waste has decomposed, the biocell can be mined to recover a compost-like material and recover valuable airspace (Hunte et al., 2011). This process is illustrated in Figure 6.

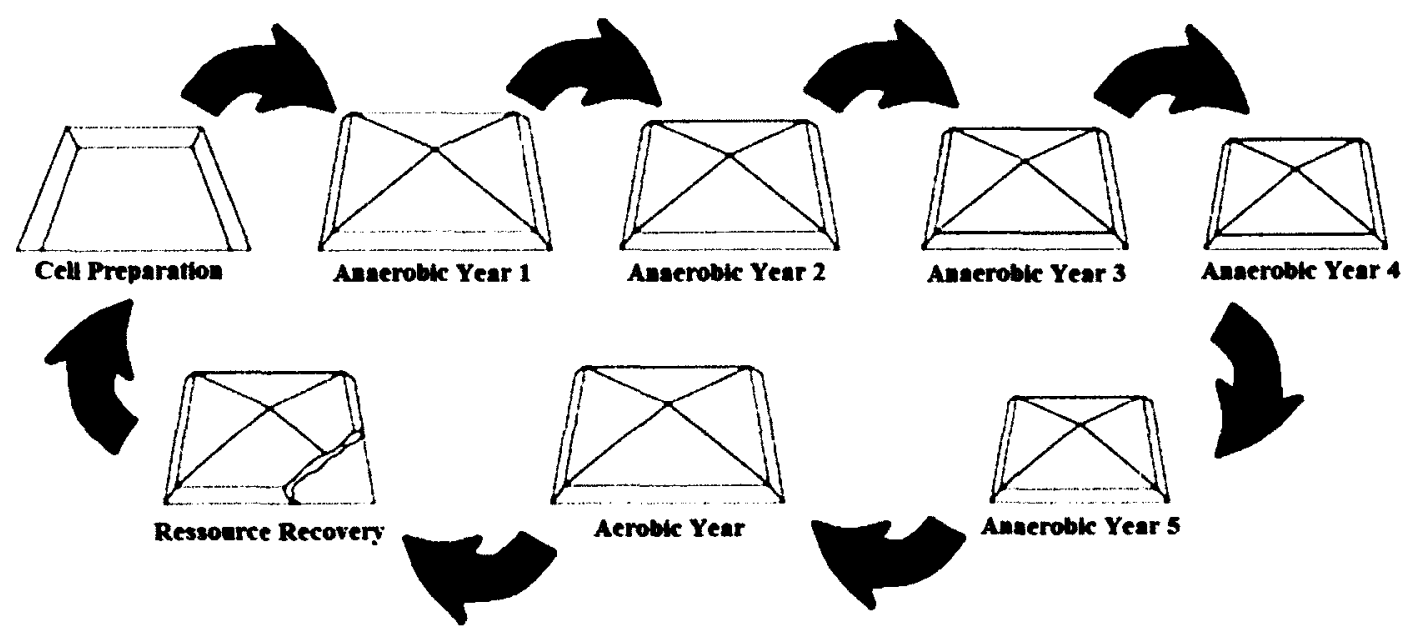

Figure 6: Biocell Schematic (modified from Davies \& Colbran, 2010)

The feasibility of this idea was evaluated in northern climates with the construction of the Calgary Biocell in 2005. The biocell was designed as an $85 \mathrm{~m}$ by $85 \mathrm{~m}$ cell with a maximum height of $15 \mathrm{~m}$, containing three waste lifts of $5 \mathrm{~m}$ each (Hunte et al., 2011). Instrumentation was installed within the biocell to measure the temperature, moisture content and settlement. However, due to the difficult conditions experienced in the field, many of the sensors failed. To illustrate this, 49 sensors were installed however only 11 were fully functional throughout the project (Davies \& Colbran, 2010). In addition, the settlement gauges went out of range when filling the biocell and therefore accurate 
settlement results could not be established (Davies \& Colbran, 2010). The moisture content measured throughout the biocell indicated unequal distribution of moisture. In areas with lower moisture levels, the gas production was significantly lower (Davies \& Colbran, 2010). It is suspected this problem was caused by some of the leachate recirculation pipes breaking during installation (Davies \& Colbran, 2010). Overall, the project demonstrates some of the difficulties associated with instrumenting a field-scale bioreactor or biocell.

\subsubsection{Northern Oaks Recycling and Disposal Facility}

A 1.2 acre full-scale bioreactor landfill was constructed at the Northern Oaks Recycling and Disposal Facility (NORDF) in Harrison, Michigan to analyze and monitor bioreactor technology in northern climates (Zhao et al., 2008; Zhao et al., 2006). The bioreactor cell accepted 32400 tons of MSW from July 2002 until March 2003 (Zhao et al., 2008). As a result, the lower waste lifts were placed in the summer and the waste at the top of the landfill was placed during the winter months. Leachate was recirculated within the bioreactor using leachate collected from other cells of the landfill as well as fresh leachate collected from the bioreactor.

The bioreactor landfill was instrumented with a moisture and temperature probe, a gas sampling port to measure gas composition and a collection basin to measure leachate composition at 48 sites throughout the landfill (Zhao et al., 2006; Zhao et al., 2008). In addition, HDPE conduits were installed at ten locations throughout the landfill to measure the settlement of the waste (Zhao et al., 2008; Zhao et al., 2006). The results from the temperature and gas composition data showed the first lift of waste placed in the summer months was actively degrading, and had high concentrations of methane of up to 
$70 \%$ (Zhao et al., 2008). In comparison, upper layers that had been placed during the winter months remained frozen. It was concluded that the insulating properties of the waste were the main reason for maintaining cold temperatures in the lifts placed during the winter months (Zhao et al., 2006; Zhao et al., 2008). The temperature data were continuously monitored after closure of the cell and it was determined that the frozen waste lifts maintained temperatures of below $0^{\circ} \mathrm{C}$ for over 6 months post-closure (Zhao et al., 2008). The settlement of the waste was measured by recording the elevation changes of the conduits installed within the waste. The highest amount of settlement occurred in the middle lifts due to the active degradation occurring in the bottom portion of the landfill (Zhao et al., 2006).

The moisture sensor measured the volumetric moisture content within the waste using the TDR technique. Similar to the results found at Sainte-Sophie (Vingerhoeds, 2011) and the NRRL (Hinkley Center et al., 2008), the moisture content sensors needed to be calibrated for the high electrical conductivity of the waste. The moisture sensor results demonstrated the moisture content steadily increased throughout the landfill upon recirculating the leachate. Furthermore, although the moisture content was not equally distributed at the beginning, one year after closure of the landfill the moisture contents throughout the waste were nearly equal (Zhao et al., 2006). This research provides optimism towards the idea that leachate recirculation can be used in a full-scale bioreactor to successfully control the moisture content. Overall, it was concluded moisture content followed by temperature are the two most important factors in starting the biodegradation process within the waste (Zhao et al., 2006). 


\subsubsection{Anchorage Regional Landfill}

At the Anchorage Regional Landfill in Anchorage, Alaska a study was performed to determine the effect of placement conditions on the rate of waste decomposition within the landfill (Hanson, 2006). The waste stabilization was tracked by installing thermocouples to measure the temperature and gas sampling ports to measure the gas quality. The temperature measurements were taken each week whereas the gas quality was recorded once a month from 2002 until 2006. Consecutive waste lifts were placed during winter months, resulting in a $7 \mathrm{~m}$ frozen layer of waste in the middle of the landfill. This section of waste remained frozen for more than two years, due to the insulating properties of the waste above and below (Hanson, 2006). Due to the overall low ambient temperatures at the site, significant methane gas generation was delayed until three years after waste placement (Hanson, 2006).

The data was modelled to determine the possibility of optimizing the sequence of waste placement to enhance the waste stabilization. Multiple scenarios were analyzed to compare placing various thicknesses of frozen waste throughout landfill. Ultimately, placement of anything beyond a single $3 \mathrm{~m}$ waste lift under winter conditions resulted in a significant delay in the waste stabilization process (Hanson, 2006). Furthermore, to minimize the effect of cold winter conditions, it was suggested that thinner lifts of waste are placed in the winter months (Hanson, 2006). This is the first example that examined modelling of heat transfer in a landfill operating in a cold climate. 


\subsection{Modelling Efforts in Municipal Solid Waste}

A number of researchers have worked on modelling the transfer and generation of heat within a landfill; however the majority of this work has analyzed landfills operating in warmer climates. Quantifying the amount of heat generation within the landfill can be extremely challenging due to the number of different biological reactions that occur, as discussed in Section 2.3 (El-Fadel et al., 1996a). The majority of heat generated in the landfill occurs in the aerobic stage, when there is still oxygen present in the pore space of the waste. Once the oxygen is depleted, the exothermic reactions that generate heat take place during acidogenesis, when complex organics are broken down into acetic, butyric and propionic acids (El-Fadel et al., 1996a).

Many researchers have determined various site specific parameters that impact the temperatures within the waste and therefore effect the rate of stabilization. Some of the main factors identified include: rate of filling, lift thickness, weather conditions, depth of waste, moisture content and waste composition (Rowe, 1998; Rowe \& Islam, 2009). The temperature of the waste at placement was identified as the principle factor in determining the rate of biodegradation (Houi et al., 1997; Hanson et al., 2006). In order to quantify the impacts of these factors, many researchers have attempted to model various aspects of landfills. Modelling efforts have included modelling the methane gas generation, settlement or heat transfer throughout the waste (Hanson et al., 2008; ElFadel et al., 1996c; Yoshida \& Rowe, 2003; Yesiller et al., 2005; Neusinger et al., 2005). 
To model heat transfer through the waste, an overall understanding of the governing equation is required. The flow of heat through the waste can be expressed as (Yoshida et al., 1997):

$$
c \rho \frac{\partial T}{\partial t}=-c_{w} \rho_{w} v_{z} \frac{\partial T}{\partial z}+k_{e} \frac{\partial^{2} T}{\partial z^{2}}+Q
$$

where $k_{e}(\mathrm{~W} / \mathrm{m} \cdot \mathrm{K})$ is effective thermal conductivity, $\rho\left(\mathrm{kg} / \mathrm{m}^{3}\right)$ is the waste density, $c$ $(\mathrm{J} / \mathrm{kg} \cdot \mathrm{K})$ is the waste specific heat, $\rho_{w}\left(\mathrm{~kg} / \mathrm{m}^{3}\right)$ is the density of water, $c_{w}(\mathrm{~J} / \mathrm{kg} \cdot \mathrm{K})$ is the specific heat of water, $v_{z}(\mathrm{~m} / \mathrm{s})$ is infiltrated water flux, $Q\left(\mathrm{~W} / \mathrm{m}^{3}\right)$ is the heat source, T $(\mathrm{K})$ is temperature, and $t(s)$ is time. The equation signifies the rate of temperature change in the landfill is related to the transfer of heat through movement of liquid, conduction and heat generation. In colder climates, the movement of liquid is often negligible at first and therefore the equation can be simplified to:

$$
c \rho \frac{\partial T}{\partial t}=k_{e} \frac{\partial^{2} T}{\partial \mathrm{z}^{2}}+Q
$$

This section examines the various models created to model heat transfer within a landfill. To date, the majority of the models simulate heat transfer within landfills operating in warmer climates (Hanson et al., 2008; Yoshida \& Rowe, 2003; Neusinger et al., 2005). These models are extremely beneficial in understanding the generation and transfer of heat, and their impact on the waste stabilization process. However, heat transfer and generation differs in northern climates, as waste is placed in a frozen state and the environmental conditions are much different.

Hanson et al. (2008) conducted a study to model and compare the waste stabilization in different climatic regions. Data was collected from landfills in Michigan, New Mexico, 
Alaska, and British Columbia (Yesiller et al., 2005; Hanson et al., 2008). At each landfill, thermocouples and gas sampling ports were placed throughout the waste in order to measure the temperature and gas composition. Temperature readings were collected once a week, while the gas was extracted and sampled on a monthly basis. A 1-D finite element analysis was used to model the temperature data recorded at all four landfills. The thermal conductivity and heat capacity values used to model the various sites are shown in Table 5.

Table 5: Thermal parameters used for modelling (Hanson et al., 2008)

\begin{tabular}{|l|l|l|l|l|}
\hline \multicolumn{1}{|c|}{ Parameter } & \multicolumn{1}{c|}{ Michigan } & New Mexico & \multicolumn{1}{c|}{ Alaska } & $\begin{array}{c}\text { British } \\
\text { Columbia }\end{array}$ \\
\hline $\mathrm{k}(\mathrm{W} / \mathrm{m} \cdot \mathrm{K})$ & 1.0 & 0.6 & 1.2 & 1.5 \\
\hline $\mathrm{C}\left(\mathrm{kJ} / \mathrm{m}^{3} \cdot \mathrm{K}\right)$ & 2000 & 1200 & 1000 & 2200 \\
\hline
\end{tabular}

The heat generation was modelled by dividing the heat generated into an aerobic and anaerobic term. It was assumed aerobic degradation occurred for the first 4 months after placement of the waste, and the remainder was considered anaerobic degradation (Hanson et al., 2008). The range of values used to model the heat generation from aerobic degradation was 2.5 to $11.3 \mathrm{~W} / \mathrm{m}^{3}$ while the range of anaerobic degradation was 0.08 to $0.38 \mathrm{~W} / \mathrm{m}^{3}$ (Hanson et al., 2008). However, Hanson et al. (2008) argued that in reality, there is not a sharp drop off in heat generation after a given time. Therefore, to improve the modelling of the heat generation term a unique approach was taken; an equation was derived to simulate the heat generation at the various sites (Hanson et al., 2008):

$$
H=A\left[\frac{B t}{B^{2}+2 B t+t^{2}}\right] e^{-\sqrt{\frac{t}{D}}}
$$


where $H\left(\mathrm{~W} / \mathrm{m}^{3}\right)$ is the heat generation rate, $t$ (day) is the time, $A\left(\mathrm{~W} / \mathrm{m}^{3}\right)$ is the peak heat generation rate factor, $B$ (day) is the shape factor and $D$ (day) is the decay rate factor. The constants $\mathrm{A}, \mathrm{B}$ and $\mathrm{D}$ were then varied in order to simulation the heat generation at the various sites. Figure 7 shows the resulting heat generation functions used to model the four landfill sites. This is the most extensive work done on modelling the heat generation term within a landfill.

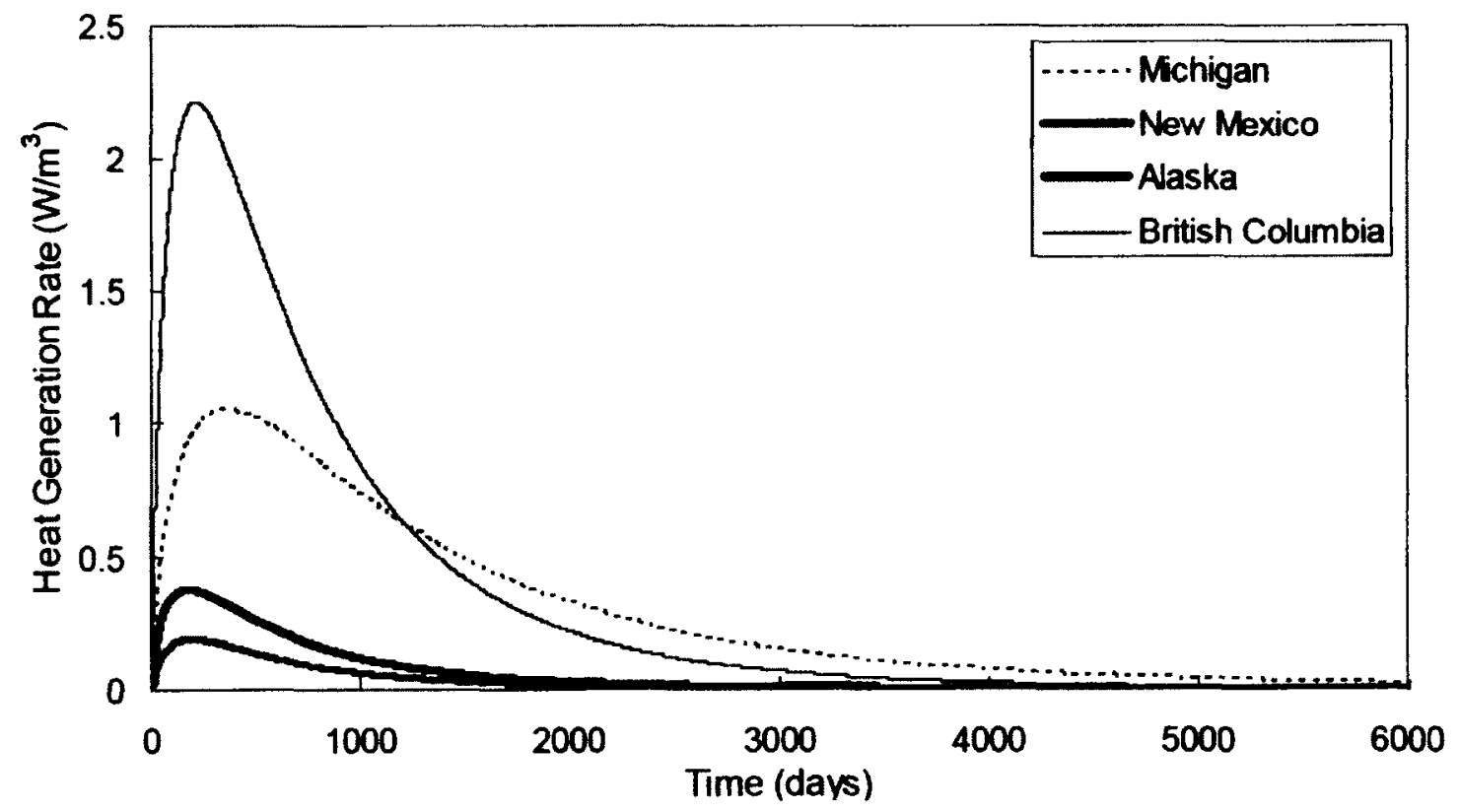

Figure 7: Heat generation functions used in model (with permission from Hanson et al., 2008)

Yoshida \& Rowe (2003) examined heat transfer in the Tokyo Port Landfill, in order to determine the impact of high temperatures in the landfill on the lifetime of engineered components such as the liner or geomembrane. The landfill cell was roughly 30 to $35 \mathrm{~m}$ high and was filled in approximately $2 \mathrm{~m}$ waste lifts (Yoshida \& Rowe, 2003). When each additional lift was placed, the fresh waste is exposed to air. The landfill was 
simulated assuming air infiltrated $1 \mathrm{~m}$ in the waste lift and thus this section was modelled as a zone of aerobic decomposition (Yoshida \& Rowe, 2003). The remaining portion of the fresh waste lift and previous waste lifts placed in the cell were modelled as a zone of anaerobic decomposition. In addition, areas of the landfill cell above the water were identified as unsaturated zones and areas below the water table were identified as saturated zones. The thermal parameters were then varied depending on the zone and type of decomposition expected in that part of the landfill, as shown in Table 6. Saturated zones within the landfill were assigned much higher thermal conductivities in comparison to areas with lower moisture contents.

Table 6: Thermal parameters used to model Tokyo Port Landfill (modified from Yoshida \& Rowe, 2003)

\begin{tabular}{|l|l|}
\hline \multicolumn{1}{|c|}{ Parameter } & \multicolumn{1}{c|}{ Value Used } \\
\hline \multicolumn{1}{|c|}{ Unsaturated Waste } & \multicolumn{1}{|c|}{} \\
\hline Density & $1157 \mathrm{~kg} / \mathrm{m}^{3}$ \\
\hline Thermal Conductivity & $0.35 \mathrm{~W} / \mathrm{m} \cdot \mathrm{K}$ \\
\hline Specific Heat & $1939 \mathrm{~J} / \mathrm{kg} \cdot \mathrm{K}$ \\
\hline \multicolumn{1}{|c|}{ Saturated Waste } & $1424 \mathrm{~kg} / \mathrm{m}^{3}$ \\
\hline Density & $0.96 \mathrm{~W} / \mathrm{m} \cdot \mathrm{K}$ \\
\hline Thermal Conductivity & $2363 \mathrm{~J} / \mathrm{kg} \cdot \mathrm{K}$ \\
\hline Specific Heat & \\
\hline \multicolumn{2}{|l|}{ Heat Generation } \\
\hline Aerobic Decomposition & $4.67 \mathrm{~W} / \mathrm{m}^{3}$ \\
\hline Anaerobic Decomposition & $0.218 \mathrm{~W} / \mathrm{m}^{3}$ \\
\hline
\end{tabular}

Neusinger et al. (2005) also derived a model that could be used to simulate the transfer of heat within a landfill. In this case, they modelled the air-waste surface using a heat transfer coefficient of $20 \mathrm{~W} / \mathrm{m}^{2} \cdot \mathrm{K}$ that accounted for both convection and radiation. To estimate the heat resulting from anaerobic decomposition, a $1 \mathrm{~W} / \mathrm{m}^{3}$ heat source from was 
applied over entire area of the landfill. The heat source was then multiplied by a scaling factor to determine how the heat generation impacted the temperatures within the landfill. Figure 8 demonstrates how the maximum temperature within the landfill increases as the rate of heat generation increases. This research illustrates the importance of the heat generation term when modelling the heat transfer throughout the waste.

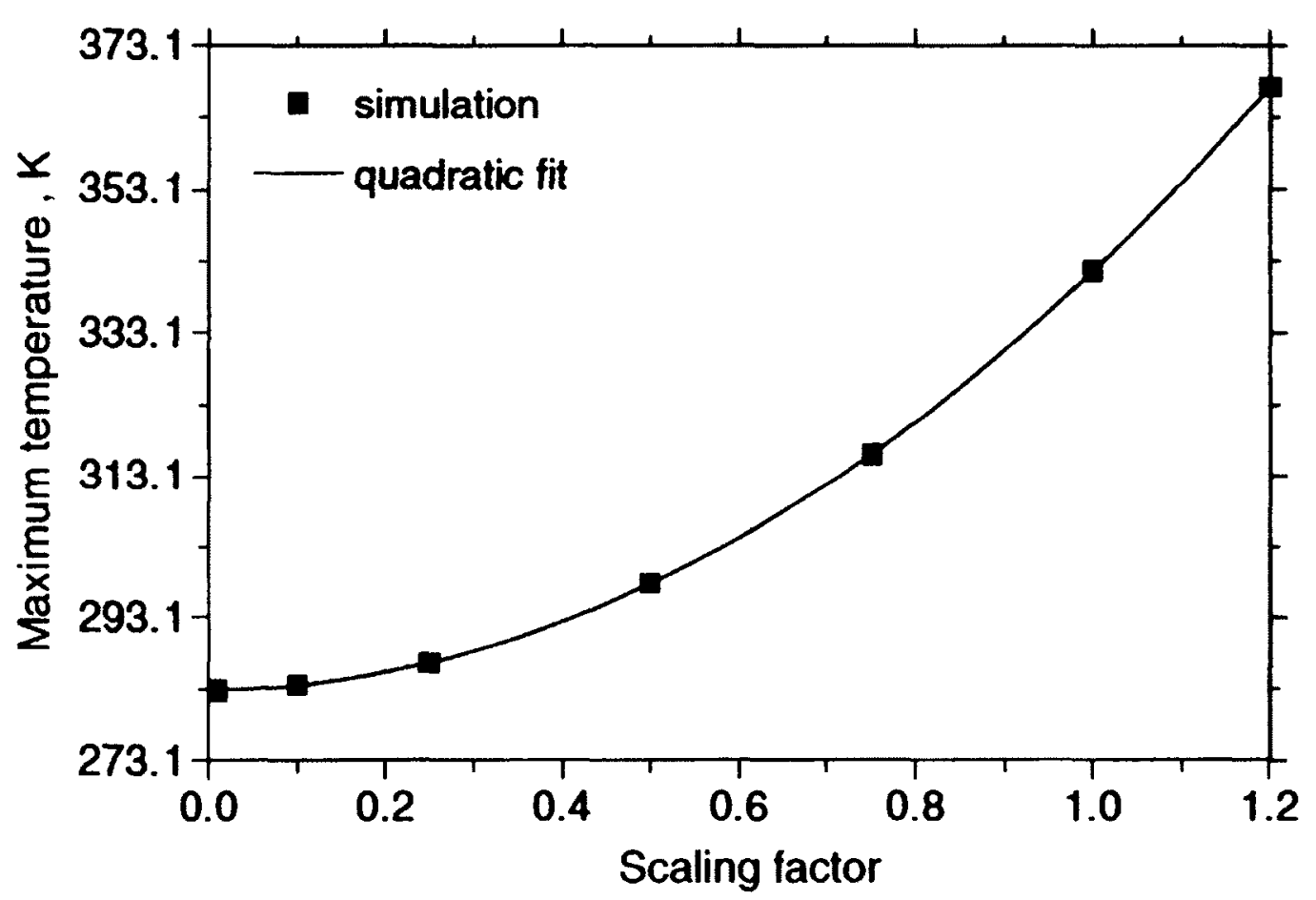

Figure 8: Scaling factor for bioheat generation (with permission from Neusinger et al., 2005) 


\section{Instrumentation of a Field Scale Bioreactor Landfill}

Several instruments were installed on a singular unit referred to as instrument bundle for placement within the Sainte-Sophie bioreactor landfill while it was progressively filled with waste. The instrument bundles included a variety of sensors that measure important waste parameters that can provide information on the stabilization process in the landfill. Specifications and figures of the individual instruments are in Appendix A. Figure 9 is a cross-section showing the placement elevations for the first ten instrument bundles within the bioreactor landfill. All bundles were equipped with a liquid settlement system, moisture and electrical conductivity sensor, oxygen sensor, and total earth pressure, while bundles 1 to 4 also included a piezometer. Figure 10 shows the total earth pressure cell, settlement system, and piezometer mounted on a $61 \mathrm{~cm}$ by $61 \mathrm{~cm}$ steel plate. Two hollow flexible tubes were installed with each instrument bundle to allow for sampling to take place or to pump oxygen out to the instrument bundles. 


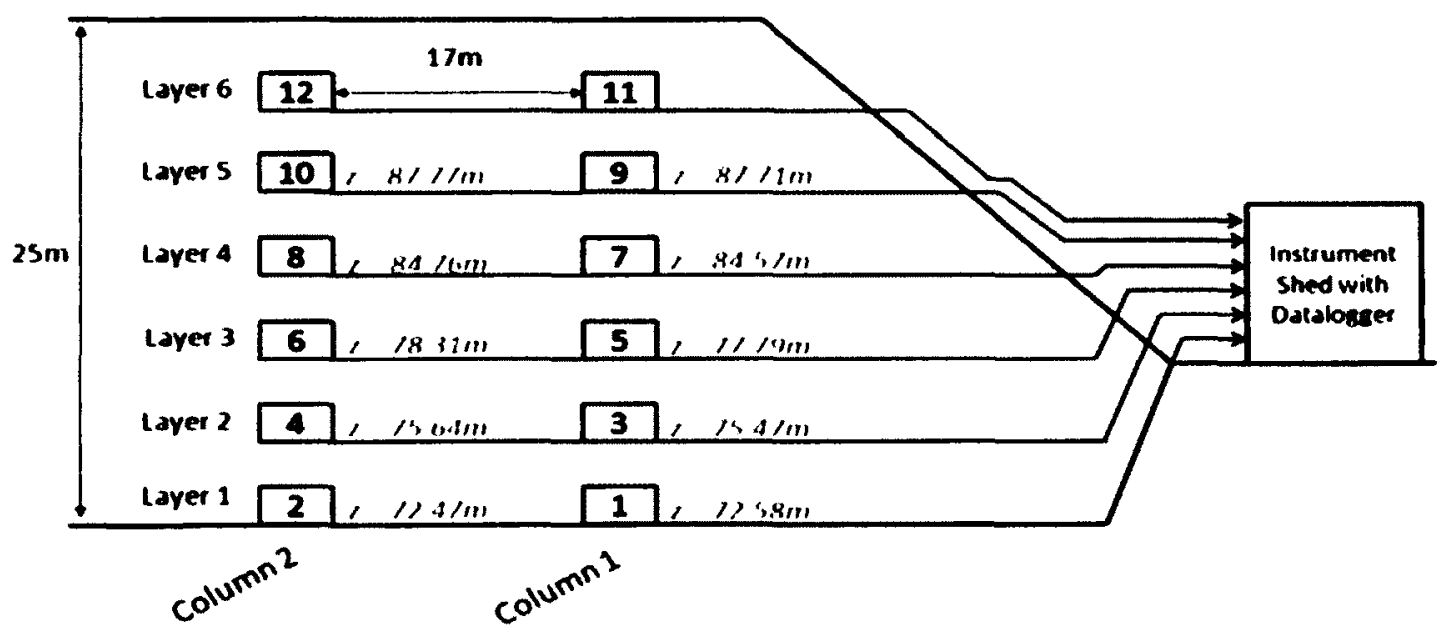

Figure 9: Instrument bundle placement elevations (Bonany et al., 2012a)

The individual sensors of each instrument bundle are wired to a central connection box shown in Figure 10. A single data cable containing 12 wire pairs exits the connection box and travels out the landfill into the data acquisition system, located in the on-site instrument shed. The CR1000 FlexDAQ datalogger was designed by RST Instruments Ltd. and collected the data from all twelve instrument bundles. Data collection was completed through the commercial software package LoggerNet 3.4.1. A modem was installed along with the data acquisition, enabling the data to be downloaded and accessed in real time. 


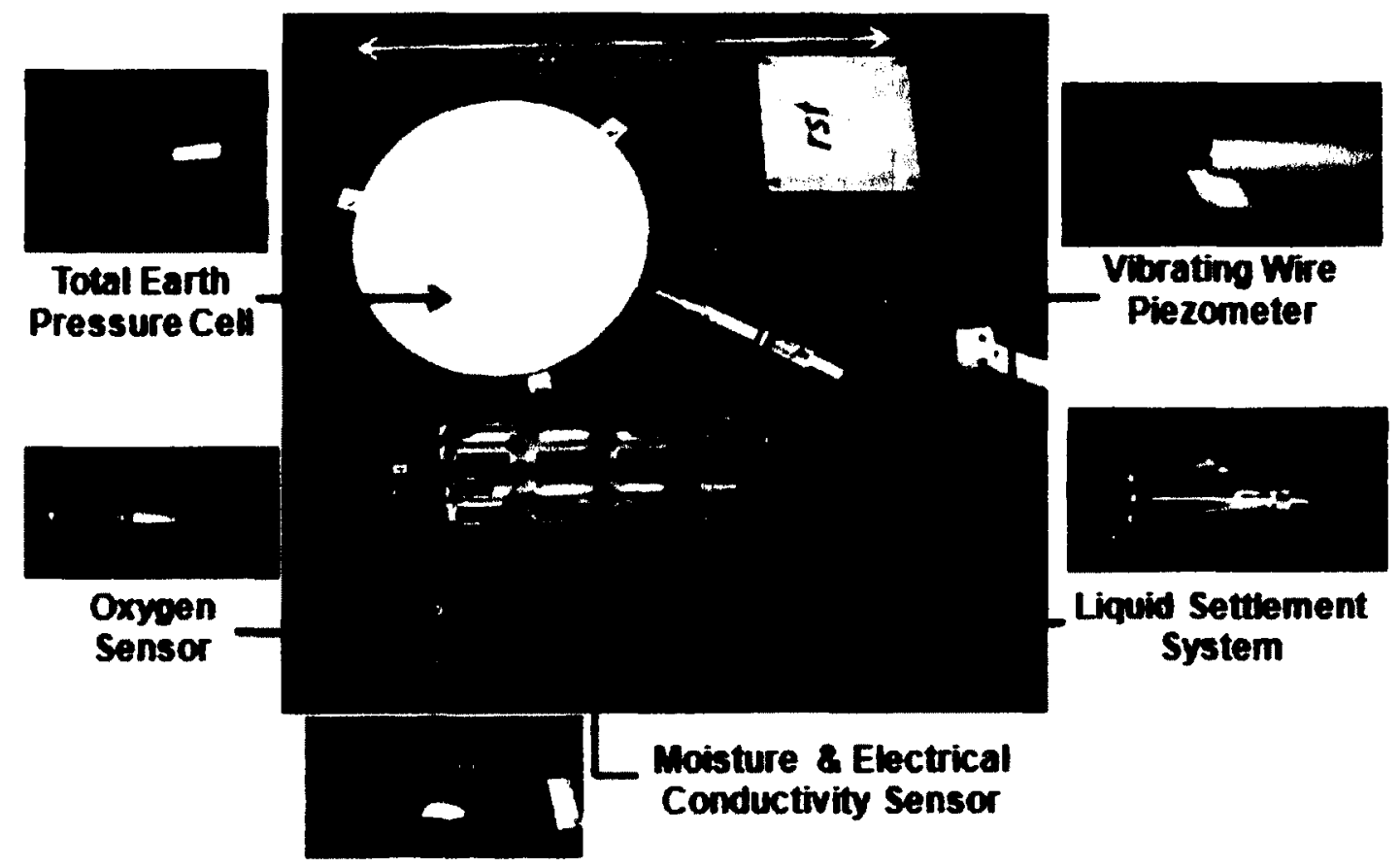

Figure 10: Instrument bundle (Bonany et al., 2012b)

A differential GPS system was used to mark the initial coordinates of the instrument bundles upon installation. The GPS system included a rover and a home base station receiver. The stationary base station receiver communicates with satellites to calculate its GPS coordinates and also communicates with the base station by using a radio communication link. The roving unit also communicates with the satellites to determine its GPS coordinates. Since the location of the base station is known, the difference experienced at the home base can be used correct the GPS coordinates recorded by the rover. This greatly improves the accuracy of the rover GPS coordinates to levels as low as $1.6 \mathrm{~cm}$ (NRC, 2007). 


\subsection{Instrument Bundle Sensors}

The instrument bundle sensors were tested within a lab setting to ensure they could withstand the harsh environmental conditions within the landfill (Van Geel et al., 2010). From this work, any necessary changes were made to the sensors to maximize their chance of survival in the harsh environmental conditions with the landfill. For example, extra epoxy was added around the moisture sensor to prevent corrosion of the sensor in the landfill. The wiring and set-up of the individual sensors on the instrument bundle was completed by RST instruments.

\subsubsection{Settlement System}

The liquid settlement system monitors settlement of the instrument bundle in the landfill by measuring the difference in pressure between a fixed pressurized reservoir in the instrument shed and the instrument bundle. Pressure transducers within the settlement system and the reservoir are hydraulically connected through a reinforced double tubing system filled with a water-glycol solution. The pressurized reservoir is at a fixed elevation, thus by knowing the pressure difference between the two transducers and the specific weight of the water-glycol solution, the elevation difference between the pressurized reservoir and the instrument bundle can be determined. A measured increase in pressure could be converted to settlement of the instrument bundle knowing the density of the water-glycol solution.

\subsubsection{Oxygen Sensor}

The oxygen sensor measures the percentage of oxygen content in the void space within the waste. The amount of current flowing between the electrodes in measured and then 
used to calculate a volumetric oxygen content. The oxygen sensor is contained within a diffusion mesh head so that gas within the waste can be measured by the sensor. It is used to determine when the oxygen content has been depleted within the waste. This will indicate when the waste degradation process has switched from aerobic to anaerobic conditions and the relative length of the aerobic phase of biodegradation.

\subsubsection{Moisture and Electrical Conductivity Sensor}

The moisture and electrical conductivity sensor measures the dielectric permittivity of the surrounding soil in order to extrapolate the water content. In addition, a two-probe electrical array is used to measure electrical conductivity of the surrounding soil, which is converted to bulk electrical conductivity in the data acquisition program. It is anticipated that an increase or decrease in moisture content of the sand will reflect an increase or decrease of moisture content of the waste. However, the moisture content of the waste will not be directly measured as it is difficult to measure the bulk moisture content of waste with a single point measurement.

\subsubsection{Total Earth Pressure Cell}

The total earth pressure cell measures stress exerted on the surface of the plate through a pressure transducer, which is then used to calculate a total load. The cell is filled with glycol and as force is exerted on the cell, the pressure change of the glycol is measured by a vibrating wire pressure transducer. By loading the cell with waste layers as the landfill is filled, the pressure within the cell increased. 


\subsubsection{Piezometer}

The piezometer utilizes a vibrating wire transducer to record any positive water pressure in the event mounding of leachate occurs over the instrument bundles.

\subsection{Instrument Bundle Installations}

Twelve instrument bundles were installed in the Sainte-Sophie bioreactor landfill over the project lifetime. All twelve instrument bundles have been placed within the waste, with two bundles installed at each layer. Bundles 11 and 12 were installed in May 2012 and are now recording data, however their analysis is not included in this thesis. Placement was planned such that there will be two vertical columns, Column 1 and Column 2, each consisting of six instrument bundles. Column 1 and 2 are separated by approximately $17 \mathrm{~m}$, and each layer of instrument bundles was to be separated by approximately 3 to $4 \mathrm{~m}$ vertically. The vertical separation changed slightly as shown in Figure 9 because of varying lift thicknesses.

The date of the installations and placement of the first five waste lifts are described in Table 7. These first three instrument layers were all installed in the first lift of waste, as highlighted in Table 7. The second waste lift was placed in December of 2010 and shortly after was covered with a third waste lift. For this reason, no instrument bundles could be installed within the second waste lift. Bundles 7 and 8 were installed in February 2011 near the top of the third waste lift. Bundles 9 and 10 were installed in September of 2011 near the top of the fourth waste lift. 
Table 7: History of instrument bundles placed in waste

\begin{tabular}{|c|c|c|l|}
\hline Waste Lift & $\begin{array}{c}\text { Date of Waste } \\
\text { Placement }\end{array}$ & \multicolumn{1}{|c|}{$\begin{array}{c}\text { Instrument } \\
\text { Bundles }\end{array}$} & \multicolumn{1}{|c|}{$\begin{array}{c}\text { Date of Bundle } \\
\text { Installation }\end{array}$} \\
\hline \multirow{2}{*}{ 1st Waste Lift } & January 8th, 2010 & 1 and 2 & November 12, 2009 \\
\cline { 3 - 4 } & & 3 and 4 & January 9, 2010 \\
\cline { 2 - 4 } & 5 and 6 & June 23, 2010 \\
\hline 2nd Waste Lift & December 13th, 2010 & Contains No Instrument Bundles \\
\hline \multicolumn{5}{|l}{} \\
\hline 3rd Waste Lift & January 28th, 2011 & 7 and 8 & February 16th, 2011 \\
\hline \multicolumn{5}{|l}{} \\
\hline 4th Waste Lift & August 23rd, 2011 & 9 and 10 & September 16th, 2011 \\
\hline
\end{tabular}

Instrument bundles 1 and 2 were installed on the base of the bioreactor landfill cell. The installation occurred in October 2009, and is shown in Figure 11. Sand was placed over the instrument bundles and cables for protection and the sand also served as a medium in which the oxygen sensor and the moisture and electrical conductivity sensor were placed. Geotextile covered the sand for additional protection and to prevent the sand from migrating into the leachate collection system below. These bundles were subsequently covered with waste in early January 2010 by the approaching waste front seen in the background of Figure 11.

For instrument bundles 3 through 10 , a $0.5 \mathrm{~m}$ trench was excavated in the waste, in which the instrument bundle and cables were placed. Sand was again placed over the instrument bundles and cables for protection, prior to being covered with waste. The typical installation procedure is illustrated in Figure 11. 

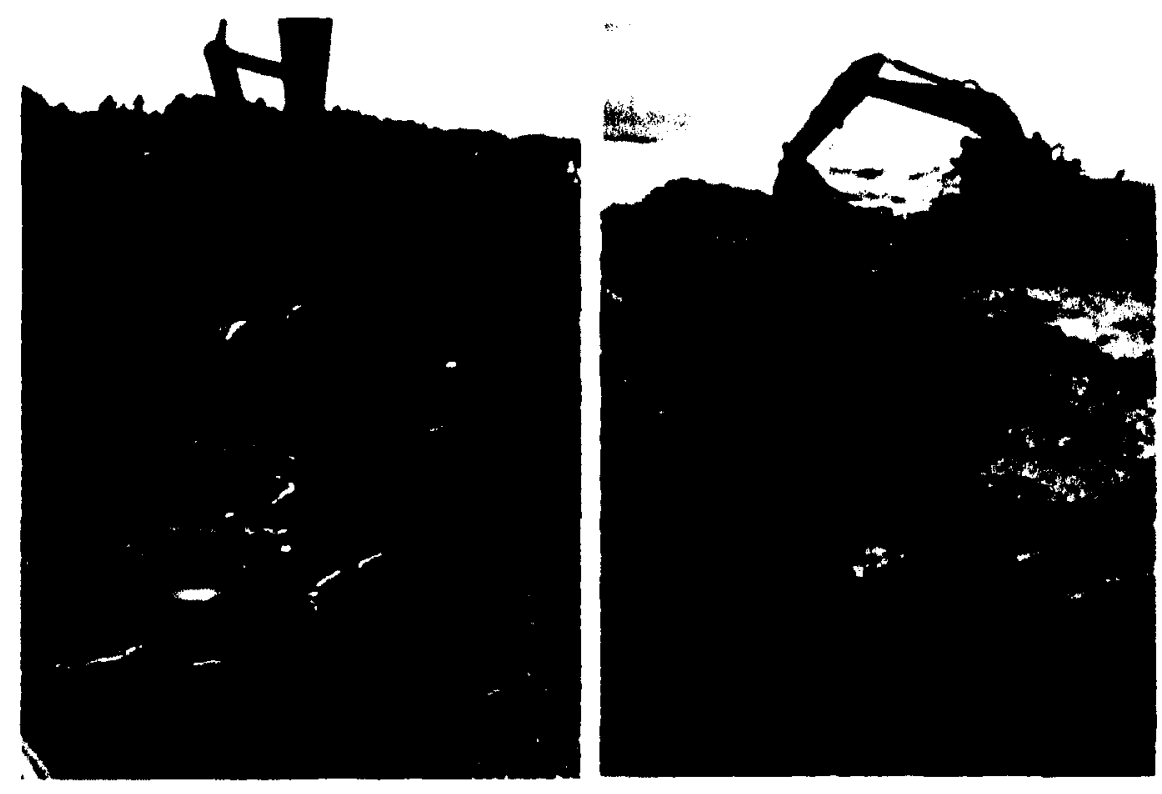

Figure 11: First layer instrument bundle installation in October 2009 (left) and fourth layer instrument bundle installation in February 2011 (right) (Bonany et al., 2012a)

The first waste lift $(\sim 6 \mathrm{~m})$ was placed in January 2010 . To facilitate the placement of bundles 3 and 4 at the centre of the first lift, WM personnel at Sainte-Sophie placed a half lift $(\sim 3 \mathrm{~m})$ over the area of the instrument bundles. Bundles 3 and 4 were installed and immediately covered with the second half lift $(\sim 3 \mathrm{~m})$ in February 2010. Bundles 5 and 6 were installed $0.5 \mathrm{~m}$ below the top of the first lift in June 2010. In December 2010 and January/February 2011 a second and third waste lift (each $\sim 3.5 \mathrm{~m}$ ) were placed above the instrument bundles. Bundles 7 and 8 were installed $0.5 \mathrm{~m}$ below the top of the third lift in February 2011. Up until this point, the first three waste lifts were placed in the winter months of December, January or February and the waste was placed in a frozen state. To avoid placing a fourth frozen waste lift, WM personnel at Sainte-Sophie agreed to place the next lift during the summer months. A fourth waste lift was placed in August 2011 . Instrument bundles 9 and 10 were installed $0.8 \mathrm{~m}$ below the top of the fourth lift in 
September 2011 , above approximately $15 \mathrm{~m}$ of waste from the base of the landfill. Therefore, bundles 1 through 8 were placed in waste lifts placed during the winter months and bundles 9 and 10 were placed in a waste lift placed during the summer. Figure 12 summarizes the history of the waste placement in Zone 4 of the landfill, with the location of instrument bundles shown in red. The divisions of blue colour in the figure were generated from the quarterly surveys completed by Genivar Inc. Each quarterly survey is assigned a colour and the monthly estimates within each quarterly survey time period are approximations based on discussion with WM personnel.

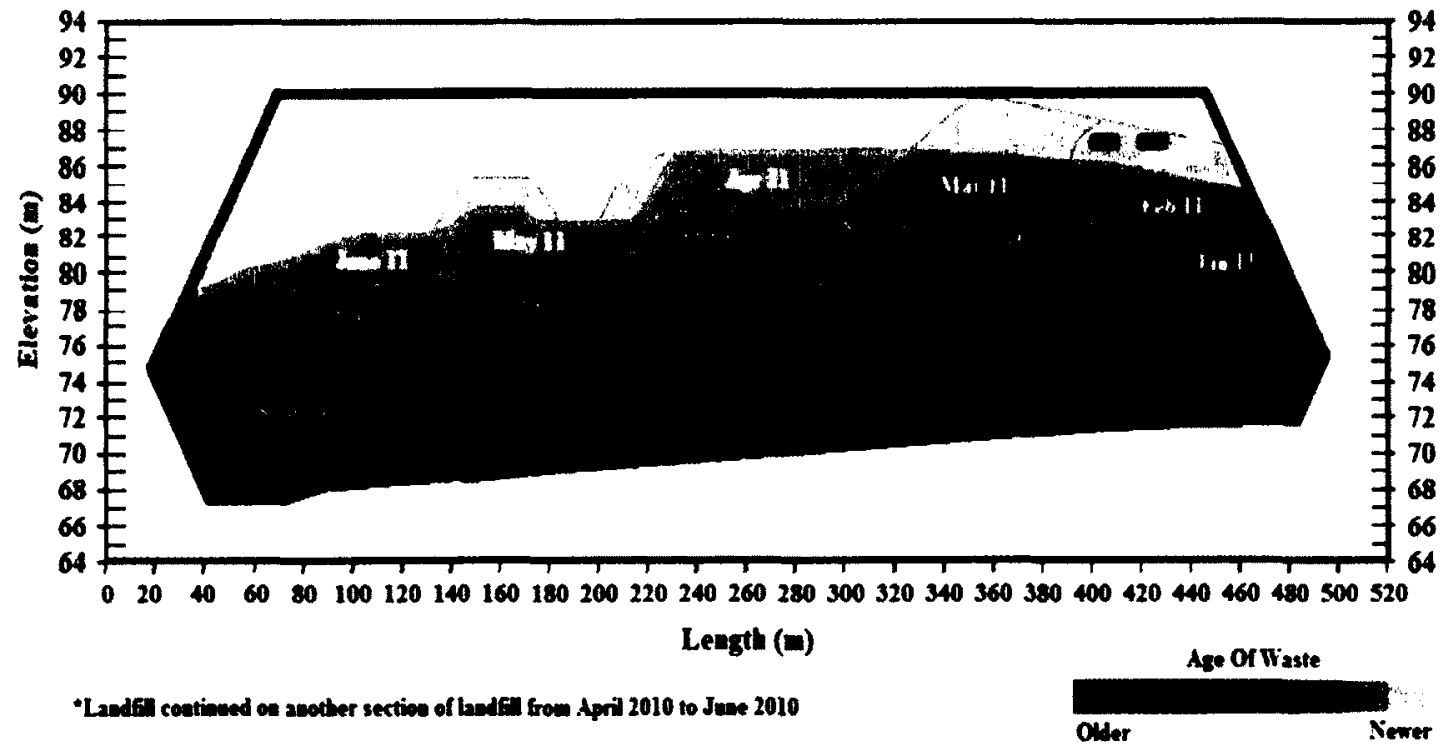

Figure 12: History of waste lift placement 


\section{Instrument Bundle Results}

This thesis discusses the data collected by the instrument bundles from November 2009 until March 2012. Data has been collected and analyzed for the moisture content and electrical conductivity, temperature, total settlement oxygen content, total load and leachate mounding. At this stage of the modelling, the oxygen content and temperature data are the most critical parameters and therefore the full analysis is presented here. It was also necessary to incorporate the settlement data in the modelling effort as discussed in Appendix D. Vingerhoeds et al. (2011) provides complete analysis of the settlement, piezometer, total earth pressure cell and moisture and electrical conductivity sensor data.

\subsection{Oxygen Sensor Results}

The data collected from the oxygen sensors in bundles 1 to 10 are shown in Figures 13 and 15 through 18. The oxygen sensor data was used in the modelling effort to determine the approximate length of the aerobic phase of biodegradation. The data from each instrument indicates the oxygen has depleted within the pore space of the waste, and therefore the majority of the landfill is operating under anaerobic conditions.

The oxygen content surrounding bundles 1 and 2 remained at approximately $21 \%$ when they were exposed to ambient air from November 2009 until January 1010, as illustrated in Figure 13. At this point, they were covered with the first $6 \mathrm{~m}$ waste lift and the oxygen content slowly declined to $0 \%$ over a two month period. The temperature of the waste during this period of time remained at approximately $-2^{\circ} \mathrm{C}$, below temperatures where significant biodegradation would occur. Even at these low temperatures, small amounts of bacterial activity could result in the oxygen being slowly depleted. However, since 
oxygen is decreasing so slowly, the amount of heat produced would not be sufficient to raise the temperature of the waste.

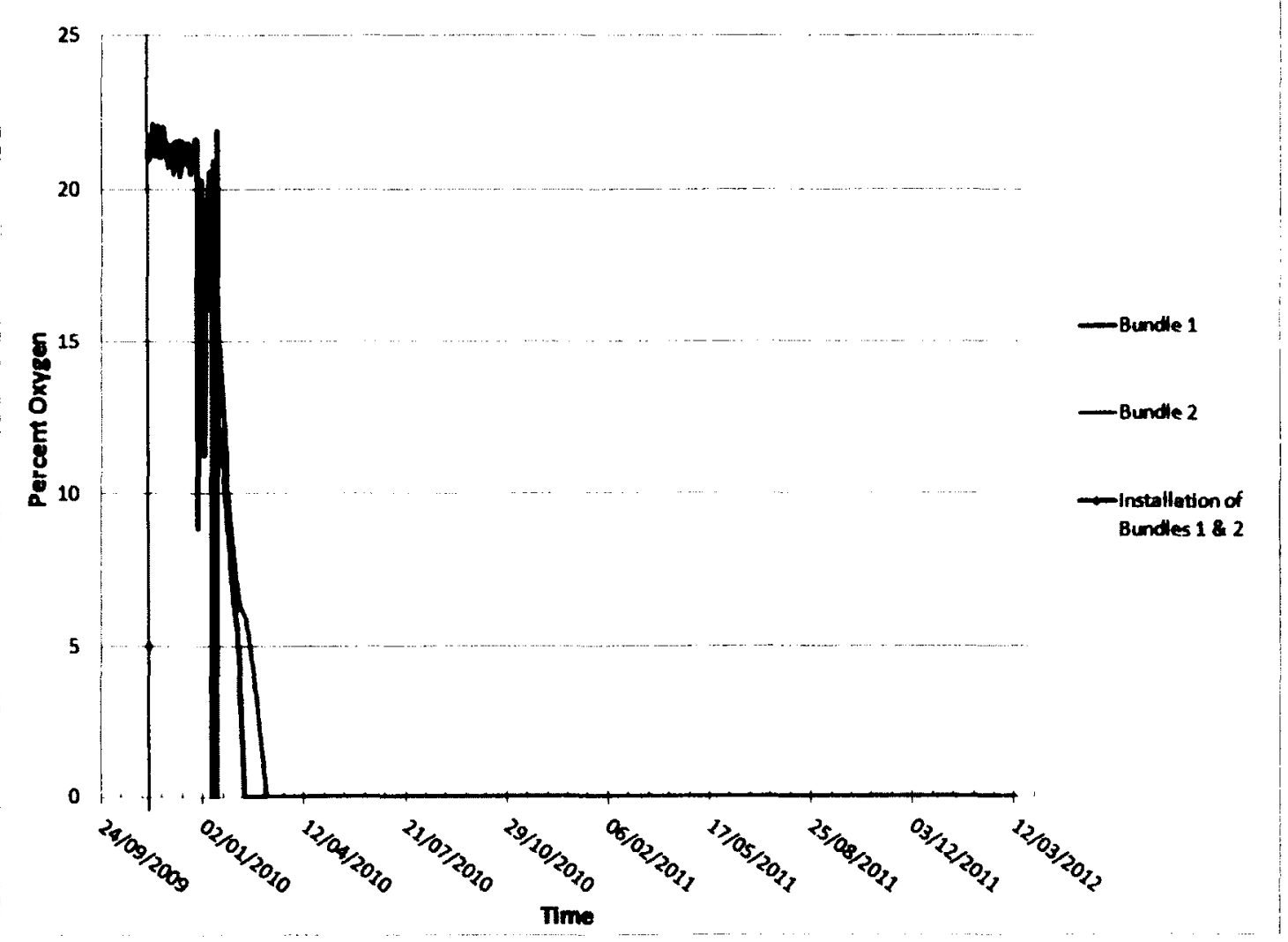

Figure 13: Oxygen content for bundles 1 and 2

Other researchers suggested the aerobic phase of biodegradation lasted anywhere from 3 to 18 months, therefore it was not anticipated the oxygen would decrease so quickly (Qian et al., 2002; Hanson et al., 2008). With the unexpected results of the oxygen content decreasing so rapidly under colder conditions, oxygen pump tests were completed to confirm the operation of the oxygen sensor data. These tests involved using a bike pump to pump air, at roughly $21 \%$ oxygen, back out to the instrument bundles via the hollow tubing as shown in Figure 14. During the first pump test, pressure built up in the 
bike pump and air was unable to reach the bundles. It is suspected that water entered the hollow tubing and froze due to the cold temperatures within the landfill, blocking the air from reaching the bundles. Judging from experience of other researchers, it was also possible the sensors had failed (Davies \& Colbran, 2010). Therefore, to confirm the oxygen sensors weren't being impacted by the harsh environmental conditions of the waste, oxygen pump tests were performed on all instrument bundles; however, this procedure could only be completed for bundles 3,5 , and 6 .

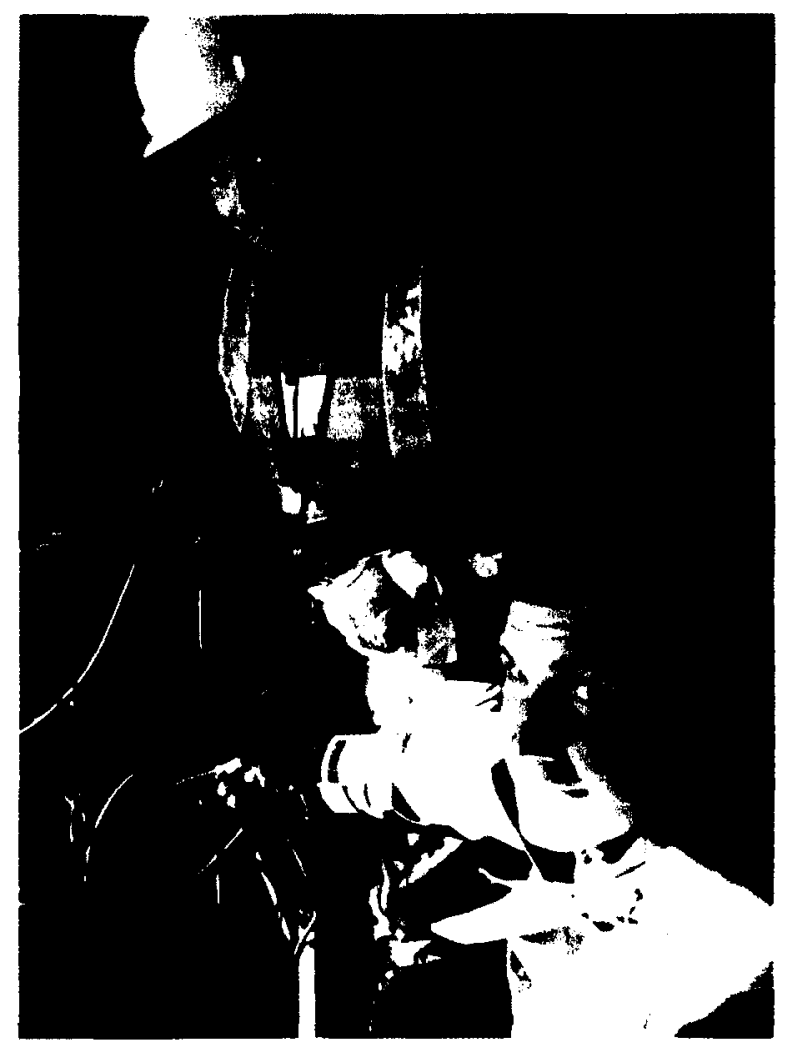

Figure 14: Oxygen pump test procedure

Figure 15 shows the oxygen content measured at bundles 3 and 4 . When bundles 3 and 4 were installed, the wiring of the oxygen sensor was incorrect and therefore the initial results were inaccurate. This issue was resolved in June 2010, approximately 6 months 
after installation. However, by this time the readings from both bundles 3 and 4 had decreased to $0 \%$ oxygen content. This data was still useful, as it confirms the duration of aerobic phase is less than 6 months, even for waste placed during the winter months. It is anticipated that the oxygen content decreased to $0 \%$ over a span of 3 months, similar to bundles 1 and 2. An oxygen sensor test was performed on June 2nd 2011 on both bundles 3 and 4 . The oxygen concentration for bundle 3 peaked at $7 \%$ during pumping, indicating the sensor was still functioning properly. However, at bundle 4 the temperatures remained below $0^{\circ} \mathrm{C}$ suggesting frozen water was preventing air to be pumped through the hollow tubing back to the instrument bundles.

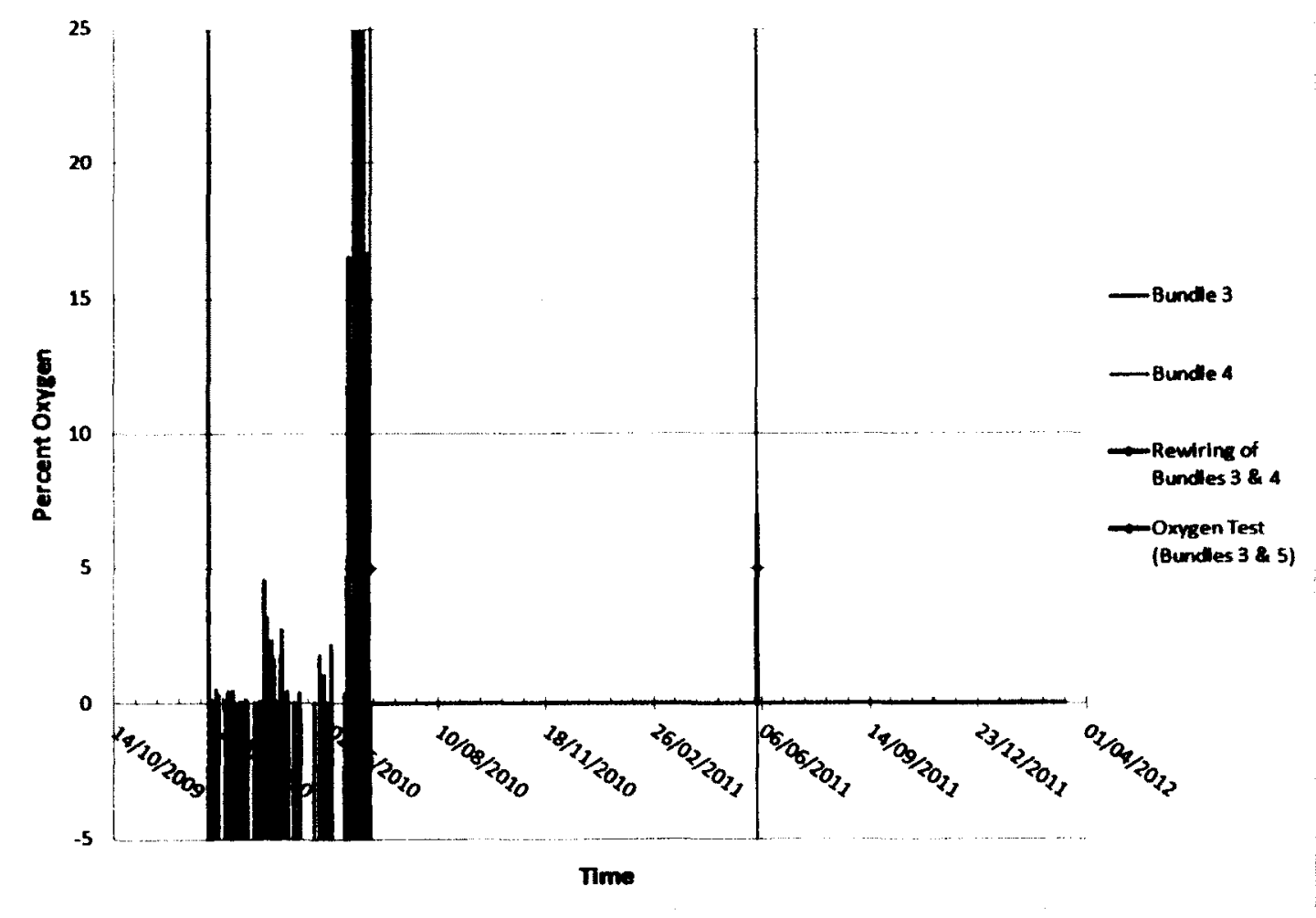

Figure 15: Oxygen content for bundles 3 and 4 
Figure 16 shows the oxygen content measured at bundles 5 and 6 . The oxygen levels surrounding the bundles were initially $21 \%$ upon installation in June 2010 , but decreased rapidly to $0 \%$ over a two day period. The temperature of the waste at installation was approximately $20^{\circ} \mathrm{C}$, and this rapid decrease in oxygen content indicates there is aerobic biodegradation occurring in the upper portion of the first waste lift at temperatures of $20^{\circ} \mathrm{C}$. This is extremely important as it indicates that under warmer temperatures, the initial oxygen in the void space of the waste is depleted in a matter of a few days. Oxygen was added by pumping air out to the instrument bundles to confirm the sensors were functioning properly on three separate occasions. During the first oxygen pump test, air was added to both bundles 5 and 6 . The oxygen readings reached $13 \%$ and $7 \%$ at bundles 5 and 6 respectively. Upon reaching these levels, it was concluded the sensors were functioning properly and pumping was stopped. The oxygen depleted over 1 to 2 days indicating rapid consumption of the oxygen in the area of the bundles. Two additional oxygen pump tests were performed on bundle 5 , and similarly to the first test, the oxygen was rapidly consumed. 


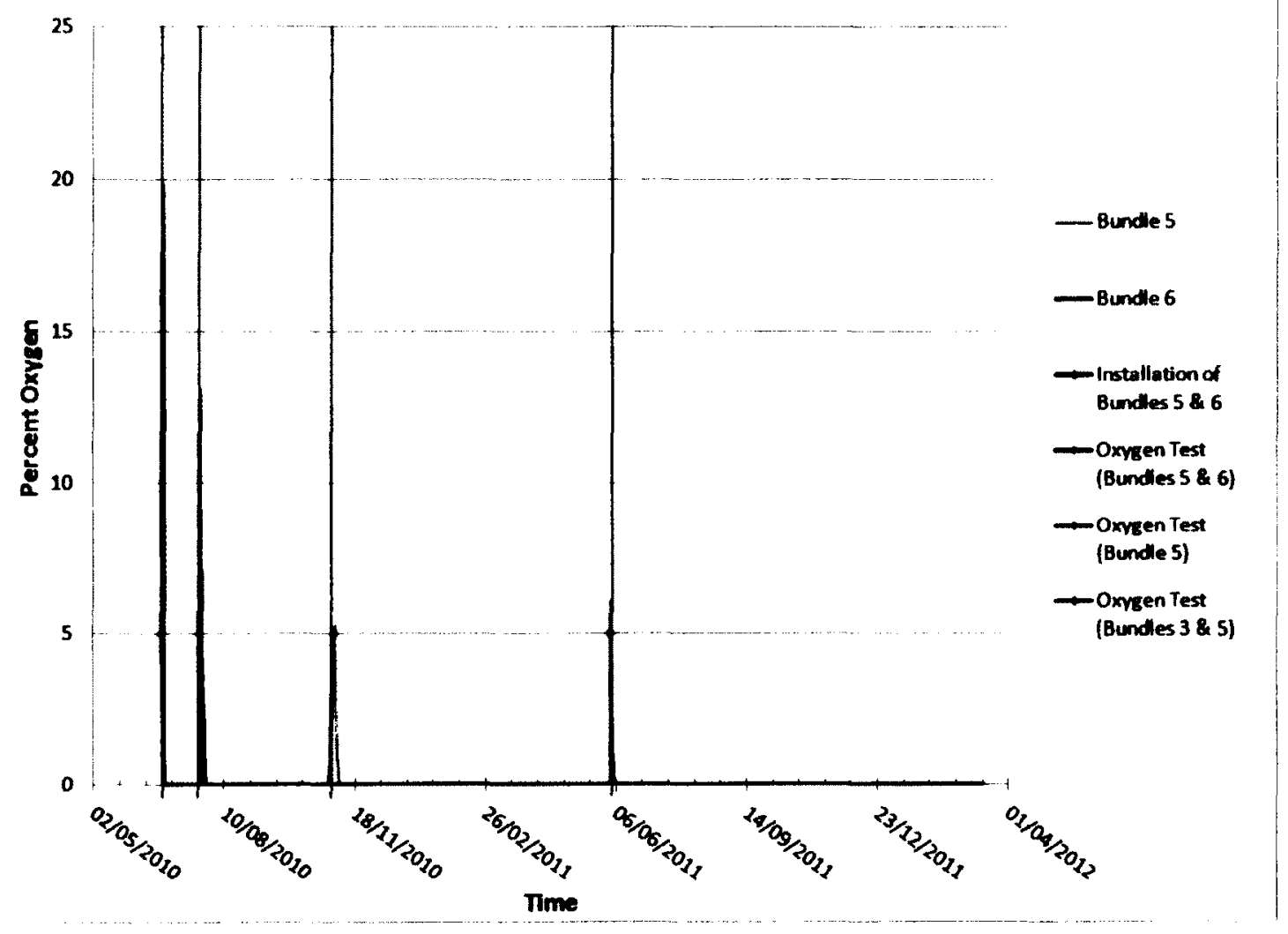

Figure 16: Oxygen content for bundles 5 and 6

Figure 17 shows the oxygen content measured at bundles 7 and 8 . The oxygen levels started at approximately $21 \%$ and decreased to under $2 \%$ within the first two weeks. At this point, bundle 8 was excavated in order to fix a problem with the installation. Bundle 7 was partially excavated although it remained covered with waste. This allowed air to infiltrate into the pore space of the waste and the oxygen levels at both bundles 7 and 8 increased to $11 \%$ and $19 \%$ respectively. The excavation above bundle 8 remained open to the atmosphere until May 2011 and hence the oxygen sensor was only covered with a thin layer of sand. As a result, the oxygen content at bundle 8 decreased at a slower rate than at bundle 7 as air may have slowing continued to infiltrate into the sand surrounding 
bundle 8. Once again, an oxygen pump test was performed; however no air could be pumped through the hollow tubing back to the instrument bundles. The installation was performed in the winter months and it is anticipated that liquid may have entered the hollow tubing and froze, preventing the air from reaching the bundles.

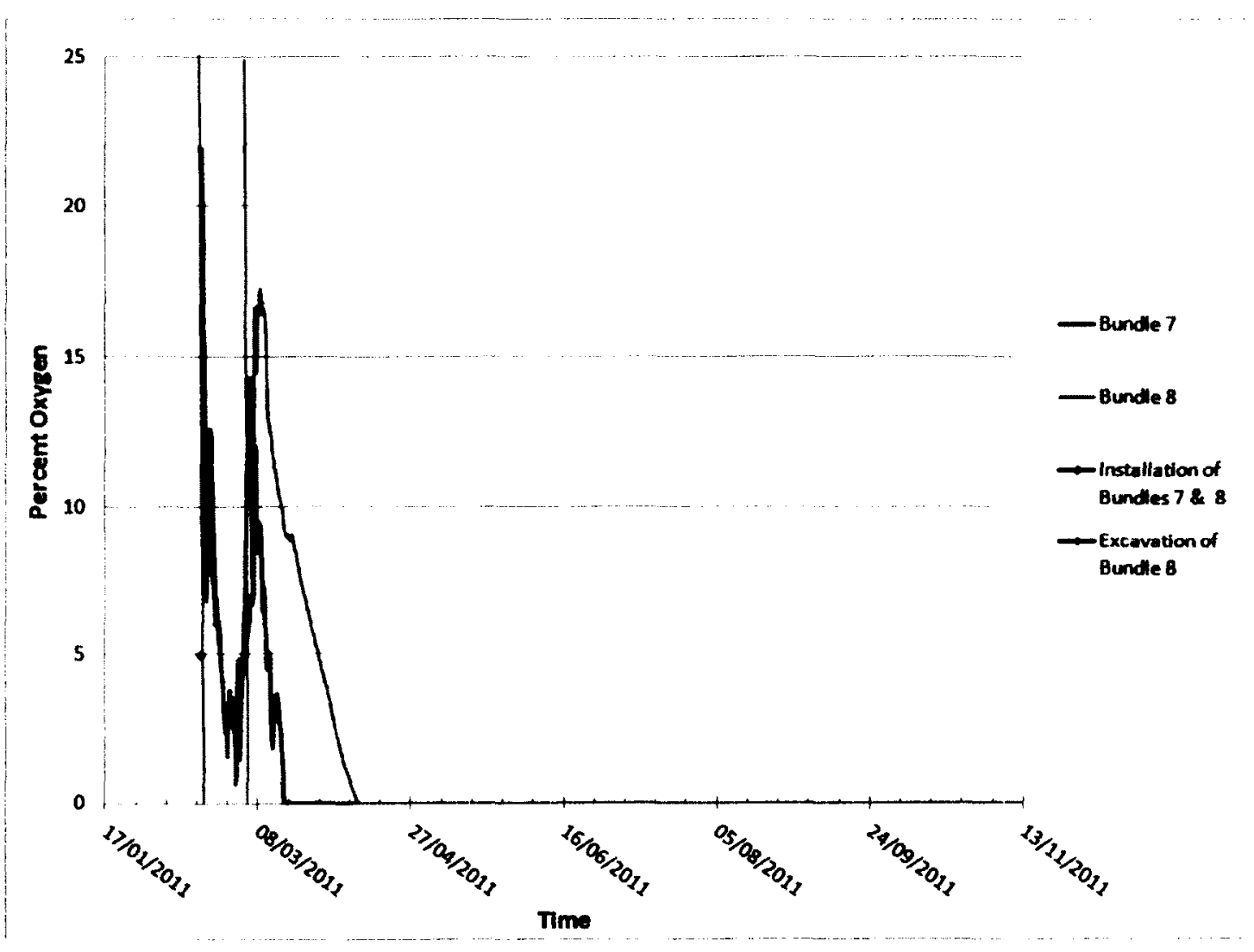

Figure 17: Oxygen content for bundles 7 and 8

Figure 18 shows the oxygen content recorded at bundles 9 and 10 over the study period compared to the average temperature of the waste. The oxygen levels began at approximately $21 \%$ and decreased to $0 \%$ over a few days. The bundles were installed approximately three weeks after the placement of waste and therefore some oxygen may have depleted prior to placing the instrument bundles. However, this still indicates the 
aerobic phase for waste placed under warm temperature conditions only lasts a few days. This is extremely important as the majority of heat released from biodegradation occurs during the aerobic phase of biodegradation.

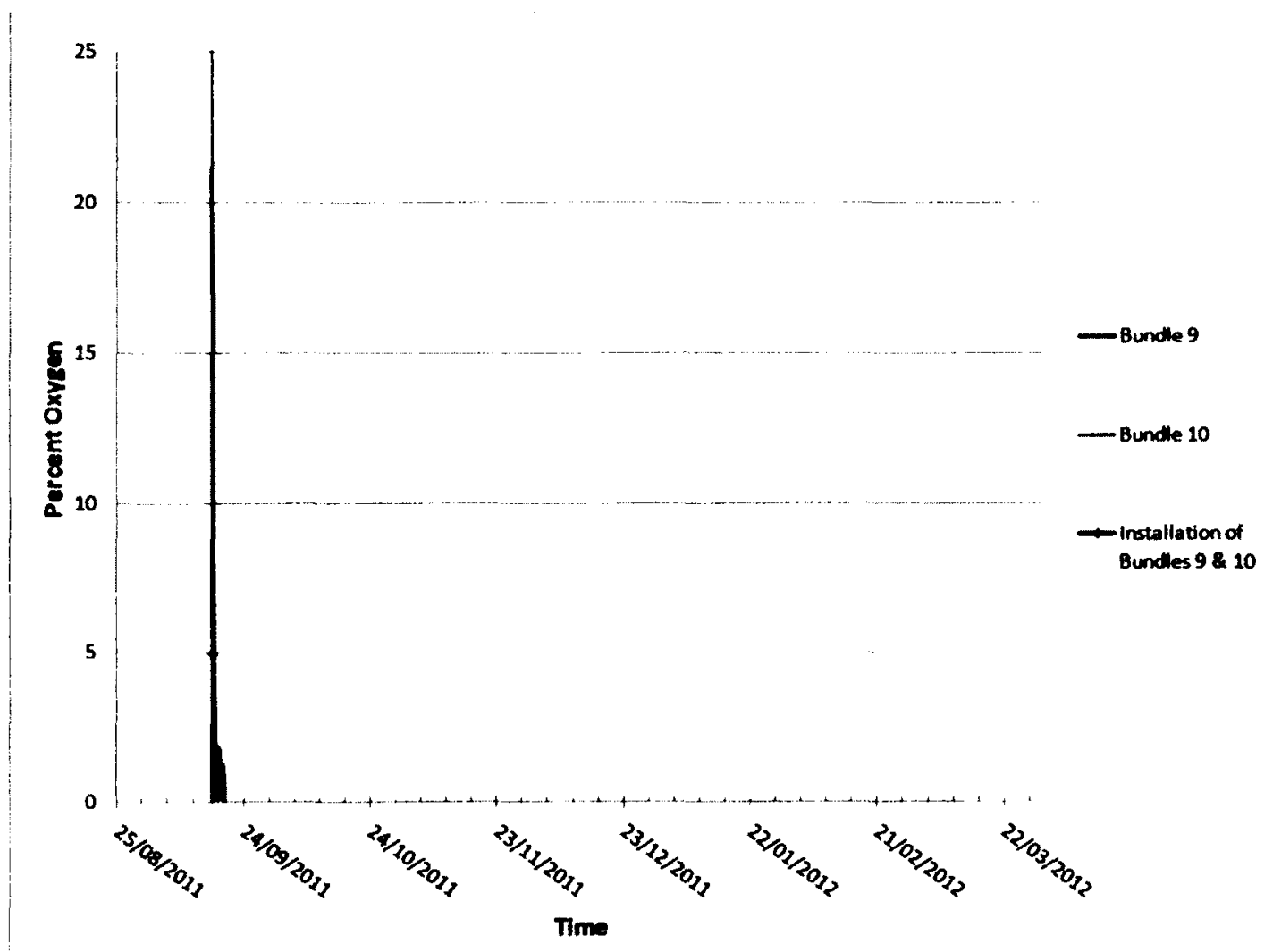

Figure 18: Oxygen content for bundles 9 and 10

\subsection{Temperature Results}

The temperature results are extremely important as they impact the rate of waste stabilization within the landfill, and subsequently the amount of landfill gas produced. Figure 19 shows a plot of the temperature data set from each instrument bundle from November 2009 to March 2012. The grey line indicates the ambient air temperatures and the coloured vertical bars indicate the placement of the first four lifts of waste. The 
temperatures were averaged from the thermistors of the liquid settlement system, moisture and electrical conductivity sensor, piezometer, and total earth pressure cell. The oxygen sensor contains an internal heater that is used to prevent condensation from impacting the oxygen readings. As a result, the temperature readings from the oxygen sensor thermistor are approximately $2^{\circ} \mathrm{C}$ higher than that of the remaining thermistors for each bundle. With the exception of the oxygen sensor, the temperature readings from the various thermistors were generally within $1^{\circ} \mathrm{C}$. The data from individual thermistor temperatures of each instrument bundle are presented in Appendix B. 


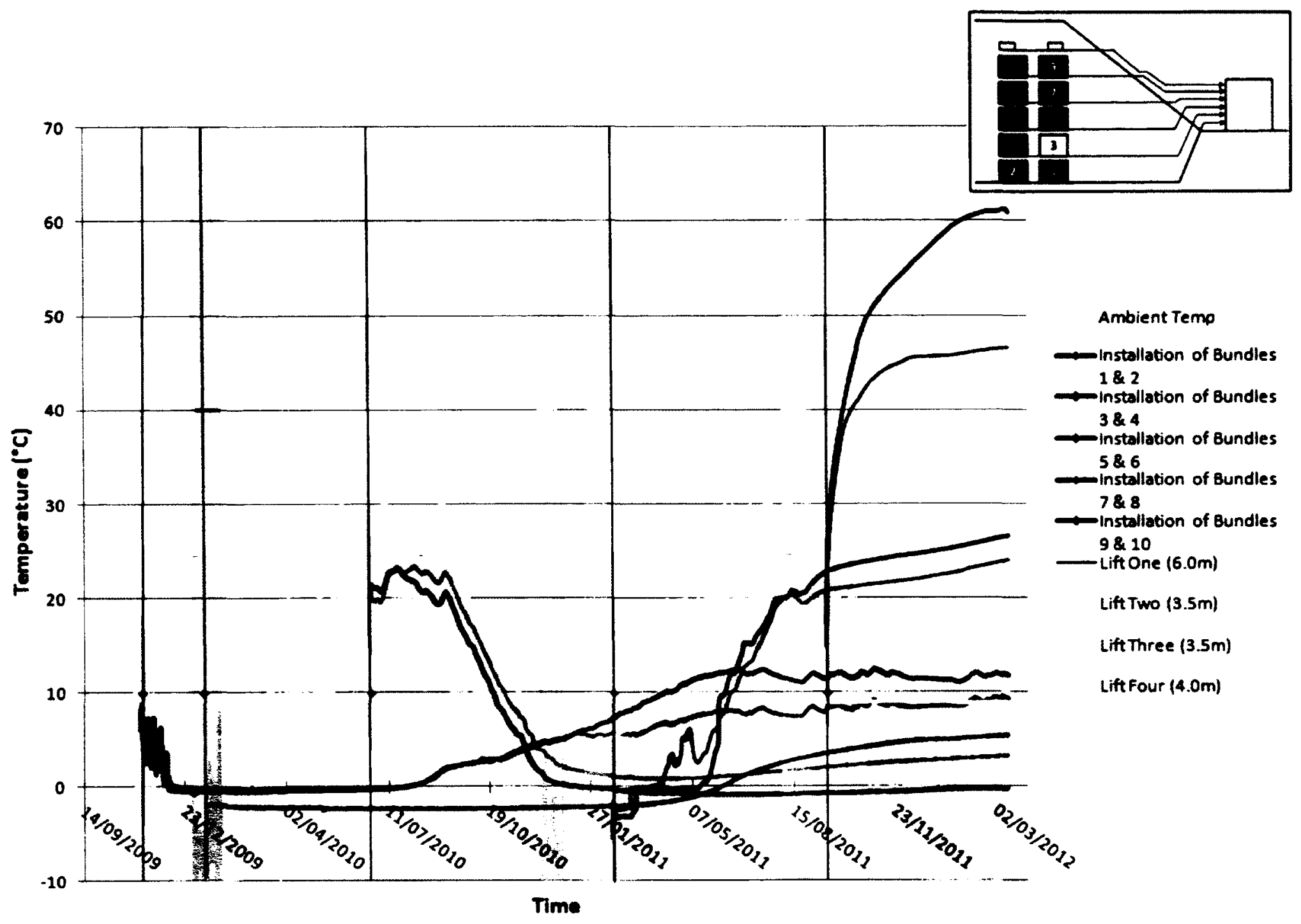

Figure 19: Average temperature for bundles 1 to 10 
As shown in Figure 19, after installation of bundles 1 and 2 on the base of the landfill, the average temperatures initially followed the positive ambient temperature as the bundles were only covered by the $0.3 \mathrm{~m}$ high protective sand layer. Once the ambient temperatures at the site dropped below $0^{\circ} \mathrm{C}$ in December 2009 , the protective sand layer over the bundles froze. At this point, the temperature readings from both bundles 1 and 2 stabilized at a temperature of approximately $-0.5^{\circ} \mathrm{C}$. In early January 2010 , the first layer of waste $(\sim 6 \mathrm{~m})$ was placed over bundles 1 and 2 . The first waste layer was placed in a frozen state at an approximate temperature of $-1.7^{\circ} \mathrm{C}$. In the summer of 2010 , the ambient temperatures at the site rose above $30^{\circ} \mathrm{C}$, and yet the instrument bundles maintained a temperature of approximately $-0.5^{\circ} \mathrm{C}$. This indicates the $6 \mathrm{~m}$ thick frozen waste layer acts as an excellent insulator due to the low thermal conductivity of waste. Eventually, at the end of August 2010, the temperatures of first two bundles reached $0^{\circ} \mathrm{C}$ demonstrating the waste at the instrument bundles was beginning to thaw. This increase in temperature is primarily attributed to an upwards heat flux from the base of the landfill reaching the bundles, as the bundles were placed on the cell floor immediately above the leachate collection system. This concept is discussed further in Section 4.2.1. The temperatures for bundles 1 and 2 continued to rise steadily until April 2011, at which point they stabilized at approximately $11^{\circ} \mathrm{C}$ and $9^{\circ} \mathrm{C}$ respectively and remained at these temperatures until March 2012. During this period of time there are small fluctuations in the temperatures that can be attributed to the bundles being placed above the leachate collection system.

Bundles 3 and 4 were installed in January 2010 in the middle of the first waste lift, $3 \mathrm{~m}$ from the base of the landfill. After installation, the bundles were immediately covered with the remaining $3 \mathrm{~m}$ of waste to complete the $6 \mathrm{~m}$ waste lift. As the installation 
occurred during the winter, the initial temperatures at bundles 3 and 4 were approximately $-1.7^{\circ} \mathrm{C}$, as shown in Figure 19 . Similarly to bundles 1 and 2 , even as the ambient temperature rose to above $30^{\circ} \mathrm{C}$ in the summer of 2010 , the temperatures in the middle of the waste profile remained frozen. This reinforces the fact that solid waste must has a low thermal conductivity thereby acting as a great insulator. In addition, this suggests a lot of energy is needed to thaw the liquid portion of frozen waste, indicating the waste has a high latent heat of fusion. In January 2011, the waste surrounding bundle 3 began to thaw as the temperatures rose above $0^{\circ} \mathrm{C}$ relatively quickly. The rapid increase in temperature occurring at bundle 3 was unexpected at this time, especially in comparison to the continuous frozen state of bundle 4 . However, if the waste has a large latent heat value as expected, small variances in heat flux between bundles 3 and 4 over the 12 months since installation could cause the waste surrounding bundle 4 to remain frozen longer than bundle 3 . In May 2011, bundle 4 showed a similar rapid temperature increase. This phenomenon is consistent with the frozen waste having a large latent heat value, as a significant amount of heat was used to convert leachate within the waste from solid to liquid state. As of March 2012, the temperatures at bundles 3 and 4 have increased to $9^{\circ} \mathrm{C}$ and $6^{\circ} \mathrm{C}$ respectively. Thus, more than two years after placement of the waste, the waste remains well below optimum temperatures for biodegradation.

Bundles 5 and 6 were installed in the June 2010 in top of the first waste lift and were covered with $0.5 \mathrm{~m}$ of waste. The ambient temperatures during installation were over $25^{\circ} \mathrm{C}$ and the initial waste temperature was close to $20^{\circ} \mathrm{C}$. However, as the bundles were only covered by $0.5 \mathrm{~m}$ of waste, the temperatures decreased, followed the average ambient temperatures lagged by a few days. The lag is a result of the limited insulation 
the $0.5 \mathrm{~m}$ waste layer provided. In December 2010, a second waste lift was placed over the instrument bundles, followed by third layer of waste in January and February 2011. Unfortunately, these additional waste layers were placed too late to contain some of the heat added during the summer as the temperatures at bundles 5 and 6 had decreased to $1{ }^{\circ} \mathrm{C}$ and $-0.4^{\circ} \mathrm{C}$, respectively. The bundles have slowly regained heat but are insulated with $7 \mathrm{~m}$ of frozen waste above and $5.5 \mathrm{~m}$ of partially frozen waste below.

Bundles 7 and 8 were installed in February 2011, within a lift of frozen waste and with $0.5 \mathrm{~m}$ of waste above the bundles. Due to the placement during the winter, bundles 7 and 8 measured temperatures of approximately $-3^{\circ} \mathrm{C}$ and $-2^{\circ} \mathrm{C}$ respectively. As shown in Figure 19 , the temperature profile for bundle 7 is quite smooth while the bundle 8 fluctuates abruptly. Bundle 8 was excavated on March 4, 2011 to adjust the bundle installation and left uncovered by waste until May 2011 causing fluctuations in the temperature data. Prior to the fourth waste lift being placed over bundles 7 and 8 , the temperatures followed but lagged the ambient air temperature. However, once the fourth waste lift was placed the temperatures begin to defer from the ambient air temperature and continue to rise. The temperatures at bundles 7 and 8 in March 2012 are $27^{\circ} \mathrm{C}$ and $24^{\circ} \mathrm{C}$ respectively.

Bundles 9 and 10 were installed in September 2011 , with $1.0 \mathrm{~m}$ of waste above the bundles. Over a span of 6 weeks, from the time of installation to end of October, both bundles measured a significant increase in temperature. Bundles have maintained these high temperatures (close to $50^{\circ} \mathrm{C}$ ) indicating the waste is actively degrading. 


\subsubsection{Anticipated Heat Flux}

Analysis of the temperature readings from the instrument bundles helped to establish how heat is transferred within the waste. Figures 21 and 22 show the temperature readings from the instruments in the first four waste lifts. The arrows in the figure indicate the direction of heat flux in the waste, from the ambient air or from the base of the landfill. The heat entering the waste from the atmosphere is in the form of a convective or radiative flux whereas the heat entering from the base of the landfill occurs via conduction.

The temperatures measured by Column 1 of the instrument bundles, located closer to the North-East edge of the landfill are presented Figure 21 . Immediately after placement of waste above bundle 1 , there is a positive heat flux coming from the leachate collection system below. This is primarily because the ground temperature in Montreal and the surrounding area is constant, at temperatures warmer than the waste above. At soil depths greater than $4 \mathrm{~m}$, the ground temperature approaches a constant value of approximately $7^{\circ} \mathrm{C}$ as shown in Figure 20 (Environment Canada, 2012). In addition, warm leachate and/or air or landfill gas from other parts of the landfill may be migrating laterally within the leachate collection system. However, despite the warm heat flux from the base of the landfill, it still takes a significant amount of time for the temperatures at bundle 1 to increase. This is indicative of the high latent heat value of the waste, as a large quantity of heat is required to thaw the liquid fraction of the waste above the bundle. Once the waste above the instrument bundle has thawed, the positive heat flux causes a gradual temperature increase. 


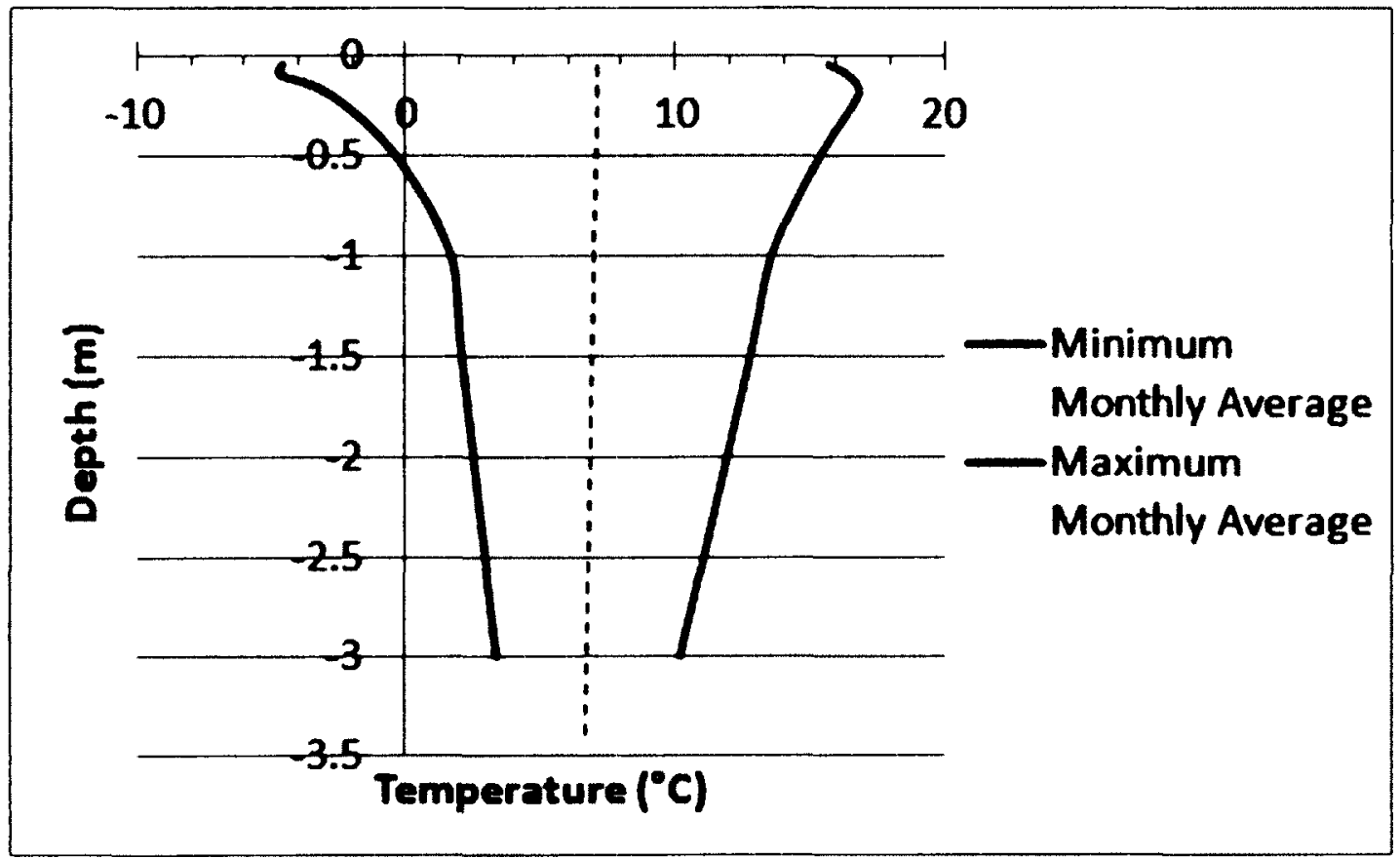

Figure 20: Temperature profile in soil with depth at Mirabel airport (Environment Canada, 2012)

The first waste lift was placed in January of 2010, and during the winter months there is a flux of heat leaving the waste as the waste temperature is much warmer than the ambient air. During the summer months, the ambient temperatures rose as high as $30^{\circ} \mathrm{C}$, and therefore there was heat entering the waste. However, the temperatures at the centre of the $6 \mathrm{~m}$ waste lift remained below $0^{\circ} \mathrm{C}$, indicating the heat from the warm ambient temperatures was not able to penetrate into the centre of the waste. This indicates the thermal conductivity of the waste is relatively low. The second and third waste lifts of 3.5 $\mathrm{m}$ each were placed over the area in December 2010 and February 2011 . Due to the waste lift being placed under winter weather conditions, it is anticipated that the waste was placed at temperatures of approximately $-2^{\circ} \mathrm{C}$. However, since these temperatures are not confirmed, a dashed line in Figure 21 represents the unknown direction of heat flux until 
a thermal gradient is established throughout lifts 2 and 3 . In the summer months of 2011 , there are positive convective and radiative heat fluxes impacting the top of lift 3 causing a transfer of heat downwards to the waste surrounding bundle 5 .

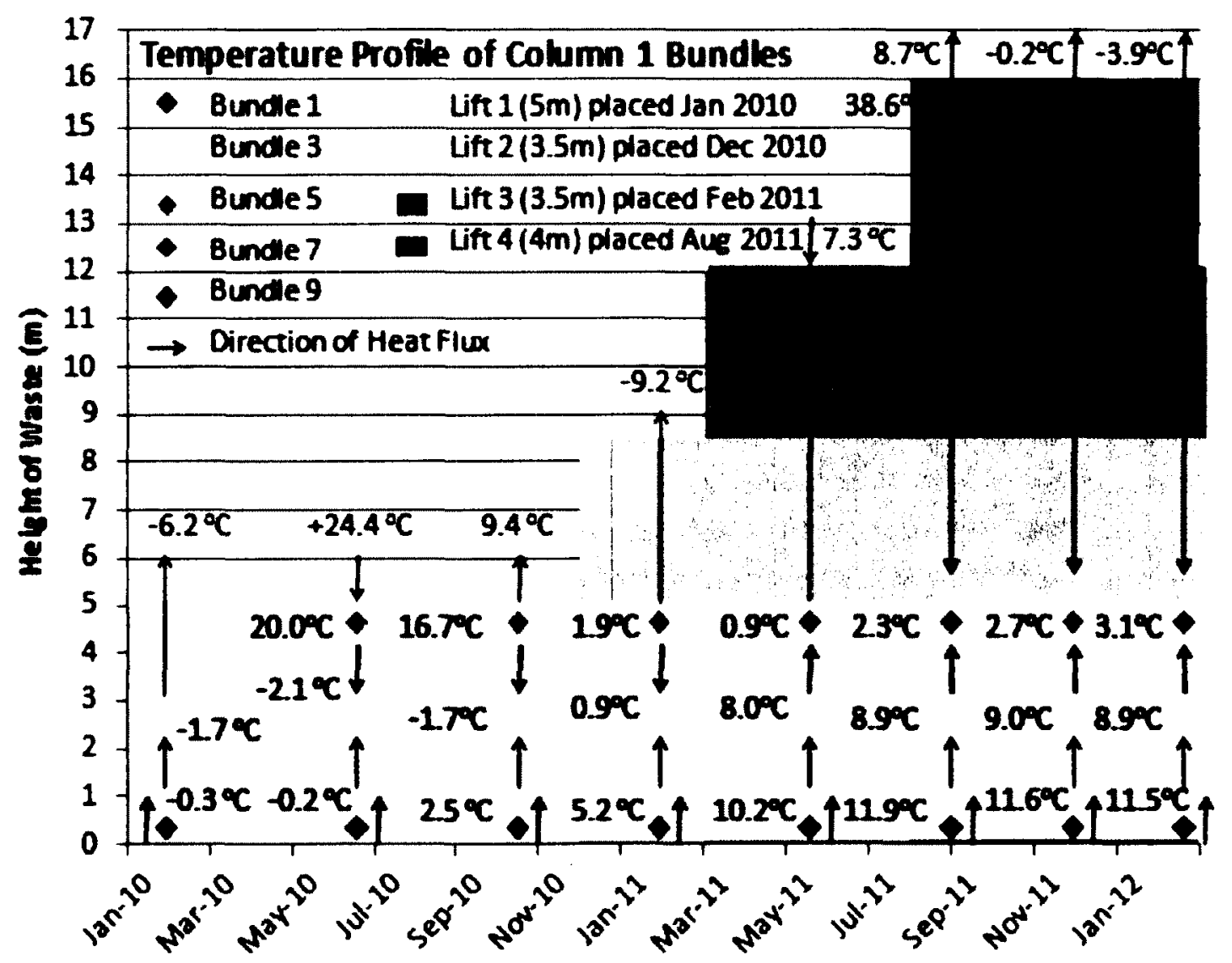

Figure 21: Temperature profile of waste in bioreactor landfill from Column 1 (modified from Vingerhoeds, 2011).

Figure 22 shows the waste temperatures measured at Column 2 of instrument bundles located further into the landfill. Bundle 2 shows similar results to bundle 1 , as there is a positive heat flux coming upwards from the underlying leachate collection system. Similarly to bundle 5 , there is a positive heat flux towards the centre of waste in the summer as shown by the temperatures at bundle 6 . However, despite the flux from both 
the top and bottom of the waste, the temperature at bundle 4 remains frozen for nearly 1.5 years. Eventually, the positive flux from the base of the landfill reaches the centre of the first waste lift causing the temperature at both bundles 3 and 4 to rise. Prior to the next waste lift being placed over bundles 7 and 8 , the temperatures for these bundles seem to be following the ambient air temperature lagged by a few days. However, once the waste lift is placed the temperatures begin to defer from the ambient air temperature and continue to rise. This indicates there is a heat flux downwards from the waste lift above. However, despite the temperatures being extremely high at bundle 10 , the downwards heat flux is still relatively slow. This supports the conclusions from Lefebvre et al. (2000) that the majority of the aerobic activity is occurring in the top $1 \mathrm{~m}$ of waste. 


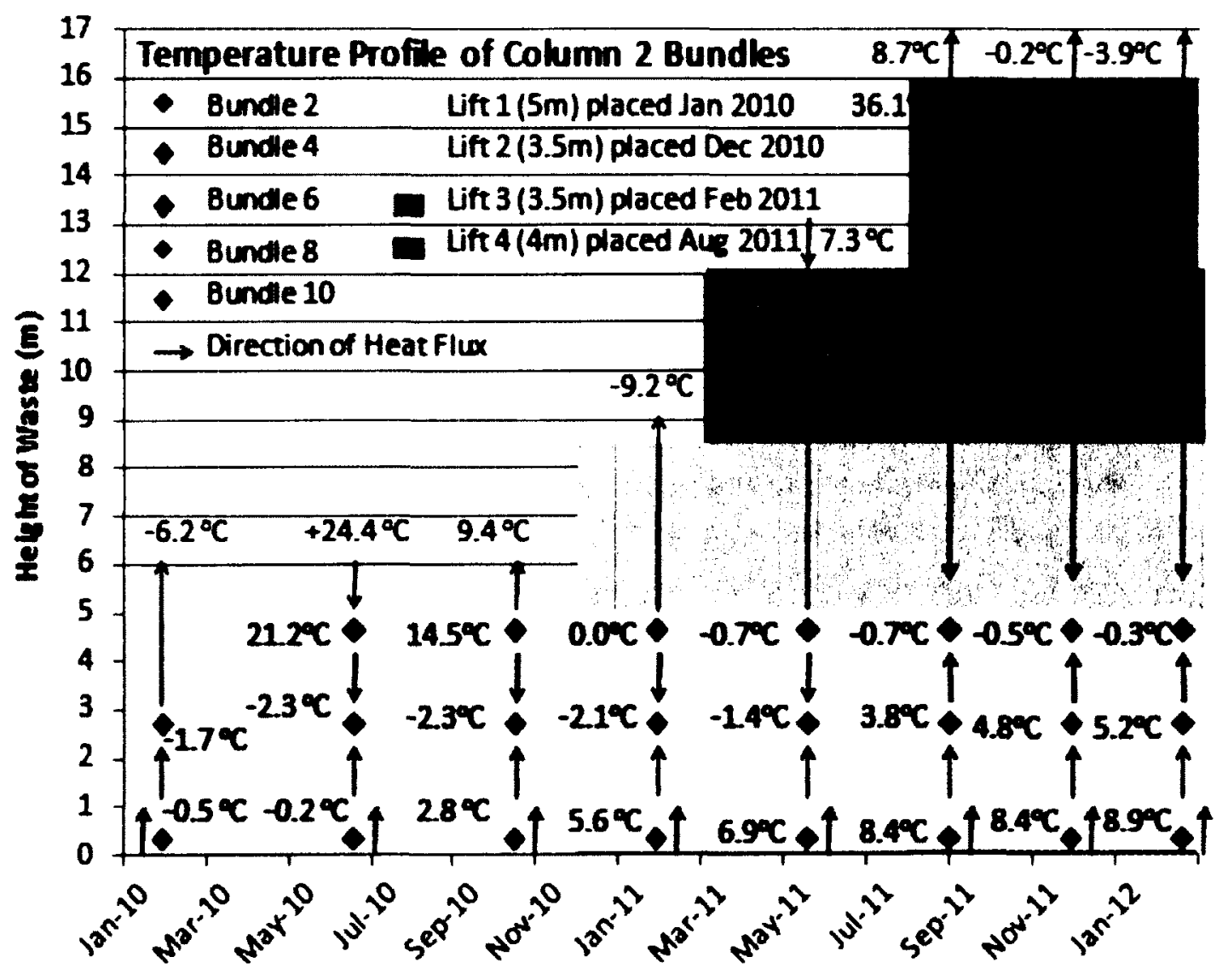

Figure 22: Temperature profile of waste in bioreactor landfill from Column 2 (modified from Vingerhoeds, 2011).

In analyzing the heat flux throughout the landfill, it is apparent that the first column of instrument bundles is consistently warmer than the second column located further into the landfill. Overall, Figures 21 and 22 demonstrate the insulating capacity of the waste. In addition, for both Columns 1 and 2, the first three waste lifts remain at relatively low temperatures and the principal heat fluxes are from either the base of the landfill, or from degradation occurring in the fourth waste lift. As the temperatures remain significantly lower than optimal temperatures for biodegradation, the heat generation within these lifts is negligible. In comparison to literature, the waste in the centre of the $6 \mathrm{~m}$ frozen waste 
lift remained at temperatures below $0^{\circ} \mathrm{C}$ for up to 1.5 years (Hanson et al., 2006; Zhao et al., 2008). However, the delay is even longer for the temperatures to reach values where the microbial activity is significant. In comparing the placement of lifts 2 and 3 to lift 4 , this illustrates the importance of considering the sequence of waste placement. Lift 2 is placed during the winter, and therefore the first waste lift lost any heat gained throughout the summer. In comparison, the fourth waste lift was placed at the end of summer. Figures 21 and 22 illustrate the placement of this waste lift successfully trapped any heat gained throughout the summer.

It is evident that the sequencing of waste placement is an important issue for landfill operators. When multiple lifts of frozen waste are placed in succession, there is no heat source to raise the temperature of the waste. This can have negative impacts on the rate of stabilization, which can have a negative impact on the amount of settlement occurring in the landfill (Hanson et al., 2006; Houi et al., 1997; Vingerhoeds, 2011). In addition, methane gas production which can be used for energy or heating will be significantly reduced in these areas of the landfill. This research illustrates landfill operators should keep track of the waste placement timeline at the site to avoid placing multiple lifts of waste on top of each other during the winter months (Hanson et al., 2006; Vingerhoeds, 2011). Furthermore, modelling the various heat fluxes within the landfill will be extremely beneficial. Once the thermal parameters of the waste are estimated, the model can be used to examine to the benefit of sequencing the waste or the possible benefit of placing a winter layer on the base of the landfill. As illustrated in Figures 21 and 22, one of the primary sources of heat in the bottom layer is an upwards flux from the leachate collection system. This upwards heat flux would be wasted if a warm layer was placed on 
the bottom, and a downwards heat flux from the warm layer would occur once the waste started actively degrading. 


\section{Modelling Overview}

The modelling results portion of this thesis has been prepared as two separate journal papers. Sections 6 and 7 have been submitted to academic journals and are co-authored. The details regarding the publications and contributions made by each author are discussed here.

The first paper is presented in Section 6 was submitted to Waste Management and presents a calibrated finite element model for the first 10.5 months of collected temperature data for the first waste lift. In addition, the paper presents a heat budget that quantifies the various heat sources/sinks that impact the waste temperature and a sensitivity analysis for the various parameters that impact the heat budget.

Title: Heat Budget for an Anaerobic Bioreactor Landfill in a Northern Climate Authors: James E. Bonany, Paul J. Van Geel, H. Burak Gunay, O. Burkan Isgor Submitted to: Waste Management

The field installation and data collection was performed by James Bonany. Modelling of the data using the finite element software was completed by James Bonany and Burak Gunay. The majority of the text was written by James Bonany and edited by Paul Van Geel and Burkan Isgor. The numerical model section was written by Burak Gunay and edited by James Bonany, Burkan Isgor and Paul Van Geel.

The second paper is presented in Section 7 was submitted to Waste Management \& Research and presents an improved calibrated finite element model for the first 19 months of collected temperature data for the first three waste lifts. The expanded 
modelling effort included separating the heat generation from biodegradation into aerobic and anaerobic terms.

Title: Simulating the impacts of temperatures in northern climates on waste stabilization at an operating bioreactor landfill in Quebec, Canada

Authors: James E. Bonany, Paul J. Van Geel, H. Burak Gunay, O. Burkan Isgor

Submitted to: Waste Management \& Research

The installation of the instrument bundles and data collection was performed by James Bonany. Modelling of the data using the finite element software was completed by James Bonany and Burak Gunay. The majority of the text was written by James Bonany and edited by Burak Gunay, Paul Van Geel and Burkan Isgor.

\subsection{Model Development}

The heat transfer process within the solid waste was simulated with a 2D finite element model using COMSOL Multiphysics v.3.5. The model simulates the heat transfer throughout the landfill from the time of first waste lift placement in January 2010 through to the placement of the fourth waste lift in August 2011. Model dimensions were determined from the GPS coordinates at the time of waste placement. The dimensions used to model the first three lifts of waste can be seen in Appendix D.

Using the range of thermal parameters found within the literature as a basis, a finite element model was developed to simulate the first 10.5 months of collected temperature data for the first waste lift. The calibrated model was then used to complete a sensitivity analysis to determine the relative importance of the various thermal parameters. Figure 23 demonstrates the progression of the model towards the base case used in Section 6 for 
the sensitivity analysis. Figure 23 displays large incremental changes to the thermal parameters as only a limited number of results are displayed in the figure. However, much smaller adjustments to the thermal parameters (approximately 0.05 and 50 for the thermal conductivity and heat capacity, respectively) were made in comparison to those shown in the figure. All values attempted were within the range of thermal parameters established in the literature.

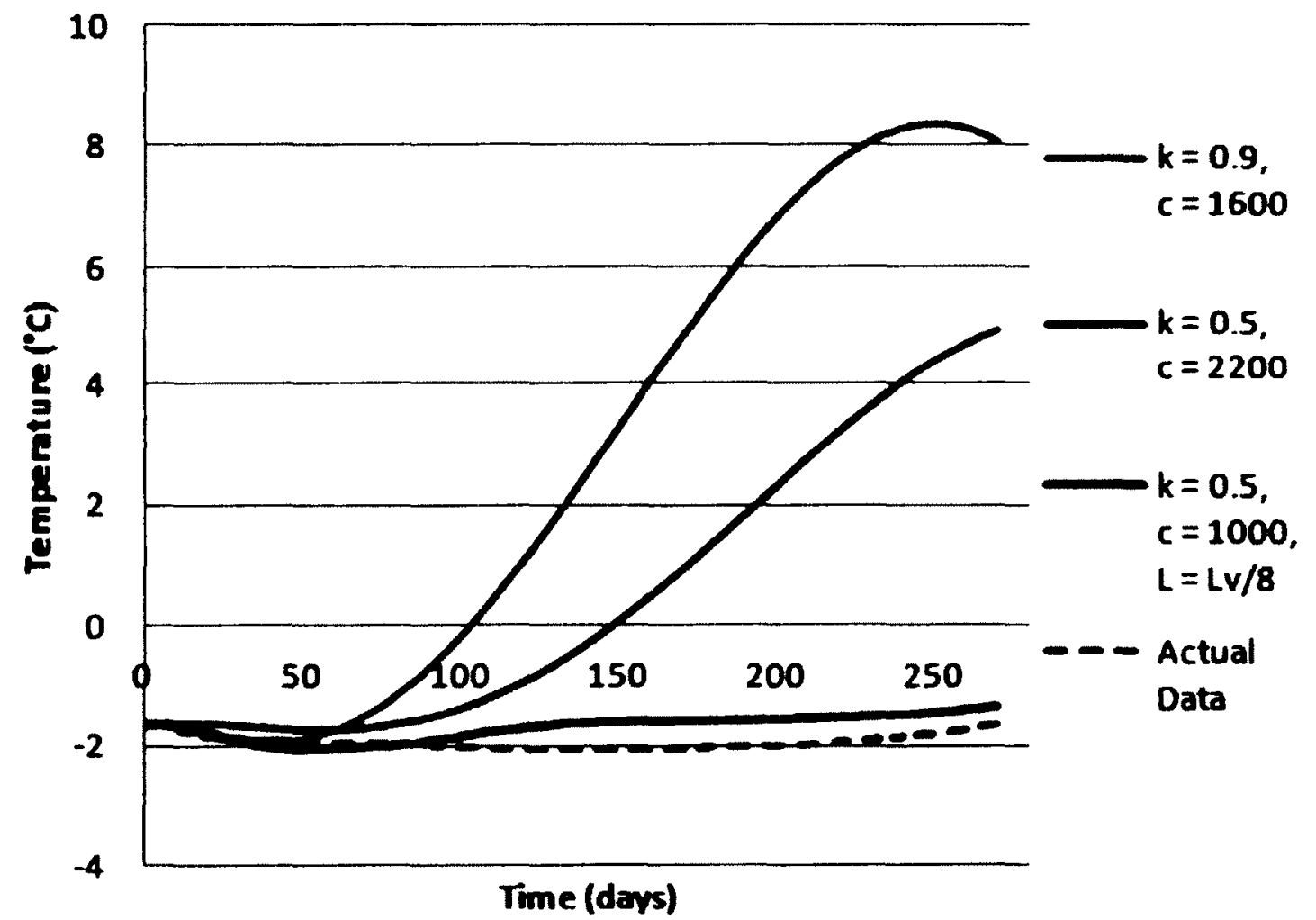

Figure 23: Progression of the model to arrive at base case

The figure illustrates the results for bundle 3, located at the centre of the first $6 \mathrm{~m}$ waste lift. The green line in the figure shows the first trial, simulated using a middle range value for both thermal conductivity and heat capacity. The results demonstrate that too large of 
a heat flux reached the centre of the waste profile. To improve the simulation, the thermal conductivity was reduced and the heat capacity was increased. The results, shown in the figure with a red line, again indicated too large of a heat flux reached the centre of the waste lift. Thus, a latent heat of fusion term was added to the equation to account for the energy required for phase change of the frozen leachate. This term has typically not been included when modelling heat transfer in MSW and it is difficult to quantity. At SainteSophie, WM typically achieves a density close to $1000 \mathrm{~kg} / \mathrm{m}^{3}$ via compaction. The moisture content at placement is typically $15-20 \%$ by volume, although not all the moisture may be frozen. Therefore, Eqn. 5 was used to determine the range of values for the latent heat of fusion of the waste ( one fifth to one tenth that of water). The latent heat of fusion value used to generate the blue line in Figure 23 was assumed to equal one eighth that of water. Thus, one eighth the amount of energy would be required to thaw the liquid fraction within a unit weight of waste in comparison to a unit weight of water. Further research is needed to characterize this term; however, the assumed latent provided a good model fit. 


\section{Heat Budget for an Anaerobic Bioreactor Landfill in a Northern Climate}

\subsection{Abstract}

Bioreactor landfills are an effective waste-to-energy technology as they promote rapid waste biodegradation and stabilization, which increases settlement and the corresponding available airspace and improves landfill gas generation. A bioreactor landfill operated in Sainte-Sophie, Québec, Canada was instrumented to better understand the waste stabilization process in northern climates. Instrument bundles were placed to monitor temperature, settlement, oxygen, moisture content, total load, mounding of leachate and electrical conductivity within the waste. A finite element model developed to simulate the heat budget was calibrated using the first 10.5 months of collected temperature data. The calibrated model was then used to complete a sensitivity analysis for the various parameters that impact the heat budget. The results of the analysis indicated that the heat required for phase change to thaw the liquid fraction within frozen waste had a significant impact on the heat budget causing sections of waste to remain frozen throughout the simulation period. This was supported by the data collected to date at Sainte-Sophie and by other researchers indicating that frozen waste placed during the winter months can remain frozen for periods in access of 1.5 years.

\subsection{Introduction}

Bioreactor landfills aim to control the conditions within waste in order to enhance the waste stabilization process, which will increase landfill gas production and promote waste settlement, maximizing usable airspace. A number of research groups have 
instrumented field-scale bioreactor landfills to monitor the conditions within waste (Yesiller et al., 2011; Reinhart et al., 2002; Augenstein et al., 1997) and some have modelled the stabilization and gas generation within bioreactors (Hanson et al., 2008; ElFadel et al., 1996c; Yoshida \& Rowe, 2003; Yesiller et al., 2005). These models provide a comprehensive understanding of how biodegradation occurs within a bioreactor landfill in warmer climates; however, cold temperatures in northern climates can make the optimization of waste stabilization challenging (Zhao et al., 2008; Hanson et al., 2006). For example, at the Northern Oaks Recycling and Disposal Facility it was found that lifts placed in the winter months remained frozen for 6 months after closure of a cell (Zhao et al., 2008). In comparison, research completed at the Anchorage Regional landfill determined that frozen waste placed in winter months could remain frozen for up to two years (Hanson et al., 2006). It was also reported the that cold conditions of the waste at placement delayed significant gas generation until three to four years after waste was placed in the landfill (Hanson et al., 2006). Therefore, the initiation of microbial biodegradation was largely dependent on the placement conditions of the waste (Houi et al., 1997; Hanson et al., 2006). Better understanding of the waste stabilization process for bioreactor landfills located in northern climates is required to overcome these challenges.

This research is part of a three-year effort to instrument a cell in waste-to-energy bioreactor landfill in Sainte-Sophie, Quebec, operated by Waste Management (WM) of Canada, as it is progressively filled with waste. Sainte-Sophie landfill generates approximately $9000 \mathrm{~m}^{3} / \mathrm{h}$ of landfill gas providing $4000 \mathrm{GJ} /$ day of energy to a nearby pulp and paper mill. To date, ten instrument bundles have been installed in the waste in two vertical profiles. The instrument bundles were designed to include sensors that 
measure important parameters impacting the degradation and stabilization processes. Figure 24 shows the various instruments used in a typical bundle to monitor temperature, settlement, oxygen, moisture content, total load, mounding of leachate and electrical conductivity within the waste. An on-site weather station records various climatic conditions at the landfill including temperature, relative humidity, wind speed and direction, barometric pressure and precipitation. The landfill gas quantity and quality are also monitored. The data collected will provide valuable insight into the key parameters that affect the waste degradation and stabilization processes. This knowledge will allow landfill operators to tailor their operational practices to minimize landfill footprint and maximize gas production.

The focus of this paper is to develop a model that simulates the heat budget for bioreactor landfills operating in northern climates where waste is placed under frozen conditions during a portion of the year. The proposed model includes the heat flux from below the landfill, from atmospheric conditions above the waste, and the heat generated via biodegradation. The heat is then stored as sensible heat increasing the temperature of the waste and latent heat for phase change to account for the heat needed to thaw the liquid fraction within the waste. The model was calibrated using the temperature data collected at the Sainte-Sophie site. The calibrated model was then used to conduct a sensitivity analysis to determine which parameters and/or processes have the largest impact on the simulated waste temperatures. The model was also used to create a heat budget to summarize the various heat sinks/sources affecting the waste. 


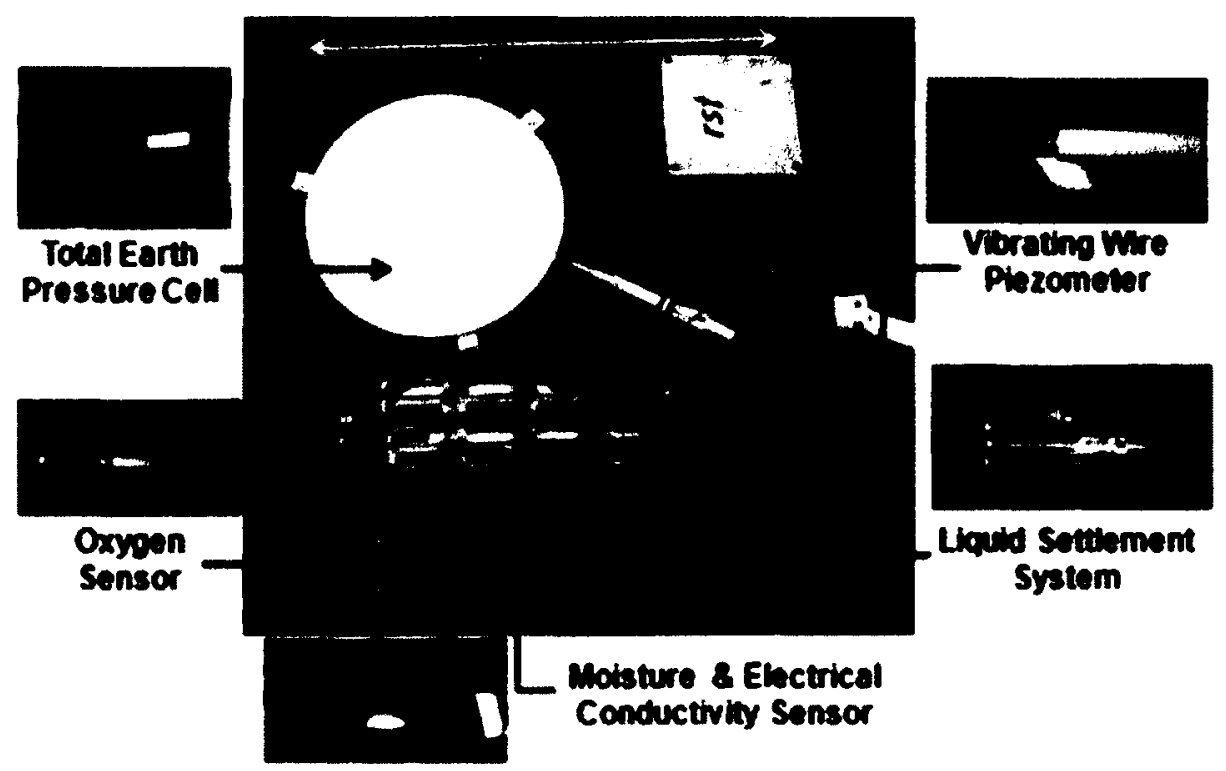

Figure 24: Instrument Bundle (Bonany et al., 2012b)

\subsubsection{Instrument Bundle Installation}

A typical instrument bundle contained thermistors, a liquid settlement system, a piezometer, a total earth pressure cell, an oxygen sensor and a moisture sensor and electrical conductivity sensor. The liquid settlement system, piezometer and total earth pressure cell are mounted on the steel plate. The oxygen sensor and moisture sensor were left unsecured from the steel plate as they must be inserted firmly into the sand placed over instrument bundle for protection. Ten instrument bundles have been placed within the waste to date, with two bundles installed at each layer. Figure 25 is a cross-section of the landfill cell, showing the placement elevations for the instrument bundles. Placement was planned such that there will be two vertical columns, Column 1 and Column 2, each consisting of six instrument bundles. Column 1 and 2 are separated by approximately 17 $\mathrm{m}$ and each layer of instrument bundles was to be separated by approximately 3 to $4 \mathrm{~m}$. 
The vertical separation between the layers changed slightly as shown in Figure 24 due to the variations in the waste lift thicknesses.

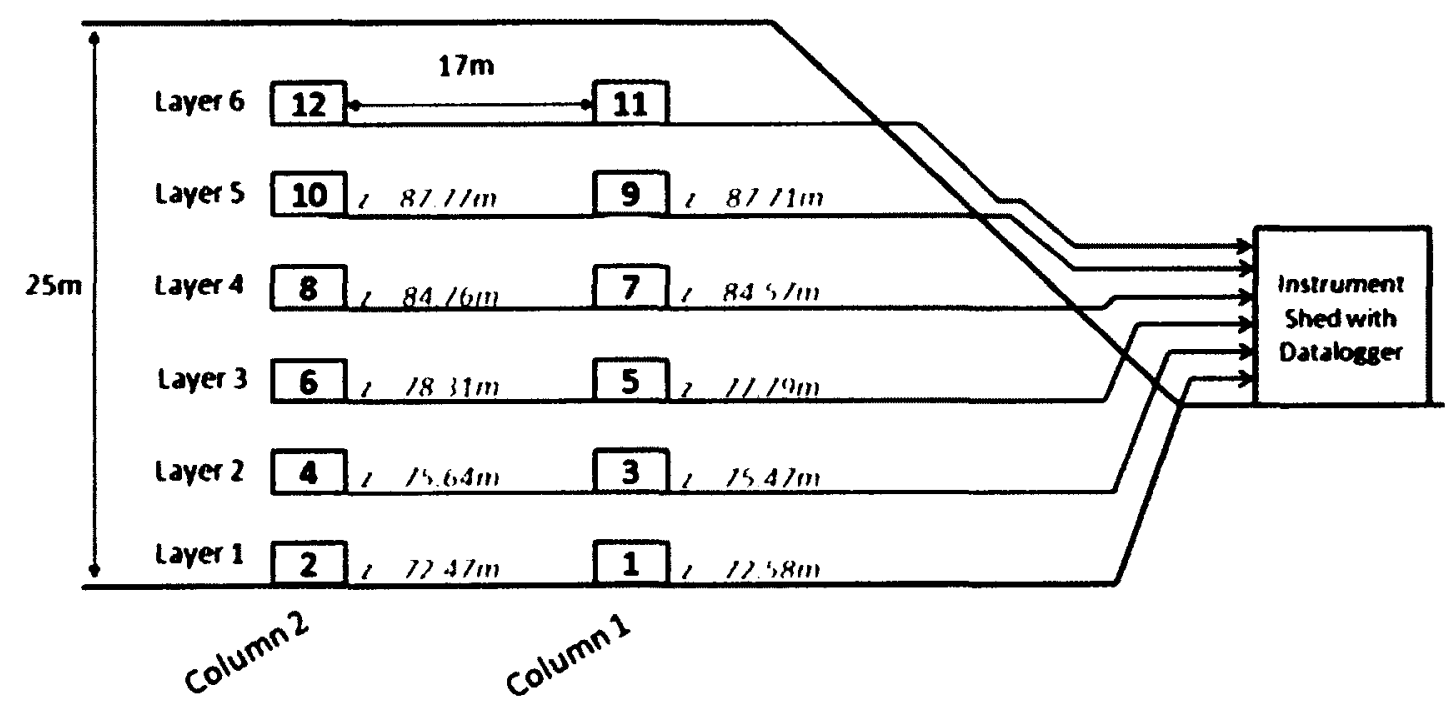

Figure 25: Elevation of Instrument Bundles at Placement (Bonany et al., 2012a)

Figure 26 shows the installation of instrument bundles 1 and 2 in October 2009, on the base of the bioreactor landfill cell. Bonany et al. (2012a) provided details of the instrument bundle installation process. A $0.3 \mathrm{~m}$ sand layer was placed over the instrument bundles and cables for protection before covering the bundles with waste. The sand also served as a medium in which the moisture and electrical conductivity sensor and oxygen sensor were placed. These bundles were covered with waste when the first waste lift $(\sim 6$ m) was placed in January 2010 . 


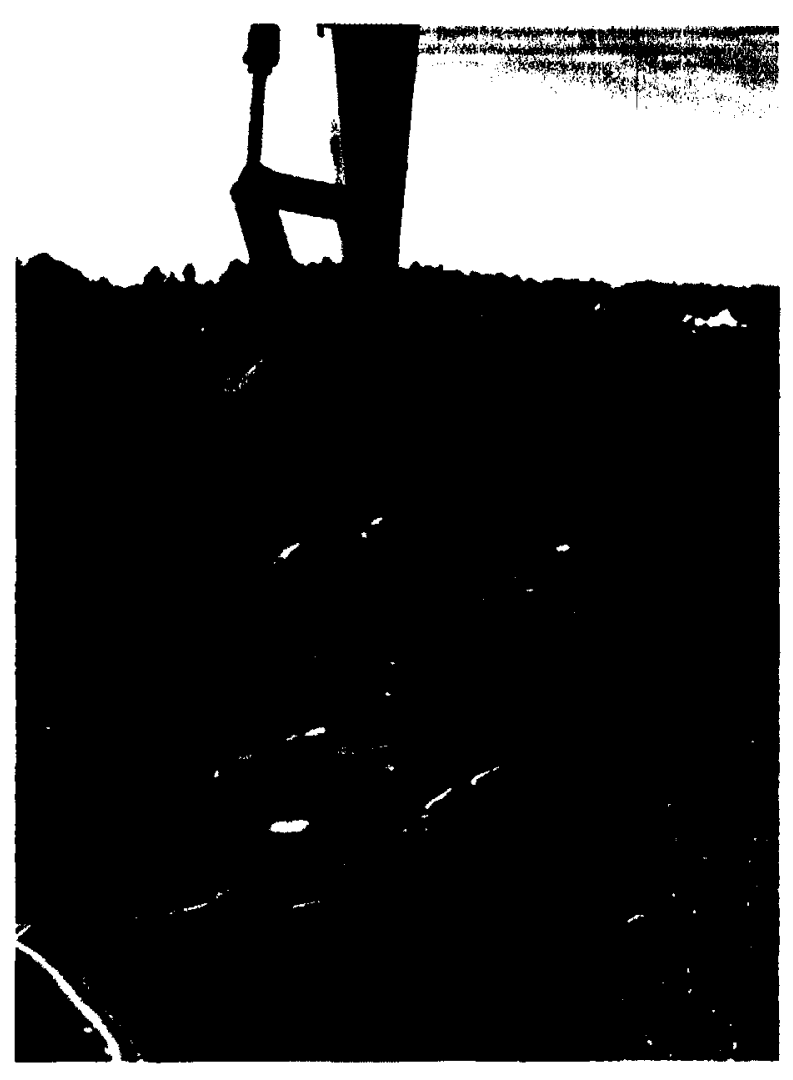

Figure 26: First Layer Instrument Bundle Installation in October 2009

For instrument bundles 3 through 10, a trench was excavated in the waste, in which the instrument bundle and cables were placed as shown in Figure 27. The instrument bundles and cables were once again covered with sand for protection. To facilitate the placement of bundles 3 and 4 at the centre of the first lift, WM personnel at Sainte-Sophie placed a half lift $(\sim 3 \mathrm{~m})$ over the area of the instrument bundles. Bundles 3 and 4 were installed and immediately covered with the second half lift $(\sim 3 \mathrm{~m})$ in February 2010 . Bundles 5 and 6 were installed $0.5 \mathrm{~m}$ below the top of the first lift in June 2010. In December 2010 and January/February 2011 a second and third waste lift (each $3.5 \mathrm{~m}$ ) were placed above the instrument bundles. Bundles 7 and 8 were installed $0.5 \mathrm{~m}$ below the top of the third lift in February 2011. It is important to note that the first three waste lifts were placed in 
the winter months and the waste was placed in a frozen state. To avoid placing another frozen waste lift in the area of the instrument bundles, the fourth waste lift was placed in August 2011. Instrument bundles 9 and 10 were installed $1.0 \mathrm{~m}$ below the top of the fourth lift in September 2011, above approximately $15 \mathrm{~m}$ of waste from the base of the landfill.

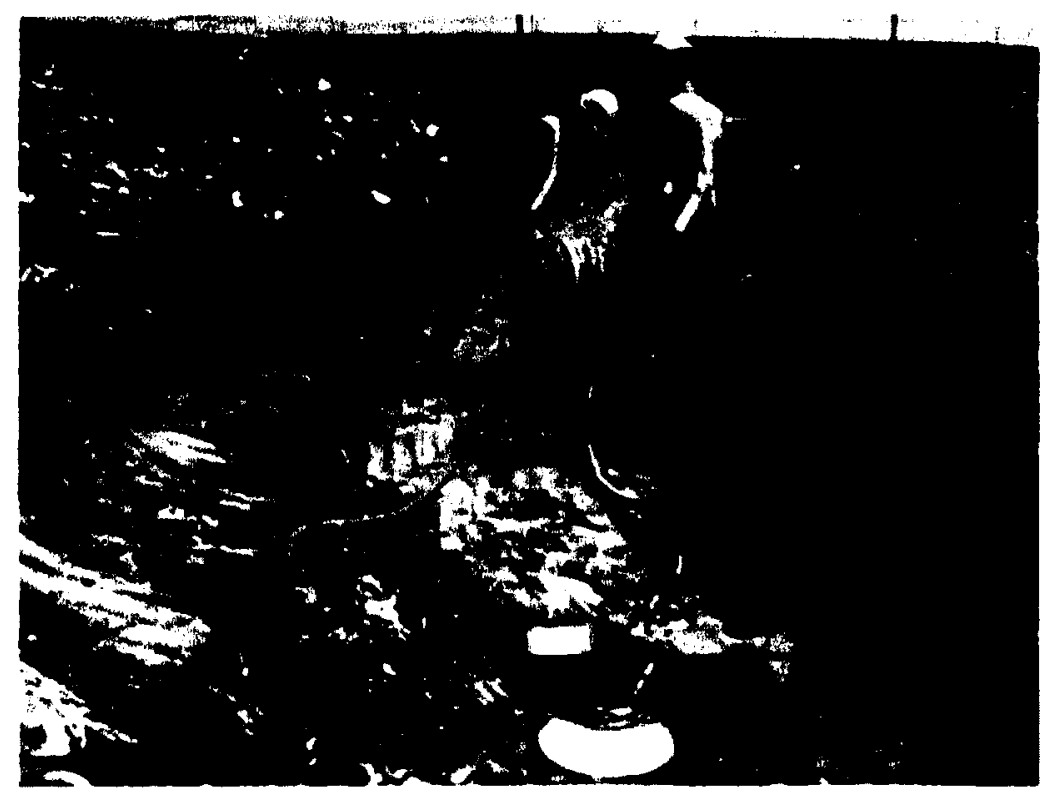

Figure 27: Third Layer Instrument Bundle Installation in June 2010

\subsubsection{Instrument Bundle Temperature Data}

Data collection began in November 2009 from the instrument bundles installed in the bioreactor landfill. Figure 28 shows a plot of the temperature data set from the first six instrument bundles from November 2009 to March 2012. The grey line indicates the ambient air temperatures and the coloured vertical bars indicate the placement of the first four lifts of waste. The temperatures represent the average temperature recorded by the thermistors of the liquid settlement system, the piezometer, and the moisture and 
electrical conductivity probe; all three temperature readings were within a range of less than $11^{\circ} \mathrm{C}$. In early January 2010 , the first layer of waste $(\sim 6 \mathrm{~m})$ was placed over bundles 1 and 2. Both bundles maintained a temperature of approximately $-0.5^{\circ} \mathrm{C}$ even as the ambient temperature increased above $30^{\circ} \mathrm{C}$. This indicates that the $6 \mathrm{~m}$ thick frozen waste layer acts as an excellent insulator, having low thermal conductivity and high latent heat of fusion. At end of August 2010, the temperatures of first two bundles rose above $0^{\circ} \mathrm{C}$, indicating that the waste at the bundles began to thaw. This increase in temperature was caused by an upwards heat flux from the ground below, as the bundles were placed on the cell floor immediately above the leachate collection system. The temperature in March 2012 was approximately $11^{\circ} \mathrm{C}$ and $9^{\circ} \mathrm{C}$ at bundles 1 and 2 respectively.

Bundles 3 and 4 were installed in January 2010 in the middle of the first waste lift. The cold ambient temperature during installation meant the initial temperatures at bundles 3 and 4 were approximately $-2^{\circ} \mathrm{C}$, as shown in Figure 28 . Similarly to bundles 1 and 2 , even as the ambient temperature rose to above $30^{\circ} \mathrm{C}$ in the summer of 2010 , the temperatures in the middle of the waste profile remained frozen. This reinforces the fact that the frozen waste must have a low thermal conductivity and that significant heat is needed to thaw the frozen liquid fraction within the waste. In January 2011, the waste surrounding bundle 3 began to thaw. The rapid increase in temperature shown at bundle 3 was unexpected at this time, especially in comparison to the continuous frozen state of bundle 4. However, if the waste has a large latent heat value, small variances in heat flux between bundles 3 and 4 over the 12 months since installation could cause bundle 4 to remain frozen longer than bundle 3. In May 2011, nearly 1.5 years after placement of the waste, bundle 4 begins to show a similar rapid temperature increase. This phenomenon is 
consistent with the frozen waste having a large latent heat value, as a significant amount of heat was used to convert the liquid fraction within the waste from a solid to a liquid state.

Bundles 5 and 6 were installed in the June 2010 and were covered with $0.5 \mathrm{~m}$ of waste. The ambient temperatures during installation were over $25^{\circ} \mathrm{C}$ and the initial waste temperature was close to $20^{\circ} \mathrm{C}$. However, as the bundles were only covered by $0.5 \mathrm{~m}$ of waste, the temperatures decreased, following the average ambient temperatures lagged by several days. The lag is a result of the limited insulation the $0.5 \mathrm{~m}$ waste layer provided. In December 2010, a second waste lift was placed over the instrument bundles, followed by third layer of waste in January and February 2011. By the time that the second waste lift was placed in December 2010, the temperatures at bundles 5 and 6 had decreased to $1^{\circ} \mathrm{C}$ and $-0.4^{\circ} \mathrm{C}$, respectively. The temperatures at bundles 5 and 6 have slowly increased but are covered with $7 \mathrm{~m}$ of waste; a portion of which may still be frozen. The temperature gradient in the waste below the bundles indicates that the temperatures may be increasing due to heat flux from the base of the landfill. 


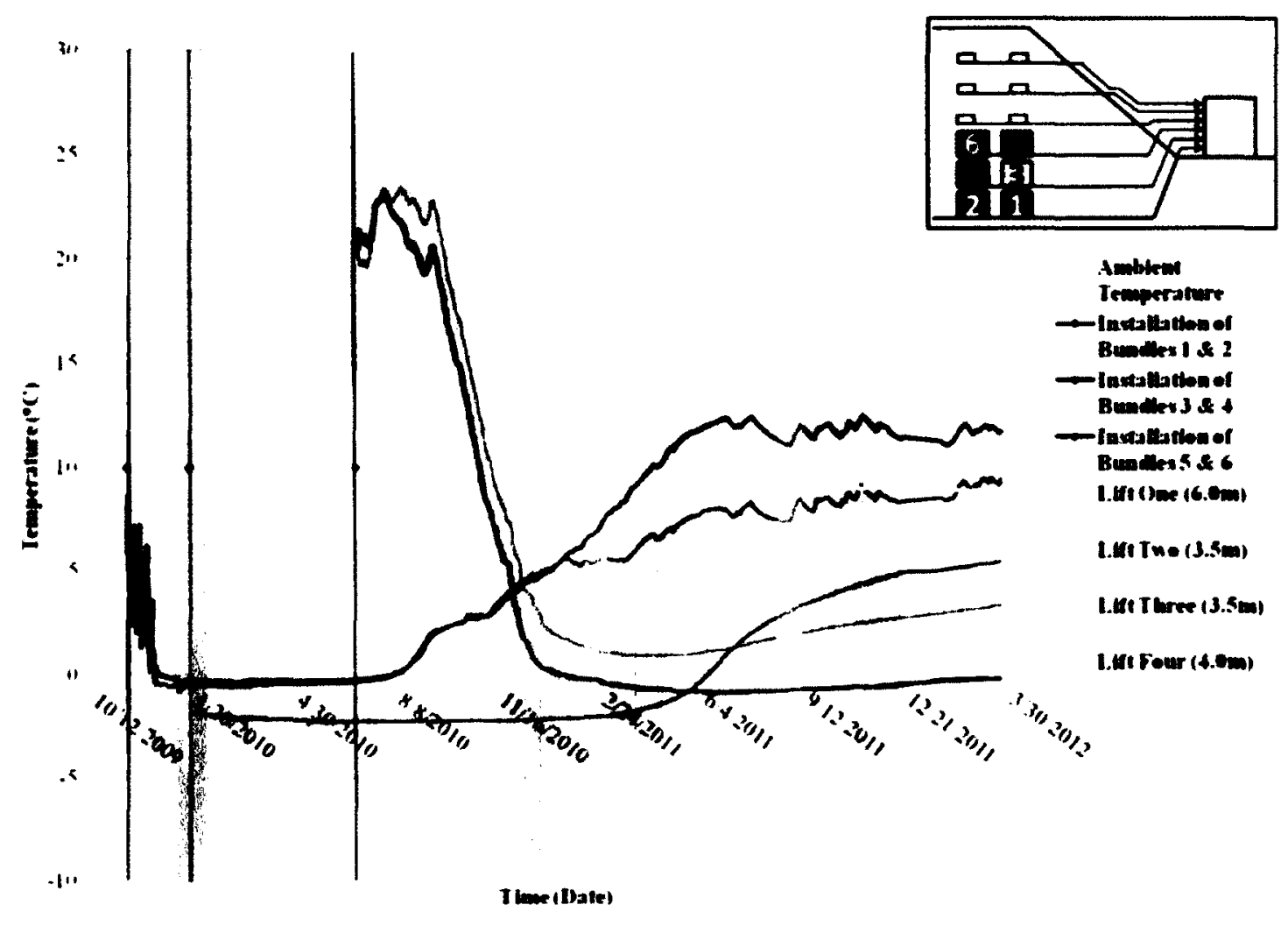

Figure 28: Average Temperatures from Bundles 1 through 6, November 2009 to March 2012

\subsection{Numerical Model}

The numerical investigation is carried out on a simplified waste lift in a landfill as shown in Figure 29. In the waste lift, heat transfer across the boundaries can take different forms: (1) heat transfer from the ambient air via convection and radiation, (2) heat transfer from the subsurface soil in the form of conduction, (3) heat transfer from the adjacent waste lifts via conduction. In addition, biodegradation of the organic waste generates heat. The redistribution of the heat within in a lift of waste takes place in the form of natural convection and conduction. Heat can be stored within the waste as sensible heat causing an increase or decrease in temperature, or as latent heat needed to 
cause a phase change; i.e. heat needed to thaw the liquid fraction within the waste and change its state from a solid (frozen) to a liquid state.

\subsubsection{Governing equation}

The heat transfer within the domain is assumed to be governed by conduction:

$$
\nabla(k \nabla T)+Q=\rho \mathrm{C}_{p} \frac{d T}{d t} \text { in } \Omega
$$

where $k(\mathrm{~W} / \mathrm{m} \cdot \mathrm{K})$ is thermal conductivity, $\rho\left(\mathrm{kg} / \mathrm{m}^{3}\right)$ is the density, $C_{p}(\mathrm{~J} / \mathrm{kg} \cdot \mathrm{K})$ is the specific heat, $Q\left(\mathrm{~W} / \mathrm{m}^{3}\right)$ is the heat source, $T(\mathrm{~K})$ is temperature, and $\mathrm{t}(\mathrm{s})$ is time.

The heat transfer within frozen solid waste is governed by conduction; however, as the waste thaws, the heat transfer mechanism was assumed to change due to the natural convection with the increasing temperature. Hence, the coefficient of thermal conductivity, $k$, was assumed to be a linear function of the temperature such that

$$
k= \begin{cases}k_{i} & T<0^{\circ} \mathrm{C} \\ k_{i}+k_{s} T & T>0^{\circ} \mathrm{C}\end{cases}
$$

where $k_{i}$ and $k_{s}$ are the coefficients analyzed in order to simulate the thermal response.

A phase change occurs for the frozen liquid fraction within the solid waste. The latent heat of fusion of the liquid fraction affects the transient heat transfer process by changing the thermal inertia of the solid waste temporarily. The latent heat of fusion of the liquid fraction is incorporated in the model by changing the specific heat, $C_{p}$, of the solid waste with a smoothened step function at the phase change temperature range, as follows (Alawadhi \& Amon, 2003): 


$$
C= \begin{cases}C_{s} & T<-1.6^{\circ} \mathrm{C} \\ \frac{L}{\Delta \mathrm{T}} & -1.6^{\circ} \mathrm{C}<T<-0.6^{\circ} \mathrm{C} \\ C_{l} & -0.6^{\circ} \mathrm{C}<T\end{cases}
$$

where $\mathrm{C}_{\mathrm{s}}(\mathrm{J} / \mathrm{kg} \cdot \mathrm{K})$ is the specific heat of the frozen waste, $L(\mathrm{~J} / \mathrm{kg})$ is the latent heat of fusion of the liquid fraction of the solid waste, $T_{m}(K)$ is the onset temperature of the phase change, $\Delta \mathrm{T}(\mathrm{K})$ is the temperature range where the phase change takes place, $C_{l}$ $(\mathrm{J} / \mathrm{kg} \cdot \mathrm{K})$ is the specific heat in the waste with the leachate in a liquid state. These parameters are analyzed in order to model the thermal response by the sensor bundles placed in the waste.

The bio-heat generation is assumed to take place as a quadratic function of temperature when a threshold temperature value is exceeded. This is incorporated in the numerical model with a non-linear smooth step function defining the heat source term, $Q$, as follows (Neusinger et al., 2005):

$$
Q=\left\{\begin{array}{cl}
0 & T<\mathrm{T}_{\text {bio }} \\
Q_{i}\left(-0.000413 T^{2}+0.27143 T-43.677\right) & \mathrm{T}_{\text {bio }}<T
\end{array}\right.
$$

where $\mathrm{T}_{\text {bio }}(\mathrm{K})$ is the onset temperature of the bio-heat generation and $Q_{i}$ is the scaling multiplier, as shown in Table $8 . \mathrm{T}_{\text {bio }}$ was assumed to be $10^{\circ} \mathrm{C}$.

\subsubsection{Boundary Conditions}

The effect of radiation and wind-governed forced convection on boundary $\Gamma_{1}$ is estimated as: 


$$
\mathbf{n} \cdot(k \nabla T)=h\left(T_{a m b}-T\right)+\varepsilon \sigma\left(T_{a m b}^{4}-T^{4}\right) \text { on } \Gamma_{1}
$$

where $T_{a m b}(\mathrm{~K})$ is the ambient air temperature, $h\left(\mathrm{~W} / \mathrm{m}^{2} \cdot \mathrm{K}\right)$ is the coefficient of convective heat transfer, $\varepsilon$ is the surface emissivity, and $\sigma\left(\mathrm{W} / \mathrm{m}^{2} \cdot \mathrm{K}^{4}\right)$ is the StefanBoltzmann constant for black body radiation.

The resistivity of convective air layer, $h\left(\mathrm{~W} / \mathrm{m}^{2} \cdot \mathrm{K}\right)$, in Eqn. 15 is defined as it is reported by De Halleux (1989):

$$
h=h_{i}\left|T_{a m b}-T\right|^{1 / 3} \text { on } \Gamma_{1}
$$

where $h_{\mathrm{i}}$ is a scaling multiplier as shown in Table 8 .

The heat flux on the remaining boundaries can be simulated using a prescribed temperature type I boundary condition or defined flux type II boundary condition.

\subsubsection{Solution Procedure}

The initial-value problem defined in Section 6.3.2 was solved using a commercial finite element analysis software package. All equations were solved using coupled transient and nonlinear solution algorithms. Because of the coupled and nonlinear nature of the problem, the computational power required was a major obstacle; therefore, a comprehensive mesh study analysis was conducted to find the optimum finite element mesh that would provide a balance between computation efficiency and accuracy. The software had its own mesh generation routines and offers several alternatives for nonlinear and transient solution algorithms. 


\subsection{Model Calibration using Sainte-Sophie Data}

The developed model was used to simulate the temperature data collected in bundles 3 through 6 within the first waste lift from January 2010, when waste was first placed over bundles 1 and 2, through to November 2010, prior to the placement of waste lifts two and three. The domain was discretized with between 3000 to 10,000 Lagrangian triangular finite elements with quadrilateral finite elements on the boundary layers as shown in Figure 29.

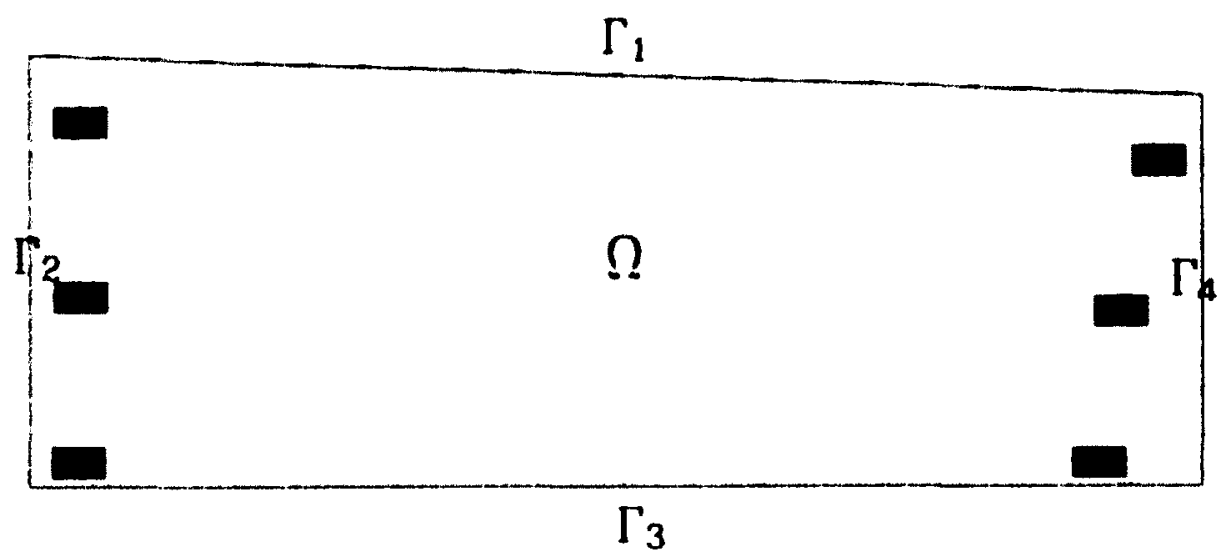

Figure 29: Analysis Domain

To set-up the top boundary condition, the ambient temperature data measured on site were fit to a $4^{\text {th }}$ order polynomial using a non-linear regression analysis package to generate a time dependent function for $T_{a m b}(\mathrm{~K})$. The resulting input function for $T_{a m b}(\mathrm{~K})$ is shown in Figure 30. The lower boundary was defined as a prescribed temperature type I boundary using the temperature data from bundles 1 and 2 . This prescribed temperature boundary will effectively simulate the heat flux from the subsurface soil. The temperature data from instrument bundles 1 and 2 were also fit to a $4^{\text {th }}$ order polynomial with a nonlinear regression analysis. This time and position dependent polynomial $T_{\text {soil }}(\mathrm{K})$, as 
illustrated in Figure 30, is then set as the temperature boundary condition on $\Gamma_{3}$. Full description of the functions used to model the top and lower boundaries can be found in Appendix C.

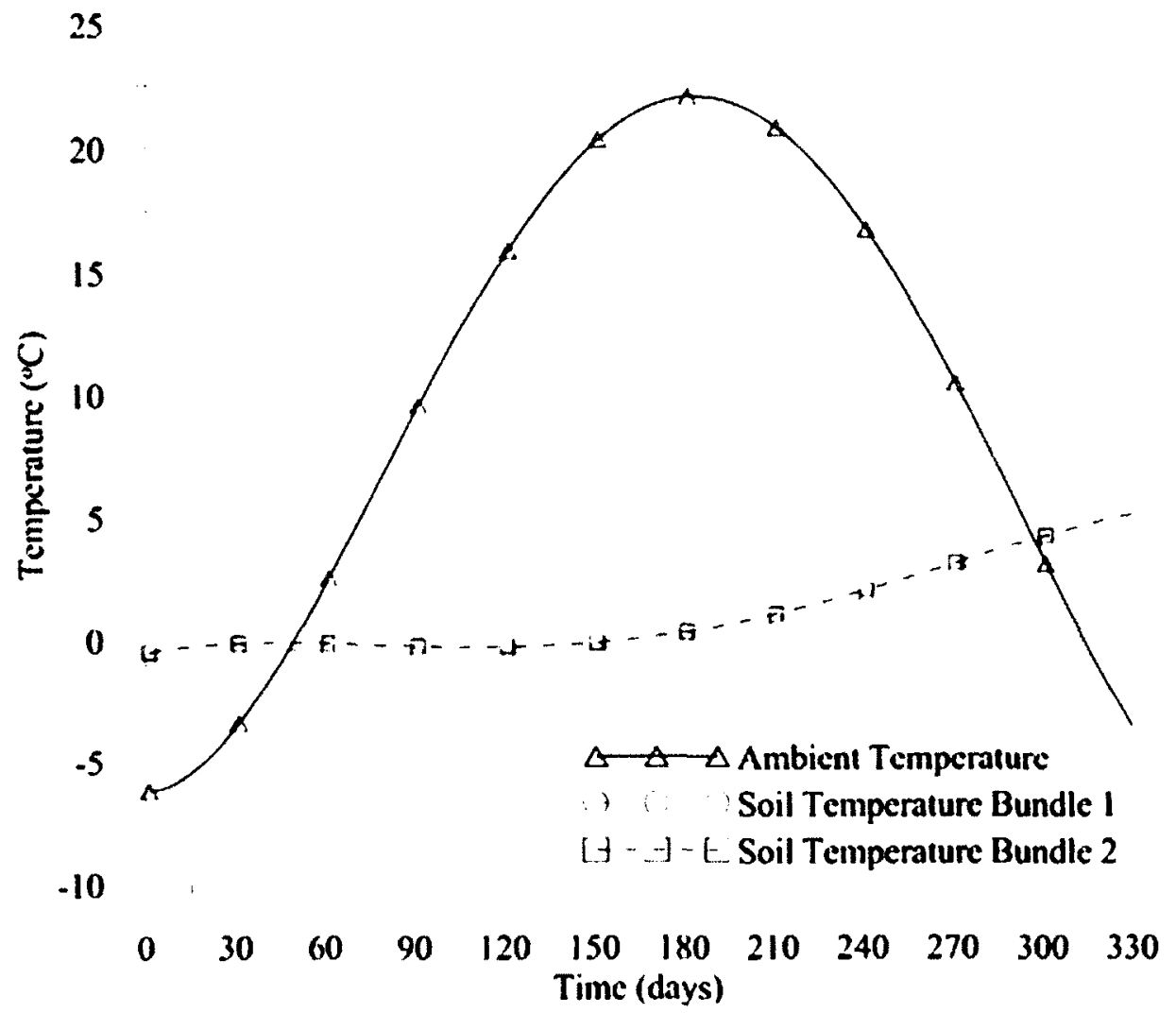

Figure 30: Ambient and soil temperatures as input to the analysis

Boundaries $\Gamma_{2}$ and $\Gamma_{4}$ were defined as no-flux boundaries as it is assumed that there is limited horizontal heat transfer to the adjacent solid waste due to its symmetry, and are defined as:

$$
\text { n. }(k \nabla T)=0 \text { on } \Gamma_{2} \text { and } \Gamma_{4}
$$


The initial temperature in the domain is interpolated in accordance with the initial temperature readings acquired from the temperature sensors at the time of the solid waste lift placement:

$$
T_{\text {init }}\left({ }^{\circ} \mathrm{C}\right)=-1.79+0.01 x
$$

where $T_{\text {init }}(\mathrm{C})$ is the initial temperature of the domain and $x(\mathrm{~m})$ is the spatial coordinate in the horizontal direction.

The parameters needed to characterize the waste include the specific heat $\left(C_{\mathrm{p}}\right)$, density $(\rho)$, thermal conductivity $(k)$, latent heat of fusion $(L)$, bioheat generation $(Q)$, surface emissivity $(\varepsilon)$, and convection coefficient $(h)$. Since most of these parameters were not known for the site, a range for each parameter was obtained from values published in the literature as shown in Table 8; the model then was calibrated using values for the parameters from each range to simulate the temperatures measured at the bundles. The input data for the modelling parameters used in the calibrated model are presented in Table 9. Using values found within the literature as a base, the thermal parameters were selected to best simulate the transfer of heat that occurs within the waste in accordance with the recorded data. The results for the first 10.5 months, from January 2010 until November 2010, are plotted in comparison to the actual data in Figure 31. The modeling results confirm that the waste is a great insulator, having a low thermal conductivity and high latent heat of fusion. 
Table 8: Analyzed thermal parameters

\begin{tabular}{|c|c|c|c|c|c|c|c|}
\hline $\begin{array}{c}k_{i}^{\prime} \\
(\mathbf{W} / \mathbf{m} \cdot \mathbf{K})\end{array}$ & $\begin{array}{c}k_{s} \\
\left(\mathbf{W} / \mathbf{m} \cdot \mathbf{K}^{2}\right)\end{array}$ & $\begin{array}{c}\rho \\
\left(\mathrm{kg} / \mathrm{m}^{3}\right)\end{array}$ & $\begin{array}{c}C_{\mathrm{p}}^{\mathrm{T}, 2} \\
(\mathrm{~kJ} / \mathrm{kg} \cdot \mathrm{K})\end{array}$ & $\begin{array}{c}Q_{i}^{2,3} \\
\left(\mathbf{W} / \mathbf{m}^{3}\right)\end{array}$ & $\begin{array}{c}L \\
(\mathrm{~kJ} / \mathrm{kg})\end{array}$ & $\varepsilon$ & $\begin{array}{c}h_{i}^{4,5} \\
\left(\mathrm{~W} / \mathrm{m}^{2} \cdot \mathrm{K}^{4 / 3}\right)\end{array}$ \\
\hline $0.3-0.9$ & $0-0.03$ & $\begin{array}{c}930- \\
1330\end{array}$ & $0.8-2.4$ & $0-24$ & $24-334$ & $\begin{array}{c}0.75- \\
0.95\end{array}$ & $1.86-10.0$ \\
\hline
\end{tabular}

Hanson et al., 2008; ${ }^{2}$ Yoshida \& Rowe, 2003; ${ }^{3}$ Rees, $1980 ;{ }^{4}$ De Halleux, $1989 ;{ }^{5}$ Silva, 1988

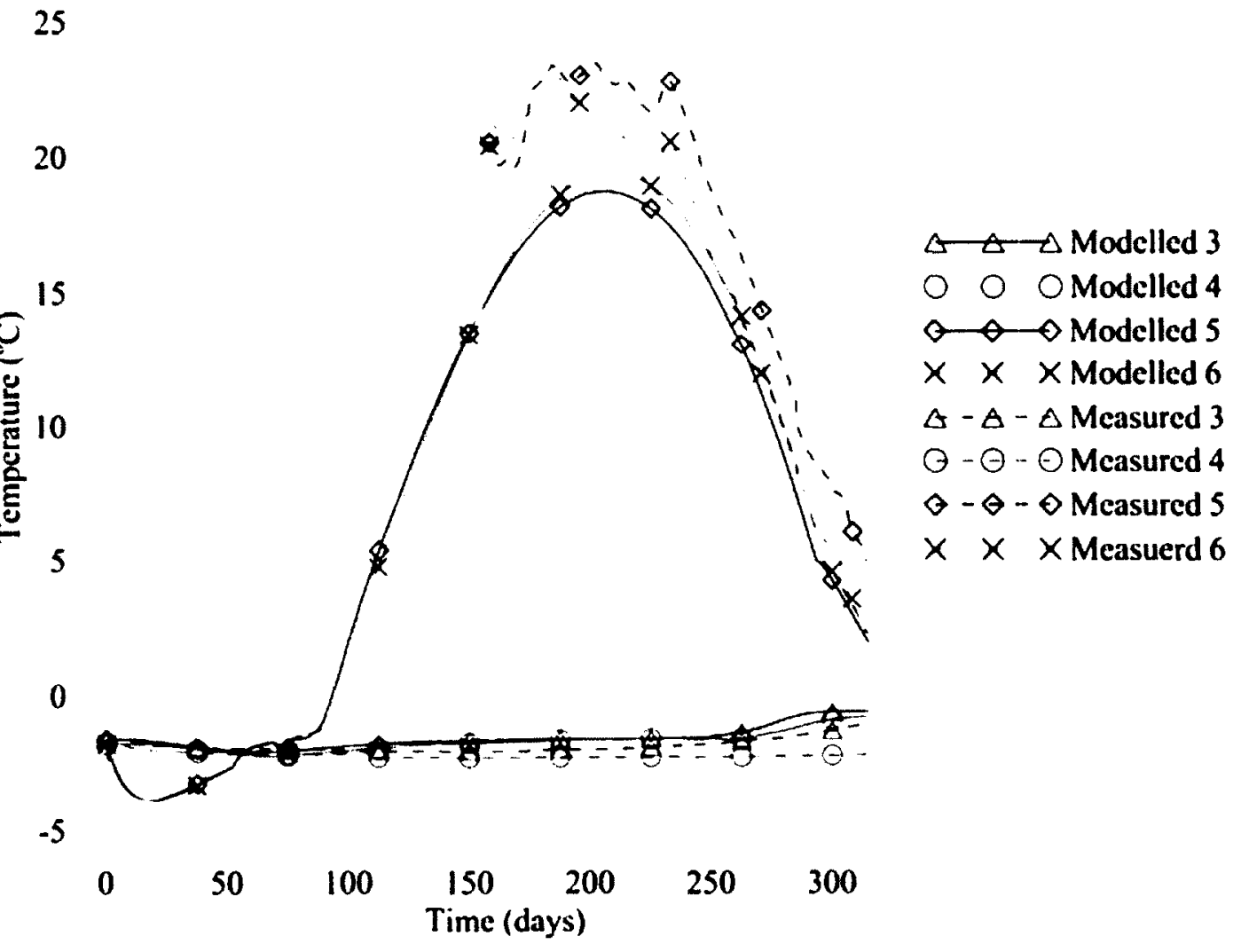

Figure 31: Modelled and measured temperatures at bundle locations at 3, 4, 5, and 6

\subsection{Results and Discussion}

Using the calibrated model, a heat budget study was carried out to reveal the significance of each heat transfer/generation mode. In addition, the calibrated model became the base 
case scenario used for the sensitivity analysis. The sensitivity of the model to the changes in each parameter was investigated within the range of the values found in the literature, as shown in Table 8. The results of the heat budget study and the sensitivity analysis are presented in this section.

\subsubsection{Heat Budget}

The calibrated thermal parameters summarized in Table 9 were also used to calculate the heat budget. The modes of heat transfer to the domain and heat generation within the domain are presented in Figure 32. The heat transfer to/from the ambient air is via convection and radiation. The heat flux from the bottom boundary occurs from the leachate collection system and soil below. Within the control volume of the solid waste lift the heat is either stored as sensible heat or latent heat for phase change. Within the domain heat is generated from the bacterial biodegradation of the waste. The heat budget study was carried out to estimate the significance of each mode of heat transfer/generation.

Table 9: Final thermal parameters

\begin{tabular}{|c|c|c|c|c|c|c|c|}
\hline $\begin{array}{c}k_{i} \\
(\mathbf{W} / \mathbf{m} \cdot \mathbf{K})\end{array}$ & $\begin{array}{c}k_{s} \\
\left(\mathbf{W} / \mathbf{m} \cdot \mathbf{K}^{2}\right)\end{array}$ & $\begin{array}{c}\rho \\
\left(\mathrm{kg} / \mathrm{m}^{3}\right)\end{array}$ & $\begin{array}{c}C_{\mathrm{p}} \\
(\mathbf{k J} / \mathbf{k g} \cdot \mathbf{K})\end{array}$ & $\begin{array}{c}Q_{i} \\
\left(\mathbf{W} / \mathrm{m}^{3}\right)\end{array}$ & $\begin{array}{c}L \\
(\mathrm{~kJ} / \mathrm{kg})\end{array}$ & $\begin{array}{c}h_{i} \\
\left(\mathrm{~W} / \mathrm{m}^{2} \cdot \mathrm{K}^{4 / 3}\right)\end{array}$ \\
\hline 0.45 & 0.025 & 930 & 1.0 & 18 & 47.7 & 0.9 & 1.86 \\
\hline
\end{tabular}




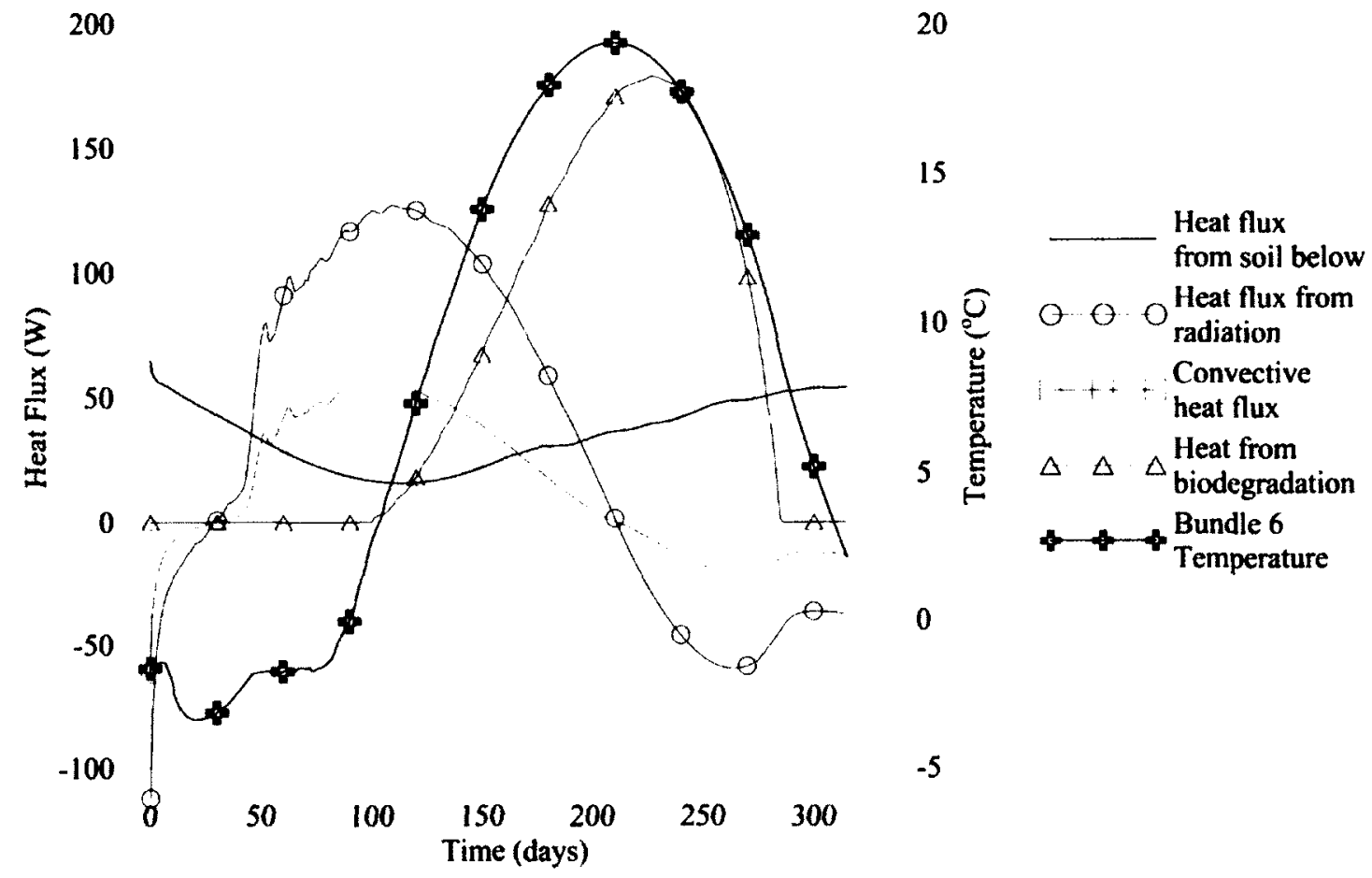

Figure 32: Heat fluxes to/from the waste

The heat budget for the first lift is presented in Figure 33. The net heat flux was found by integrating the area under the simulated heat flux curves in Figure 32. The net heat flux was calculated to be $0.4 \mathrm{GJ} / \mathrm{m}, 1.6 \mathrm{GJ} / \mathrm{m}, 0.9 \mathrm{GJ} / \mathrm{m}$, and $0.9 \mathrm{GJ} / \mathrm{m}$ for convection, biodegradation, radiation and conduction from the soil below, respectively. Therefore, $3.8 \mathrm{GJ} / \mathrm{m}$ of energy was generated/transferred to the waste lift over a period of 10.5 months. This energy is stored in terms of sensible and latent heat within the waste. 


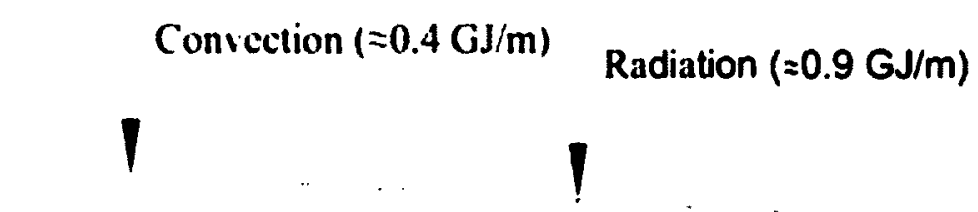

\author{
Bioheat Gencrauion $(=1.6 \mathrm{GJ} / \mathrm{m})$ \\ Sensible Heat Storage $(=0.4 \mathrm{GJ} / \mathrm{m})$ \\ Latent Heat Storage $(=3.4 \mathrm{GJ} / \mathrm{m})$ \\ Wastc Lift \\ Conduction from soil $(\approx 0.9 \mathrm{GJ} / \mathrm{m})$ \\ Figure 33: Summary of heat budget
}

In Eq. 13, the amount of heat required for phase change, when $T_{m}<T<T_{m}+\Delta T$, is

$L \cdot \rho / \Delta T$. The model results for the simulation period indicated that approximately $70 \%$ of the frozen waste volume had completely thawed. The amount of heat required to change the frozen liquid fraction within this waste to a liquid state was estimated to be $3.4 \mathrm{GJ} / \mathrm{m}$. In comparison, the amount of heat required for temperature rise when not undergoing a phase change was estimated using $\mathrm{C}_{s} \cdot \rho$ when $\mathrm{T}<\mathrm{T}_{\mathrm{m}}+\Delta \mathrm{T}$ and $\mathrm{C}_{l} \cdot \rho$ when $\mathrm{T}>\mathrm{T}_{\mathrm{m}}+\Delta \mathrm{T}$. The amount of energy required to raise the average temperature in the waste was approximately $0.4 \mathrm{GJ} / \mathrm{m}$. This indicates that when waste is placed in the winter months, the quantity of energy required to increase the temperature of the waste is dominated by the energy required for phase change.

\title{
6.5.2 Sensitivity Analysis
}

The range of thermal parameters used for the sensitivity analysis is shown in Table 8. The results from the calibrated model presented in Table 9 are shown in Figures 33 to 41 as a 
solid black line. The range of parameters selected was based on the range of parameters found within the literature. When literature values were not available, in the case of latent heat of fusion or emissivity, values were based from materials with similar characteristics as solid waste. The maximum quantity for the latent heat of fusion was based on that of water. The maximum value tested for emissivity represented that of a solid black material.

The two thermal conductivity parameters presented in $\mathrm{Eq} .12, \mathrm{k}_{\mathbf{i}}$ and $\mathrm{k}_{\mathrm{s}}$, were varied independently in the sensitivity analysis. The results in Figures 34 and 35 demonstrate the impact changing the thermal conductivity has within the domain. The results show that changing the thermal conductivity has little impact on the bundles 5 and 6 . However as both $k_{i}$ and $k_{s}$ are increased, a greater amount of heat reaches bundles 3 and 4 .

In Eq. 11, the right side of the equation is referred to as the volumetric heat capacity that represents the waste's ability to store energy while undergoing a temperature change. The relative sensitivity of changing the volumetric heat capacity was measured by adjusting both $\rho$ and $\mathrm{C}_{\mathrm{p}}$. Figures 36 and 37 demonstrate the impact of changing the thermal inertia within the domain. The results show that the model is relatively insensitive to changes in volumetric heat capacity. For larger increases in $\rho$ and $C_{p}$, the results show it takes a longer period of time for the waste to increase in temperature. For bundles 3 and 4 , this resulted in less heat reaching the bundles, and for bundles 5 and 6 , the resulting peak temperature is lower. 

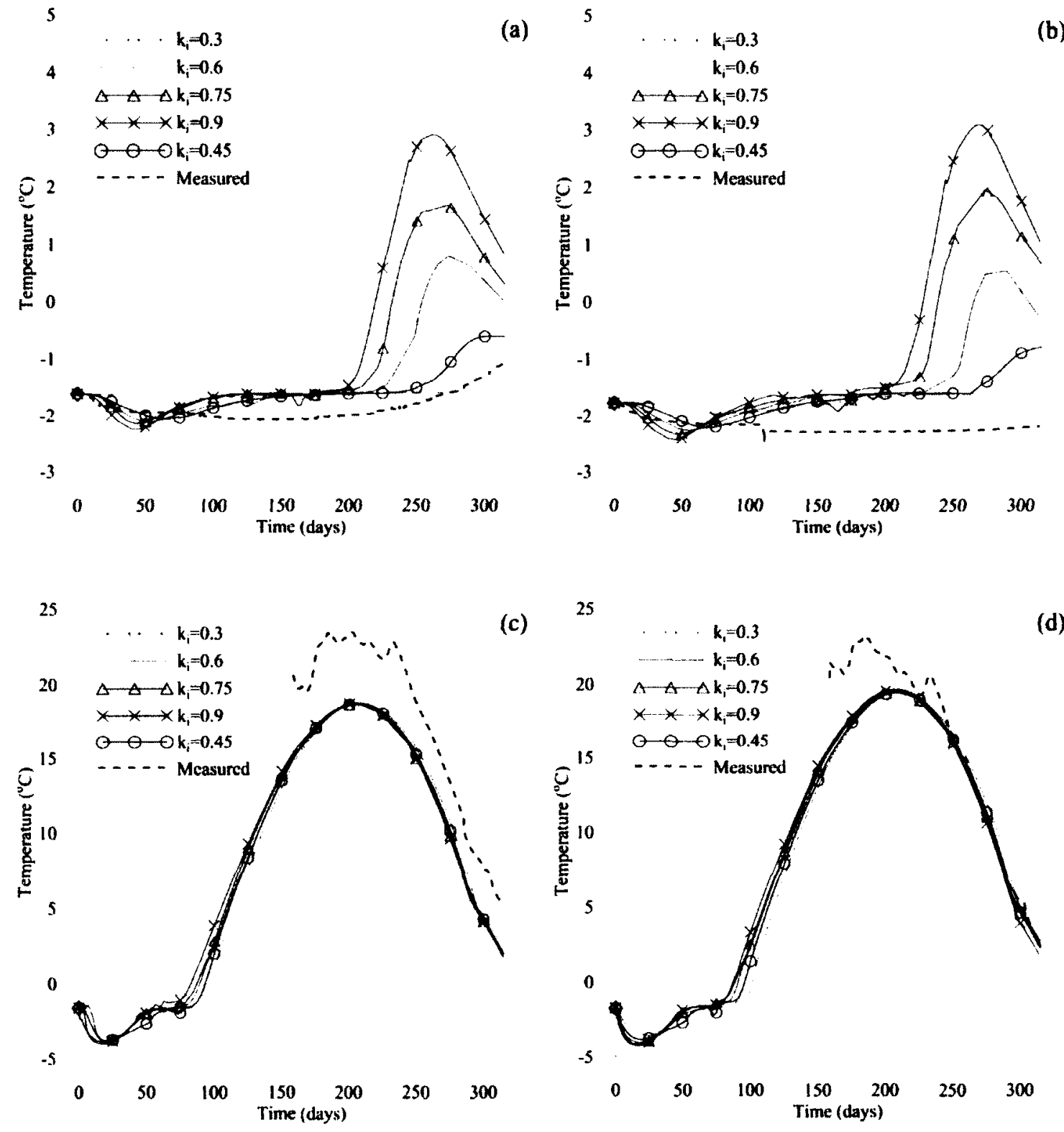

Figure 34: Sensitivity analysis of the thermal conductivity parameter $k_{i}(W / m \cdot K)$ at instrument (a) bundle 3, (b) bundle 4, (c) bundle 5, and (d) bundle 6 


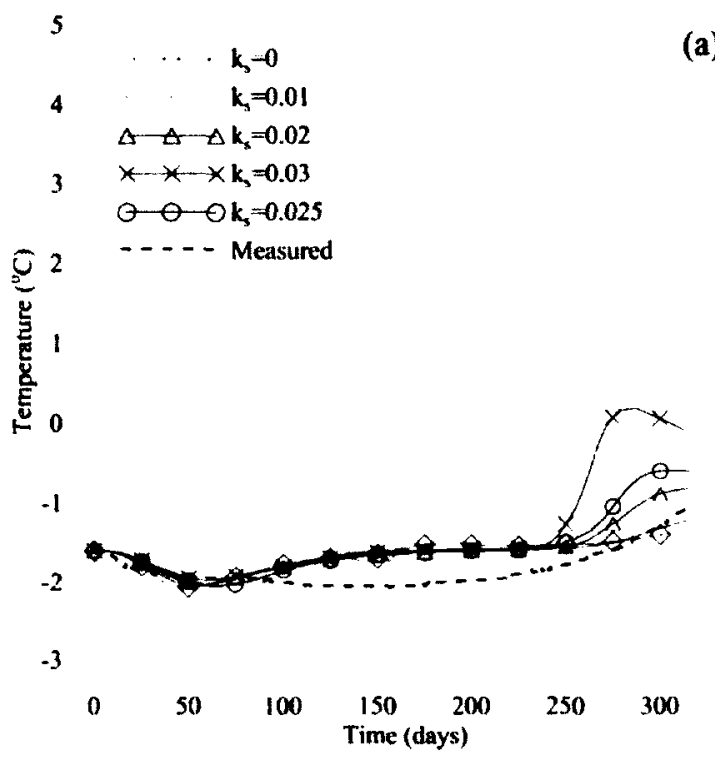

(a) $5 \quad \ldots, k=0$

(b)
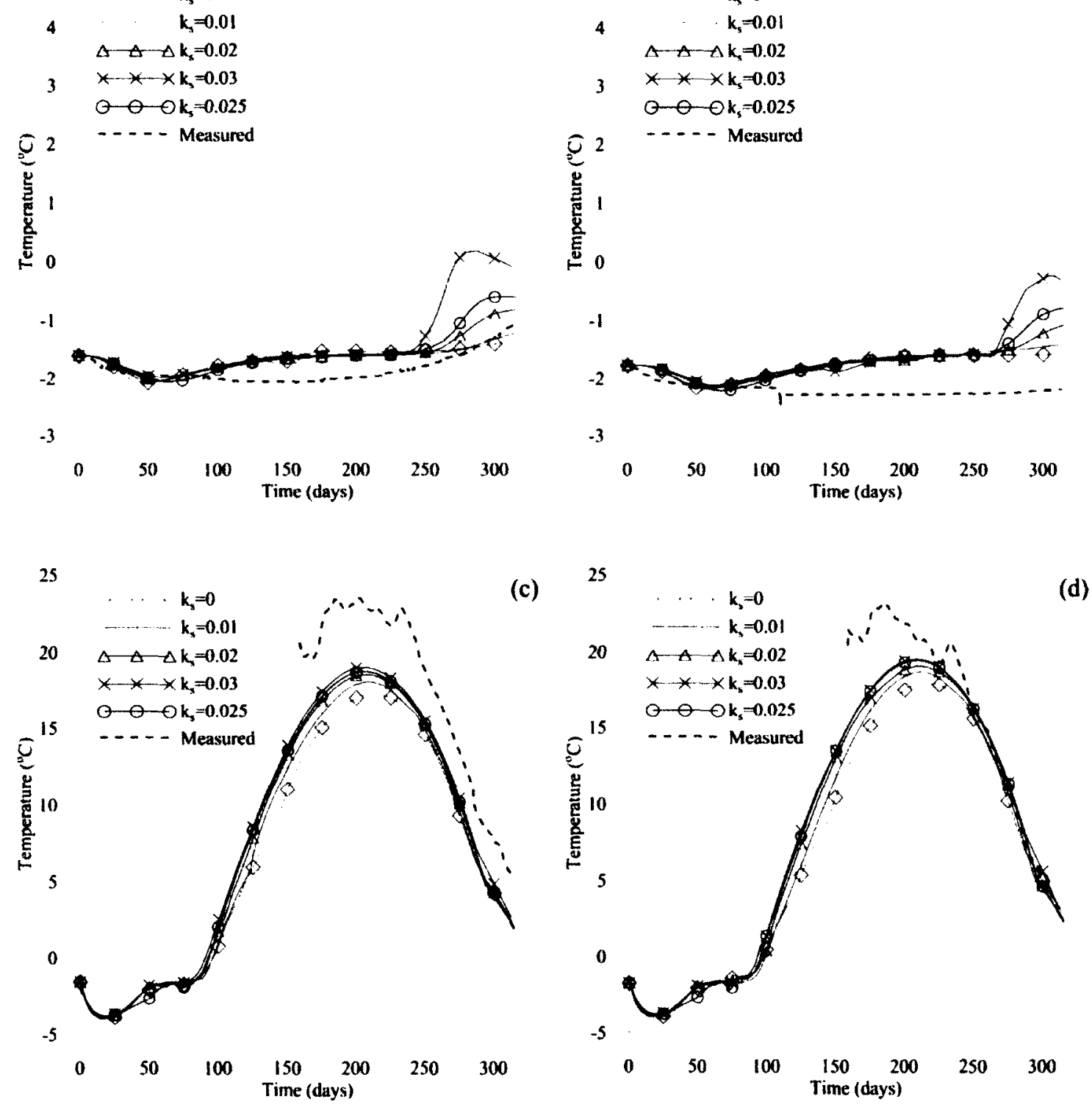

Figure 35: Sensitivity analysis of the thermal conductivity parameter $k_{s}\left(W / m \cdot K^{2}\right)$ at instrument (a) bundle 3, (b) bundle 4, (c) bundle 5, and (d) bundle 6 


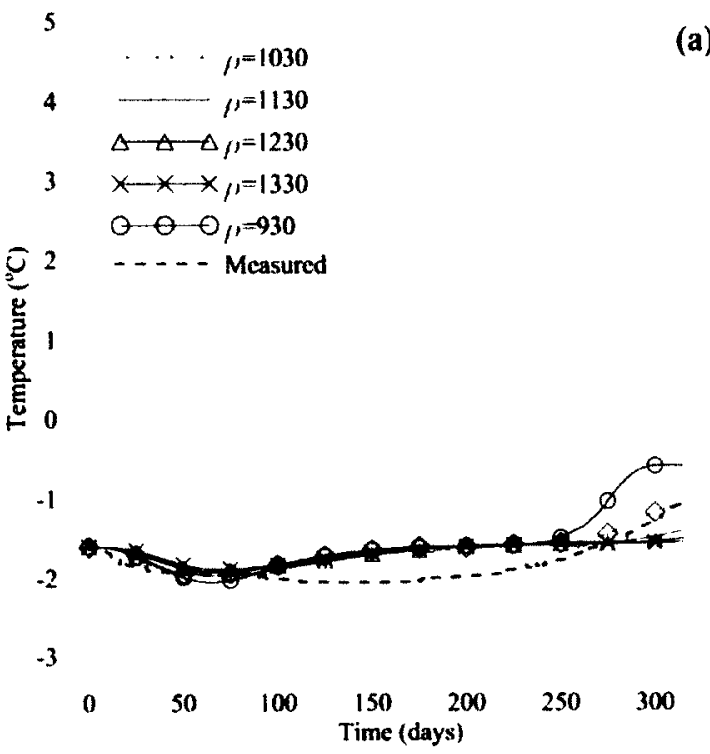

(a) $5 \quad \ldots, f, 1030 \quad$ (b)
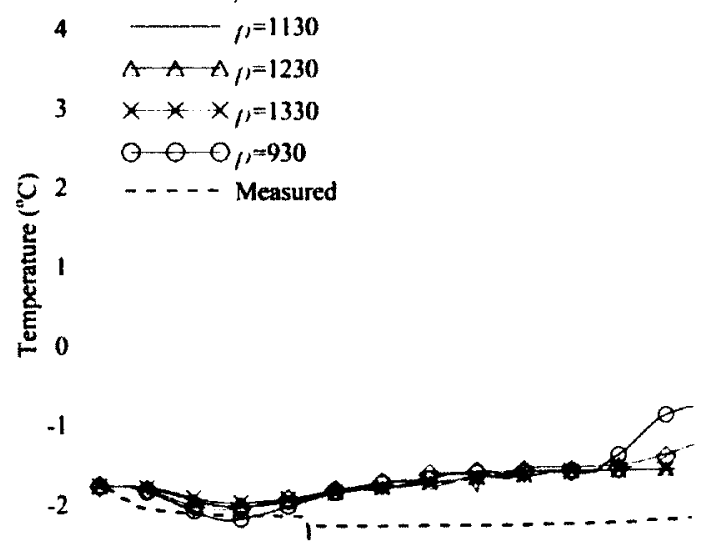

$-3$

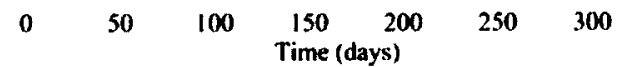
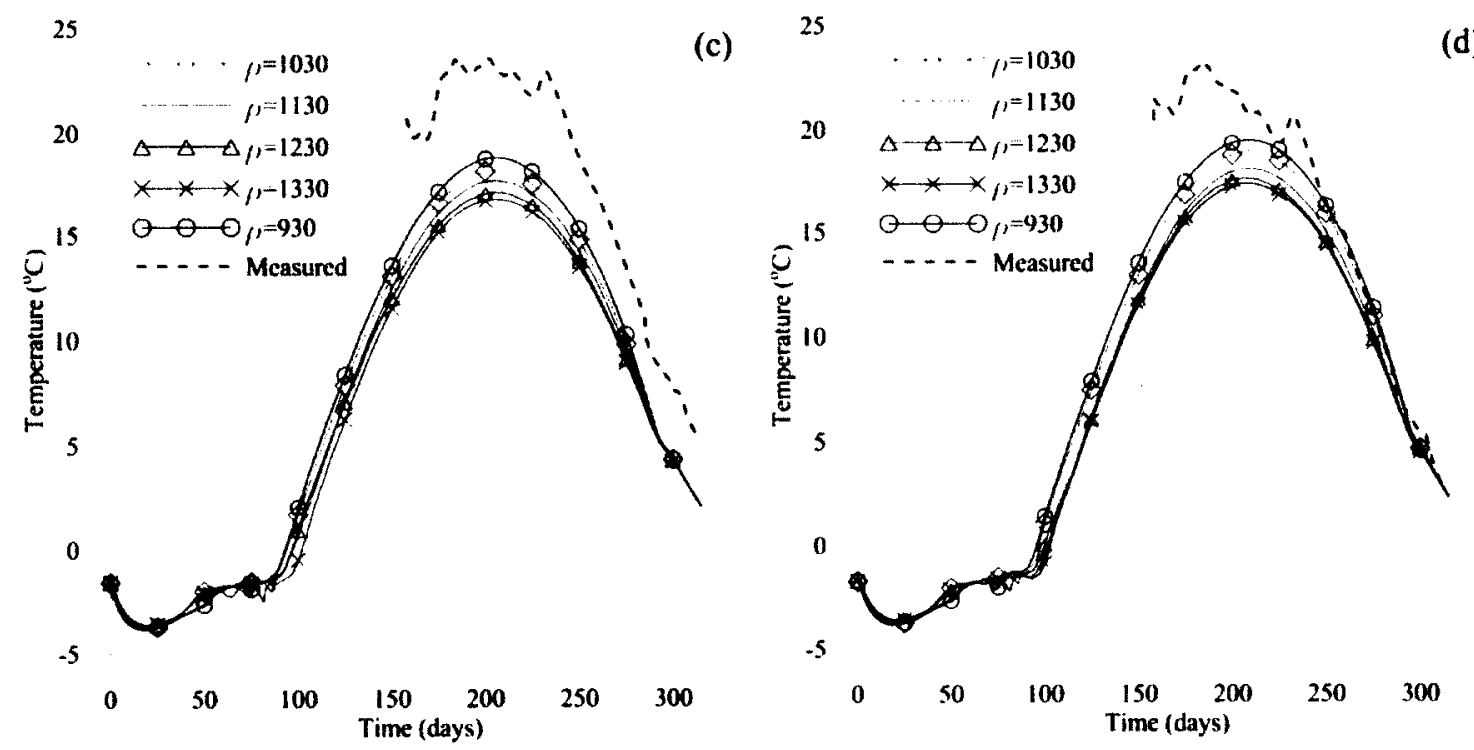

Figure 36: Sensitivity analysis of the density $\rho\left(\mathrm{kg} / \mathrm{m}^{3}\right)$ at instrument (a) bundle 3, (b) bundle 4 , (c) bundle 5 , and (d) bundle 6 

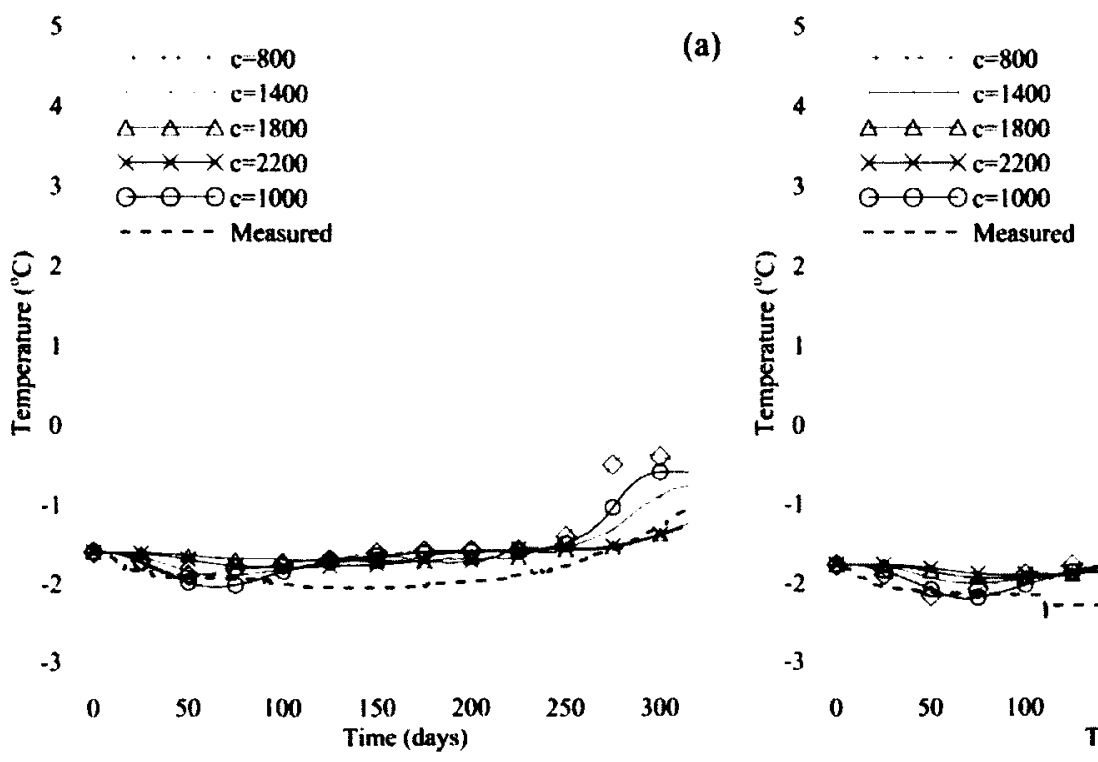

(b)
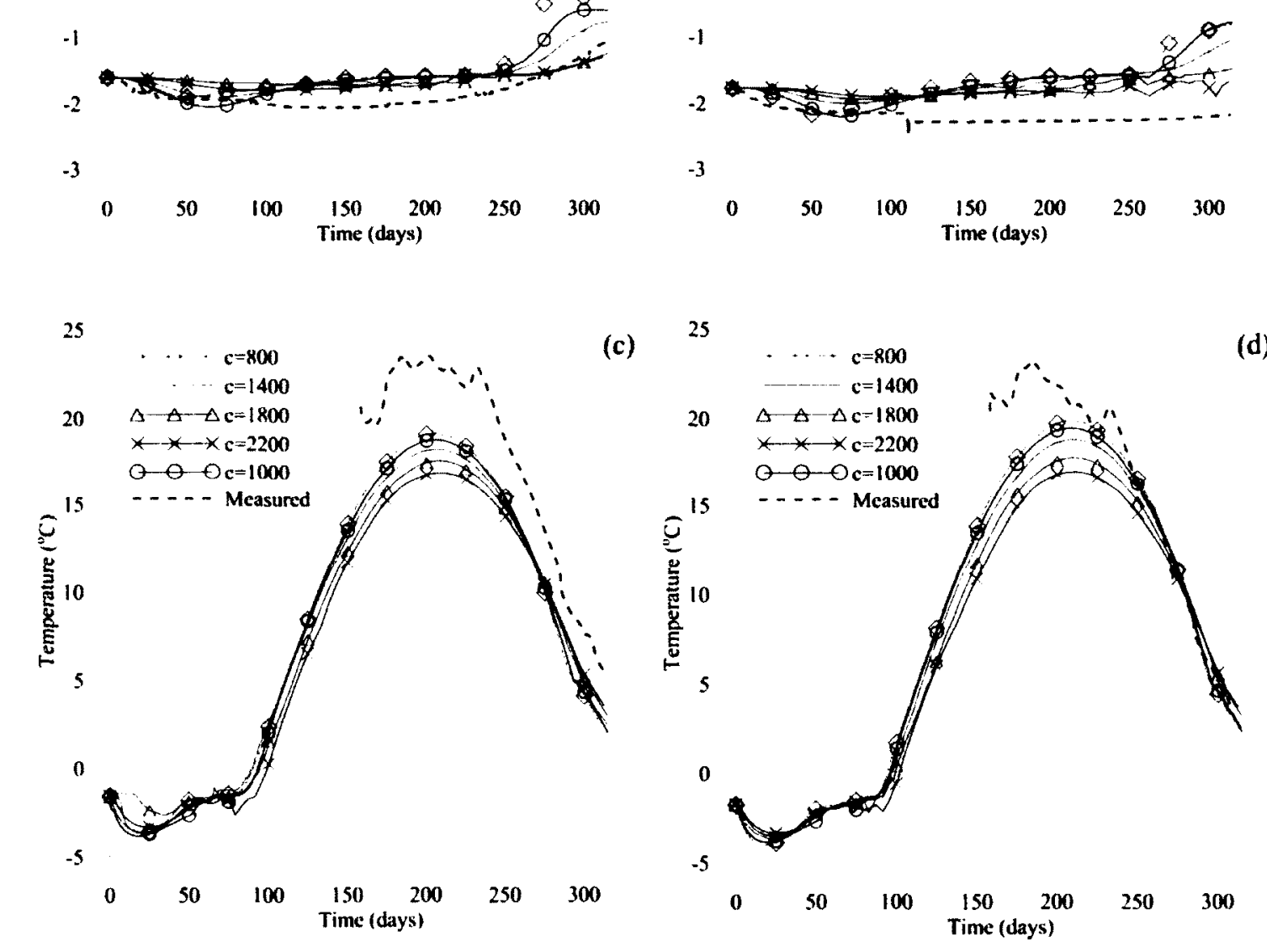

Figure 37: Sensitivity analysis of the specific heat $C_{p}(J / k g \cdot K)$ at instrument (a) bundle 3 , (b) bundle 4, (c) bundle 5 , and (d) bundle 6

The relative sensitivity of the model to adjustments in biological heat generation within the domain is studied by adjusting the heat generation term multiplier, $Q_{i}$. The results in Figure 38 demonstrate the impact of changing the biological heat generation within the 
domain. The model is found to be sensitive to changes in bacterial heat generation. As $Q_{i}$ was increased, more heat was produced throughout the domain. However, since temperatures over $10^{\circ} \mathrm{C}$ were only reached in the upper portion of the domain, the increase heat generation was confined to this region. As a result, adjusting $Q_{i}$ had a significant impact on bundles 5 and 6 . It is anticipated that as the temperatures in this layer and subsequent layers reach and exceed $10^{\circ} \mathrm{C}$, that the heat generated via biodegradation will have a significant impact on the simulated temperatures and the simplified heat generation model used for this simulation will require further research.

The effect of changing the latent heat of fusion, $\mathrm{L}$, is demonstrated in Figure 39. Results reveal that the model is most sensitive to changes in the latent heat of fusion. For bundles 5 and 6, a decrease in $L$ resulted in a higher peak temperature as less heat was required for phase change more heat waste stored as sensible heat leading to an increase in the waste's temperate. For bundles 3 and 4 , adjusting the latent heat of fusion also has a significant impact. As $\mathrm{L}$ is increased, more energy is used for phase change and less waste thaws over the course of the summer to the point where the waste in the location of bundles 3 and 4 remains frozen.

The sensitivity of the model to the changes in heat flux from the ambient air to the waste was measured by adjusting the emissivity, $\varepsilon$, and the coefficient of convection, $h$. The results in Figures $\mathbf{4 0}$ and $\mathbf{4 1}$ demonstrate the impact of changing the heat flux from the ambient air on the analysis domain. As both $h$ and $\varepsilon$ are increased, the magnitude of heat flux from the ambient air to the waste increases. However, the results show that the 
model is relatively insensitive to changes in the parameters used to simulate the ambient heat flux.
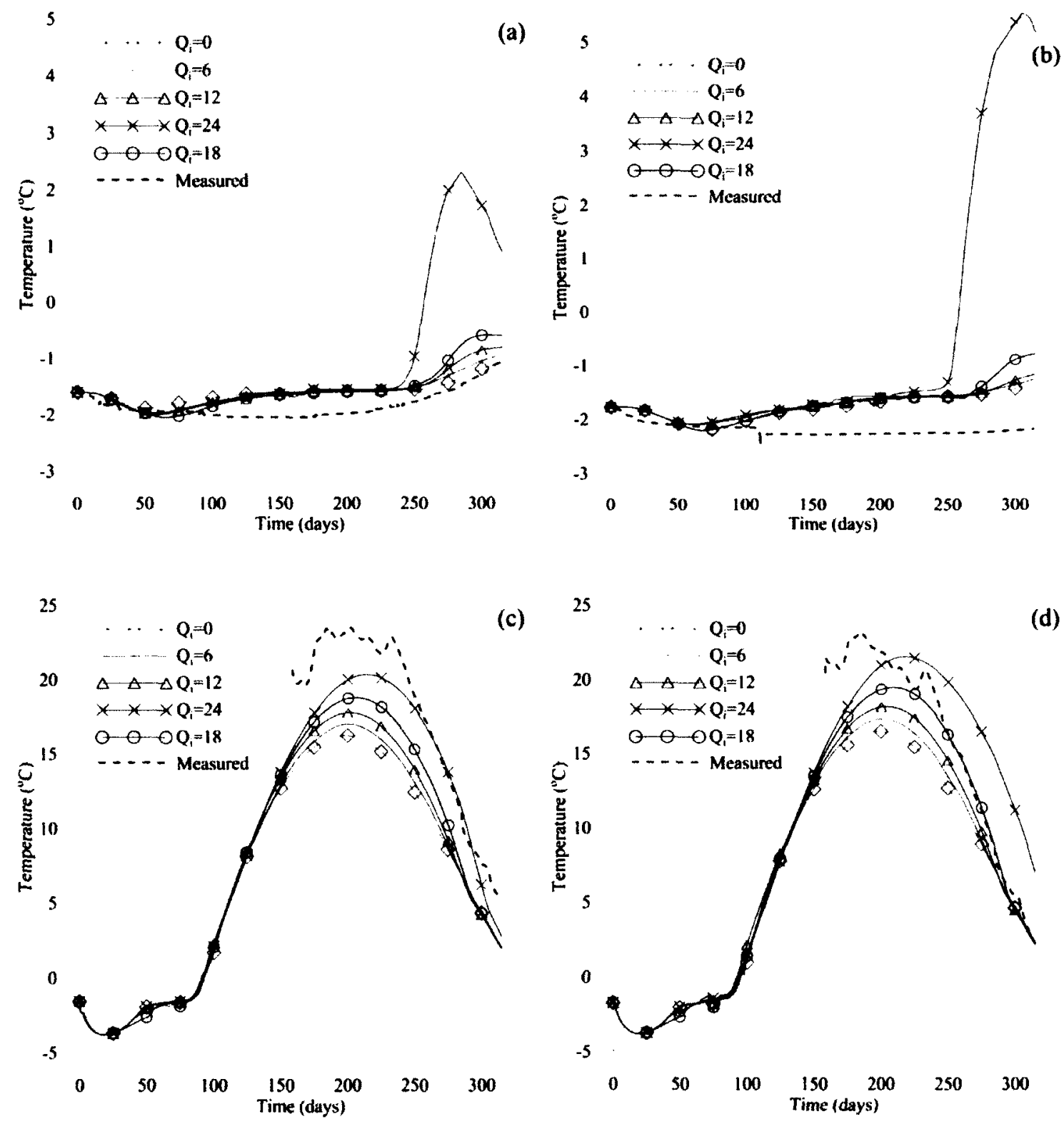

Figure 38: Sensitivity analysis of the heat generation parameter $Q_{i}\left(W / \mathrm{m}^{3}\right)$ at instrument (a) bundle 3, (b) bundle 4, (c) bundle 5, and (d) bundle 6 

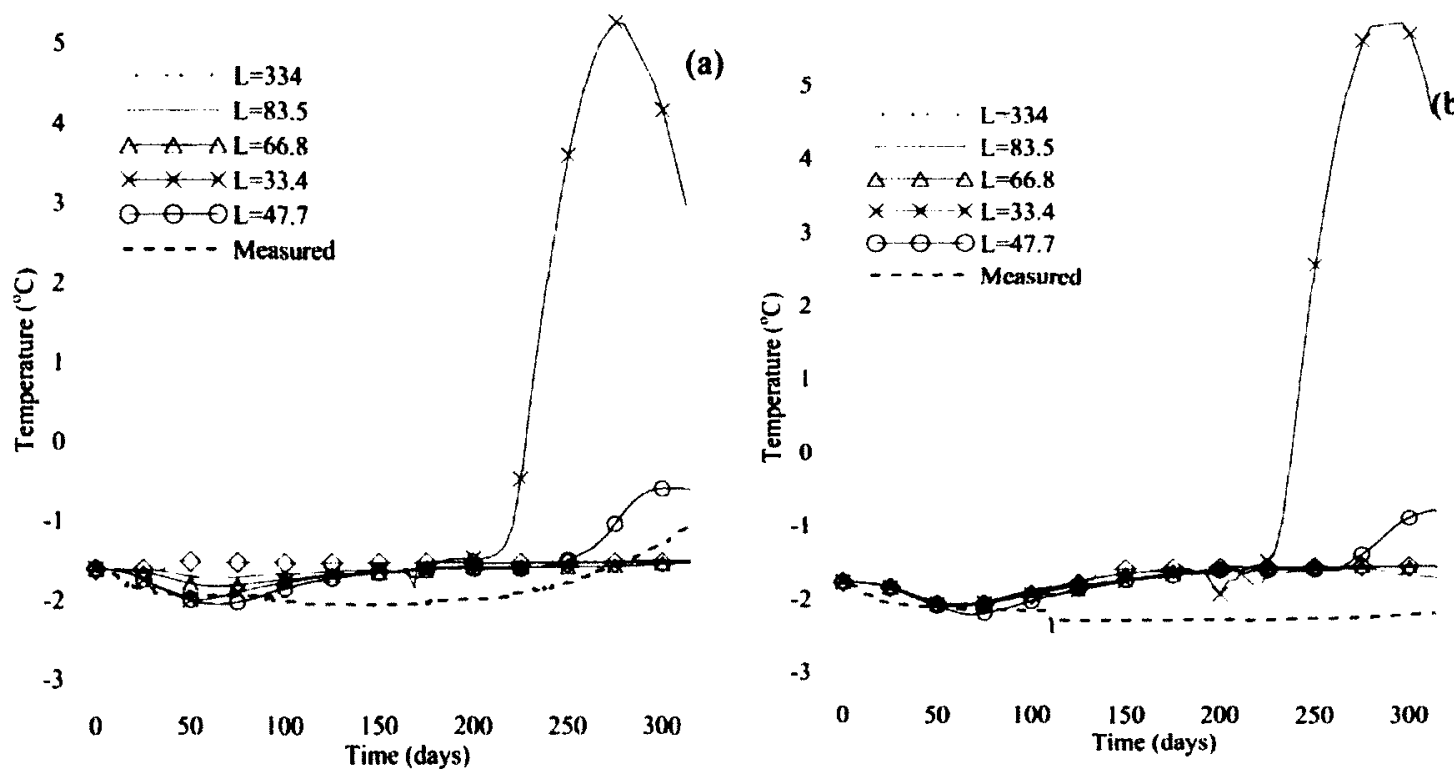

(b)
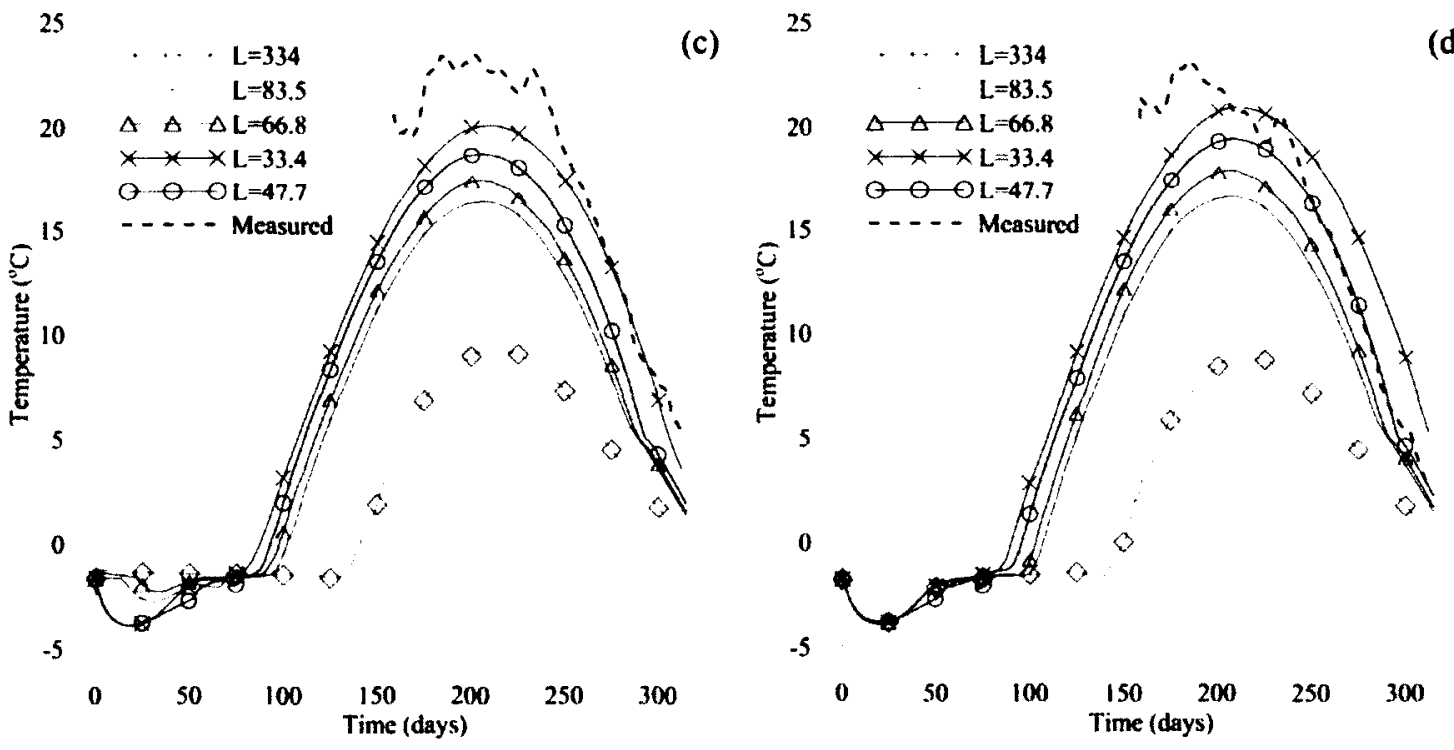

Figure 39: Sensitivity analysis of the latent heat of fusion $L(\mathrm{~kJ} / \mathrm{kg})$ at instrument (a) bundle 3, (b) bundle 4, (c) bundle 5 , and (d) bundle 6 

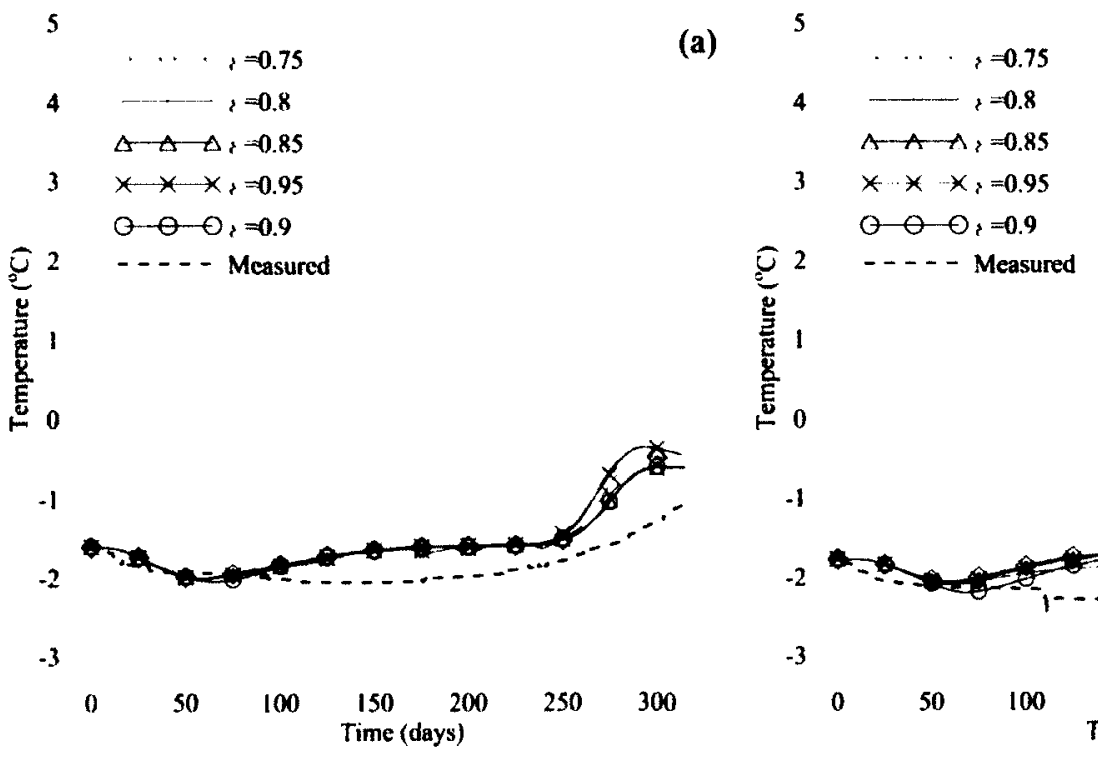

(b)
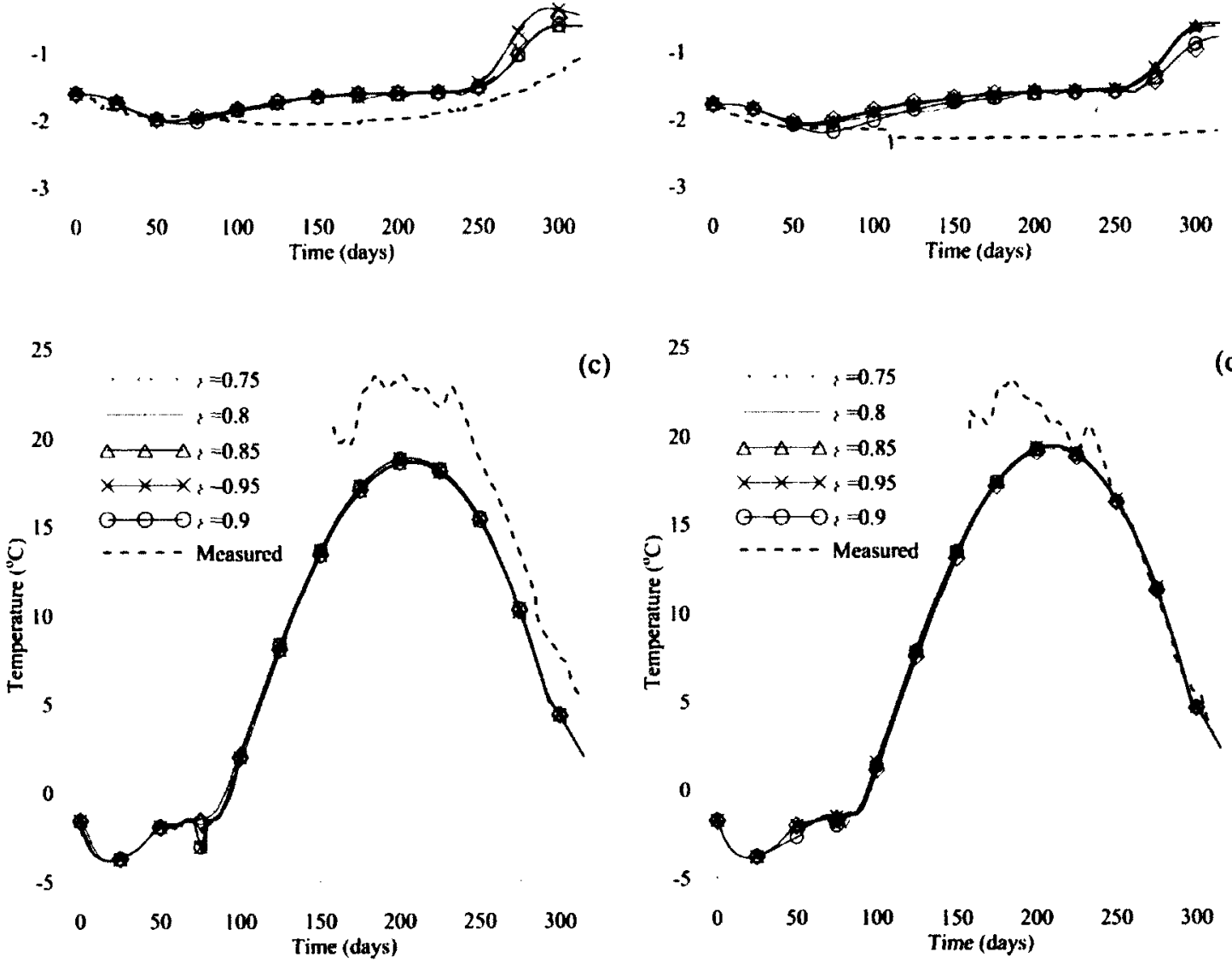

Figure 40: Sensitivity analysis of the emissivity constant $\varepsilon$ at instrument (a) bundle 3 , (b) bundle 4, (c) bundle 5, and (d) bundle 6 


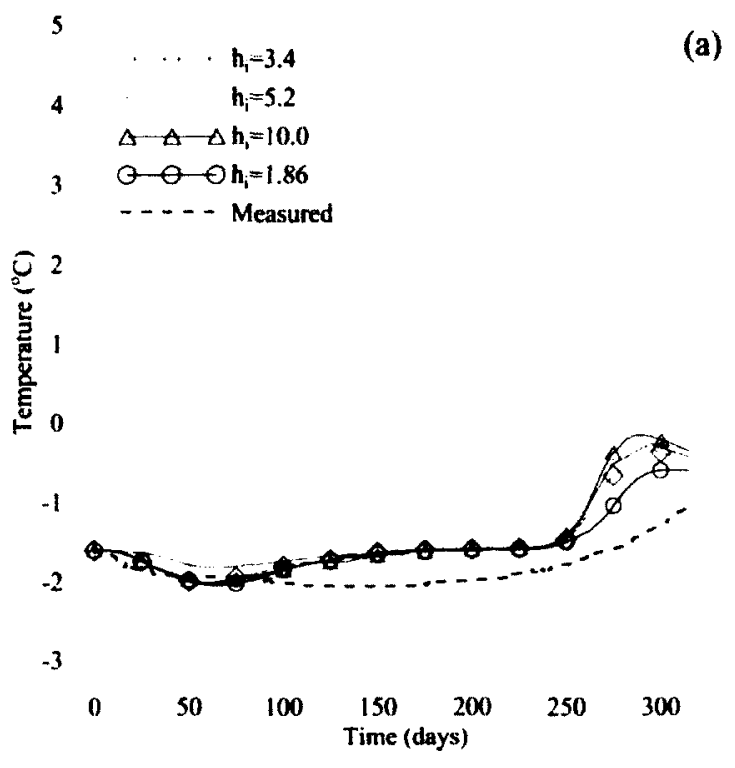

(a) $\begin{array}{ccc}5 & \ldots & h_{i}=3.4 \\ & 4 & h_{i}=5.2 \\ & \triangle \triangle h_{i}=10.0 \\ 3 & \oplus \odot h_{i}=1.86 \\ & \cdots-\text { Measured }\end{array}$
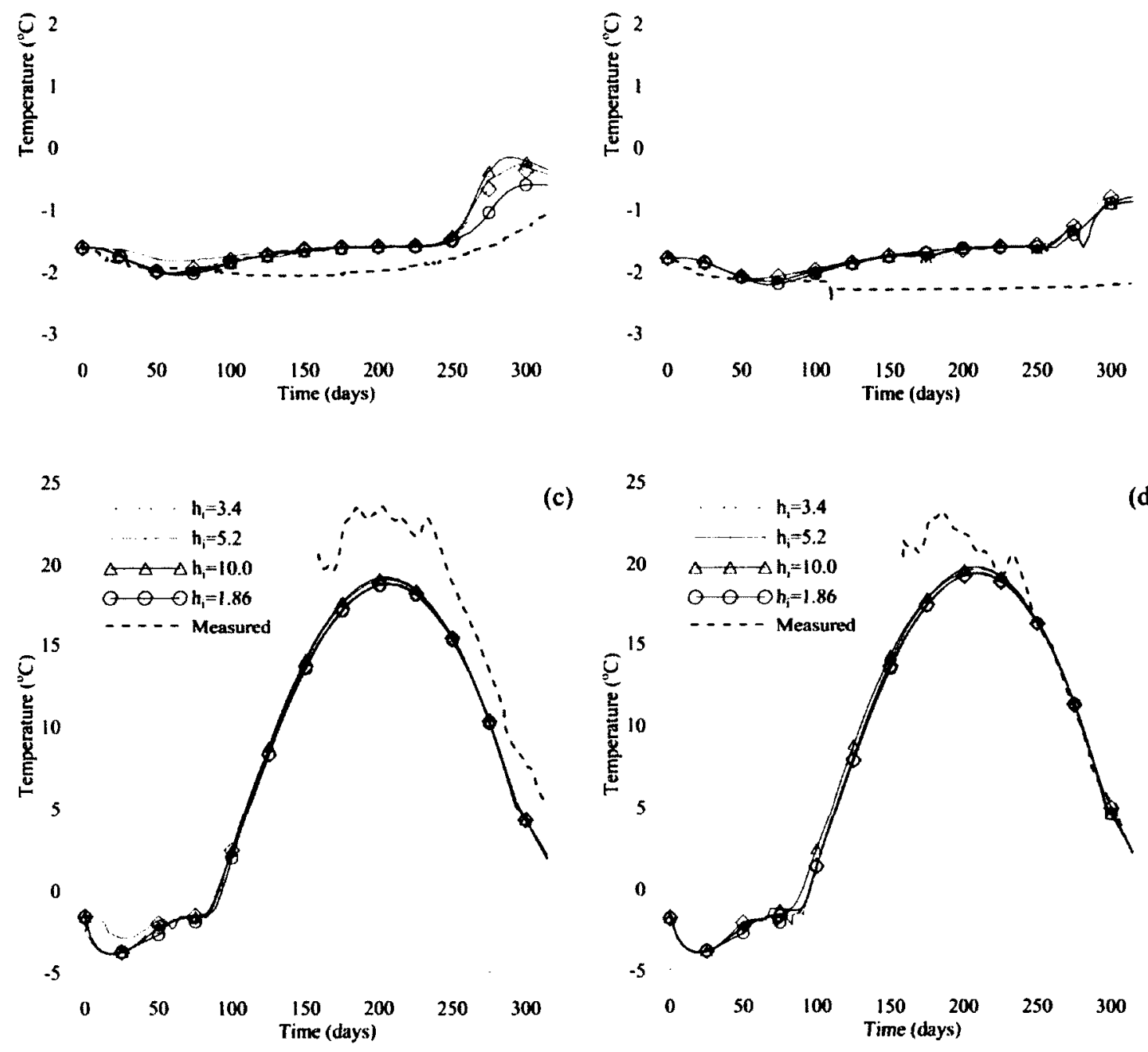

Figure 41: Sensitivity analysis of the coefficient of convection parameter $\boldsymbol{h}_{\boldsymbol{i}}$ $\left(\mathrm{W} / \mathrm{m}^{2} \cdot \mathrm{K}\right.$ ) at instrument (a) bundle 3 , (b) bundle 4 , (c) bundle 5 , and (d) bundle 6

Overall, the sensitivity analysis indicates the model is most sensitive to changes in the latent heat of fusion, biological heat generation and thermal conductivity, respectively. In addition, changes to the waste parameters have a much higher impact in comparison to the environmental parameters such as emissivity and convection. The results show the 
importance of the latent heat of fusion and biological heat generation when analyzing the stabilization of waste in northern climates.

\subsection{Conclusions and Future Work}

The ten instrument bundles installed in the Sainte-Sophie bioreactor landfill are providing valuable insight into the waste degradation and stabilization processes at an operating bioreactor landfill exposed to northern climatic conditions. The temperature data collected at the site indicate much of the waste placed during the winter months remains frozen even as ambient temperatures rise above $30^{\circ} \mathrm{C}$ during the summer months. This indicates that the biodegradation and stabilization processes are inhibited by the cold temperatures of the waste at placement (Hanson et al., 2006) and the insulation properties of the waste.

To assess the thermal properties of the frozen waste, an initial modeling study is carried out for the first waste lift from the time of placement in January 2010 through November 2010. The lower boundary was a prescribed temperature boundary set equal to the temperatures measured at the two bottom instrument bundles. The upper boundary was simulated as a flux boundary to account for radiation and wind-induced convective flux between the ambient air above the waste and the top of the waste layer. When the data were modeled using a finite model approach, the relatively low thermal conductivity of the waste confirms the insulating properties of the waste. In addition, in order to simulate the field data, a latent heat of fusion term was included to account for the phase change of the liquid fraction within the waste. The model indicated that the high latent heat of 
fusion for phase change is a significant component of the energy budget, and as a result the waste remains frozen longer than expected.

In comparison to literature (Zhao et al., 2008; Hanson et al., 2006), the waste in the centre of $6 \mathrm{~m}$ waste profile remained frozen at temperatures below $0^{\circ} \mathrm{C}$ for up to 1.5 years. More importantly however, the lag time is even longer for temperatures to reach $20^{\circ} \mathrm{C}$, the point where the biodegradation will become significant. The heat budget indicates that a significant amount of heat is required for phase change within frozen waste.

A sensitivity analysis was performed in order to access the relative importance of the various thermal parameters within the model and to ensure the best possible simulation of heat transfer within the modeled domain. Changes to the thermal waste parameters are found to have a much greater impact in comparison to the environmental parameters such as emissivity and convection. The analysis confirms that the latent heat of fusion and heat resulting from biodegradation are extremely important factors in analyzing the waste stabilization process in northern climates.

Future work will include continued modeling of the waste temperatures in the subsequent waste layers and over time. In addition, the settlement and moisture content data will be incorporated in the model, thus changing the characteristics of the waste as time progresses. As the waste temperatures increase, the biological heat generation term will become more important as the biological activity within the waste will increase. Thus, when moving forward with modeling lifts placed during summer months, more work will 
be required to understand and properly model the heat generated throughout biodegradation. 


\section{Simulating the impacts of temperatures in northern climates}

\section{on waste stabilization at an operating bioreactor landfill in}

\section{Quebec, Canada}

\subsection{Abstract}

A bioreactor landfill operated in Sainte-Sophie, Québec, Canada was instrumented to better understand the waste stabilization process in northern climates. Instrument bundles were placed within the waste to monitor temperature, oxygen, moisture content, settlement, total load, mounding of leachate and electrical conductivity. A finite element model was developed to simulate the heat fluxes to/from the waste as well as heat generation within the waste from both anaerobic and aerobic processes. The results of the analysis suggest the majority of the aerobic activity occurs in the top portion of the waste lift exposed to ambient air. In addition, the model indicates that frozen waste lifts require a significant amount of heat to thaw the liquid fraction. The model also demonstrates that when a lift of cold waste is placed at the bottom of the landfill, the subsurface acts as a significant source of heat.

\subsection{Introduction}

Bioreactor landfills aim to optimize the conditions within the waste to enhance waste stabilization, which increases landfill gas production and maximizes usable airspace. Many bioreactor landfills have been instrumented with sensors to monitor the stabilization process in order to evaluate the effectiveness of the bioreactor technology (Augenstein et al., 1997; Hunte et al., 2011; Zhao et al., 2008; Yesiller et al., 2011; 
Reinhart et al., 2002). Modelling by El-Fadel et al. (1996c), Hanson et al. (2008), Yoshida and Rowe (2003) and Yesiller et al. (2005) has improved our understanding of waste stabilization and gas generation in bioreactor landfills. However, the majority of the previous modelling efforts simulate bioreactor landfill operation in warmer climates; cold temperatures in northern climates can significantly impact waste stabilization (Zhao et al., 2008; Hanson et al., 2006). The optimum temperatures for methane production are approximately 41 to $42^{\circ} \mathrm{C}$ (Hartz et al., 1982; Pfeffer, 1974), and the cold ambient temperatures make it more difficult to reach these temperatures.

Instrumentation of landfills in northern climates has been implemented by researchers in Alberta (Hunte et al., 2011; Davies \& Colbran, 2010), Alaska (Hanson et al., 2006), and Michigan (Zhao et al., 2008; Zhao et al., 2006). At the Northern Oaks Recycling and Disposal Facility in Harrison, Michigan results from the temperature and gas composition data showed the first lift of waste placed in the summer months was actively degrading and produced high concentrations of methane gas whereas waste placed during the winter months remained frozen for 6 months post-closure (Zhao et al., 2008). In comparison, research at the Anchorage Regional Landfill determined that waste placed in the winter months could remain frozen for up to two years and delay significant gas generation for three to four years after placement (Hanson et al., 2006). Therefore, the initiation of microbial biodegradation was found to be largely dependent on the temperature of the waste at placement (Houi et al., 1997; Hanson et al., 2006). Hanson et al. (2006) modeled the Anchorage Regional Landfill in a number of scenarios to determine the possibility of optimizing the sequence of waste placement to enhance waste stabilization; they concluded that, during the winter, the placement of a single waste lift of a thickness 
greater than $3 \mathrm{~m}$ resulted in a significant delay in the waste stabilization process. These earlier studies indicate that better understanding of the waste stabilization process for bioreactor landfills located in northern climates is required in order to optimize the waste stabilization process.

The first phase of biodegradation in waste is a short aerobic phase where the oxygen within the pore space is depleted (Christensen and Kjeldsen, 1989; Reinhart \& Townsend, 1998; Warith et al., 2005; Pichtel, 2005). Some researchers suggested that an aerobic zone is maintained within the top layer of waste due to oxygen diffusion into the waste from the atmosphere (Warith, 2003; Lefebvre et al., 2000). This zone is generally confined to the top Im of waste (Christensen and Kjeldsen, 1989; Yoshida \& Rowe, 2003). In examining the heat balance within a landfill, Lefebvre et al. (2000) determined the heat produced from the consumption the oxygen initially within the void space was responsible for only $18.5 \%$ of the temperature rise within the waste. Hence, it has been postulated that a significant portion of the temperature increase within the waste results from aerobic activity occurring in the top $1 \mathrm{~m}$ layer of waste due to a continuous source of oxygen diffusing from the ambient air (Lefebvre et al., 2000).

The focus of the current study is to develop a model that simulates the heat budget for bioreactor landfills operating in northern climates. The proposed model includes the heat flux from below the landfill, from atmospheric conditions above the waste, and the heat generated via aerobic and anaerobic biodegradation. It also includes the storage of heat as sensible heat for increasing the temperature of the waste and as latent heat for the phase change needed to thaw the frozen liquid fraction of the waste. The thermal parameters within the model were calibrated using temperature data collected at Waste Management 
(WM) of Canada's Sainte-Sophie bioreactor landfill located in Sainte-Sophie, Québec. Twelve instrument bundles have been installed within the landfill as it was progressively filled with waste. The bundles contain sensors that measure important parameters impacting the degradation and stabilization processes. The quantity and quality of landfill gas at the site are also monitored. The resulting modelled heat budget quantifies the various heat sinks and sources impacting the waste temperature and rate of stabilization.

\subsection{Numerical model}

The finite element software package COMSOL Multiphysics v.3.5 was used to simulate the fluxes of heat that impact the temperature of the waste. Heat transfer/generation in the waste occurs: (1) from the ambient air via convection and radiation, (2) from the subsurface soil in the form of conduction, (3) from the adjacent waste lifts via conduction and (4) from biodegradation of the organic waste. The heat transfer within the waste occurs primarily through conduction. Heat can be stored within the waste as either sensible or latent heat. Sensible heat represents the portion of energy used to increase or decrease the temperature of the waste whereas latent heat represents the portion of energy used for phase change of the frozen liquid fraction within the solid waste.

\subsubsection{Governing equation}

The heat transfer within the waste is assumed to be governed by conduction:

$$
\nabla(\mathrm{k} \nabla T)+\mathrm{Q}=\rho \mathrm{C}_{\mathrm{p}} \frac{d T}{d t}
$$

where $\mathrm{k}(\mathrm{W} / \mathrm{m} \cdot \mathrm{K})$ is thermal conductivity, $\rho\left(\mathrm{kg} / \mathrm{m}^{3}\right)$ is the density, $\mathrm{C}_{\mathrm{p}}(\mathrm{J} / \mathrm{kg} \cdot \mathrm{K})$ is the specific heat, $\mathrm{Q}\left(\mathrm{W} / \mathrm{m}^{3}\right)$ is the heat source, $T(\mathrm{~K})$ is temperature, and $\mathrm{t}(\mathrm{s})$ is time. 
A phase change occurs for the frozen liquid fraction within the solid waste. The latent heat of fusion of the liquid fraction is accounted for by changing the specific heat, $C_{\mathrm{p}}$, of the solid waste with a smoothened step function at the phase change temperature range, as follows (Alawadhi and Amon, 2003):

$$
C_{\mathrm{p}}= \begin{cases}C_{p w} & T<-1.6^{\circ} \mathrm{C} \\ \frac{L}{\Delta \mathrm{T}} & -1.6^{\circ} \mathrm{C}<T<-0.6^{\circ} \mathrm{C} \\ C_{p w} & -0.6^{\circ} \mathrm{C}<T\end{cases}
$$

where $\mathrm{C}_{\mathrm{pw}}(\mathrm{J} / \mathrm{kg} \cdot \mathrm{K})$ is the specific heat of the waste, $L(\mathrm{~J} / \mathrm{kg})$ is the latent heat of fusion of the waste, and $\Delta T(K)$ is the temperature change during the phase change.

The bio-heat generation, $Q$, was modelled using a quadratic function of temperature when a threshold temperature value is exceeded, as follows (Neusinger et al., 2005):

$$
Q=\left\{\begin{array}{cl}
0 & T<\mathrm{T}_{\text {bio }} \\
Q_{i}\left(-0.000413 T^{2}+0.27143 T-43.677\right) & \mathrm{T}_{\text {bio }}<T
\end{array}\right.
$$

where $\mathrm{T}_{\text {bio }}(\mathrm{K})$ is the onset temperature of the bio-heat generation and $Q_{i}$ is the scaling multiplier, as shown in Table $10 . \mathrm{T}_{\text {bio }}$ was assumed to be $10^{\circ} \mathrm{C} . Q_{i}$ was varied depending on whether the biodegradation was anaerobic $\left(Q_{i \text {,anaerobic }}\right)$ or aerobic $\left(Q_{i \text {,acrobic }}\right)$, as aerobic biodegradation generates significantly more heat per mass of organic waste than anaerobic biodegradation. The magnitudes of the functions were calculated using values for $Q_{i \text { aerobic }}$ of 16 and $Q_{i \text {,anaerobic }}$ of 0.3 . The heat produced from aerobic degradation of the oxygen initially within the void space was ignored in the model, as the temperatures upon placement were below those necessary to support significant biological activity. 
Table 10: Range of analyzed thermal parameters

\begin{tabular}{|c|c|c|c|c|c|c|}
\hline $\begin{array}{c}k^{1} \\
(\mathbf{W} / \mathbf{m} \cdot \mathbf{K})\end{array}$ & $\begin{array}{c}\rho \\
\left(\mathbf{k g} / \mathbf{m}^{3}\right)\end{array}$ & $\begin{array}{c}C_{\mathrm{p}}^{1.2} \\
(\mathbf{k J} / \mathbf{k g} \cdot \mathbf{K})\end{array}$ & $\begin{array}{c}Q_{i}^{2,3} \\
\left(\mathbf{W} / \mathbf{m}^{3}\right)\end{array}$ & $\begin{array}{c}L \\
(\mathbf{k J} / \mathbf{k g})\end{array}$ & $E$ & $\begin{array}{c}h_{i}^{4,3} \\
\left(\mathbf{W} / \mathbf{m}^{2} \cdot \mathbf{K}^{4 / 3}\right)\end{array}$ \\
\hline $0.3-1.5$ & $930-1330$ & $1000-2363$ & $0.218-34.79$ & $24-334$ & $0.75-0.95$ & $1.86-10.0$ \\
\hline
\end{tabular}

${ }^{1}$ Hanson et al., 2008; ${ }^{2}$ Yoshida \& Rowe, $2003 ;{ }^{3}$ Rees, $1980 ;{ }^{4}$ De Halleux, $1989 ;{ }^{5}$ Silva, 1988

\subsubsection{Boundary Conditions}

The heat transfer between ambient air and the solid waste on the top boundary is as follows:

$$
\mathbf{n} \cdot(\mathrm{k} \nabla T)=\mathrm{h}\left(\mathrm{T}_{\mathrm{amb}}-T\right)+\varepsilon \sigma\left(\mathrm{T}_{\mathrm{amb}}^{4}-T^{4}\right)
$$

where $T_{a m b}(K)$ is the ambient air temperature, $h\left(W / m^{2} \cdot K\right)$ is the coefficient of convection, $\varepsilon$ is the surface emissivity constant which is taken as 0.9 , and $\sigma\left(W / \mathrm{m}^{2} \cdot \mathrm{K}^{4}\right)$ is the Stefan-Boltzmann constant for black body radiation.

The coefficient of convection, $\mathrm{h}\left(\mathrm{W} / \mathrm{m}^{2} \cdot \mathrm{K}\right)$, in Eqn. 22 is defined as it is reported by De Halleux (1989):

$$
\mathrm{h}=1.86\left|\mathrm{~T}_{\mathrm{amb}}-T\right|^{1 / 3}
$$

The top boundary condition simulated convection and radiation from the atmosphere. The lower boundary was defined as a prescribed temperature boundary using the temperature data from bundles 1 and 2 . The lateral boundaries were defined as no-flux boundaries as it is assumed that there is limited horizontal heat transfer to the adjacent solid waste and the instrumented waste column is sufficiently far from the sides of the landfill that impacts from the side slopes can be neglected. Details of the initial conditions and boundary conditions can be found in Bonany et al. (2012c). 


\subsection{Instrumentation of the Sainte-Sophie Landfill and Results}

The instrument bundles installed at the Sainte-Sophie landfill contain various instruments to monitor temperature, settlement, oxygen, moisture content, total load, mounding of leachate and electrical conductivity within the waste. Figure 42 shows the liquid settlement system, the piezometer and the total earth pressure cell mounted on a steel plate. The oxygen and moisture sensors were placed into a thin sand layer that covered the instrument bundle for protection.

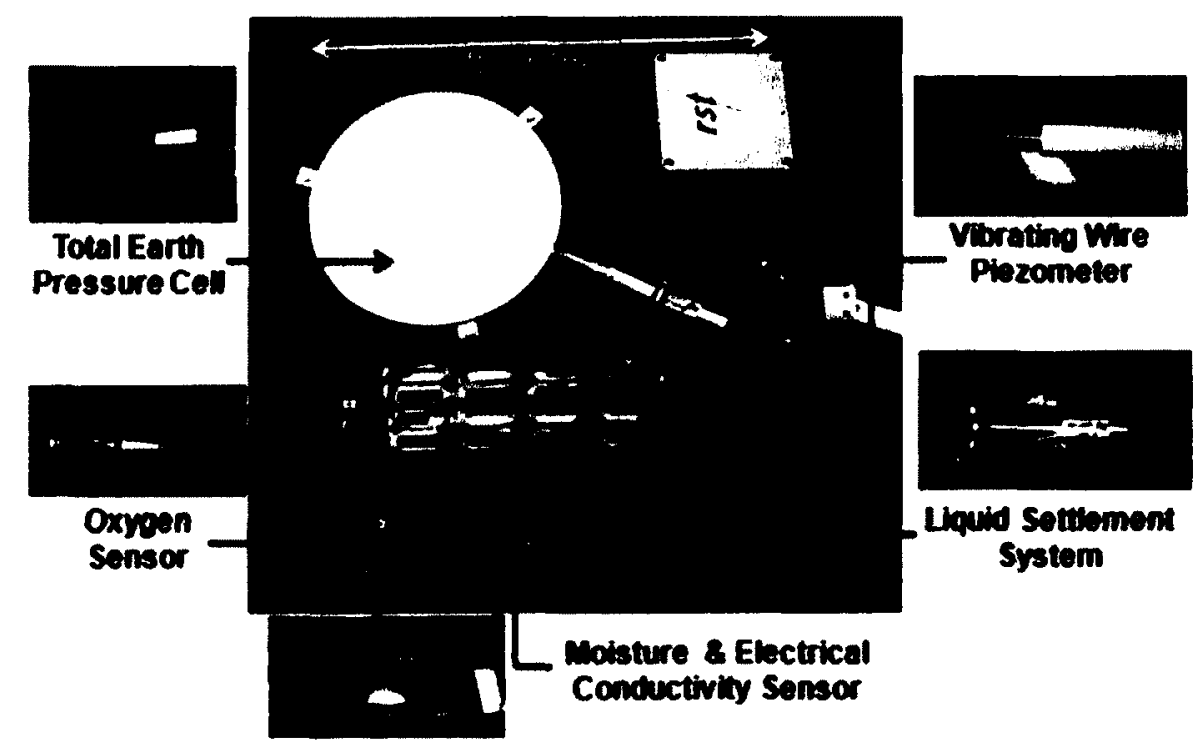

Figure 42: Instrument Bundle (Bonany et al., 2012b)

Instrument bundles were placed in two vertical columns, Column 1 and Column 2 , each consisting of six bundles. Column 1 and 2 are separated by approximately $17 \mathrm{~m}$ and each layer of instrument bundles was to be separated by approximately 3 to $4 \mathrm{~m}$. Figure 43 displays the placement elevations of the first ten instrument bundles. The vertical separation between the layers changed slightly due to the variations in the waste lift 
thicknesses and timing in bundle installation. The locations of bundles 1 and 2 on the base of the landfill were just above the leachate collection system. Bundles 3 and 4 were placed in the centre of a $6 \mathrm{~m}$ waste lift placed in January/February of 2010. Bundles 5 and 6 were installed in the top of the $6 \mathrm{~m}$ waste lift in June of 2010. At this time, the landfilling continued in other sections of the landfill until WM returned to the area of the bundles with placement of the second and third waste (each $3.5 \mathrm{~m}$ ) lifts in December of 2010 and February of 2011. Bundles 7 and 8 were installed in the top of the third waste lift. The first $13 \mathrm{~m}$ of waste in this section of the landfill was placed during the winter months. To avoid placing an additional lift during the winter, WM personnel agreed to place a fourth waste lift in August of 2011. In the succeeding month, bundles 9 and 10 were installed at the top of the fourth waste lift. 


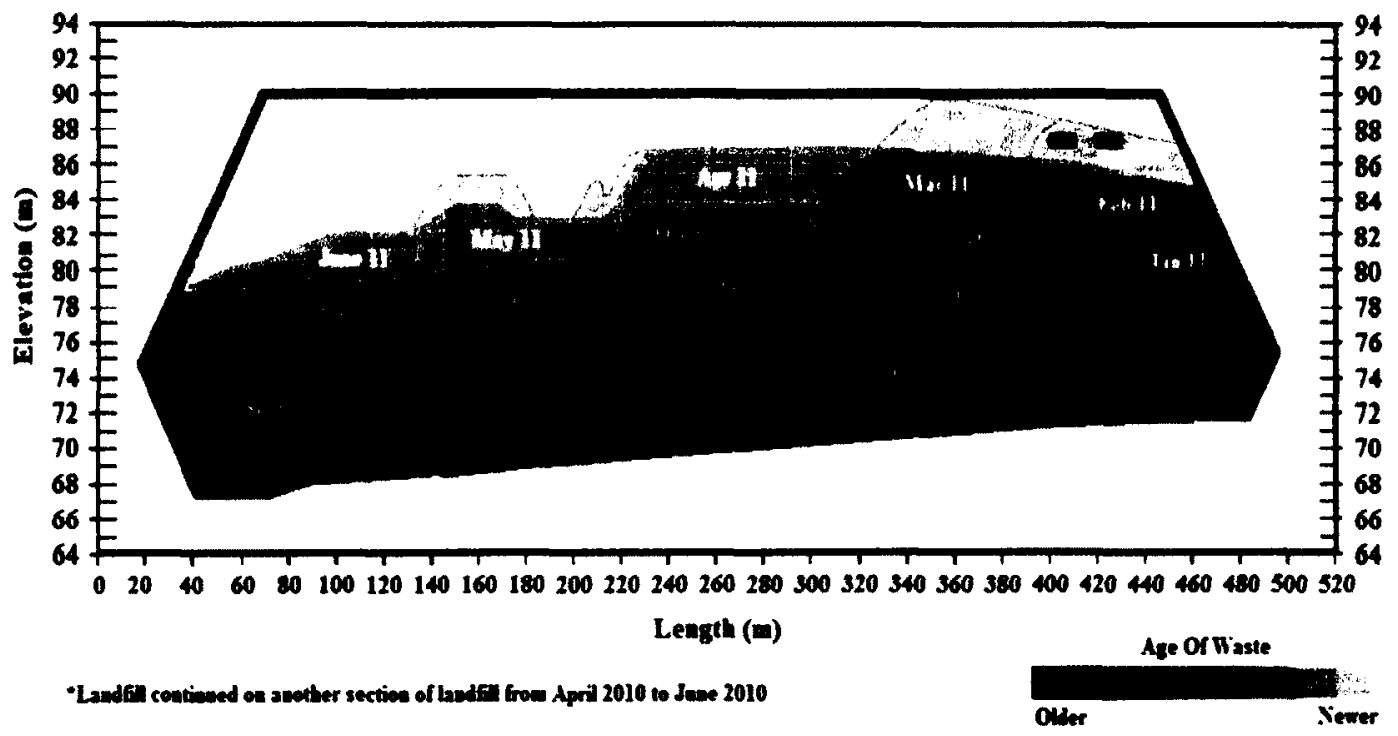

Figure 43: Timeline of waste lift placement in Sainte-Sophie landfill

\subsubsection{Instrument Bundle Results}

Figure 44 shows the average temperature readings with time throughout the first four waste lifts. The temperatures represent the average of the temperatures recorded by the thermistors contained in several instruments, including the liquid settlement system, the piezometer, total earth pressure cell and the moisture and electrical conductivity probe. The arrows in the figure indicate the direction of heat flux through the waste based on the temperature gradient between bundles and the ambient air above the waste. The heat entering the waste from the ambient air is represented in the model as convection or radiation. Similarly, the heat flux from the landfill base is modelled as conduction. 


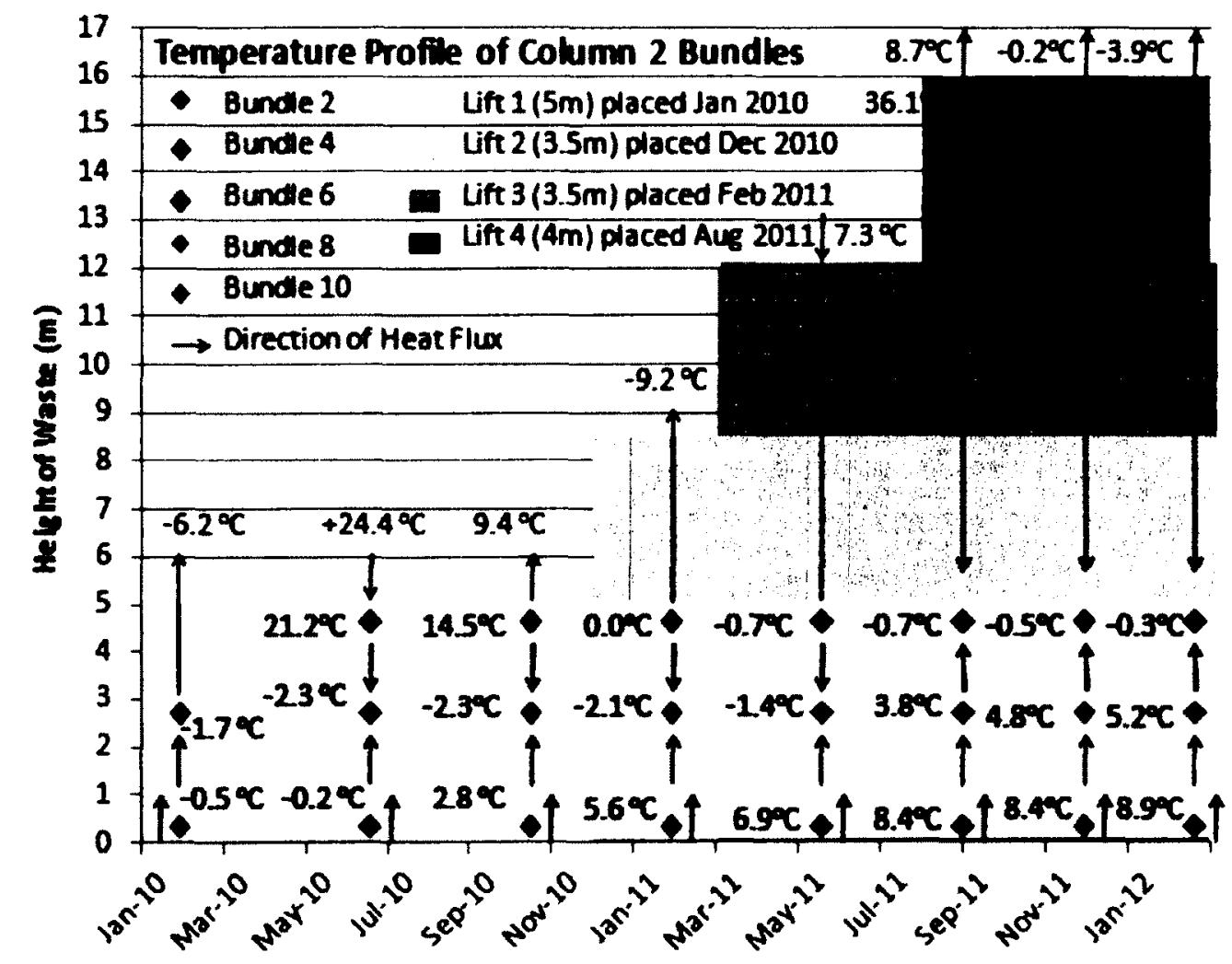

Figure 44: Heat fluxes for Column 2 of instrument bundles with time (modified from Vingerhoeds, 2011)

The first waste lift was placed in January of 2010. During the subsequent winter months there was a flux of heat leaving the waste as the waste temperature $\left(\sim-2^{\circ} \mathrm{C}\right)$ was greater than the ambient air temperature. During the summer months, where the ambient temperatures rose above $30^{\circ} \mathrm{C}$, there were strong radiative and convective heat fluxes entering the waste. Despite this source of heat, the temperatures at the centre of the $6 \mathrm{~m}$ waste lift remained below $0^{\circ} \mathrm{C}$, indicating the heat from ambient air did not reach the centre of the waste. This suggests the thermal conductivity of the waste is relatively low. In addition, it suggests that a significant amount of heat may be required to thaw the frozen liquid fraction within the waste. Approximately 1.5 years after placement, the 
temperatures at the centre of the first waste lift began to increase. At this time, $7 \mathrm{~m}$ of frozen waste had been placed above the bundles and therefore it was assumed that the temperature increase was caused by a positive heat flux from the base of the landfill.

The second and third waste lifts of $3.5 \mathrm{~m}$ each were placed over the area in December 2010 and February 2011. Temperature readings from bundles 7 and 8 suggest the $7 \mathrm{~m}$ waste layer was placed at temperatures of approximately $-2^{\circ} \mathrm{C}$. A dashed line in Figure 44 represents the unknown direction of heat flux until a thermal gradient is established throughout lifts 2 and 3. In the summer months of 2011 , there was a downward heat flux towards the second and first lifts as illustrated by the steep temperature gradient. Prior to the fourth waste lift being placed over bundles 7 and 8 , the temperatures for these bundles followed the ambient air temperature, lagged by a few days. Upon placement of the fourth waste lift, the temperatures deviated from the ambient air temperature and continued to increase. This indicates there was a downward heat flux from the waste lift above which was actively degrading. However, despite the high temperature of the waste in the vicinity of bundle 10 , the downward heat flux and subsequent temperature increase occurs relatively slowly. If aerobic biodegradation was occurring throughout the entire fourth lift, it is expected the temperature increase would be more rapid. This supports the conclusions from Lefebvre et al. (2000) that suggested the majority of heat generation is from aerobic activity occurring in the top $1 \mathrm{~m}$ of waste.

Overall, analysis of temperature data and derived heat transfer throughout the landfill demonstrates the insulating capacity of the waste. Even 2.5 years after placement of the first waste lift, the temperatures within the first three layers remain relatively low. The principal heat fluxes originate from either the base of the landfill, or from aerobic 
degradation occurring in the fourth waste lift. Furthermore, as the temperatures within these first three lifts remain much lower than optimum for biodegradation, the heat generation within these lifts is negligible.

The current study confirms the sequencing of waste placement is an important issue for landfill operators in northern climates (Hanson et al., 2006). When multiple lifts of waste are placed in succession during the winter months, the available heat sources are limited and the thermal conductivity is low such that it will take months to years to increase the temperature of the waste to temperatures needed to support aerobic and anaerobic biodegradation. This will have negative impacts on the rate of stabilization, which will reduce the amount of settlement occurring in the landfill (Hanson et al., 2006; Houi et al., 1997; Vingerhoeds, 2011) and can additionally reduce the methane gas production. The Saint-Sophie landfill gas data provided by WM indicated that there was more landfill gas being produced in the west end of the cell (left side of Figure 43) where waste was placed during the summer months in comparison to east end of the cell where waste was placed during the winter months and where the instrument bundles were installed. This is largely attributed to the temperature of the waste at the time of placement; it is hypothesized that the initial temperature of waste lifts placed in the summer months and the heat generated during the initial aerobic degradation phase are sufficient to sustain microbial activity and waste stabilization. Waste lifts placed during the winter months have insufficient initial heat to initiate or sustain microbial activity and have to rely on the flux of heat from above and below the waste lift. 


\subsubsection{Modelling of the Sainte-Sophie Temperature Data}

The developed model was used to simulate the temperature data collected in bundles 3 through 8 within the first three waste lifts from January 2010 through to August 2011, prior to the placement of the fourth waste lift. The simulation was divided into three time periods: (a) placement of first waste lift through to placement of the second waste lift, (b) placement of second waste lift through to placement of the third waste lift and (c) placement of the third waste through to placement of the fourth waste lift. The domains used for each time period illustrating the relative location of the instrument bundles throughout the three lifts are shown in Figure 45. The figure delineates the top $1 \mathrm{~m}$ of each waste lift as it was assumed that aerobic degradation occurred in this zone when the layer was not covered with waste. Lefebvre et al. (2000) demonstrated the importance of incorporating aerobic biodegradation in the top portion of the waste. Hence, the aerobic heat generation model was assumed for the top $1 \mathrm{~m}$ thick layer of waste that was exposed to the ambient air conditions for the three simulation periods. Despite the low temperatures for instrument bundles located in the cold waste, the oxygen sensors indicated that the oxygen content degraded slowly over a span of 3 months, suggesting there is a small amount of aerobic biodegradation occurring within the waste. However, during this time there was no temperature increase throughout the waste and therefore it was suspected the heat produced was negligible in comparison to the other sources of heat. 


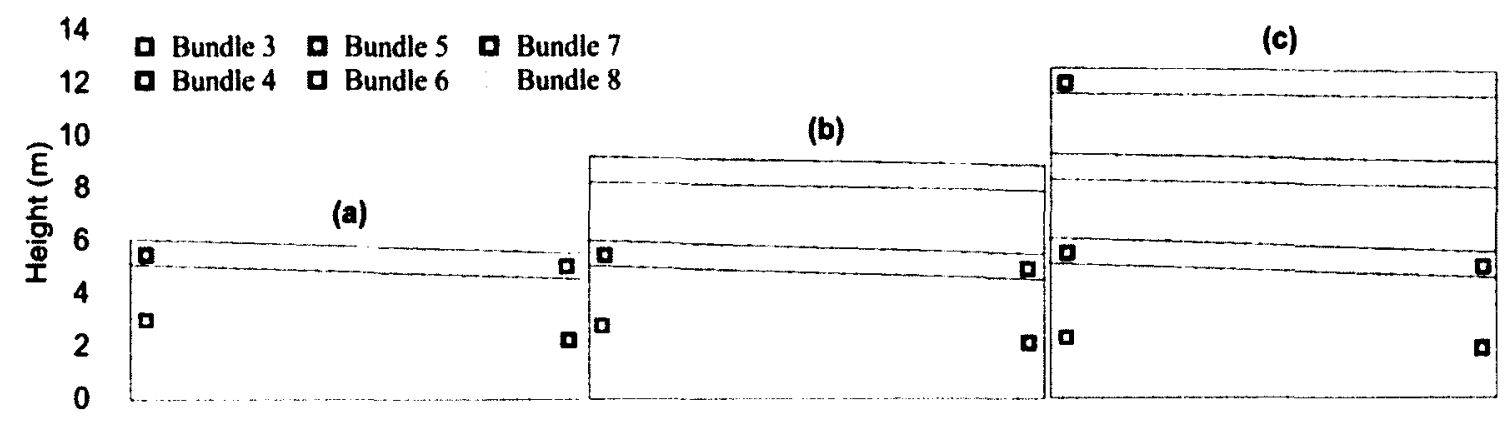

Figure 45: Modelled domains used in (a) first, (b) second and (c) third time periods

In order to properly simulate the temperatures at bundles 3 and 4 , the settlement that was recorded by the bundles had to be addressed in the comparison of the actual and simulated data. During the 19-month simulation period, bundles 3 and 4 settled $0.82 \mathrm{~m}$ and $0.85 \mathrm{~m}$, respectively, and as a result the instrument bundles are significantly closer to the lower domain boundary and impacted by the vertical heat flux from the lower boundary. Therefore, as illustrated in the figure, the location of these instrument bundles was adjusted with time in order to avoid overestimating the heat flux from the base of the landfill. Bundles 5 and 6 also settled, however, they are not impacted by the heat flux from the lower boundary. During the first simulation period, their distance from any heat flux at the surface remains constant, and hence a similar adjustment for elevation was not needed in order to compare the actual and simulated data. Prior to the placement of the second lift in December 2010, the temperatures at bundles 5 and 6 approached zero degrees Celsius as the ambient temperatures decreased. After the placement of the second and third lift, the bundles are located far enough from any heat flux at the upper and lower boundaries and hence, their elevation was not adjusted during the second and third simulation periods. As recommended in the conclusions and future work, settlement should be incorporated in the model to better reflect the conditions in the field. The first 
waste lift was initially simulated by Bonany et al. (2012c) for the period of initial placement through to November 2010 and was resimulated here. The addition of the second and third waste lifts was assumed to occur in December 2010 and February 2011 respectively and the entire domain was modelled through to August 2011. The initial temperatures for the first time period were based on the initial temperatures recorded at bundles 3 through 4 . The temperatures simulated at the end of the first time period were used as the initial temperatures for the first lift of waste during the second simulation period. Given that no instrument bundles were contained within the second waste lift, the initial temperatures were assumed to be $-1.8^{\circ} \mathrm{C}$ and were based on the initial temperatures of bundles $3,4,7$ and 8 . The temperatures in the first two lifts at the end of the second simulation period were used as the initial temperatures for the third time period. The initial temperatures in the third waste lift were set equal to the initial temperatures recorded at bundles 7 and 8 .

The range of thermal parameters needed to characterize the waste was obtained from values published in the literature as shown in Table 10. Bonany et al. (2012c) performed a sensitivity analysis on the range of thermal parameters which indicated the model is most sensitive to the changes in the latent heat of fusion and biological heat generation. The thermal parameters were calibrated to simulate the heat transfer and generation observed within the instrumented waste column of the Sainte-Sophie landfill.

\subsection{Model Results and Discussion}

The simulation results for the first 19 months, from January 2010 until August 2011, are plotted in comparison to the actual data in Figure 46. The final thermal parameters used for the simulation are presented in Table 11. The modelling results provide convincing 
evidence that the solid waste is an effective insulator, with a low thermal conductivity and high latent heat of fusion. The simulation results were used to estimate the overall heat budget for the waste. Figure 47 shows the magnitude of various heat fluxes to/from the waste throughout the simulation as well as the quantity of heat generated from anaerobic and aerobic biodegradation. Throughout the summer months there are strong positive convective and radiative fluxes while these fluxes are negative throughout the winter. As expected, the model indicates that the heat contribution from anaerobic activity was negligible in comparison to the heat generated via aerobic degradation. The figure illustrates the aerobic degradation heat source term lags the convection and radiation terms. This is because it takes time for the convective and radiation heat flux to increase the temperature of the waste above $10^{\circ} \mathrm{C}$ to allow biodegradation as per Eqn. 21 .

Table 11: Final thermal parameters

\begin{tabular}{|c|c|c|c|c|c|c|c|}
\hline $\begin{array}{c}k \\
(W / m \cdot K)\end{array}$ & $\begin{array}{c}\rho \\
\left(\mathrm{kg} / \mathrm{m}^{3}\right)\end{array}$ & $\begin{array}{c}C_{\mathrm{p}} \\
(\mathrm{kJ} / \mathrm{kg} \cdot \mathrm{K})\end{array}$ & $\begin{array}{l}Q_{\text {i,erobic }} \\
\left(\mathrm{W} / \mathrm{m}^{3}\right)\end{array}$ & $\begin{array}{c}Q_{\text {inmerobic }} \\
\left(\mathrm{W} / \mathrm{m}^{3}\right)\end{array}$ & $\begin{array}{c}L \\
(\mathrm{k} J / \mathrm{kg})\end{array}$ & $\varepsilon$ & $\begin{array}{c}h_{i} \\
\left(W / m^{2} \cdot K^{4 / 3}\right)\end{array}$ \\
\hline 0.67 & 930 & 1.4 & 16.5 & 0.3 & 38.0 & 0.9 & 1.86 \\
\hline
\end{tabular}




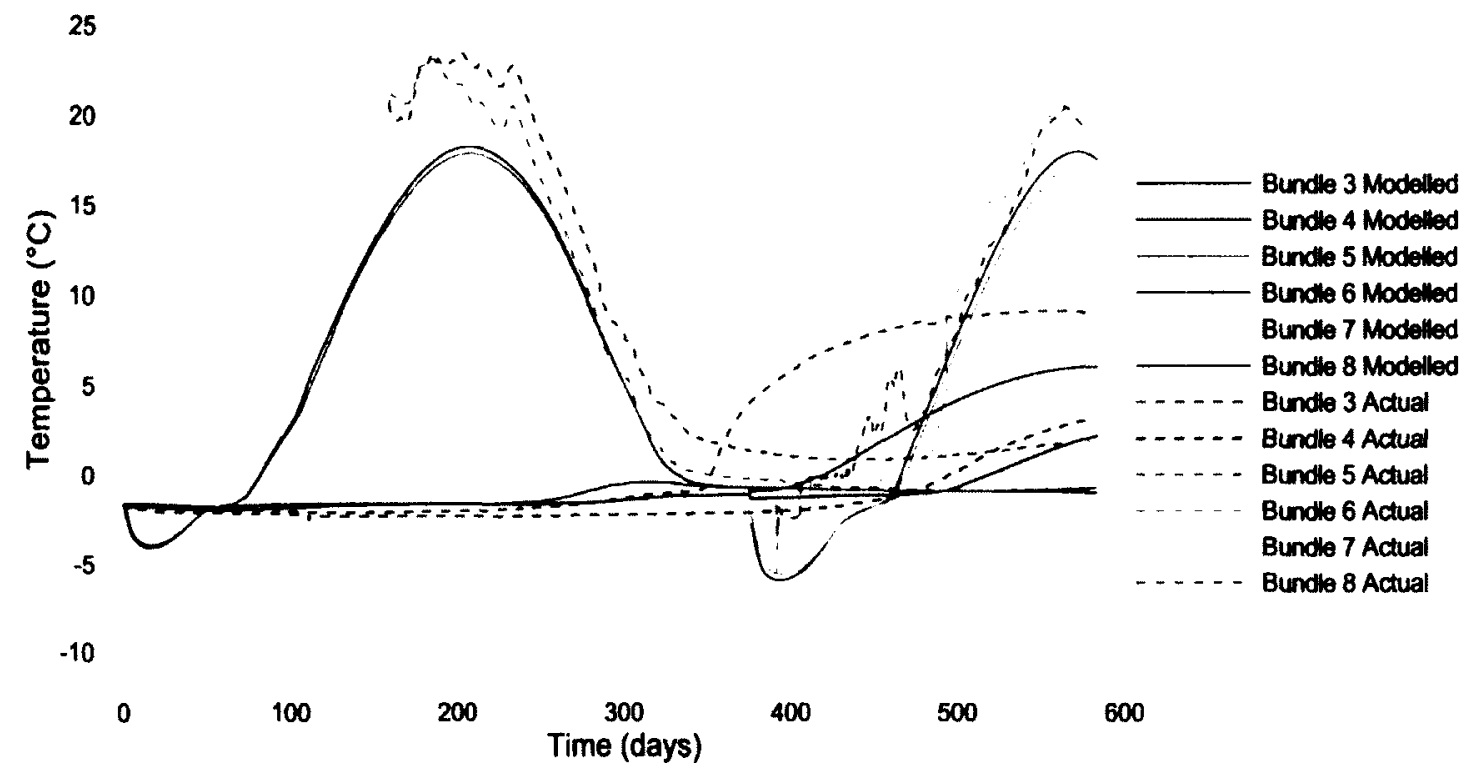

Figure 46: Modelled and measured temperatures at instrument bundle locations 3, $4,5,6,7$ and 8

The total net heat flux of each heat transfer/generation term was found by integrating the area under the simulated heat flux curves in Figure 47. The net heat flux was calculated to be $1.1 \mathrm{GJ} / \mathrm{m}, 2.4 \mathrm{GJ} / \mathrm{m}, 1.2 \mathrm{GJ} / \mathrm{m}$ and $2.4 \mathrm{GJ} / \mathrm{m}$ for convection, radiation, aerobic biodegradation and conduction from the underlying soil respectively. The heat entering the domain is stored as either latent heat or sensible heat. The amount of heat required to change the frozen liquid fraction within this waste to a liquid state was estimated to be $6.2 \mathrm{GJ} / \mathrm{m}$. In comparison, approximately $0.9 \mathrm{GJ} / \mathrm{m}$ of energy was stored as sensible heat. 


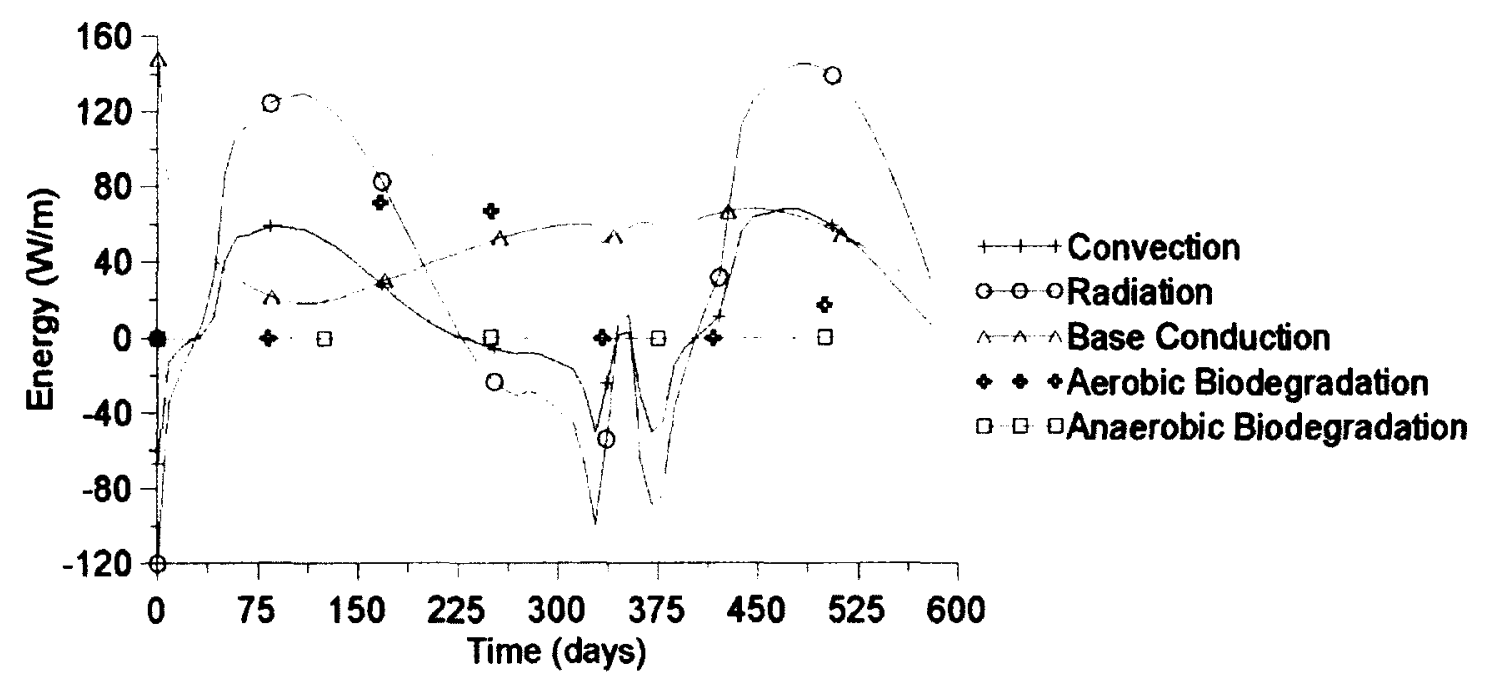

Figure 47: Heat fluxes to/from the waste column

The results for the modelled domain indicate that over a third of the net heat flux to the waste can be attributed to conduction from the base of the landfill. Once the thermal parameters of the waste are estimated, the model can be used to examine the benefits of sequencing the waste placement or the possible benefit of placing a winter layer on the base of the landfill. The upward heat flux can help to raise the temperature of a cold waste lift placed on the base, whereas a warm layer would actually lose heat through the base of the landfill.

The implications for waste placed in a frozen state are that the quantity of energy required to increase the temperature of the waste is dominated by the energy required for phase change (Bonany et al., 2012c). Figure 48 illustrates the final simulated temperature profile in August 2011. Due to the insulating capacity of the waste, high latent heat storage capacity, and the sequence of waste placement at the site, the majority of the waste remains close to freezing temperatures. With the only sources of heat originating from the bottom and top of the waste profile, the waste could maintain these low 
temperatures for several years. This will have negative impacts on the rate of stabilization, reducing the usable airspace and methane gas production from this portion of the waste.

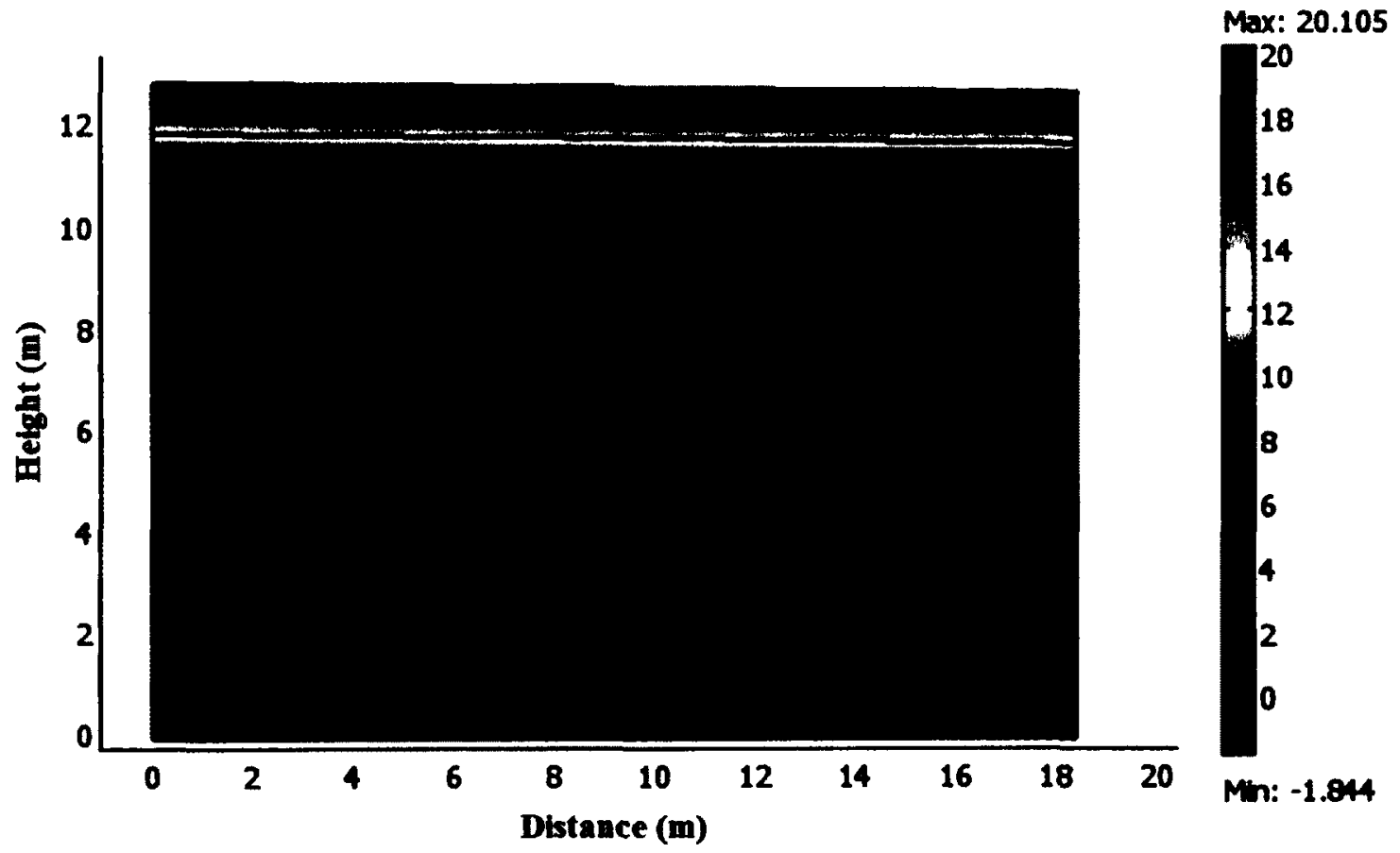

Figure 48: Domain temperature distribution $\left({ }^{\circ} \mathrm{C}\right)$ in the final time step of the analysis

\subsection{Conclusions and Future Work}

The instrument bundles installed within the Sainte-Sophie bioreactor landfill are improving our understanding of the impacts of cold climatic conditions on waste stabilization. The temperature data collected at the site indicate much of the waste placed during the winter months remains frozen even with the high solar radiation and thermal heat gains from the ambient air during the summer months. 
A finite element model was developed to evaluate the different modes of heat transfer and generation within the waste column. In order to simulate the temperatures recorded at Ste. Sophie, a low thermal conductivity had to be used, which is consistent with the literature, and a term to account for the latent heat of fusion had to be included as a significant amount of energy is used to thaw frozen waste. As a result, the simulated temperatures are consistent with the recorded temperatures and indicate that the waste can remain frozen for extended periods of time (months to years). The simulated heat budget for the modelled domain indicates that the primary sources of heat include convection, radiation and aerobic activity in the top $1 \mathrm{~m}$ of waste and conduction from the base of the landfill. The degradation of the initial oxygen content in the airspace generates relatively little heat in comparison to the aforementioned sources (Lefebvre et al., 2000). As a result, when multiple frozen waste lifts are placed in succession, there is no significant source of heat within the waste to raise the temperature of the waste and this volume of waste has to rely on heat conduction from above and below, which is limited by the low thermal conductivity of the waste and the high latent heat of fusion or energy needed to thaw any frozen waste. The temperature data confirms the biodegradation and stabilization processes are significantly inhibited by the cold temperatures of the waste at placement (Hanson et al., 2006; Zhao et al., 2008) and the low thermal conductivity and high latent heat of waste.

As waste placement and data collection continue at the Sainte-Sophie site, the heat budget model presented herein should continue to be developed to better represent several of the key processes occurring in the field. For example, the impacts of settlement should be incorporated in the model, as settlement will cause the thermal characteristics 
of the waste to change over time. Similarly, at later times, leachate migration will impact the heat flux within the waste and the thermal conductivity of the waste. The biological heat model presented herein and the characterization of an aerobic zone and an anaerobic zone over-simplifies biological heat generation within waste. More research is needed to better quantify heat generation rates under aerobic and anaerobic conditions and to simulate the oxygen diffusion-limited aerobic activity in the top $1 \mathrm{~m}$ of waste. Ultimately, the model can be used as a tool to optimize landfill operating practices in northern climates. The results of the model to date confirm landfill operators should consider staging waste placement to avoid placing consecutive frozen waste lifts in succession (Hanson et al., 2006; Houi et al., 1997; Vingerhoeds, 2011). The model also suggests a cold layer of waste placed on the base of the landfill can be warmed from conduction below. In addition, the model provides a better understanding of the quantity of heat required to raise the temperature of the waste when placed in a frozen state. Thus, the model could be used to analyze scenarios such adding air to the waste in order to promote aerobic heat generation. The model could determine if such an approach is feasible, and the quantity of air required to sufficiently increase the temperature of the waste to promote biodegradation. 


\section{Overall Conclusions and Recommendations}

Instrument bundles were installed in an operating bioreactor landfill located in SainteSophie, Québec to improve our understanding of the impacts of cold climatic conditions on waste stabilization. This research focused on the development of a heat budget for waste placed in northern climates where the waste is often placed in a frozen state for period of the year. The conclusions from this research were drawn from the interpretation of the field data collected to date and from the processes and parameters included in the numerical model in order to effectively simulate the temperature data collected to date.

The temperature data collected to date indicates that waste placed during the winter months can remain at temperatures well below those needed for active biodegradation and waste stabilization for periods of months to years. The placement of multiple frozen waste lifts placed in succession will further increase the delay in waste stabilization and hence landfill operators should avoid this and optimize their waste placement staging to maximise waste stabilization throughout the landfill. The data collected from the oxygen sensors confirms the fact that the temperature of the waste has a significant impact on the biodegradation activity within the waste. In areas of the landfill where the waste was placed under colder temperatures, the oxygen depleted over the course of 2 months. In comparison, when waste was placed in warmer months, the results suggested the aerobic phase is no more than a few days or weeks.

To better understand the impacts of cold climates on waste temperature and waste stabilization and to quantify the heat sources, sinks and transfer within an anaerobic landfill operated in a northern climate, a conceptual and corresponding numerical model 
were developed to simulate the conditions and data collected at Sainte-Sophie. In order to effectively simulate the measured temperatures, a low thermal conductivity had to be used, which is consistent with the literature, and a term to account for the latent heat of fusion had to be included as a significant amount of energy is used to thaw frozen waste. As a result, the simulated temperatures are consistent with the recorded temperatures and indicate that the waste can remain frozen for extended periods of time (months to years). A sensitivity analysis of the various thermal parameters within the model demonstrated changes to the thermal waste parameters had a much greater impact in comparison to the environmental parameters such as emissivity and convection. The analysis confirms that the latent heat of fusion and heat resulting from biodegradation are extremely important factors impacting the temperature of the waste and the waste stabilization process in northern climates.

The simulated heat budget for the modelled domain indicates that the primary sources of heat include convection, radiation and aerobic activity in the top $1 \mathrm{~m}$ of waste and conduction from the base of the landfill. The degradation of the initial oxygen content in the airspace generates very little heat in comparison to the aforementioned sources. Therefore, when multiple frozen waste lifts are placed during the winter months, the majority of heat impacting these waste lifts is limited to conduction from above and below. Furthermore, the amount of heat required to thaw any frozen waste is significant due to the high latent heat of fusion, while the heat transfer is limited by the low thermal conductivity of the waste. The temperature data confirms the biodegradation and stabilization processes are significantly inhibited by the cold temperatures of the waste at 
placement (Hanson et al., 2006; Zhao et al., 2008) and the low thermal conductivity and high latent heat of waste.

The temperature data for the first three lifts has currently been modelled however future work will expand the modelling effort to include data from the fourth and fifth lifts of waste. In addition, the settlement and moisture content data will be incorporated in the model and will allow the characteristics of the waste to change as time progresses, improving the simulation. The biological heat model presented in this thesis oversimplifies biological heat generation within waste. Further research is required to better quantify heat generation rates under aerobic and anaerobic conditions and to simulate the aerobic activity in the top portion of the waste. Ultimately the model can be used to determine what can be done to improve current operating practices at landfills in northern climates. The results of the model to date confirm landfill operators should consider staging waste placement to avoid placing consecutive waste lifts during the winter months (Hanson et al., 2006; Houi et al., 1997; Vingerhoeds, 2011). The model also suggests conduction from the soil and leachate collection system below can warm a cold layer of waste placed on the base of the landfill. In addition, the model gives us a better understanding of the quantity of heat required to raise when temperature of the waste when placed in a frozen state. Therefore, the model could be used to analyze proactive approaches such injecting air into the waste to promote heat generation from aerobic biodegradation. The model would enable us to determine if such an approach is feasible, and the quantity of air required to sufficiently increase the temperature of the waste to promote biodegradation. 


\section{References}

Alawadhi, E.M., \& Amon, C.H. (2003) PCM thermal control unit for portable electronic devices: experimental and numerical studies. Components and Packaging Technologies, Institute for Electrical and Electronics Engineers, 26: 116-125.

Andersland, O.B., \& Anderson, D.M. (1978) Geotechnical Engineering for Cold Regions, McGraw-Hill Book Co., New York, N.Y.

American Heritage $B_{3}$ Science Dictionary. Dictionary.com, "waste". Houghton Mifflin Company. Available: http://dictionary.reference.com/browse/waste. Accessed: November 08, 2011.

Apogee Instruments Inc. (2009) Oxygen Sensor SO-100 \& 200 Series Owners Manual. Logan, UT.

Augenstein, D., Yazdani, R., More, R. \& Dahl, K. (1997) Yolo County Controlled Landfill Demonstration Project. Proceedings of the 20th Annual Solid Waste Association of North America Landfill Gas Symposium, August, Sacramento, CA. P43-87.

Axelsson, S.R.J. (1984) Thermal-IR emissivity of soils and its dependence on porosity, surface roughness and soil-moisture. Proceedings of 5th International Congress on Photogrammetry and Remote Sensing, Brazil, June 18-29, 1984.

Bonany, J., Van Geel, P. \& Gunay, H. (2012a) Process Optimization at the Sainte-Sophie Anaerobic Bioreactor Landfill, Quebec, Canada. Proceedings of Canadian Society for Civil Engineering 12th International Environmental Specialty Conference. Edmonton, AB.

Bonany, J., Van Geel, P., Gunay, H. \& Isgor, B. (2012b) Heat Budget for the SainteSophie Anaerobic Bioreactor Landfill in Quebec, Canada. Proceedings of the 105th Annual Air \&Waste Management Association Conference \& Exhibition. San Antonio, CA.

Bonany, J., Van Geel, P., Gunay, H. \& Isgor, B. (2012c) (Under Review). Heat Budget for an Anaerobic Bioreactor Landfill in Ste. Sophie, Quebec. Waste Management.

Campbell Scientific, Inc. (2006) CR 1000 Measurement and Control System Overview Revision 11/06. Logan, UT.

Cengel, Y.A. (2002) Heat transfer: a practical approach. McGraw-Hill, N.Y.

Christensen, T.H. \& Kjeldsen, P. (1989) In Sanitary Landfilling - Process, Technology, and Environmental Impact. Basic Biochemical Processes in Landfills. Christensen, Cossu \& Stegmann, (Eds.), San Diego, Academic Press. 
Davies, D. \& Colbran, C. (2010) Sustainable Landfill Biocell: An Innovative Technology to Biostabilize Organic Fraction of Municipal Solid Waste. Proceedings of Remediation Technologies Symposium 2010. Banff, AB

Decagon Devices, Inc. (2010) 5TE Water Content, EC and Temperature Sensors Operator's Manual - Version 5. Pullman, WA.

De Halleux, D. (1989) Dynamic model of heat and mass transfer in greenhouses: theoretical and experimental study. Ph.D. Thesis, Gembloux, Belgium

El-Fadel, M., Findikakis, A.N. \& Leckie, J.O. (1996a) Biochemical and physical processes in landfills. Waste Management and Research, 23(3), 131-143.

El-Fadel, M., Findikakis, A.N. \& Leckie, J.O. (1996b) Estimating and enhancing methane yield from municipal solid waste. Hazardous Waste \& Hazardous Materials 13 (3), 309-331.

El-Fadel, M., Findikakis, A.N. \& Leckie, J.O. (1996c) Numerical modelling of generation and transport of gas and heat in sanitary landfills: I. model formulation. Waste Management \& Research 14, 483-504.

El-Fadel, M., Findikakis, A.N. \& Leckie, J.O. (1996d) Numerical modelling of generation and transport of gas and heat in sanitary landfills: II. model application. Waste Management \& Research 14, 537-552.

El-Fadel, M. (1999) Simulating Temperature Variations in Landfills. Journal of Solid Waste Technology and Management, 26(2), pp 78-86.

Environment Canada. (2012) Canadian Climate Normals 1971-2000: Montreal/Mirabel International Aiport. National Climate Data and Information Archive. Available: http://www.climate.weatheroffice.gc.ca/climate normals/results_e.html?stnID=5616\&pr ov $=\&$ lang $=$ e\&dCode $=4 \&$ dispBack $=1 \&$ StationName $=$ Mirabel $\&$ Search Type $=$ Contains\&p rovince $=\mathrm{ALL \& provBut}=\&$ month $1=0 \&$ month2=12. Accessed: July 2012.

Farouki, O.T. (1981) Thermal Properties of Soils. Hanover (NH): US Army Cold Regions Research and Engineering Laboratory. Monograph 81-1.

Gawande, N.A., Reinhart, D.R., Thomas, P.A., McCreanor, P.T. \& Townsend, T. (2003) Municipal Solid Waste In Situ Moisture Content Measurement Using An Electrical Resistance Sensor. Waste Management, 23, pp 667-674.

Genivar. (2008) Figure 4, Configuration du réseau de captage du biogaz zone IV. L.E.S. de Sainte-Sophie. Project number Q110532. Prepared for: Waste Management.

Gholamifard, S., Eymard, R. \& Duquennoi, C. (2008) Modeling anaerobic bioreactor landfills in methanogenic phase: Long term and short term behaviors. Water Research 42:5061-5071. 
Hanson, J.L., Yesiller, N. \& Kendall, L.A. (2005) Integrated Temperature and Gas Analysis at a Municipal Solid Waste Landfill. Proceedings of the 16th International Conference on Soil Mechanics \& Geotechnical Engineering, Millpress Science Publishers, Rotterdam, the Netherlands, Vol. 4, 2265-2268.

Hanson, J.L., Yesiller, N., Howard, K.A., Liu, W.-L. \& Cooper, S.P. (2006) Effects of Placement Conditions on Decomposition of Municipal Solid Wastes in Cold Regions. Current Practices in Cold Regions Engineering. Proceedings of the $13^{\text {th }}$ International Conference on Cold Regions Engineering, Orono, ME.

Hanson, J. L., Liu, W.-L. \& Yesiller, N. (2008) Analytical and numerical methodology for modeling temperatures in landfills. Geotechnics of waste management and remediation, American Society of Civil Engineers GSP No. 177, M. V. Khire, A. N. Alshawabkeh, and K. R. Reddy, (Eds.), ASCE, Reston, Va., 24-31.

Hartz, K.E., Klink, R.E., \& Ham, R.K. (1982) Temperature effects: methane generation from landfill samples. Journal of the Environmental Engineering Division, American Society of Civil Engineers, 108 (4), 629-638.

Hinkley Center for Solid and Hazardous Waste Management, University of Florida, \& University of Central Florida. (2008) Florida Bioreactor Landfill Demonstration Project: Final Report. Available: http://www.bioreactor.org/ExecSum.pdf. Accessed April 2012.

Holman, J. (2010) Heat Transfer, 10th edn. McGraw-Hill, London.

Holmes, R. (1983) The Absorptive Capacity of Domestic Refuse from a Full-Scale Active Landfill, Waste Management, 73(11): 581.

Houi, D., Paul, E. \& Couturier, C. (1997) Heat and mass transfer in landfills and biogas recovery. Proceedings of the 6th International Waste Management and Landfill Symposium, T. H. Christensen et al., (Eds)., Vol. I, CISA, Italy, 101-108.

Hunte, C., Hettiaratchi, J., Meegoda, J. \& Hettiarachchi, C. (2011) Performance of a Waste Cell in Cold Climate Operated As an Anaerobic Landfill Bioreactor. Proceedings of Geo-Frontiers 2011. Dallas, TX. 1276-1286

Karthikeyan O.P. \& Joseph, K. (2007) Bioreactor landfills for sustainable solid waste management. Proceedings of National Conference on Sustainable Energy and Waste Management, Coimbatore, India, April 27-28, 2007

Kasali G.B. \& Senior, E. (1989) Effects of temperature and moisture on the anaerobic digestion of refuse. Journal of Chemical Technology \& Biotechnology. 44(1): $31-41$

Kim, J. \& Pohland, F.G. (2003) Process Enhancement in Anaerobic Bioreactor Landfills, Water Science and Technology, 48 (4), 29-36.

Koerner, R.M. \& Daniel, D.E. (1997) Final covers for solid waste landfills and abandoned dumps. American Society of Civil Engineers. Reston, VA. 
Lamrani M.A., Boulard, T., Roy J.C. \& Jaffrin, A. (2001) Airflows and temperature patterns induced in a confined greenhouse. Journal of Agricultural Engineering Research, $78,75-88$

Lefebvre, X., Lanini, S. \& Houi, D. (2000) The Role of Aerobic Activity on refuse Temperature Rise, I. Landfill Experiment Study. Waste Management \& Research, 18, pp 444-452.

Mata-Alvarez, J. \& Martinez-Viturtia, A. (1986) Laboratory simulation of municipal solid waste fermentation with leachate recycle. Journal of Chemical Technology \& Biotechnology., 36 (12), 547-556

Ministry of the Environment. (2010) Landfill Standards: A Guideline on the Regulatory and Approval Requirements for New or Expanding Landfilling Sites. Ontario Ministry of the Environment, 2010, pp 1-108.

Mitchell, J.K. (1993) Fundamentals of soil behavior, 2nd edition. New York: John Wiley \& Sons.

Neusinger, R., Drach, V., Ebert, H. \& Fricke, J. (2005) Computer simulations that illustrate the heat balance of landfills. International Journal of Thermophysics, 26, 519530.

NRC. (2007) Canadian Spatial Reference System: GPS Accuracy Levels. National Resources Canada. Available: http:/www.geod.nrcan.gc.ca/edu/geod/gps/gps13_e.php. Accessed: May 2012.

Ontario Auditor General. (2010) "Non-Hazardous Waste Disposal and Diversion". Annual Report 2010. Chapter 3, p 213-239.

Pacey, J., Augenstein, D., Mork, R., Reinhart, D. \& Yazdani, R. (1999) The Bioreactor landfill: an innovation in solid waste management. Proceedings of SWANA, Silver Springs, Maryland.

Pfeffer, J. T. (1974) Temperature effects on anaerobic fermentation of domestic wastes. Biotechnology and Bioengineering. 16:771-787.

Pichtel, J. (2005) Waste Management Practices: Municipal, Hazardous, and Industrial. CRC Press Taylor \& Francis Group, Boca Raton, FL.

Pohland, F.G. (1975) Sanitary Landfill Stabilization with Leachate Recycle and Residual Treatment. Prepared for the Office of Research and Monitoring - United States Environmental Protection Agency. Cincinnati, Ohio.

Qian, X., Koerner, R.M., \& Gray, D.H. (2002) Geotechnical Aspects of Landfill Design and Construction, Prentice Hall, Upper Saddle River, New Jersey, 717p. 
Rees, J.F. (1980) Optimization of Methane Production and Refuse Decomposition in Landfills by Temperature Control. Journal of Chemical Technology \& Biotechnology, 30, pp 458-465.

Reinhart, D.R. (1996) Full-scale Experiences with Leachate Recirculating Landfills: Case Studies. Waste Management \& Research, 14, pp 347-365.

Reinhart, D.R. \& Al-Yousfi, A.B. (1996) The Impact of Leachate Recirculation on Municipal Solid Waste Landfill Operating Characteristics. Waste Management \& Research, 14, pp 337-346.

Reinhart, D.R. \& Townsend, T.G. (1998) Landfill Bioreactor Design and Operation. Lewis Publishers, Boca Raton, FL.

Reinhart, D.R., McCreanor, P.T. \& Townsend, T.G. (2002) The Bioreactor Landfill: Its Status and Future. Waste Management, 20, pp 172-186.

Reinhart, D.R., Townsend, T.G. \& McCreanor, P.T. (2002) Florida Bioreactor Demonstration Project - Instrumentation. Proceedings of Waste Tech 2002, Coral Springs, FL.

Rouse, W.R. (1984) Microclimate of the Arctic tree line. 2: Soil microclimate of tundra and forest. Water Resources Research, 20(1), 67-73

Rowe, R.K. \& Islam, M.Z. (2009) Impact of Landfill Liner Time-Temperature History on the Service Life of HDPE Geomembranes. Waste Management, 29, 2689-2699.

Rowe, R.K., Quigley, R.M., Brachman, R.W.I. \& Booker, J.R. (2004) Barrier Systems for Waste Disposal Systems. Second Edition. Spon Press, New York, NY.

RST Instruments Ltd. (2004a) RST Flexi-Mux Instruction Manual - Revision 1.1. Coquitlam, BC.

RST Instruments Ltd. (2004b) Total Earth Pressure Cell Instruction Manual - Revision 1.3. RST Instruments Ltd. Coquitlam, BC.

RST Instruments Ltd. (2006) Vibrating Wire Piezometer Model VW2100 Instruction Manual - Revision 1.6. Coquitlam, BC.

RST Instruments Ltd. (2008) VW Liquid Settlement System Instruction Manual Revision 3. Coquitlam, BC.

Sharma, H.D. \& Reddy, K.R. (2004) Geoenvironmental Engineering: Site Remediation, Waste Containment, and Emerging Waste Management Technologies. John Wiley \& Sons, Inc., Hoboken, NJ.

Silva, A.M. (1988) A contribution to the study of the greenhouse climate: the analysis of some processes of energy transfer. Ph.D. Thesis, University of Evora, Portugal, 350pp 
Statistics Canada. (2011) "Managing Solid Wastes." Human Activity and the Environment - Economy and the Environment. Statistics Canada Catalogue no. 16-201X. Ottawa, Ontario. p. 36-37. Available: http://www.statcan.gc.ca/pub/16-201-x/16-201x2011000-eng.pdf. Accessed December 2011.

Swati, M. \& Joseph, K. (2005) Bioreactor Landfills. A global vista on the emerging technology for sustainable management of municipal solid waste. Proceedings of Prithvi 2005: Global Ecomeet - Sustainable Land use and Waste Management. Thiruvananthapuram, Kerala.

Tchobanoglous, G., Theisen, H. \& Vigil, S.A. (1993) Integrated Solid Waste Management. McGraw-Hill. Inc., Singapore, pp. 418-419.

Tittlebaum, M.E. (1982) Organic carbon content stabilization through landfill leachate recirculation. Journal of the Water Pollution Control Federation. 54(5): 428-433.

Townsend, T., Kumar, D. \& Ko, J. (2008) Bioreactor Landfill Operation: A Guide for Development, Implementation and Montoring: version 1.0 (July 1, 2008). Prepared for the Hinkley Center for Solid and Hazardous Waste Management, Gainesville, FL.

Van Geel, P.J., Vingerhoeds, E. \& Samson, C. (2010) Process Optimization at a Bioreactor Landfill in Québec, Canada, Proceedings of WASTECON 2010, Boston, August 15-17, 2010.

Vingerhoeds, E. (2011) Instrument Installation and Preliminary Data in a Full-Scale Anaerobic Bioreactor Landfill, Sainte-Sophie, Quebec, Canada. M.A.Sc. Thesis, Ottawa, Canada.

Vinson, T.S. \& Jahn, S.L. (1985) Latent heat of frozen saline coarse grained soil. Journal of Geotechnical Engineering. 111(5), 607-623.

Warith, M. (2002) Bioreactor Landfills: Experimental and Field Results. Waste Management, 22, pp 7-17.

Warith, M.A. (2003) Solid waste management: new trends in landfill design. Emirates Journal of Engineering Research. 8 (1), 61-70.

Warith, M., Li, X. \& Jin, H. (2005) Bioreactor Landfills: State-of-the-Art Review. Emirates Journal for Engineering Research, 10(1), pp 1-14.

Waste Management. (2004) The Bioreactor Landfill: Next Generation Landfill Technology. Waste Management Bioreactor Program. Available: http://www.wm.com/sustainability/pdfs/bioreactorbrochure.pdf. Accessed April 2012

Yazdani, R., Dahl, K., Byars, M., Mansoubi, A. \& Augenstein, D. (2000) A Beneficial Investment in Trash. Yolo County Public Works and Division of Integrated Waste Management. Report to the Urban Consortium Energy Talk Force. 
Yesiller, N., Hanson, J.L. \& Liu. W.L. (2005) Heat Generation in Municipal Solid Waste Landfills. Journal of Geotechnical and Geoenvironmental Engineering, 131(11), pp 13301344.

Yesiller, N., Hanson, J. \& Yoshida, H. (2011) Landfill Temperatures Under Variable Decomposition Conditions. Proceedings of the Geo-Frontiers 2011 Conference. Dallas, TX.

Yoshida, H. \& Rowe, R.K. (2003) Consideration of landfill liner temperature. Proceedings of the 9th International Waste Management and Landfill Symposium, Christensen, T.H. et al., (Eds.), CISA, ltaly.

Zhao, X., Musleh, R., Maher, S., Khire, M.V., Voice, T.C. \& Hashsham, S.A. (2008) Start-up Performance of a Full-Scale Bioreactor Landfill Cell Under Cold-Climate Conditions. Waste Management, 28, pp 2633-2634.

Zhao, X., Voice, T.C. \& Hashsham, S.A. (2006) Bioreactor Landfill Research and Demonstration Project Northern Oaks Landfill, Harrison, MI: Final Report. Prepared for the Environmental Research and Education Foundation, Gainesville, FL.

Zimmerman R.E. \& Issacson, R. (1988) Toxic and non-toxic components in MSW landfill gases. Proceedings of Institute of Gas Technology - Energy from Biomass and wastes, New Orleans, Louisiana, pp. 503-515. 


\section{Appendix A - Instrument Specifications}

Information regarding the sensors contained in the instrument bundles is described in

Tables A1 to A5 below. Figures A1 to A5 are photographs of the individual sensors.

Table A1: Liquid settlement system (RST Instruments Ltd., 2008)

\begin{tabular}{|l|l|}
\hline Name of Sensor & Vibrating Wire Liquid Settlement System \\
\hline Manufacturer & RST Instruments Ltd. \\
\hline Model & SSVW105-17 \\
\hline Reservoir Type & $\begin{array}{l}10 \text { psi pressure accumulator (Bundles 1-6) } \\
\text { Weighted accumulator (Bundles 7-12) }\end{array}$ \\
\hline Sensor Range & $170.0 \mathrm{kPa}$ \\
\hline Accuracy & $0.1 \%$ of full-scale \\
\hline Sensitivity & $0.05 \%$ of full-scale \\
\hline Fluid in Tubing & Distilled water and ethylene glycol (50/50 mix) \\
\hline Thermistor Type & $3 \mathrm{k} \Omega$ \\
\hline Temperature Range & $-20^{\circ} \mathrm{C}$ to $80^{\circ} \mathrm{C}$ \\
\hline
\end{tabular}

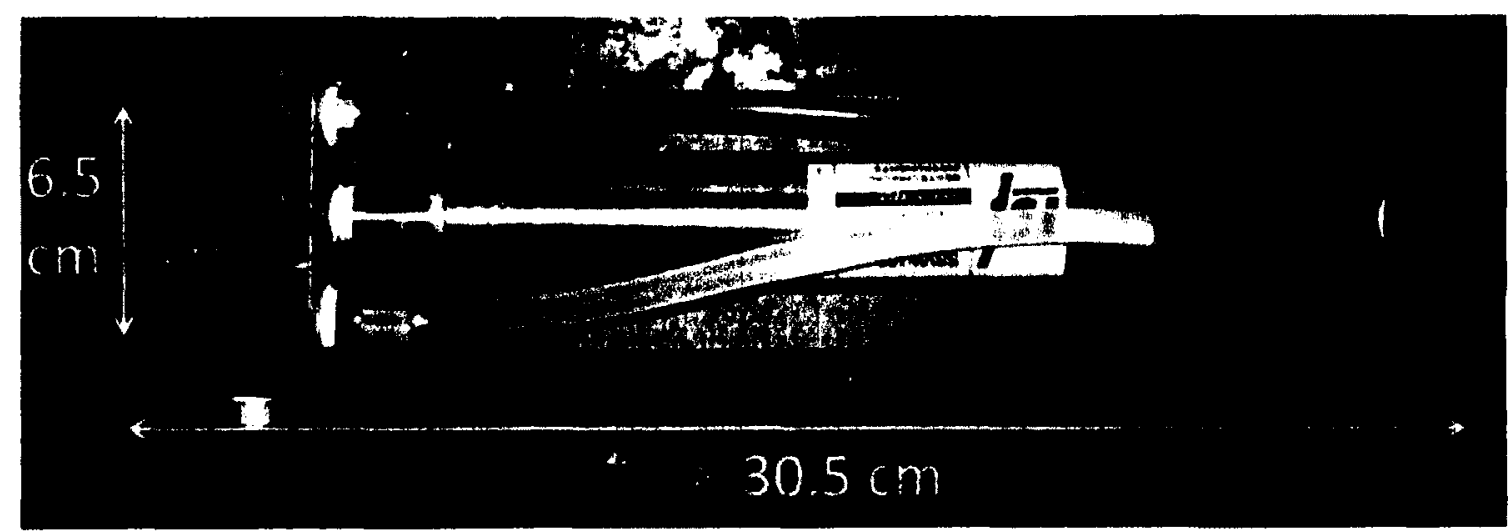

Figure A1: Liquid settlement system 
Table A2: Oxygen sensor (Apogee Instruments Inc., 2009)

\begin{tabular}{|l|l|}
\hline Name of Sensor & Oxygen Sensor \\
\hline Manufacturer & Apogee Instruments Inc. \\
\hline Model & SO-200 \\
\hline Operating Environment & $\begin{array}{l}0 \text { to } 100 \% \mathrm{RH} \\
60 \text { to } 140 \mathrm{kPa}\end{array}$ \\
\hline Sensor Range & 0 to $100 \% \mathrm{O}_{2}$ \\
\hline Accuracy & $<0.02 \% \mathrm{O}_{2}$ drift per day \\
\hline Repeatability & $\pm 0.001 \% \mathrm{O}_{2}$ \\
\hline Thermistor Range & $-20^{\circ} \mathrm{C}$ to $60^{\circ} \mathrm{C}$ \\
\hline
\end{tabular}

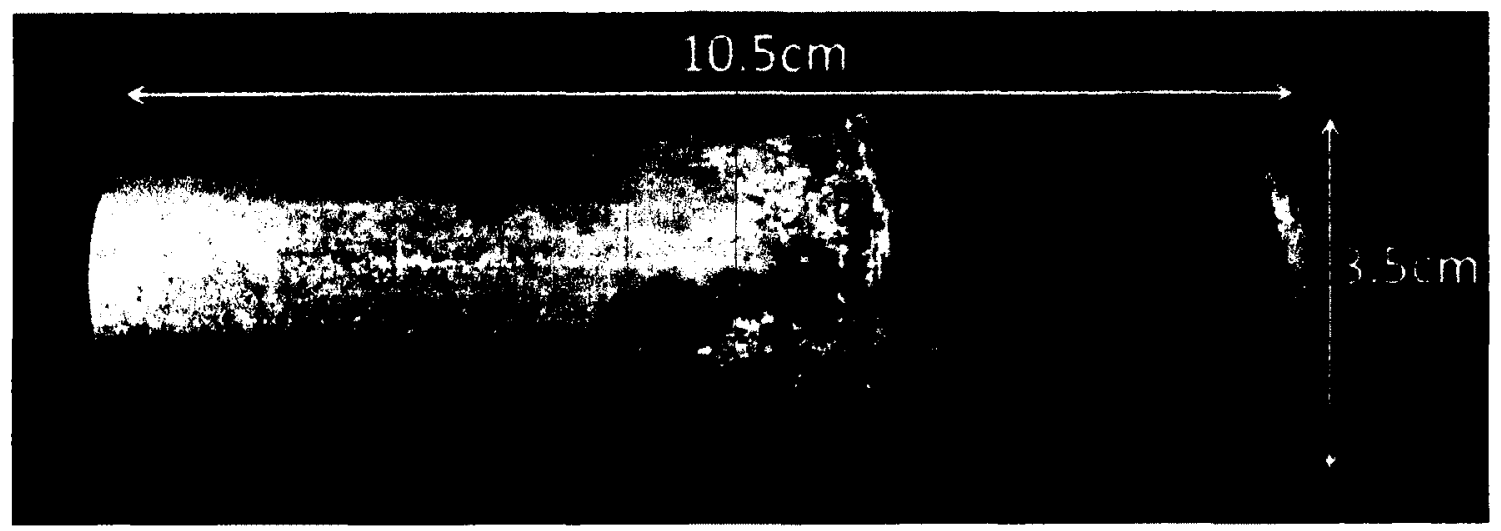

Figure A2: Oxygen sensor 
Table A3: Moisture and electrical conductivity sensor (Decagon Devices, Inc., 2010)

\begin{tabular}{|c|c|}
\hline Name of Sensor & 5TE Soil Moisture, Temperature, and Electrical Conductivity \\
\hline Manufacturer & Decagon Devices Inc. \\
\hline Model & 40559 \\
\hline Sensor Range & $\begin{array}{l}\text { Dielectric permittivity: } 1 \text { (air) to } 80 \text { (water) } \\
\text { Electrical Conductivity (bulk): } 0-23.1 \mathrm{dS} / \mathrm{m}\end{array}$ \\
\hline Accuracy & $\begin{array}{l}\text { Dielectric permittivity: } \pm 1 \text { (unitless) from } 1-40, \pm 15 \% \text { from } 40-80 \\
\text { VWC: } \pm 3 \% \text { VWC } \\
\text { Electrical Conductivity (bulk): } \pm 10 \% \text { from } 0-7 \mathrm{dS} / \mathrm{m} \text {, calibration } \\
\text { required above } 7 \mathrm{dS} / \mathrm{m}\end{array}$ \\
\hline Sensitivity & $\begin{array}{l}\text { Dielectric permittivity: } \pm 1 \text { (unitless) from } 1-20,<0.75 \text { from } 20-80 \\
\text { VWC: } 0.08 \% \text { VWC from } 0-50 \% \text { VWC } \\
\text { Electrical Conductivity (bulk): } 0.01 \mathrm{dS} / \mathrm{m} \text { from } 0-7 \mathrm{dS} / \mathrm{m}, 0.05 \mathrm{dS} / \mathrm{m} \\
\text { from } 7 \text { to } 23.1 \mathrm{dS} / \mathrm{m}\end{array}$ \\
\hline Thermistor Range & $-40^{\circ} \mathrm{C}$ to $50^{\circ} \mathrm{C}$ \\
\hline Thermistor Accuracy & $\pm 1^{\circ} \mathrm{C}$ \\
\hline Thermistor Sensitivity & $0.1^{\circ} \mathrm{C}$ \\
\hline
\end{tabular}

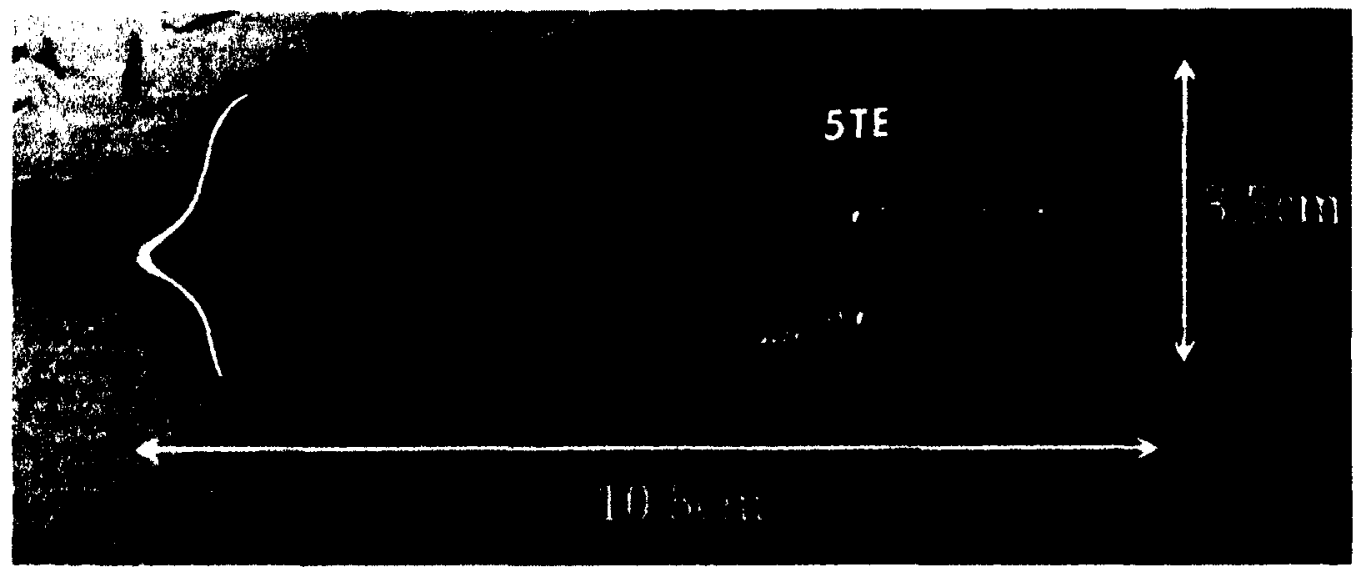

Figure A3: Moisture and electrical conductivity sensor. 
Table A4: Total earth pressure cell (RST Instruments Ltd., 2004b)

\begin{tabular}{|l|l|}
\hline Name of Sensor & Vibrating Wire - Total Earth Pressure Cell \\
\hline Manufacturer & RST Instruments Ltd. \\
\hline Model & LPTPC12-V-M \\
\hline Transducer Type & Vibrating Wire Pressure Transducer \\
\hline Sensor Range & $500 \mathrm{kPa}$ \\
\hline Accuracy & $0.1 \%$ of full-scale \\
\hline Sensitivity & $0.025 \%$ of full-scale \\
\hline Thermistor Type & $3 \mathrm{k} \Omega$ \\
\hline Thermistor Range & $-29^{\circ} \mathrm{C}$ to $65^{\circ} \mathrm{C}$ \\
\hline
\end{tabular}

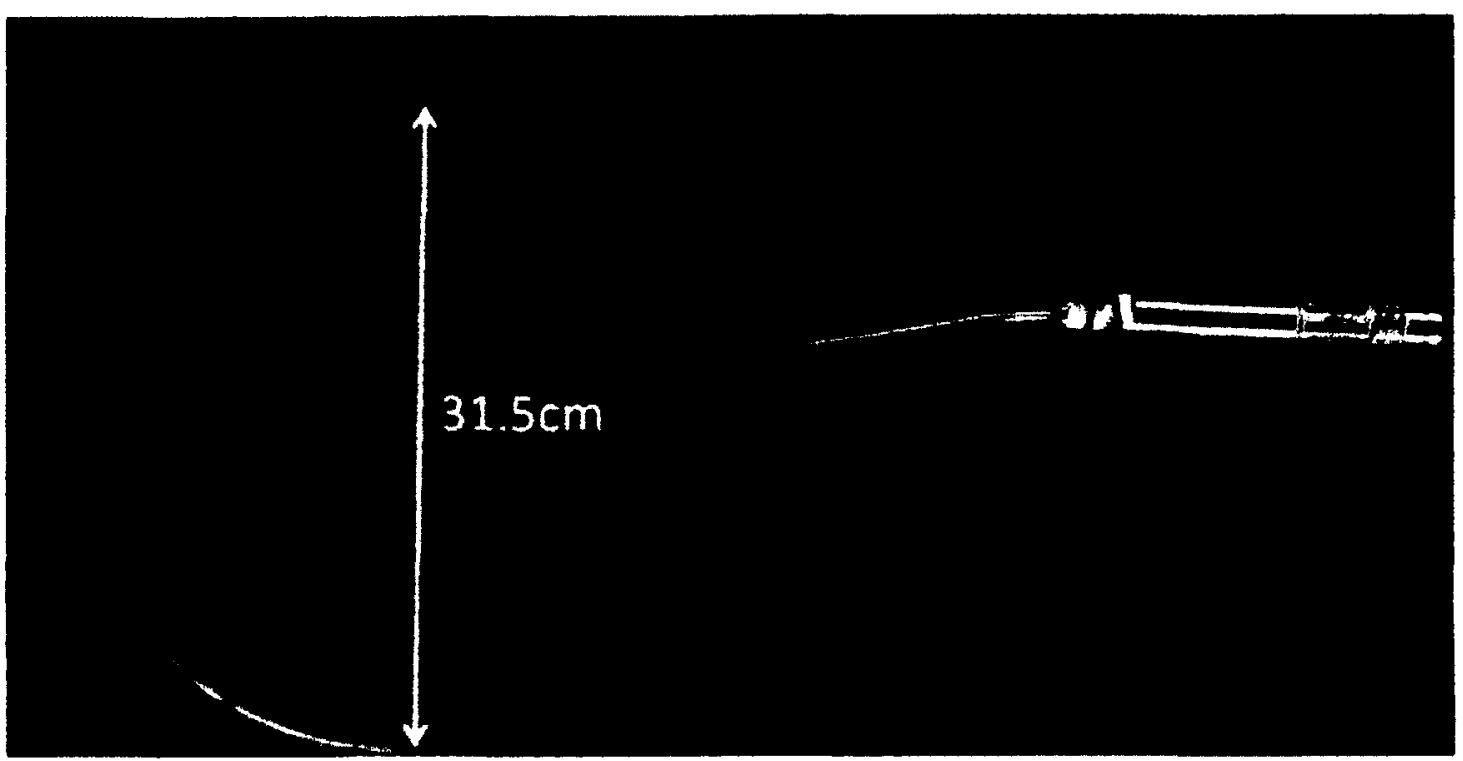

Figure A4: Total earth pressure cell 
Table A5: Vibrating wire piezometer (RST Instruments Ltd., 2006)

\begin{tabular}{|l|l|}
\hline Name of Sensor & Vibrating Wire Piezometer \\
\hline Manufacturer & RST Instruments Ltd. \\
\hline Model & PPA0094-0.35 \\
\hline Transducer Type & Vibrating wire pressure transducer \\
\hline Filter & 50 micron sintered filter \\
\hline Sensor Range & $350 \mathrm{kPa}$ \\
\hline Accuracy & $0.1 \%$ of full-scale \\
\hline Sensitivity & $0.025 \%$ of full-scale \\
\hline Thermistor Type & $\mathrm{NTC} 3 \mathrm{k} \Omega\left(925^{\circ} \mathrm{C}\right.$ \\
\hline Thermistor Range & $-20^{\circ} \mathrm{C}$ to $80^{\circ} \mathrm{C}$ \\
\hline Thermistor Accuracy & $\pm 0.2^{\circ} \mathrm{C}$ \\
\hline
\end{tabular}

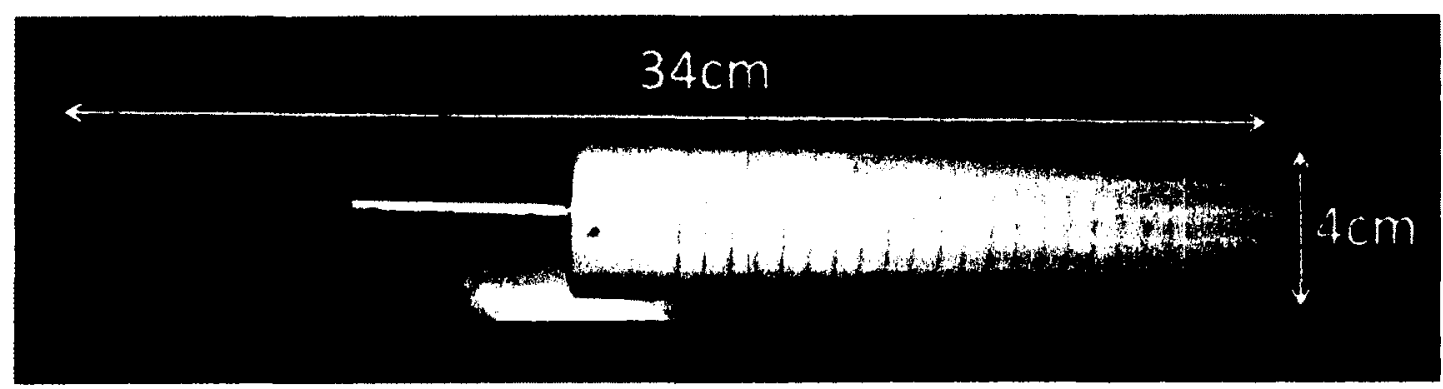

Figure A5: Vibrating wire piezometer 


\section{Appendix B - Thermistor Temperature Data}

Figures B1 through B10 show the temperatures measured by the thermistors from each instrument in the ten bundles. Bundles 1 to 4 have temperature readings from the piezometer, moisture sensor, settlement sensor and oxygen sensor. Bundles 5 and 6 have temperature readings from the piezometer, moisture sensor and oxygen sensor. Bundles 7 to 10 have temperature readings from the total earth pressure cell, settlement sensor, moisture sensor and oxygen sensor. The temperatures measured by the total earth pressure cell, settlement sensor, piezometer, and moisture sensor were generally within $1{ }^{\circ} \mathrm{C}$ of one another. However, the oxygen sensor measures temperature values approximately $2^{\circ} \mathrm{C}$ higher in comparison to the other thermistors as the oxygen sensor contains a small heater used to prevent condensation. The heat generated from the internal heater is minimal and therefore is not sufficient to impact the temperature of the surrounding waste.

The average temperatures were calculated using all of the thermistors with the exception of the oxygen sensor. Due to the harsh conditions in the landfill, some of the thermistors stopped working throughout the project and therefore their results were not included in the average temperature calculation. As shown in Figure B3, the moisture sensor in bundle 3 stopped working in May of 2011. The settlement sensor thermistor in bundle 4 was not wired correctly upon installation in January 2010. In May 2010 this issue was resolved and the data was included in the average temperature calculation. In bundles 4, 7 and 8 the thermistors from the moisture sensors also stopped functioning. Figures B9 and B10 illustrate the moisture sensors in bundles 9 and 10 failed in September and December 2011 , respectively. The moisture sensors work in temperature ranges of $-40^{\circ} \mathrm{C}$ 
to $50^{\circ} \mathrm{C}$ and therefore it is suspected the sensors failed due to the high temperatures within the waste.

Overall, the thermistors from the settlement sensors, piezometers, total earth pressure cells and oxygen sensors have correlated well for each instrument bundle, indicating the sensors continue to generate accurate results. However, the temperature measured from many of the moisture sensors have begun to deviate from the other thermistors. It is suspected these sensors stopped functioning properly due to the high electrical conductivity experienced by the sensors while in the landfill. 


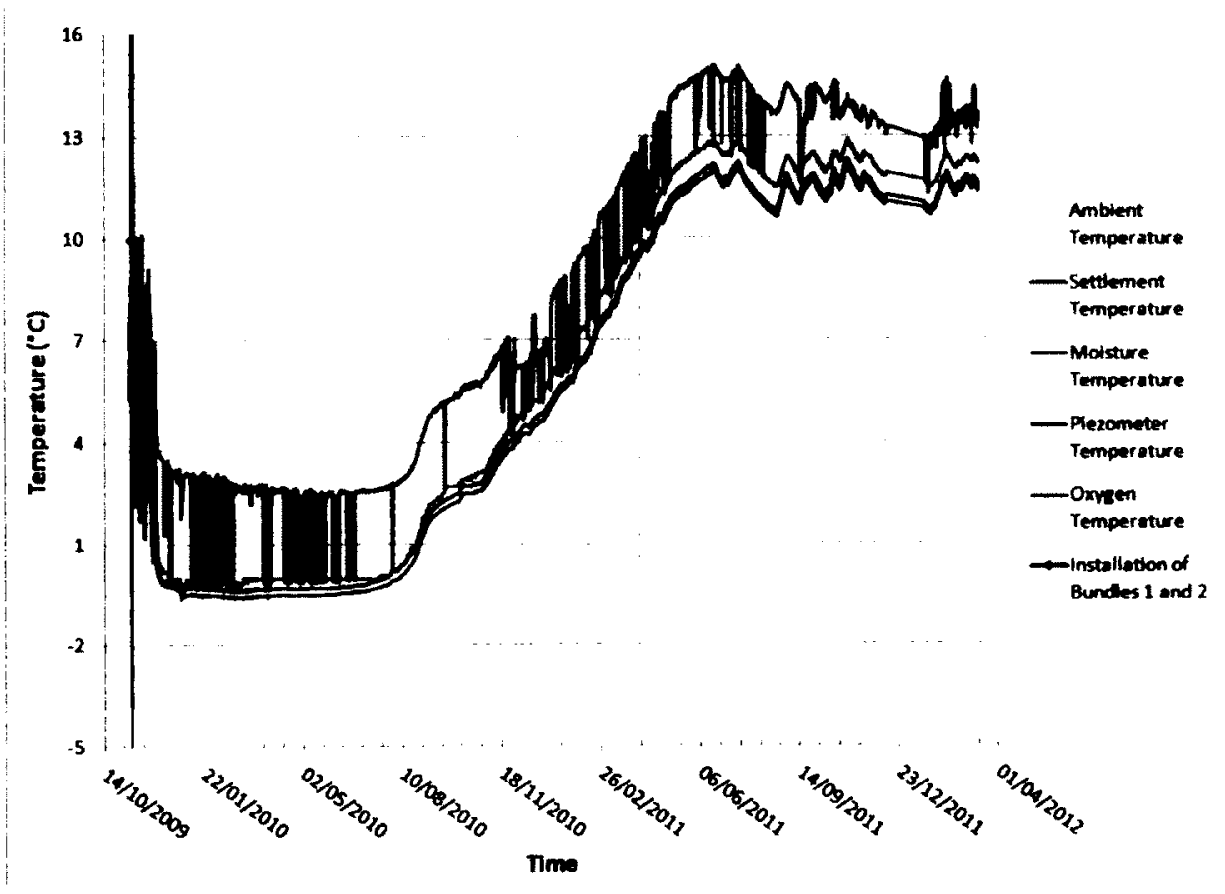

Figure B1: Thermistor temperatures for bundle 1

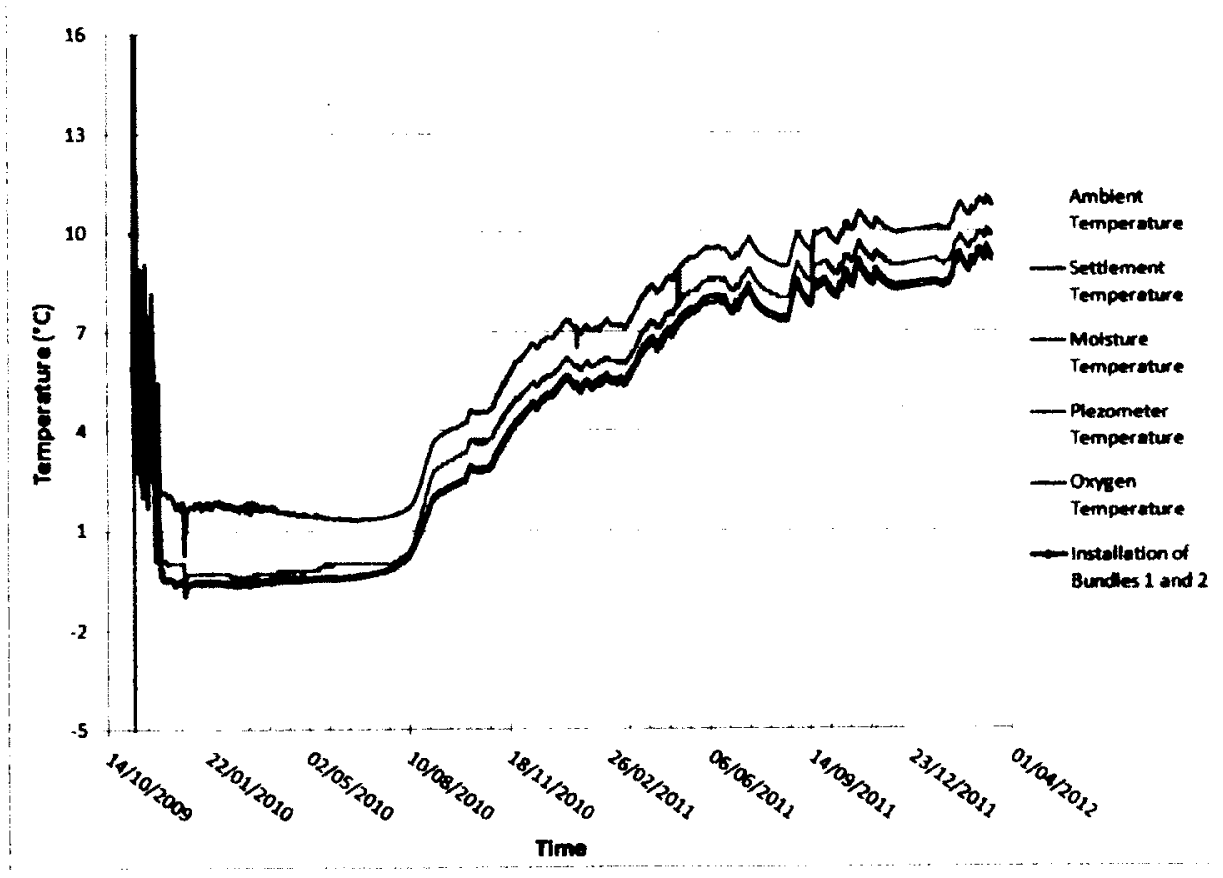

Figure B2: Thermistor temperatures for bundle 2 


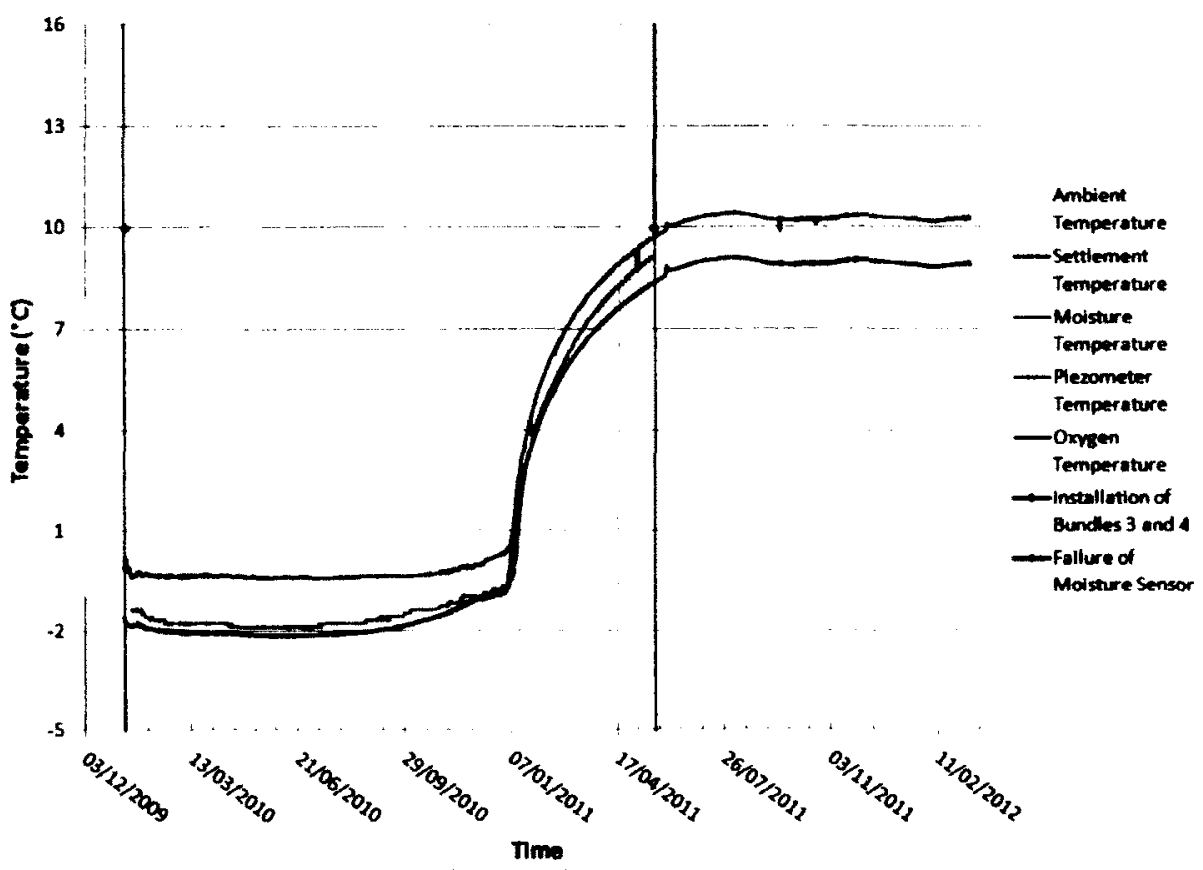

Figure B3: Thermistor temperatures for bundle 3

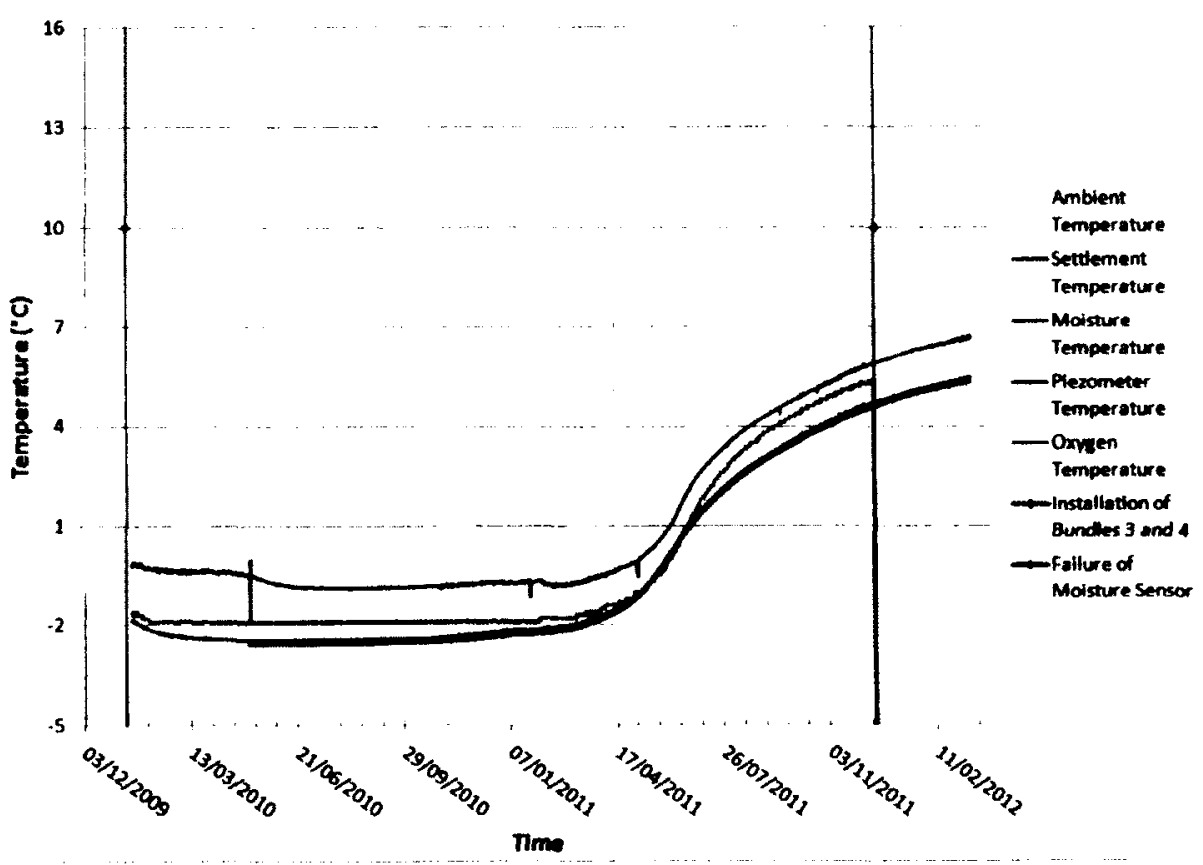

Figure B4: Thermistor temperatures for bundle 4 


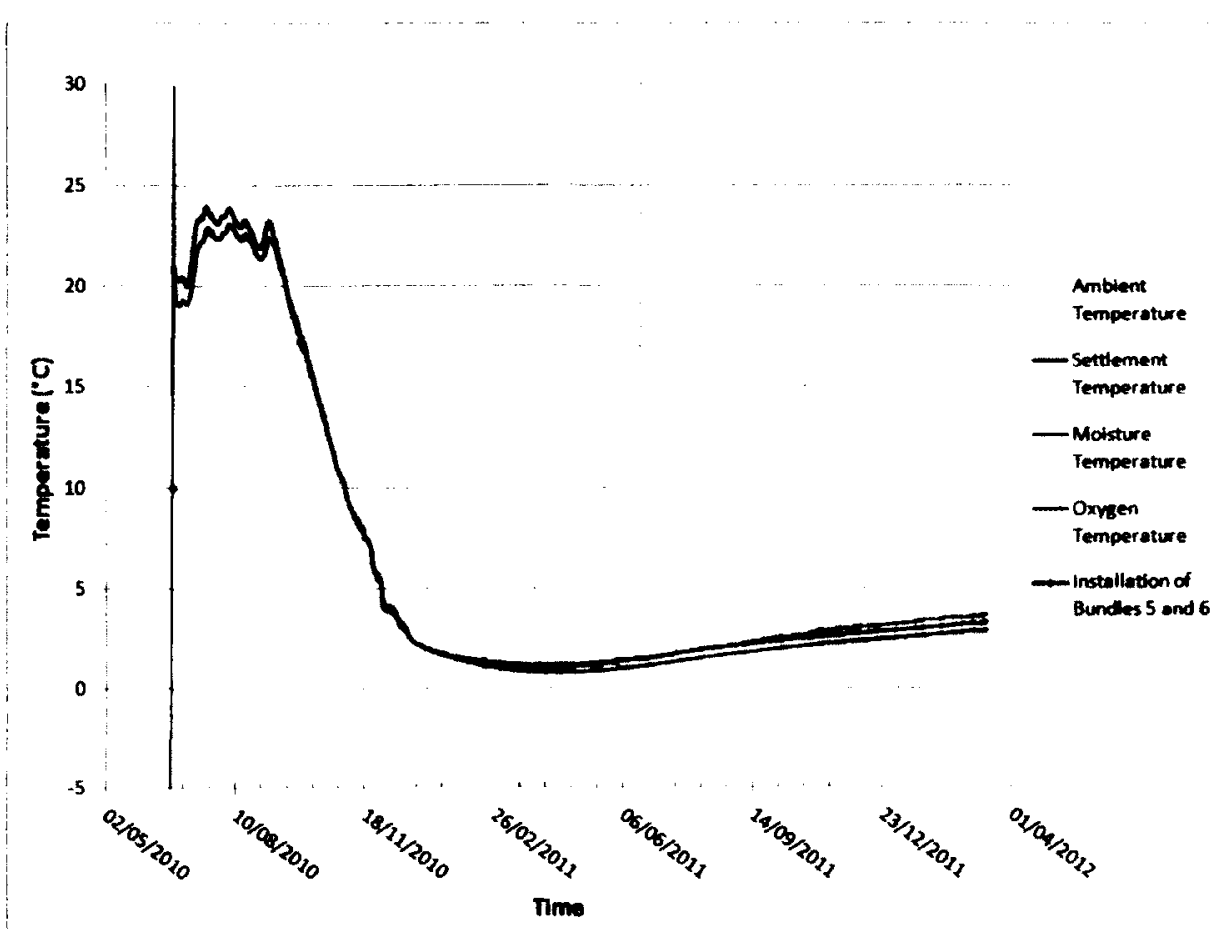

Figure B5: Thermistor temperatures for bundle 5

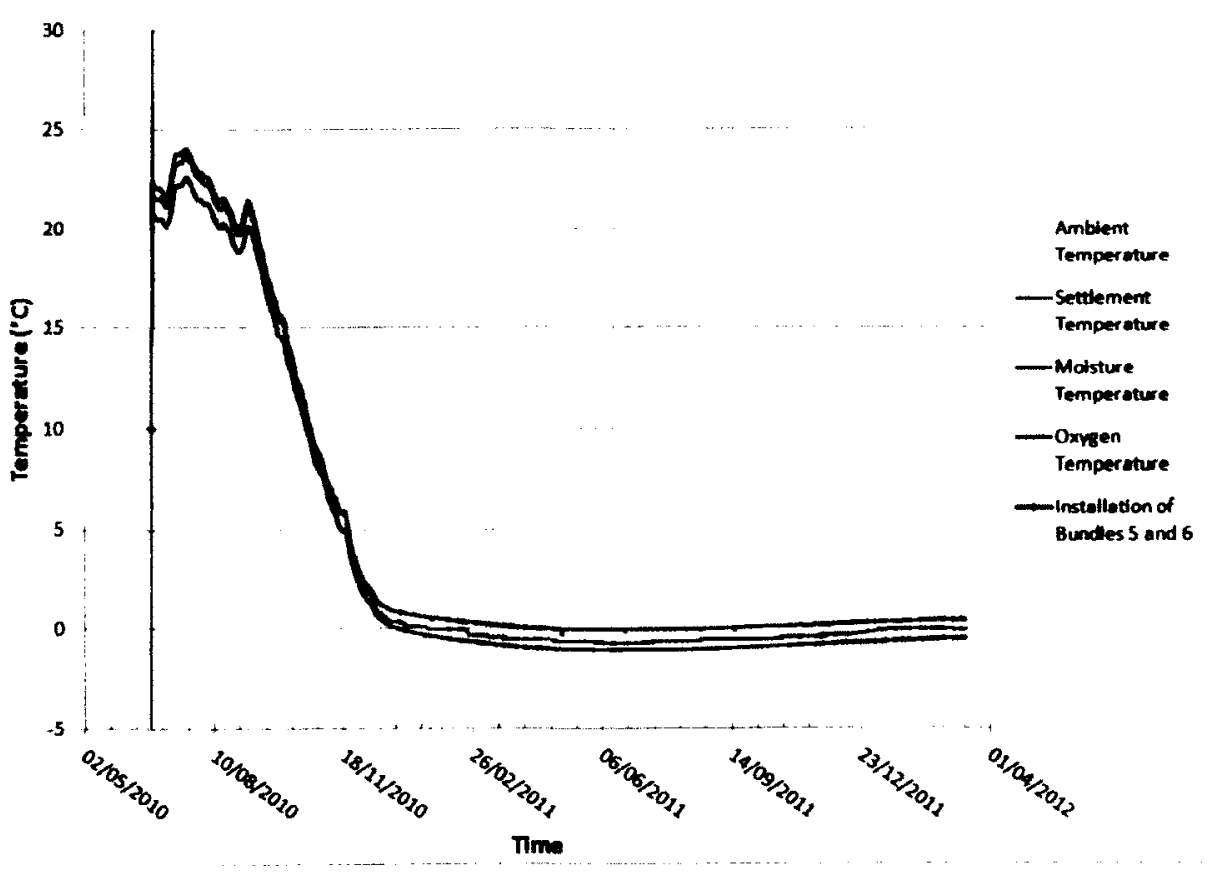

Figure B6: Thermistor temperatures for bundle 6 


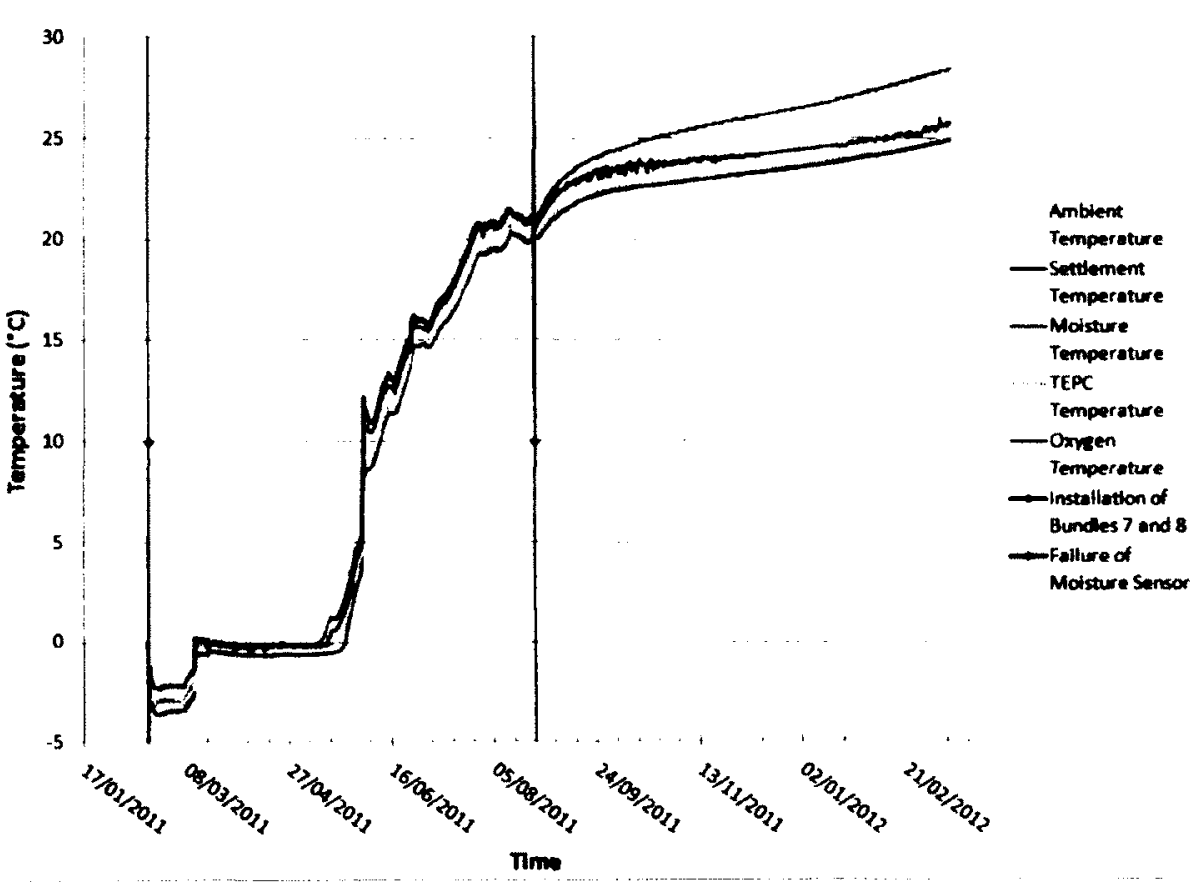

Figure B7: Thermistor temperatures for bundle 7

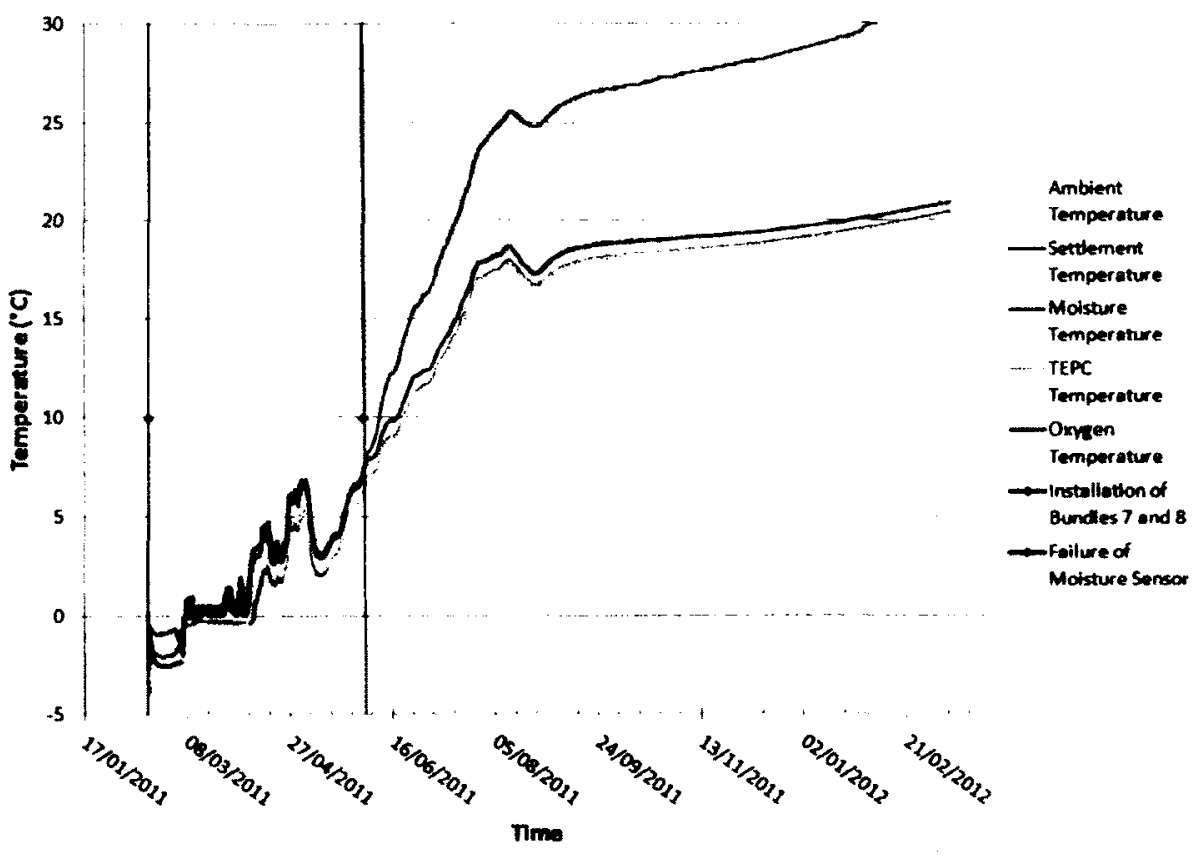

Figure B8: Thermistor temperatures for bundle 8 


\section{Appendix C - Temperature Data Linear Regression Analysis}

The ambient temperature data measured on site is fitted to a $\mathrm{n}^{\text {th }}$ order polynomial such that the average ambient temperatures were used upper boundary term. The equation was fit using a non-linear regression analysis carried out by the commercial software package NLREG v6.3. In addition, the bottom boundary temperature data was fit to a $\mathbf{n}^{\text {th }}$ order polynomial to match the temperature data from bundles 1 and 2 . The polynomial was derived in order to match the temperatures at either bundle 1 or bundle 2 . The selection based upon data that had less noise, and the temperatures were assumed to vary linearly between bundles 1 and 2. To maximize computational efficiency, the polynomial order was increased until there was minimal improvement in the fit of the function to the actual data. Figures $\mathrm{Cl}$ to $\mathrm{C} 6$ show the ambient and base temperature functions used to model the data from January 16th, 2010 until August 22nd, 2011. 
Lift 1 (January $16^{\text {th }}$ to December $\left.12^{\text {th }} 2010\right)$ :

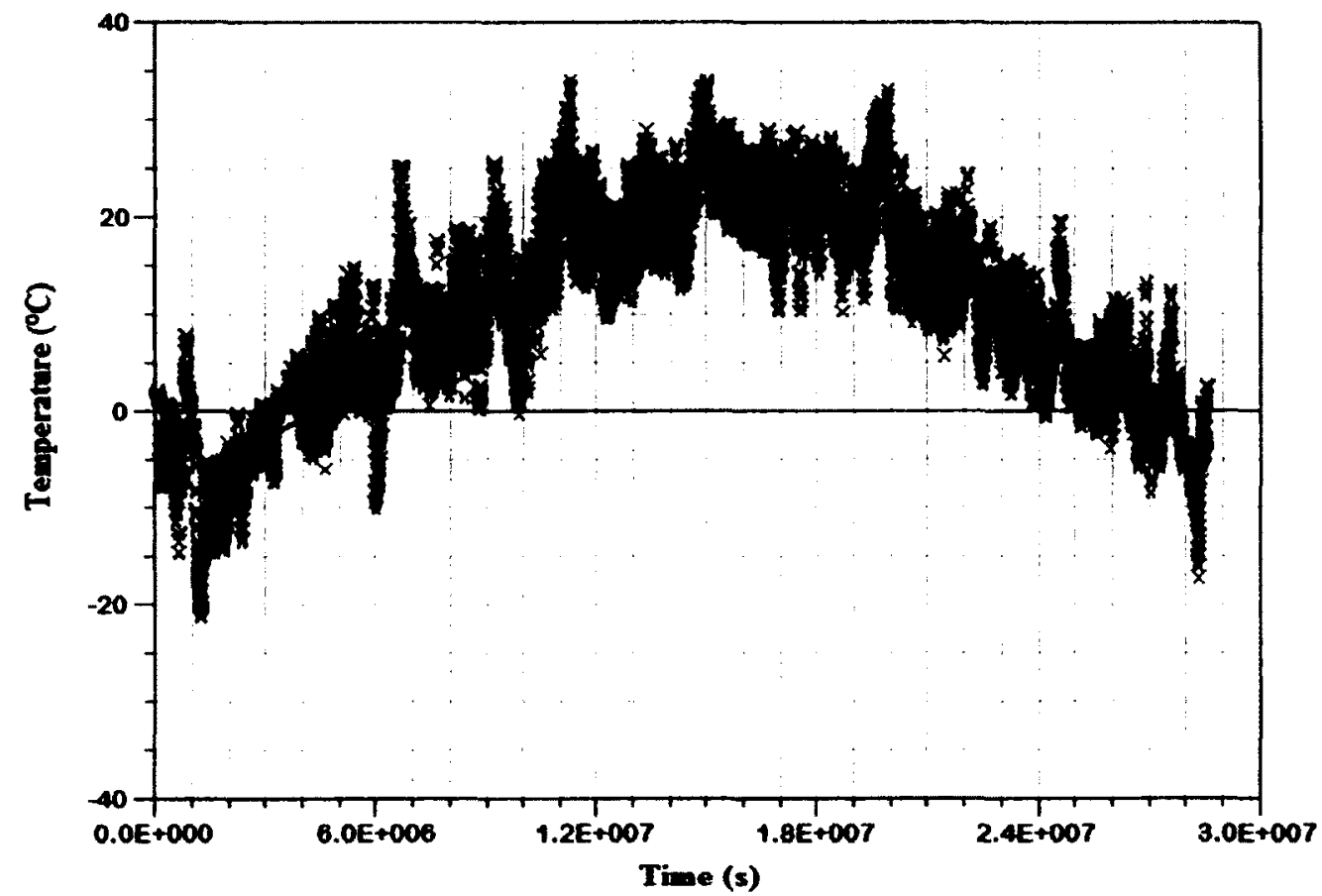

Figure C1: Ambient temperature function for first time period - January $16^{\text {th }}$ to December 12 $12^{\text {th }}, 2010$

Ambient Temperature $=\left(2.427 \mathrm{E}-8 *\left(\mathrm{t}^{4} / 86400^{4}\right)\right)-\left(1.7904 \mathrm{E}-5 *\left(\mathrm{t}^{3} / 86400^{3}\right)\right)+(0.003261$ $\left.*\left(\mathfrak{t}^{2} / 86400^{2}\right)\right)+(0.0086390 *(t / 86400))-6.2162$

Proportion of variance explained $\left(R^{2}\right)=0.7922$ 


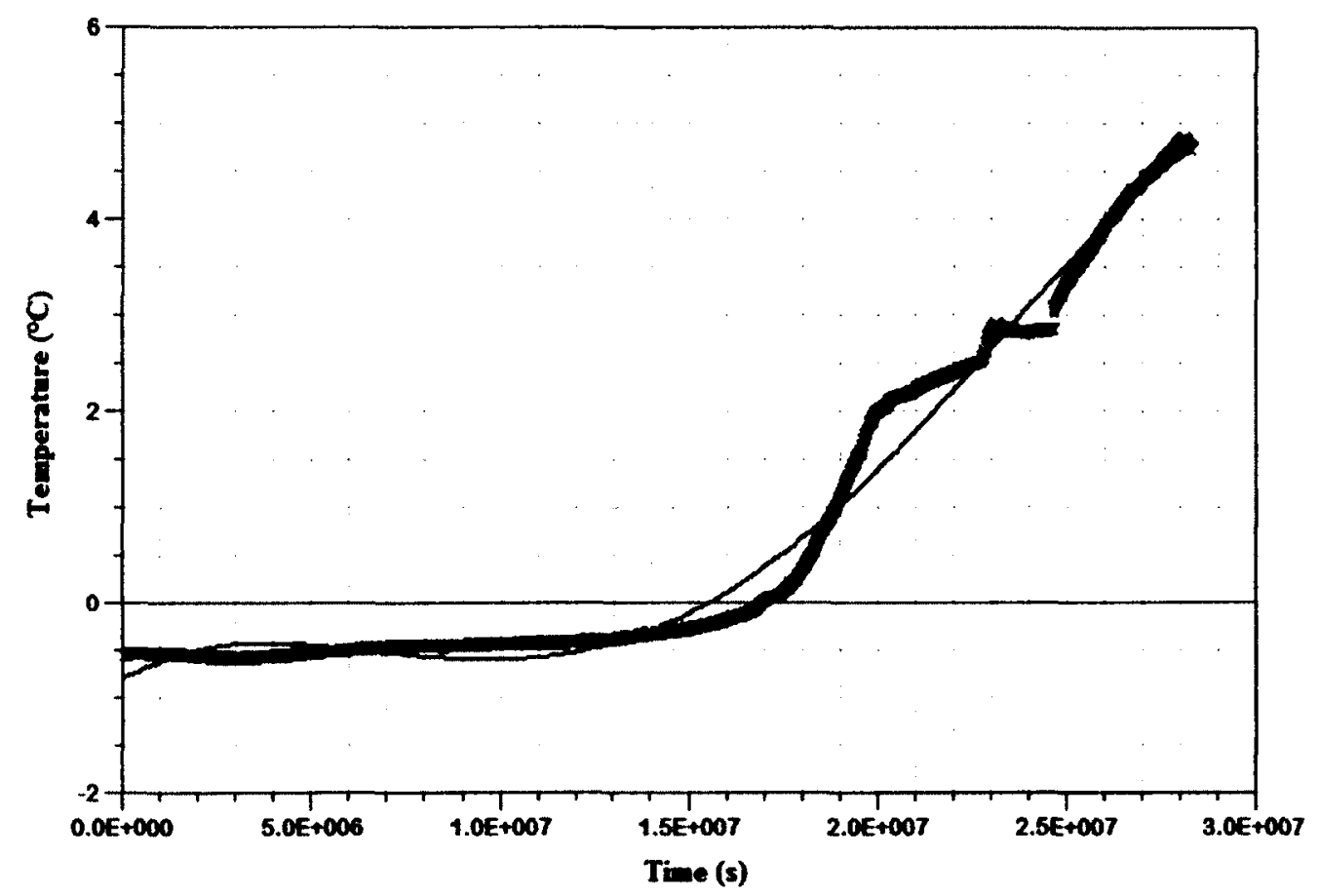

Figure C2: Bottom boundary temperature function for first time period - January $16^{\text {th }}$ to December $12^{\text {th }}, 2010$

Base Temperature $=-\left(2.8345 \mathrm{E}-9 *\left(\mathrm{t}^{4} / 86400^{4}\right)\right)+\left(1.9633 \mathrm{E}-6^{*}\left(\mathrm{t}^{3} / 86400^{3}\right)\right)-(0.000349$ $\left.*\left(\mathfrak{t}^{\wedge} / 86400^{\wedge 2}\right)\right)+(0.02023 *(t / 86400))-0.7921$

Proportion of variance explained $\left(\mathrm{R}^{2}\right)=0.9841$

Note: The above equation is for bundle 2 , thus $\left(0.016^{*} \mathrm{x}\right)$ was added to linearly interpolate the temperature difference between bundles 1 and 2 . 


\section{Lift 2 (December $13^{\text {th }} 2010$ to January $27^{\text {th }} 2011$ ):}

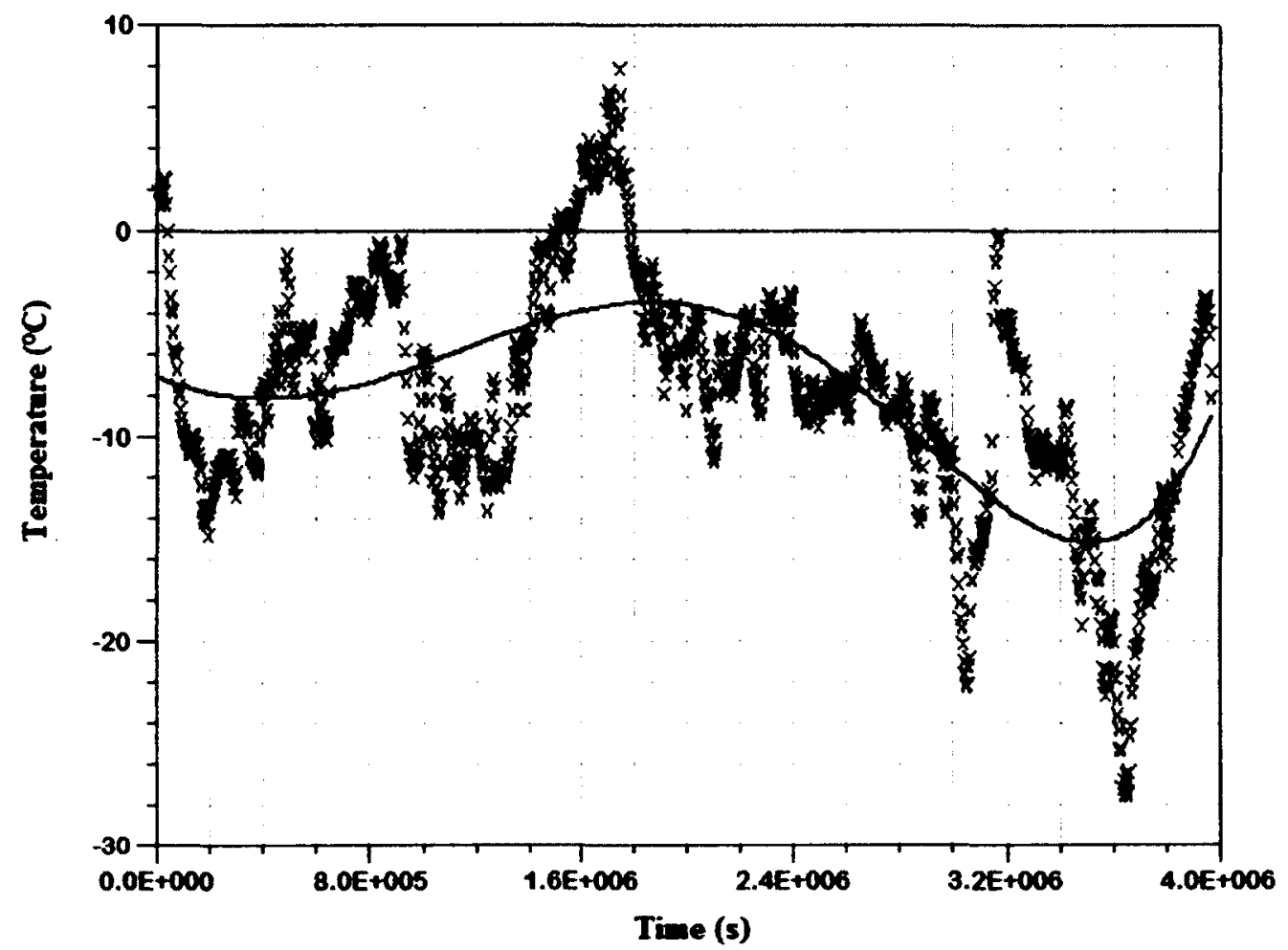

Figure C3: Ambient temperature function for second time period - December $13^{\text {th }}$, 2010 to January $27^{\text {th }}, 2011$

Ambient Temperature $=\left(1.7344 \mathrm{E}-6 *\left(\mathrm{t}^{5} / 86400^{5}\right)\right)-\left(0.000118 *\left(\mathrm{t}^{4} / 86400^{4}\right)\right)+(0.001008$ $\left.*\left(\mathrm{t}^{3} / 86400^{3}\right)\right)+\left(0.04426 *\left(\mathrm{t}^{2} / 86400^{2}\right)\right)-(0.4425 *(\mathrm{t} / 86400))-7.0404$

Proportion of variance explained $\left(R^{2}\right)=0.4164$ 


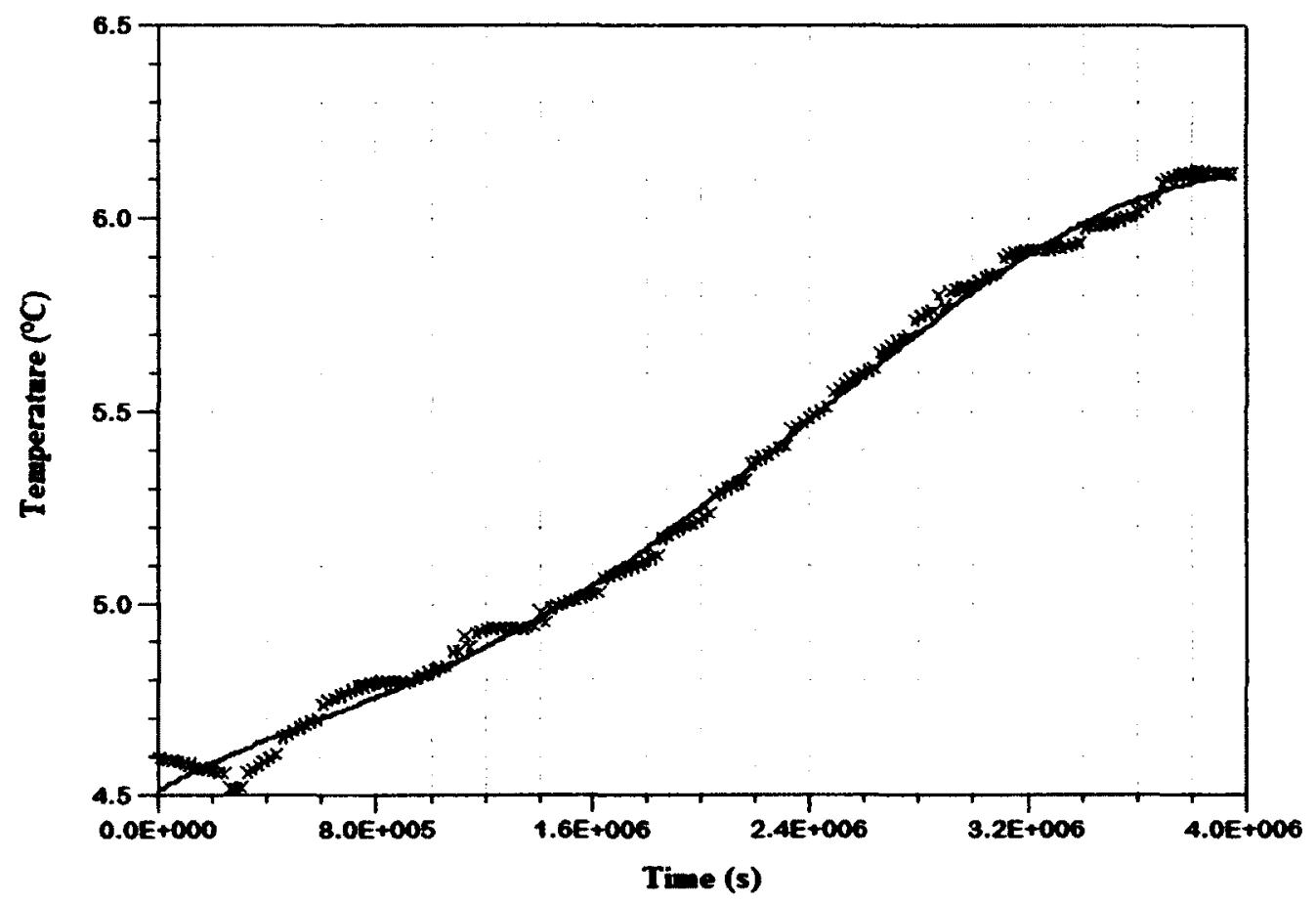

Figure C4: Bottom boundary temperature function for second time period December $13^{\text {th }}, 2010$ to January $27^{\text {th }}, 2011$

Base Temperature $=\left(1.7276 \mathrm{E}-8 *\left(\mathrm{t}^{5} / 86400^{5}\right)\right)-\left(2.8247 \mathrm{E}-6^{*}\left(\mathrm{t}^{4} / 86400^{4}\right)\right)+(0.0001366 *$ $\left.\left(\mathrm{t}^{3} / 86400^{3}\right)\right)-\left(0.001995 *\left(\mathrm{t}^{2} / 86400^{2}\right)\right)+(0.03508 *(\mathrm{t} / 86400))+4.5154$

Proportion of variance explained $\left(R^{2}\right)=0.9967$

Note: The above equation is for bundle 1 , thus $(-0.091+(0.0055 * x))$ was added to linearly interpolate the temperature difference between bundles 1 and 2 . 


\section{Lift 3 (January $28^{\text {th }}$ to August 22 $\left.{ }^{\text {nd }}, 2011\right)$ :}

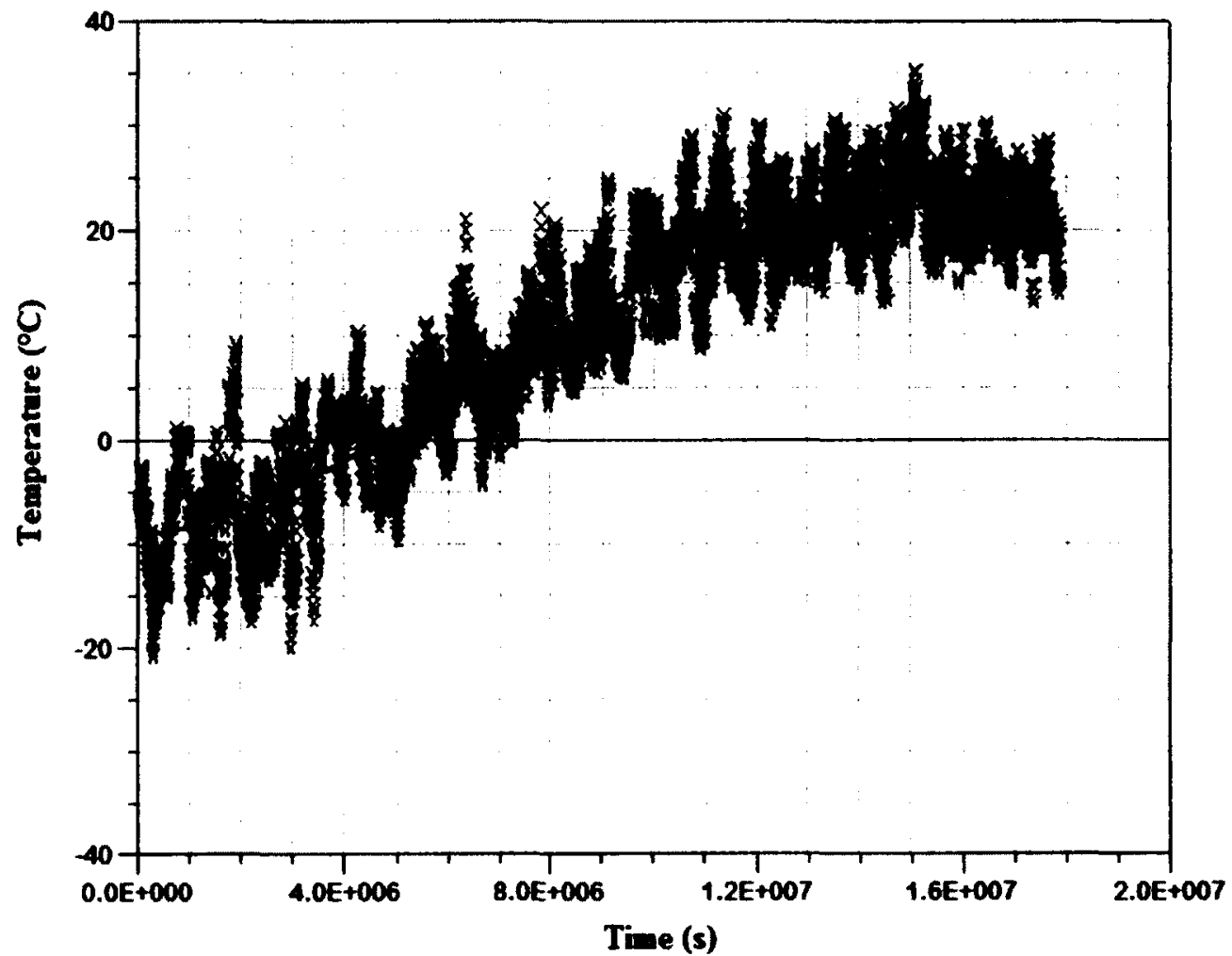

Figure C5: Ambient temperature function for third time period - January $28^{\text {th }}$ to August 22 ${ }^{\text {nd }}, 2011$

Ambient Temperature $=\left(7.7315 \mathrm{E}-9 *\left(\mathrm{t}^{4} / 86400^{4}\right)\right)-\left(1.2861 \mathrm{E}-5 *\left(\mathrm{t}^{3} / 86400^{3}\right)\right)+$ $\left(0.002742 *\left(\mathrm{t}^{2} / 86400^{2}\right)\right)+(0.05729 *(\mathrm{t} / 86400))-9.1707$

Proportion of variance explained $\left(\mathrm{R}^{2}\right)=0.8610$ 


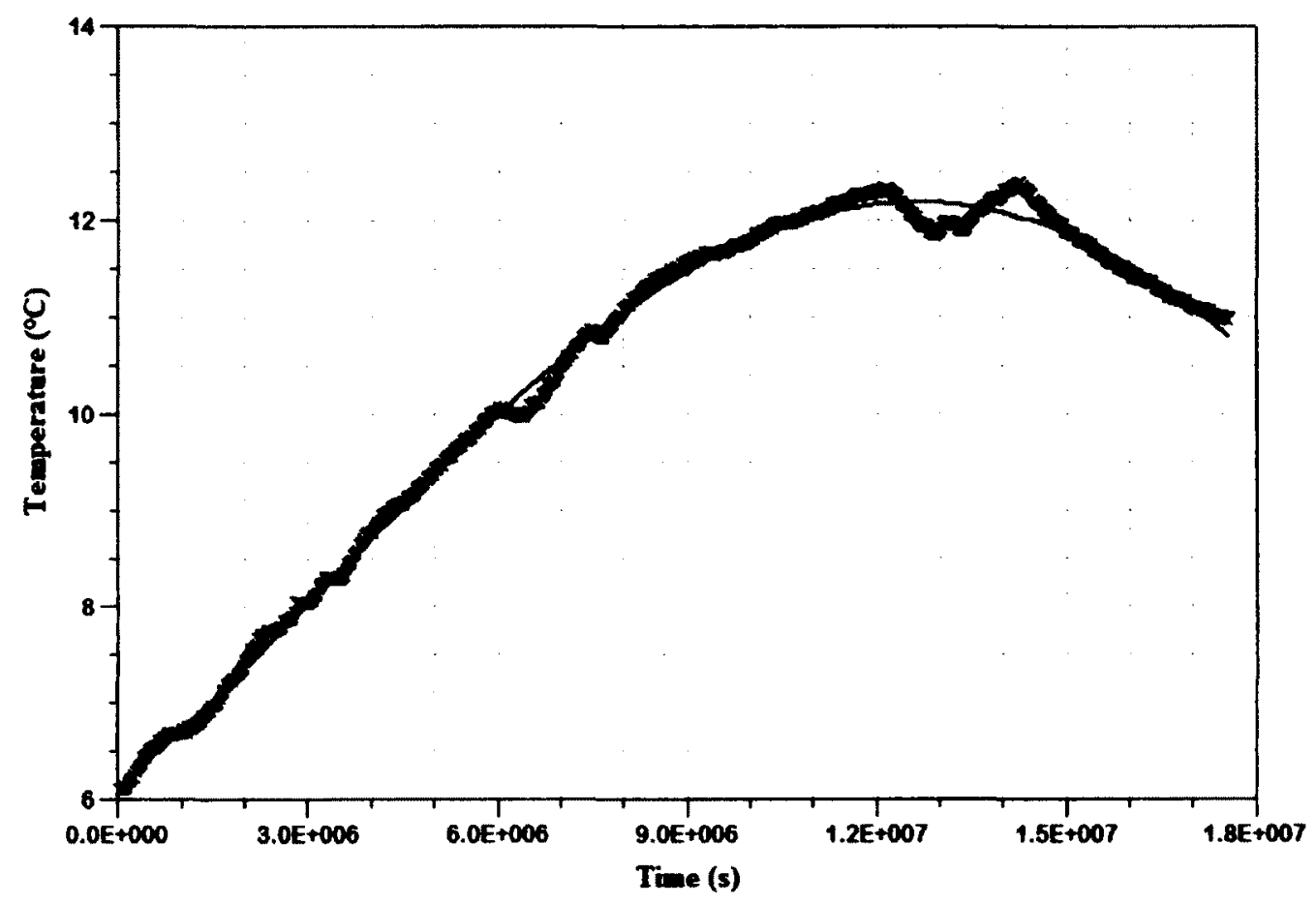

Figure C6: Bottom boundary temperature function for third time period - January $28^{\text {th }}$ to August $22^{\text {nd }}, 2011$

Base Temperature $=\left(4.3534 \mathrm{E}-9 *\left(\mathrm{t}^{4} / 86400^{4}\right)\right)-\left(2.8559 \mathrm{E}-6 *\left(\mathrm{t}^{3} / 86400^{3}\right)\right)+(0.0002737$ $\left.*\left(t^{2} / 86400^{2}\right)\right)+(0.04884 *(t / 86400))+6.1381$

Proportion of variance explained $\left(R^{2}\right)=0.9966$

Note: The above equation is for bundle 1 , thus $\left(-3.414+\left(0.207^{*} \mathrm{x}\right)\right)$ was added to linearly interpolate the temperature difference between bundles 1 and 2 . 


\section{Appendix D - Model Dimensions with Bundles}

The model dimensions were determined by analyzing the GPS coordinates of the instrument bundles at the time of placement. The horizontal and vertical spacing between each layer of instrument bundles is presented in Table D1. The maximum horizontal spacing was determined to be $18.39 \mathrm{~m}$ between bundles 5 and 6 and therefore this was used as a basis for the width of the model. Figure D1 illustrates the relative placement of instrument bundles. The figure illustrates two vertical columns of instruments bundles were maintained throughout placement in the various waste lifts.

Table D1: Horizontal and vertical separation of bundle layers

\begin{tabular}{|c|c|c|c|c|c|c|c|}
\hline Bundle & Northing & Easting & $\begin{array}{c}\text { Elevation } \\
\text { (masl) }\end{array}$ & $\begin{array}{c}\text { ANorthing } \\
\text { (m) }\end{array}$ & $\begin{array}{c}\text { AEasting } \\
\text { (m) }\end{array}$ & $\begin{array}{c}\text { AHorizontal } \\
\text { (m) }\end{array}$ & $\begin{array}{c}\text { AVertical } \\
(\mathbf{m})\end{array}$ \\
\hline 1 & 5070937.1 & 273057.1 & 72.58 & \multirow{2}{*}{12.10} & \multirow{2}{*}{11.70} & \multirow{2}{*}{16.83} & \multirow{2}{*}{-0.11} \\
\hline 2 & 5070925.0 & 273045.4 & 72.47 & & & & \\
\hline 3 & 5070938.06 & 273056.75 & 75.46 & \multirow{2}{*}{13.00} & \multirow{2}{*}{11.85} & \multirow{2}{*}{17.59} & \multirow{2}{*}{0.173} \\
\hline 4 & 5070925.06 & 273044.90 & 75.63 & & & & \\
\hline 5 & 5070938.76 & 273057.28 & 77.79 & \multirow{2}{*}{13.62} & \multirow{2}{*}{12.36} & \multirow{2}{*}{18.39} & \multirow{2}{*}{0.52} \\
\hline 6 & 5070925.14 & 273044.92 & 78.31 & & & & \\
\hline 7 & 5070938.01 & 273056.42 & 84.57 & \multirow{2}{*}{12.68} & \multirow{2}{*}{11.28} & \multirow{2}{*}{16.97} & \multirow{2}{*}{0.20} \\
\hline 8 & 5070925.33 & 273045.14 & 84.76 & & & & \\
\hline 9 & 5070938.36 & 273056.48 & 87.71 & \multirow{2}{*}{12.96} & \multirow{2}{*}{12.15} & \multirow{2}{*}{17.76} & \multirow{2}{*}{0.06} \\
\hline 10 & 5070925.4 & 273044.33 & 87.77 & & & & \\
\hline
\end{tabular}




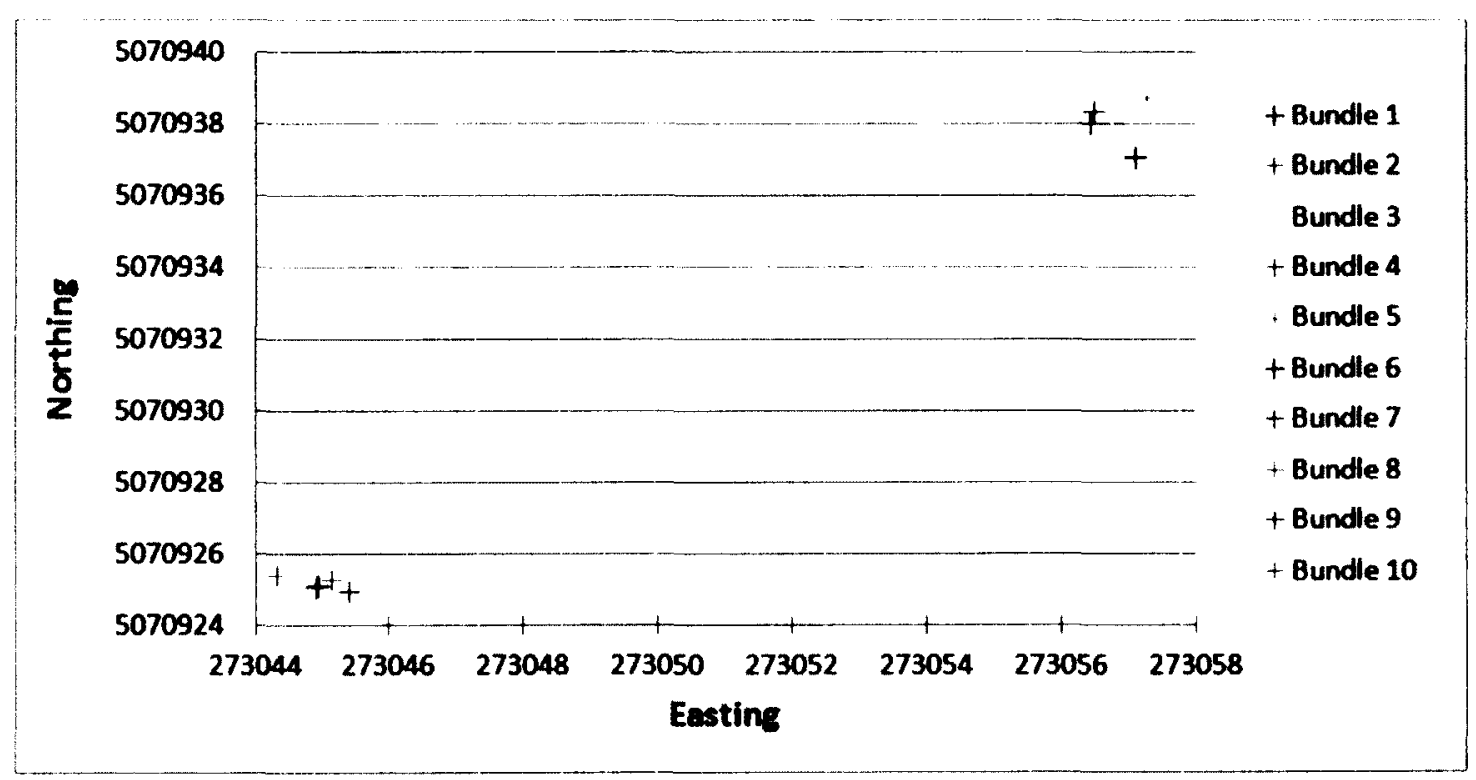

Figure D1: Relative placement of instrument bundles

The settlement data was not incorporated into the model in order to impact the properties of waste with time. As the waste settles, the pore space will decrease, resulting in an increase in volumetric moisture content and density. In addition, this will have an impact on the thermal parameters of the waste including an increase in thermal conductivity. In the future, the model will include settlement data and the parameters of the waste can be adjusted with time.

The settlement data however, had to be incorporated in the model to account for the heat flux affecting bundles 3 and 4. From analyzing the settlement data in Table D2, it is apparent the settlement data must be considered. The first waste lift was modelled using the dimensions as of June 10th, 2010. At this time, the thickness of waste between bundles 3 and 4 and the base of the landfill is $2.49 \mathrm{~m}$ and $2.64 \mathrm{~m}$ respectively. However, prior to placing the fourth waste lift in August of 2011 , this thickness had decreased to $2.04 \mathrm{~m}$ and $2.34 \mathrm{~m}$ respectively. This reduction of waste thickness is substantial when 
considering the principal heat flux is from the base of the landfill. For example, an increase in temperature of the waste surrounding bundle 4 does not occur until 1.5 years after waste placement. At this time, the only source of heat must be from the base of the landfill as approximately $10 \mathrm{~m}$ of cold waste rests above the bundles. Therefore the locations of bundles 3 and 4 were adjusted to avoid overestimating the heat flux from the base of the landfill.

Table D2: Settlement of instrument bundle locations (masl) with time

\begin{tabular}{|c|r|r|r|r|r|r|}
\hline Bundle & 12-Nov-09 & 17-Jan-10 & 23-Jun-10 & 19-Feb-11 & 23-Aug-11 & 16-Sep-11 \\
\hline 1 & 72.58 & 72.57 & 72.63 & 72.48 & 72.51 & 72.47 \\
\hline 2 & 72.47 & 72.47 & 72.57 & 72.36 & 72.31 & 72.29 \\
\hline 3 & & 75.46 & 75.12 & 74.64 & 74.55 & 74.49 \\
\hline 4 & & 75.63 & 75.21 & 74.75 & 74.65 & 74.58 \\
\hline 5 & & & 77.79 & 76.88 & 76.85 & 76.73 \\
\hline 6 & & & 78.31 & 77.13 & 77.10 & 76.95 \\
\hline 7 & & & & 84.57 & 84.02 & 83.61 \\
\hline 8 & & & & 84.76 & 84.18 & 83.80 \\
\hline 9 & & & & & & 87.71 \\
\hline 10 & & & & & & 87.77 \\
\hline
\end{tabular}

